\author{
UNIVERSIDADE DE SÃO PAULO \\ ESCOLA DE ENGENHARIA DE SÃO CARLOS \\ DEPARTAMENTO DE ENGENHARIA DE ESTRUTURAS
}

\title{
CONTRIBUIÇÃO AO PROJETO DE PILARES DE PONTES DE CONCRETO ARMADO COM CONSIDERAÇÃO DAS NÃO-LINEARIDADES FÍSICA E GEOMÉTRICA E INTERAÇÃO SOLO -ESTRUTURA
}

\section{Magid Elie Khouri}

Tese apresentada à Escola de Engenharia de São Carlos da Universidade de São Paulo como parte dos requisitos para obtenção do título de Doutor em Engenharia de Estruturas.

Orientador: Prof ${ }^{\mathfrak{Q}}$. Dr. Mounir Khalil El Debs

São Carlos - SP 
A nossa passagem por São Carlos foi uma dádiva; revimos amigos e cultivamos amizades; convivemos com jovens puros e conscientes; não sabiam zangar-se facilmente. Abriram-se várias janelas; somos gratos a DEUS por tudo.

Marilda R. Junqueira Khouri

À minha querida Marilda e aos meus filhos ,Eduardo e Marcelo, dedico esse trabalho 


\section{AGRADECIMENTOS}

Ao Prof. Dr. MOUNIR KHALIL EL DEBS, pela orientação, pelo permanente incentivo e amizade demonstrada durante a realização desse trabalho;

Ao Prof. Dr. NELSON AOKI, pela sua paciência e sugestões;

Ao Prof. Dr. MÁRCIO R. S. CORRÊA sou grato pelas suas sugestões;

Ao Prof. PhD JOHN E. BREEN pela remessa de material bibliográfico;

Aos amigos do departamento, com os quais mais de perto convivi; fico eternamente grato. Aos Professores José Samuel Giongo, Eloy F. Machado Jr., Libânio, Sergio P. B. Proença e Takeia Toshiaki;

Aos meus amigos Ana Elisabete P. Guimarães, Bertini, Faustino, Ângelo Mendonça, Pedro Wellington pelo apoio e amizade;

Serei eternamente grato ao amigo Prof. Daniel L. Araújo e a sua esposa Roberta, que pacientemente leram e revisaram o texto deste trabalho;

À Maria Nadir Minatel pelo apoio na busca de referências bibliográficas;

Ao Francisco C. G. Brito e à Sylvia H. M. Villani pela contribuição na parte gráfica desse trabalho;

Ao meu irmão caçula Walid que alertou-me sobre um perigo - “ Se você enveredar pelo campo da pesquisa como um fanático, você vai se tornar um refém de si mesmo; leia mais sobre outras coisas - sobre a vida, por exemplo";

À Universidade Federal de Goiás - UFG e CAPES/PICDT pelo apoio financeiro que possibilitou a realização deste trabalho;

À EESC - USP pelo acolhimento. 


\section{SUMÁRIO}

SUMÁRIO . $\mathbf{i}$

LISTA DE FIGURAS........................................................................................................................................... iv

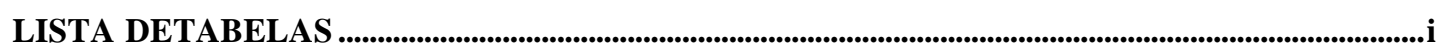

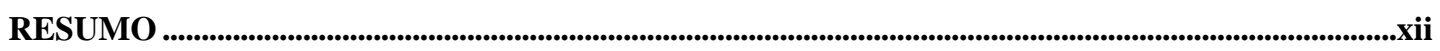

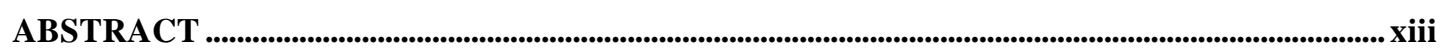

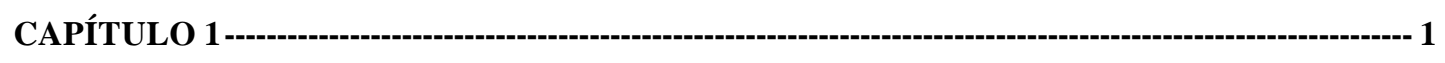

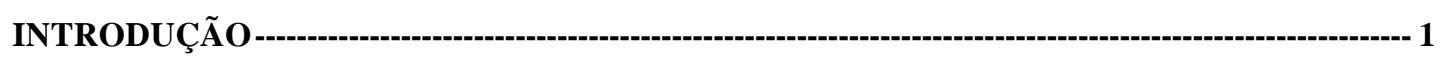

1.1 - ASPECTOS DO PROJETO DAS PONTES

1.1.1 - GENERALIDADES --1

1.1.2 - AS DIFICULDADES DA ANÁLISE ESTRUTURAL -

1.1.2.1 - Preliminares

1.1.2.2 - Módulo de Elasticidade do Concreto ---

1.1.2.3 - Rigidez à Flexão das Seções de Concreto---o-_-

1.1.2.4 - Interação Solo-Estrutura --

1.2 - OBJETIVOS DESTE TRABALHO -

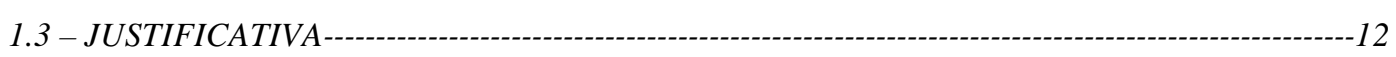

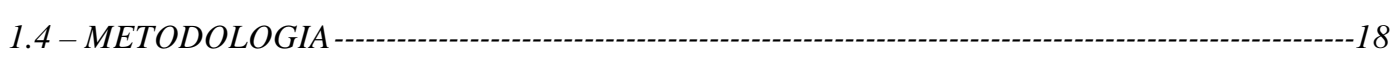

1.5 - APRESENTAÇÃO DO TRABALHO

CAPÍTULO 2 2 -23

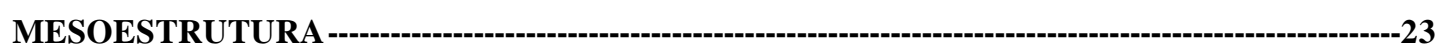

2.1 - GENERALIDADES-1-

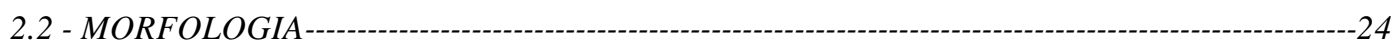

2.3 - ESBELTEZ DOS PILARES

2.4 - ESBELTEZ E TIPO DE RUÍNA DOS PILARES

CAPÍTULO 3 - 35

INTERAÇÃO SOLO - ESTRUTURA - 35

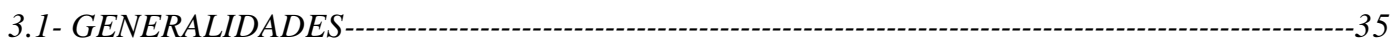

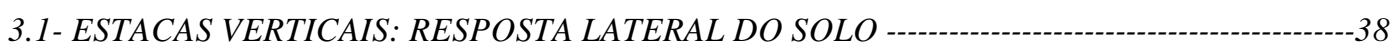

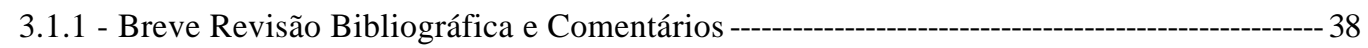




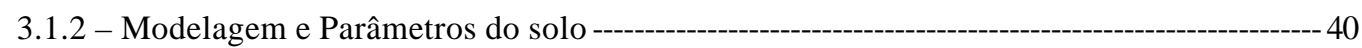

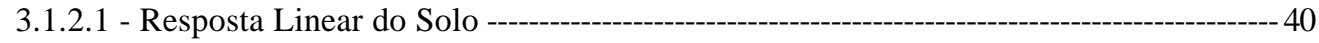

3.1.2.2 - Resposta Não linear do Solo----------------------------------------------------------------------- 43

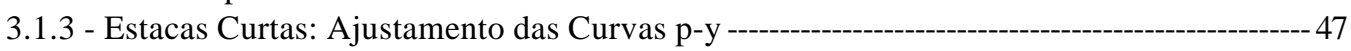

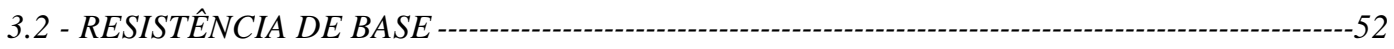

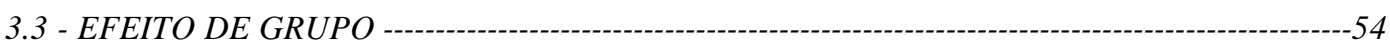

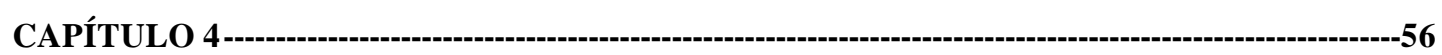

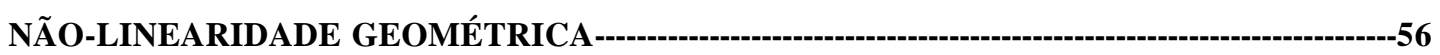

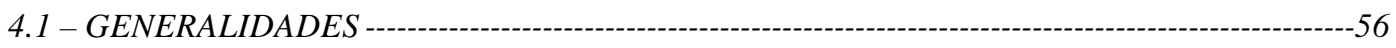

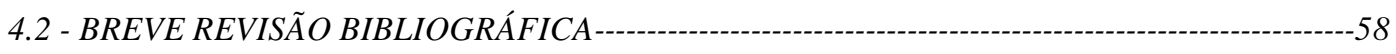

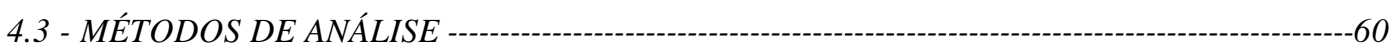

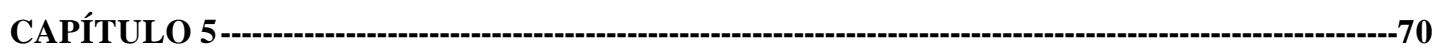

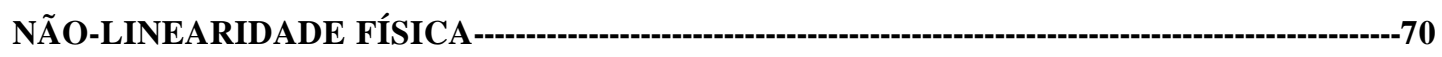

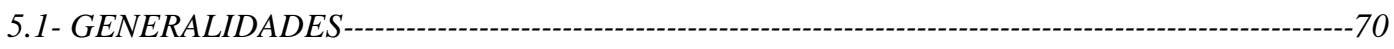

5.2 - RELAÇÃO CONSTITUTIVA DO CONCRETO

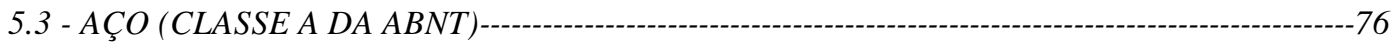

5.4 - ELEMENTO LINEAR DE CONCRETO ARMADO------------------------------------------77

5.4.1 - Deformações para Cargas de Curta Duração------------------------------------------------------ 77

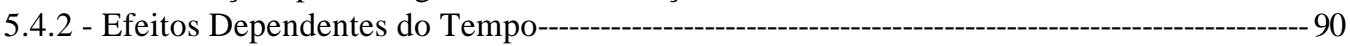

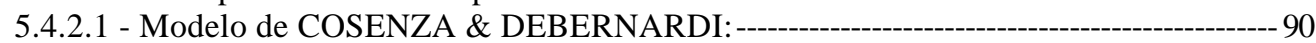

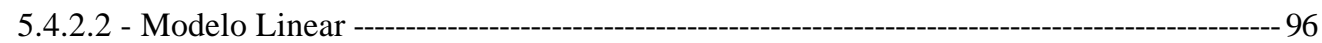

CAPÍTULO 6-1-1-

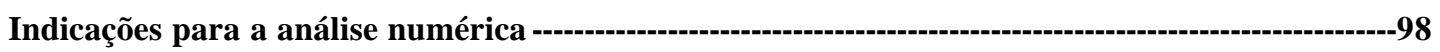

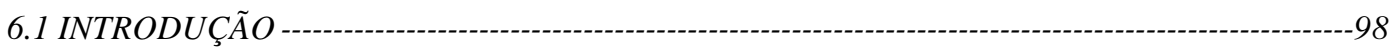

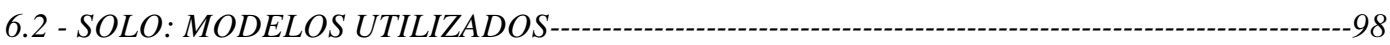

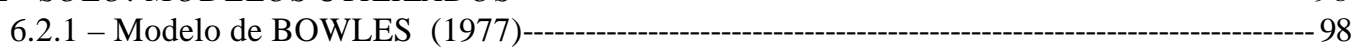

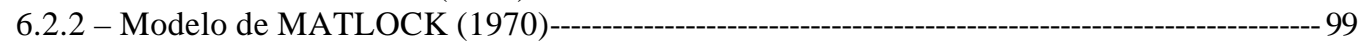

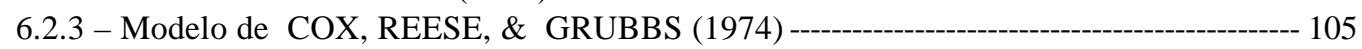

6.3 - SIMULAÇÃO DOS APARELHOS DE NEOPRENE ---

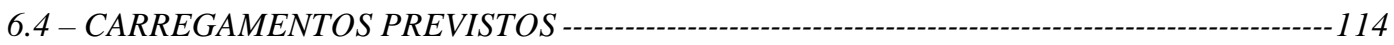

6.4.1 - Ações Típicas nas pontes ------------------------------------------------------------------------ 114

6.4.2 - combinações das ações --------------- 115

6.4.2.1 - Pilhas previstas para os Estados Limites de Utilização: ---------------------------------- 115

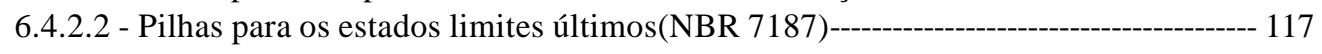

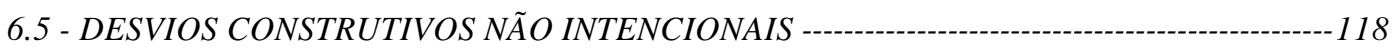

CAPÍTULO 7 ----119

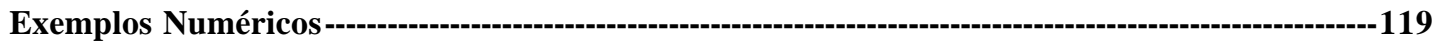

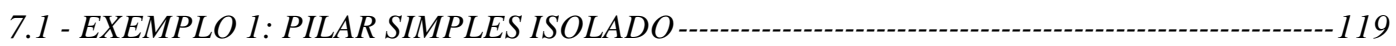


7.2 - EXEMPLO 2: PONTE FERROVIÁRIA - 128

7.3 - EXEMPLO 3: PONTE FERROVIÁRIA -

7.4 - EXEMPLO 4: PONTE RODOVIÁRIA--_-_- 151

CAPÍTULO 8- 8

conclusões---182

REFERÊNCIAS BIBLIOGRÁFICAS

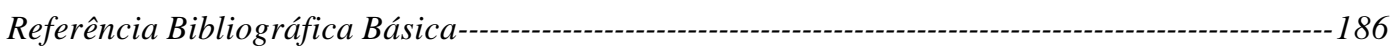

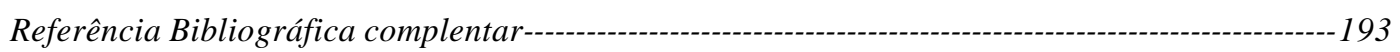

ANEXOS - 196

Anexo A (Complementa o Capítulo 4) - 196

Anexo B (Complementa o Capítulo 5)---o-'--199

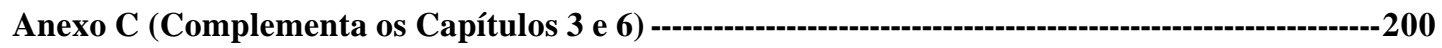

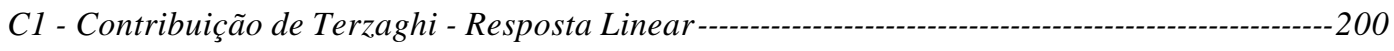

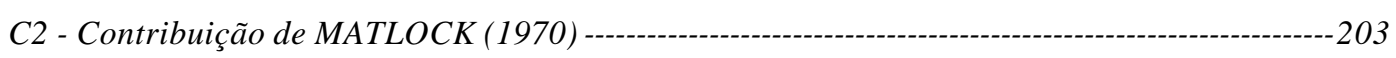

C3 - Contribuição de REESE et al. (1975) ---206

C3 - Contribuição de COX, REESE, \& GRUBBS (1974) ---- 


\section{LISTA DE FIGURAS}

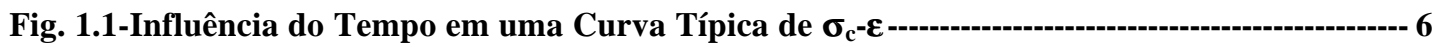

Fig. 1.2 - Variação Típica da Rigidez a Flexão E

Fig. 1.3 - Curva Típica Carga vs. Deslocamento em Vigas de Concreto Armado --------------------- 8

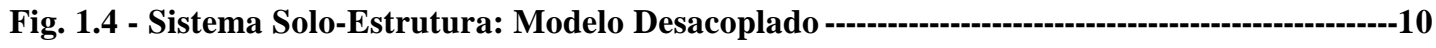

Fig. 1.5 - Sistema Solo-estrutura: Modelo Acoplado [adaptado de AOKI (1986)] ------------------11

Fig. 1.6(a, b, c) - Influência das Condições de Apoio no Valor de $\mathrm{kL}_{\mathrm{u}}$-------------------------------14

Fig. 1.7 - Ábacos para a Determinação do Parâmetro k (adaptado da NBR 8800 - ABNT) -----17

Fig. 1.8 - Estruturas Típicas objeto de análise ----------------------------------------------------------20

Fig. 2.1-Arranjos de Pilares em Pontes: Ocorrência -----------------------------------------------------25

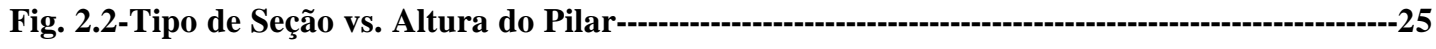

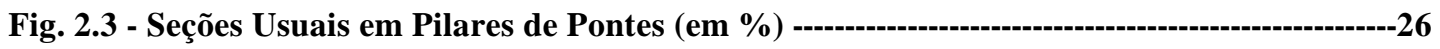

Fig.2.4-Configurações Verticais em Arranjos Simples de Pilares ---------------------------------------28

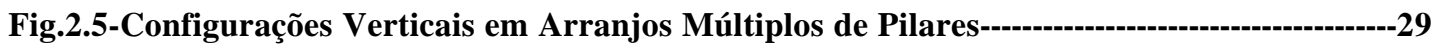

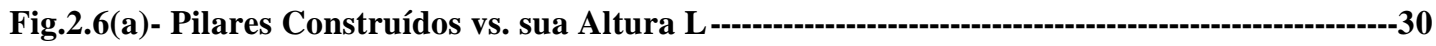

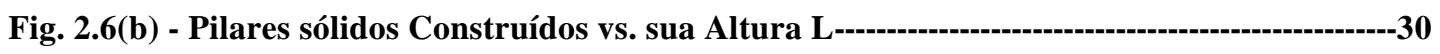

Fig. 2.6(c)- Pilares Construídos Vazados vs. sua Altura L ------------------------------------------30

Fig. 2.7-Distribuição de L/r para Arranjos Simples de Pilares ----------------------------------------32

Fig. 2.8 - Distribuição de L/r para Arranjos de Pilares Múltiplos -------------------------------------32

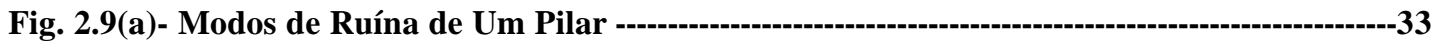

Fig. 2.9(b)- Modos de Ruína de Um Pilar [adaptado de MAcGREGOR et al. (1970)] -------------34

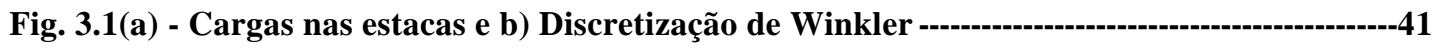

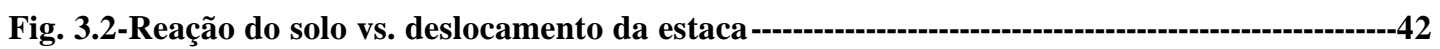


FIG. 3.3 - Variação do Módulo de Reação Horizontal: a)Solos coesivos pré-adensados: $K_{h}$ constante, b) Solos granulares, siltes normalmente carregados, e argilas: . $K_{h}$ linear -----------43

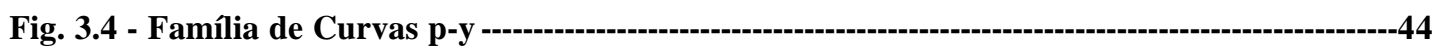

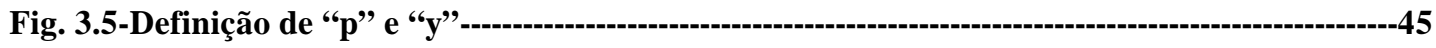

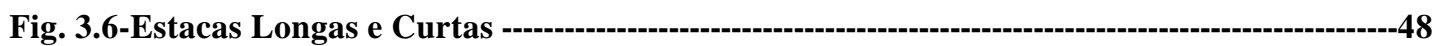

Fig. 3.7-Modos de Ruptura: a) formação de cunhas e b) por escoamento do solo.------------------52

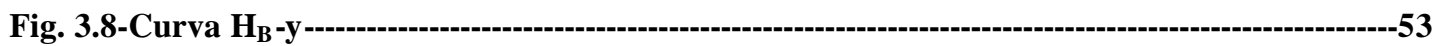

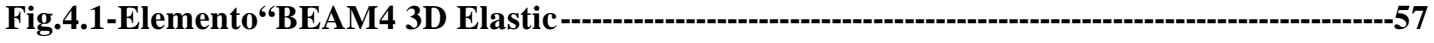

Fig. 4.2 - Configuração Genérica em Equilíbrio - Unidimensional (Adaptado de KRÜGER 1989).

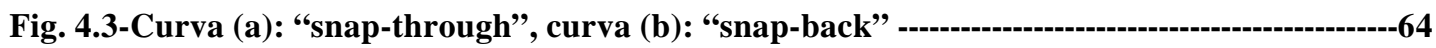

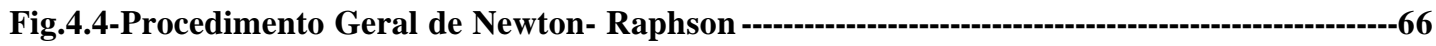

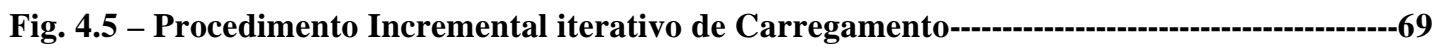

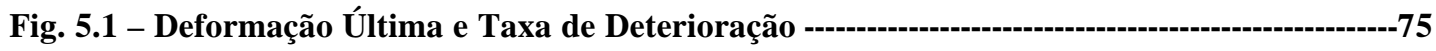

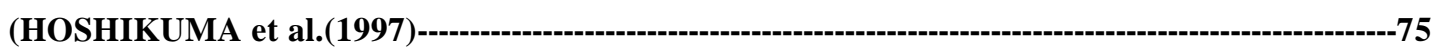

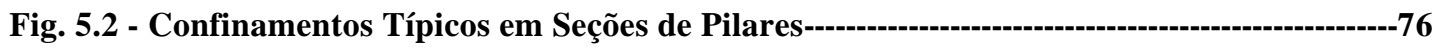

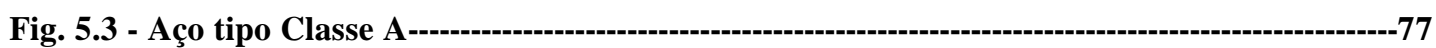

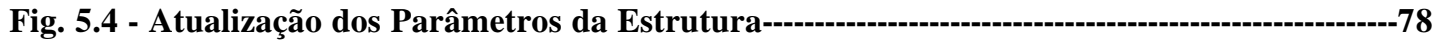

Fig. 5.5(a) - Discretização: Conformação Curvilínea --------------------------------------------------80

Fig. 5.5(b) - Discretização: Conformação Tronco - piramidal ------------------------------------------80

Fig. 5.5(c) - Discretização: Conformação Prismática----------------------------------------------------81

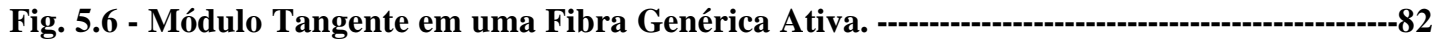

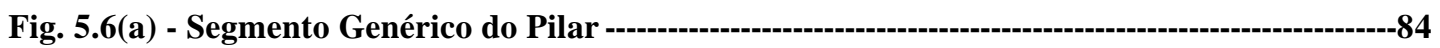

Fig. 5.7 - Discretização da Seção de Concreto Armado-------------------------------------------------85 
Fig.5.10 - Fluxograma Esquemático do Programa NLF

Fig. 5.8 - Deformações na Seção Não Fissurada.

Fig. 5.9 - Deformações na Seção Fissurada na Idade $-95$

Fig. 5.10 - Consideração do efeito da fluência do concreto 97

Fig. 6.1 - Curva p-y para Argila Mole - Carga Estática 102

Fig. 6.2 - Resistência $S_{u}$ vs. $\boldsymbol{E}_{50}$ 102

Fig. 6.3 - Resistência $p_{u}$ da Argila Média Submersa 103

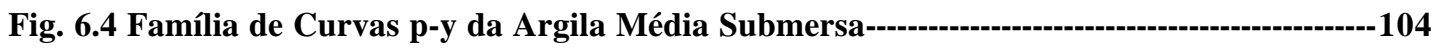

Fig. 6.5 - Resistência $p_{u}$ da Argila Rija Não Submersa-------on

Fig. 6.6 - Família de Curvas p-y da Argila Rija Não Submersa (carga estática) -----------------105

Fig. 6.7 - Valores de $A_{s}$ e $A_{c}$ $-106$

Fig. 6.8 - Valores de $B_{s}$ e $B_{c}$ 107

Fig. 6.9 - Características de uma Família de Curvas p-y para a Areia[COX, REESE, \& GRUBBS (1974)] 109

Fig. 6.10 - Resistência Última da Areia Média Submersa Adotada 110

Fig. 6.11 Curvas p-y para uma areia submersa de compacidade média 110

Fig. 6.12 - Elemento de contato CONTAC52 (Biblioteca do ANSYS) 112

Fig. 6.13 Rigidez a distorção do aparelho 113

Fig.6.14 - Rigidez normal do aparelho de apoio 114

Fig. 6.15 - Esquema Geral para a Análise de um Pilar Esbelto 118

Fig. 7.1 - Esquema do Pilar P1 do Eixo 3 120

Fig. 7.2 - Elemento COMBIN39 (ANSYS) 122

Fig. 7.3 - Discretização do Solo e do Conjunto Pilar-tubulão $-122$ 
Fig.7.4 - Deslocamentos do Conjunto nas Direções x e z ( com e sem NLG)

Fig. 7.5 - Momentos $M_{z}$ e $M_{x}$ com NLG

Fig. 7.6 - Momentos $M_{x}$ e $M_{z}$ sem NLG 125

Fig. 7.7 Deslocamentos Ux para 0,80EI 126

Fig. 7.8 Momento Fletor $M_{z}$ para a rigidez reduzida $0,8 E I$ 127

Fig. 7.9 - Esquema do Exemplo 2 128

Fig. 7.10 - Detalhes do modelo - Exemplo 2: Discretização - vista geral e mod. do solo -------134

Fig. 7.11 - Pórtico de Apoio do Eixo 2

Fig. 7.12 - Detalhe do Aparelho de Apoio de Neoprene 135

Fig. 7.13 - $M_{Z}$ no Tubulão T2 do Eixo 1 (Pilha 3) 135

Fig. 7.14 - Deslocamentos $U_{x}(m)$ no Tubulão $T 2$ do Eixo 1 136

Fig. 7.15 - Deslocamentos $U_{x}(m)$ no Tubulão T4 do Eixo 2 137

Fig. 7.16 - $M_{z}$ no Eixo 1(T2) para Pilha 1 de Ações 137

Fig. 7.17 - $M_{z}$ no Eixo 2(T4) para Pilha 1 de Ações 138

Fig. - 7.18 - Deslocamento $U_{x}$ nos Tubulões do Eixo 1(T2) $\mathbf{- 1 3 8}$

Fig. 7.19 - Deslocamento $U_{x}$ nos Tubulões do Eixo 2(T4) 139

Fig. 7.20 - Esquema do Exemplo 3 141

Fig. 7.21 - Vista Geral - Exemplo 3 145

Fig. 7.22 - Vista Geral - Simulação do Solo 146

Fig. 7.23 - Detalhes dos Apoios Lateral e Central146

Fig. 7.24 - Detalhes do Apoio da Superestrutura no Eixo Central 146

Fig. 7.25 - Deslocamentos Uz e Uz do Tubulão 6 147

Fig. 7.26 - Deslocamentos Ux e Uz no Pilar Central 148 
Fig. 7.27 - Momentos Fletores $M_{y}(k N . m)$ - Pilar Central -------------------------------------------149

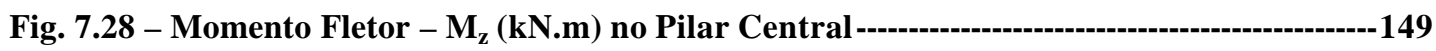

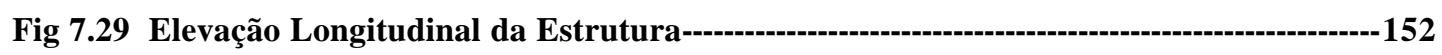

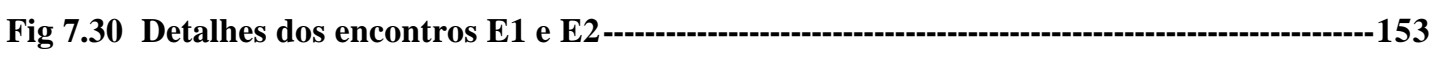

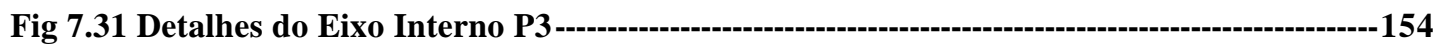

Fig 7.32 Seção transversal típica do tabuleiro ---

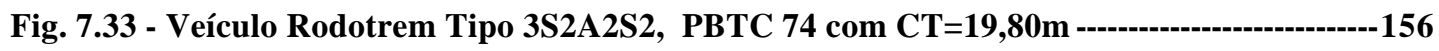

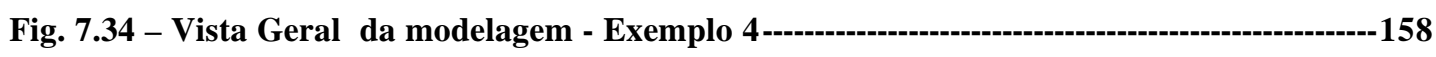

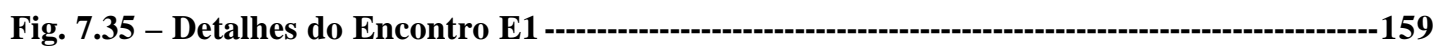

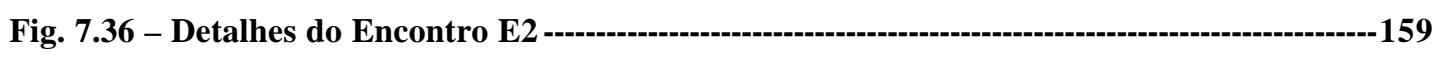

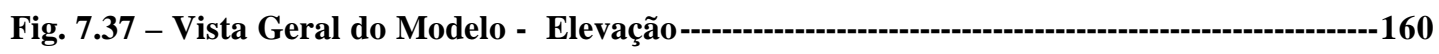

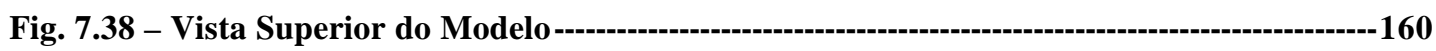

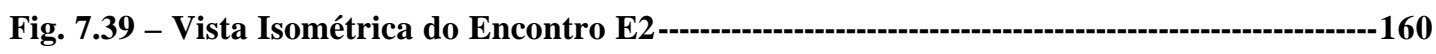

Fig. 7.40 - Eixo Interno Típico - Vista Isométrica do Eixo P2 ---------------------------------161

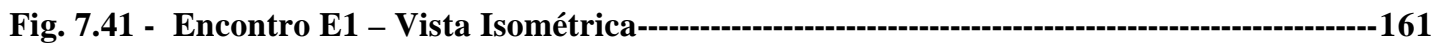

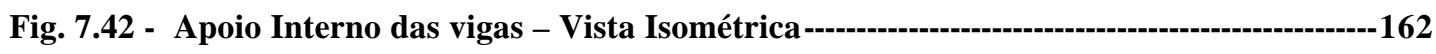

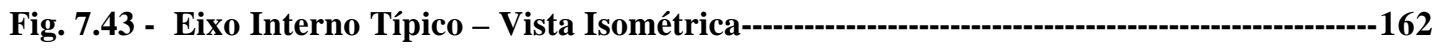

Fig. 7.44 - Disposição dos Aparelhos de Apoio nos Eixos Internos - Vista Isométrica-----------163

Fig. 7.45 - Detalhes do Apoio das Vigas nos Eixos Internos - Vista Isométrica -------------------163

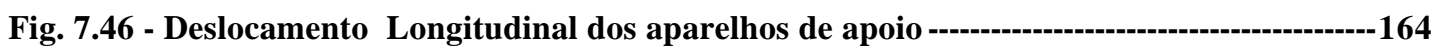

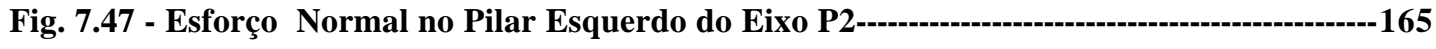

Fig. 7.48 - Momento Fletor Longitudinal no Pilar Esquerdo do Eixo P2-----------------------------165

Fig. 7.49 - Momento Fletor Transversal no Pilar Esquerdo do Eixo P2 ------------------------------166 
Fig. 7.50 - Deslocamento Longitudinal dos Aparelhos de Apoio

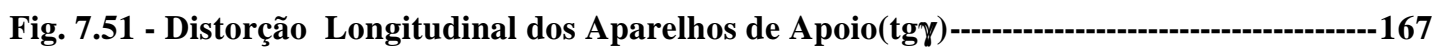

Fig. 7.52 - Esforço Axial no Pilar Esquerdo do Eixo P2 --------------------------------------------168

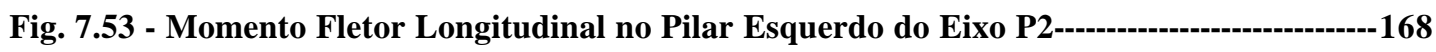

Fig. 7.54 - Momento Fletor Transversal no Pilar Esquerdo do Eixo P2 --------------------------169

Fig. 7.55 - Abertura Total das Juntas do Tabuleiro - Combinação Rara das Ações -------------169

Fig. 7.56 - Deslocamento Longitudinal dos Neoprenes para o Veículo Rodotrem Tipo 3S2A2S2,

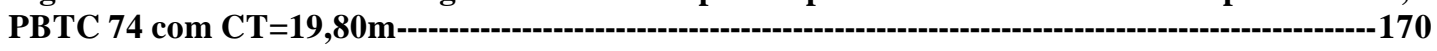

Fig. 7.57 - Deslocamento Longitudinal dos Neoprenes para Frenagem da Multidão -------------171

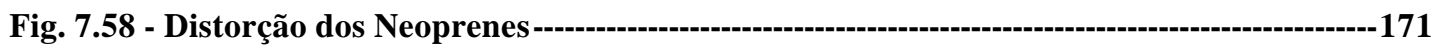

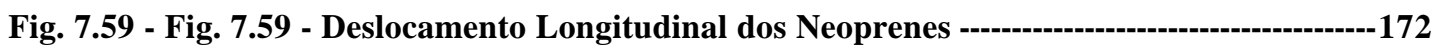

Fig. 7.60 - Momento Fletor Transversal Mx no Eixo P2 - Análise Linear -------------------------173

Fig. 7.61 - Momento Fletor Longitudinal Mz no Eixo P2 - Análise Linear-------------------------173

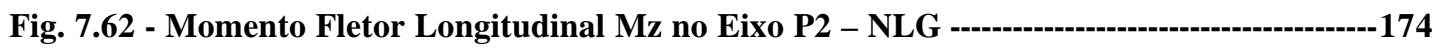

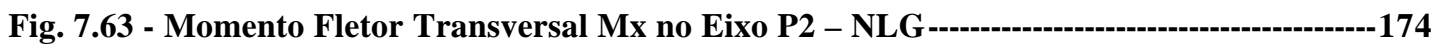

Fig. 7.64 - Esforço Axial no Pórtico do Eixo P2 - Análise Linear-------------------------------175

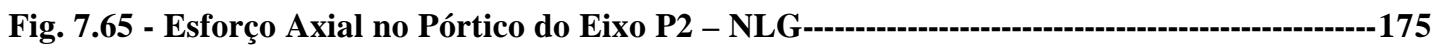

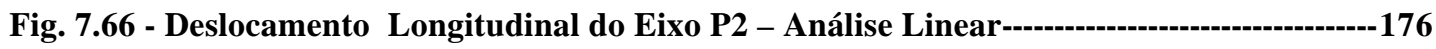

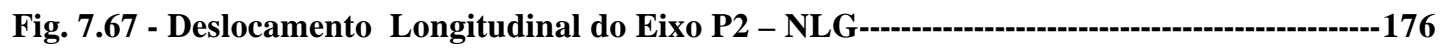

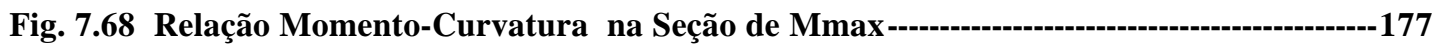

Fig. 7.69 - Relação Momento-Curvatura na Seção de Nmax -------------------------------------178

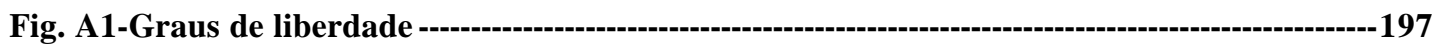

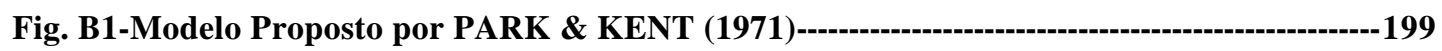


Fig. C1 - Módulos de reação horizontal adotados

Fig. C2 - Curva p-y para Argila Mole-Carga Estática$-206$

Fig. C3 - Curva p-y para Argila Mole-Carga Cíclica $-206$

Fig. C4 - Valores das Constantes $A_{s}$ e $A_{c}$ $-207$

Fig. C5 - Forma Característica das Curvas p-y para Argila Dura Submersa [Carregamento Estático (REESE et al - 1975)]

Fig. C6 - Forma Característica das Curvas p-y para Argila Dura Submersa - Carregamento

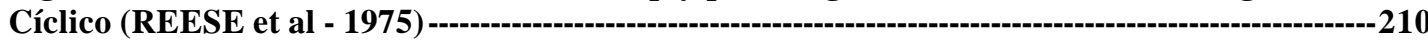

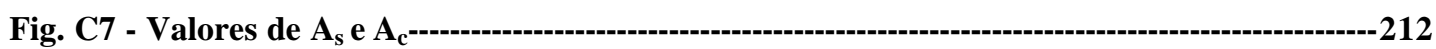

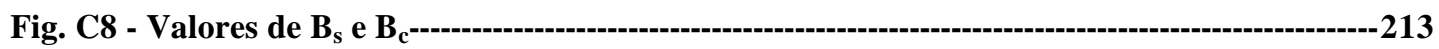

Fig. C9 - Características de uma Família de Curvas p-y p/ a Areia[COX, REESE, \& GRUBBS

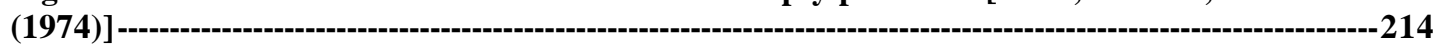




\section{LISTA DETABELAS}

Tabela 3.1 - Coeficiente deAjustamento C $-51$

Tabela 6.1 - Constantes de Reação Horizontal $k_{h}$ BOWLES(1977) $--99$

Tabela 6.2 - Valores típicos de $\varepsilon_{50}$ $\mathbf{- 1 0 0}$

Tabela 6.3 - Valores médios de $\gamma_{\mathrm{m}}$ para a argila $\mathbf{1 0 2}$

Tabela 6.4 - Valores Representativos de $k_{\mathrm{s}}$ para Areia $\mathbf{- 1 0 8}$

Tabela 6.5 - Curvas p-y para uma Areia Média Submersa$-111$

Tabela C1 - Valores de $\overline{\mathrm{K}}_{\mathrm{s} 1}\left(\mathrm{~N} / \mathrm{cm}^{3}\right)$ $-202$

Tabela C2 - Valores de $n_{h}\left(N / \mathrm{cm}^{3}\right)$ $-203$

Tabela C3 - Valores típicos de $\boldsymbol{\varepsilon}_{50}$ $-205$

Tabela C4: Valores de $k_{\mathrm{s}} k_{\mathrm{c}}$ e $\boldsymbol{\varepsilon}_{50}$ $-208$

Tabela C5 Valores representativos de $k$ para areia $-214$ 


\section{RESUMO}

KHOURI, M. E. (2001). Contribuição ao Projeto de Pilares de Pontes de Concreto Armado com Consideração das Não-linearidades Física e Geométrica e Interação Solo-estrutura. São Carlos, 2001, 231 p. Tese (Doutorado) - Escola de Engenharia de São Carlos, Universidade de São Paulo.

Este trabalho consiste no estudo dos fatores envolvidos no projeto estrutural de pontes, mais especificamente aqueles relacionados com o comportamento dos seus pilares. A análise é efetuada mediante uma modelagem única da estrutura integrada ao maciço de solos, onde as não-linearidades física e geométricas e interação solo-estrutura são consideradas. Inicialmente é feita uma abordagem sobre a concepção do projeto dos pilares e seus arranjos, destacando os problemas diretamente envolvidos no seu cálculo. É apresentada uma formulação simples, baseada em uma só fibra ativa, para levar em consideração a não linearidade física do concreto armado. A não-linearidade geométrica é tratada quanto aos seus aspectos e critérios de utilização, e também é apresentada uma formulação baseada na Energia Potencial Total para a obtenção da matriz de rigidez tangente da estrutura. O maciço de solos é modelado com dispositivos discretos parametrizados através de curvas de resistência lateral p-y. Os aparelhos de apoio são modelados através de elementos de contato devidamente parametrizados. Finalmente, são incluídos alguns exemplos numéricos de casos típicos de pontes.

Palavras-chave: Pilares; Pontes de concreto; Não-Linearidade Geométrica; Não-Linearidade Física; Interação solo-estrutura. 


\begin{abstract}
KHOURI, M. E. (2001). Contribution to the design of reinforced concrete bridges piers with consideration of material nonlinearity, change in geometry and interaction soil - structure. São Carlos, 2001, 231p. Ph.D. - Escola de Engenharia de São Carlos, Universidade de São Paulo.
\end{abstract}

This work deals with the study of factories involved in bridge structural design, specifically in regards with column behavior. The analysis is made by a unique model integrated in the soil massy, where the geometric and physics non-linearity and soil-structure interactions are taken into account. At first, it is made an approach about criteria and details of bridge column design. It is showed a simple formulation; based in one unique active fiber discretization, to consider the physics non-linearity of reinforced concrete Main aspects of geometrical non-linearity are presented. Also it is showed a formulation based in Total Potential Energy in order to obtain the structure tangent stuffiness matrix. The soil massy is modeled with discrete mechanisms by p-y lateral resistance curves. The bearing cushion pads are modeled by contact elements. At end, they are included some numerical examples of bridge typical structures.

Key-word column, concrete bridges, soil-structures interaction analysis, geometric non-linearity, physics and soil-structures interaction analysis non-linearity 


\section{CAPÍTULO 1}

\section{INTRODUCÃO}

\section{1 - ASPECTOS DO PROJETO DAS PONTES}

\subsection{1 - GENERALIDADES}

Em uma ponte, como nas demais obras de engenharia, há uma condição fundamental relativa a sua função: ter estabilidade e durabilidade por um certo período previamente estabelecido. Essas condições, se bem que essenciais em uma ponte, não devem ser únicas e nem exclusivas. De modo geral, a engenharia não deve se limitar ao mero estudo da estabilidade de suas construções. A idéia de responder, em parte, às exigências de concepção cada vez mais arrojadas das estruturas de pontes motivou esse trabalho nos termos em que foi proposto. Por outro lado a constante motivação econômica, existente em todos os empreendimentos, deve ser sempre levada em efeito, objetivando minimizar os custos e a utilização dos recursos disponíveis. Todos esses aspectos têm exigido do engenheiro a necessidade de um conhecimento cada vez mais preciso e refinado do comportamento estrutural dessas obras. É oportuno revisar, mesmo que de modo sucinto, o conceito de cálculo estrutural e, em particular, a fenomenologia existente no processo de análise de uma estrutura genérica.

Segundo QUIROGA (1983), pode-se distinguir três fases fundamentais no processo de análise de uma estrutura: Idealização, Cálculo e Interpretação. 
Introdução

Na primeira fase a obra de engenharia é convertida em um modelo matemático ou estrutural onde são inseridas as propriedades mais relevantes em relação a sua estabilidade. Na segunda fase, objeto específico do cálculo estrutural, analisa-se, mediante recursos procedentes de outras áreas (Matemática, Mecânica, Ciência dos Materiais, etc.), o modelo matemático da primeira fase, com o objetivo de obter uma série de resultados, cujo significado e aplicação à realidade da estrutura constitui a última fase do processo, denominada Interpretação. Compreende-se que, a Idealização Estrutural e a Interpretação dos resultados contêm elevada dose de experiência e intuição. É evidente que, por outro lado, essas fases se encontram profundamente inter-relacionadas. Com efeito, a interpretação e aplicação dos resultados de um cálculo, na realidade, dependem em grande parte da idealização do modelo considerado, e, contrariamente, a idealização pode ser influída de modo extraordinário pela classe particular de resultados ou efeitos estruturais, cujo conhecimento é o objeto da análise.

Em uma ponte, as considerações anteriores são de fundamental importância, uma vez que ela pode ser modelada em diversos tipos estruturais, aplicando-se ao cálculo da mesma ponte diferentes idealizações simultâneas. É necessário dar ênfase às diferentes técnicas e modelos de cálculo, e, ainda, estudar a conveniência, em cada caso, da idealização considerada e sua possível categoria de validade em relação aos resultados obtidos.

Provavelmente, um dos modelos mais significativos de cálculo é obtido com a introdução do conceito de linearidade.

Como é sabido, uma estrutura de comportamento linear deve cumprir simultaneamente as três condições básicas da linearidade:

- o material constitutivo deve ser linear elástico;

- o equilíbrio da estrutura é satisfeito considerando a estrutura não deformada, isto é, na sua configuração original;

- os quadrados dos deslocamentos e deformações são desprezíveis em comparação com a unidade, ou seja, a estrutura apresenta pequenas deformações. 
Introdução

Se alguma das condições anteriores não é satisfeita pela estrutura, o comportamento desta é não linear, surgindo, portanto, fundamentalmente algumas formas de não-linearidade:

- Estrutura de material não linear;

- Estrutura geometricamente não linear;

- Estruturas com grandes deformações,

- Mudança de "status"(alterações do modelo no decorrer da análise),

etc..

Outro aspecto, importante no cálculo das estruturas, surge ao se introduzir a dimensão do tempo na aplicação das cargas. Desse modo, pode-se falar em cálculo dinâmico, se as forças de inércia são levadas em consideração, e cálculo estático no caso contrário. Indubitavelmente, a aplicação de um cálculo estático ou dinâmico em uma estrutura real depende da importância das forças de inércia envolvidas e dos efeitos que se deseja conhecer na estrutura. Analogamente, pode-se aplicar essas considerações com referência à conveniência ou precisão de um modelo linear para descrever uma estrutura real. A decisão de se adotar um modelo ou outro depende de cada situação específica e constitui a essência da fase do processo da análise, denominada Idealização ou Modelagem, conforme comentado anteriormente.

A variável "tempo" pode, segundo outro enfoque de cálculo de estrutura, além das aplicações na dinâmica das ações, ser aplicada na descrição das características constitutivas dos materiais. Com efeito, a influência dos estados de carga anteriores na resposta estrutural, particularmente nas relações constitutivas do material componente (materiais com memória), implica em uma divisão dos modelos estruturais em modelos com ou sem fluência. Outra situação extremamente importante a ser observada, com relação à memória do material, se refere ao regime de carga e descarga, muito freqüente nas estruturas de pontes. A consideração da fluência nas pontes de concreto é clara, particularmente nos processos construtivos com esquemas estruturais evolutivos, isto é, que se modificam com o tempo, como o que ocorre nas "Pontes Integrais" (pontes cuja modelagem é alterada pela eliminação 
das juntas do tabuleiro prevista no projeto original) ou na técnica construtiva dos balanços sucessivos, onde o estado de deformação na estrutura é afetado pelo tempo. Não se deve esquecer também que o regime de carga e descarga do concreto pode afetar as características de rigidez global da estrutura pela redução da rigidez do material no decorrer desse processo. Atualmente, as três grandes divisões indicadas anteriormente, linear ou não, dinâmico ou estático, com fluência ou não, foram unificadas com o advento do computador, tanto do ponto de vista conceptual como metodológico. Isto não implica que a idealização em cada caso seja diferente ou específica. Por exemplo, o cálculo de estruturas de pontes tão distintas como o de uma viga contínua com laje de concreto ou de uma ponte estaiada pode ser realizado mediante o mesmo programa de computador formulado por elementos finitos: SAP, STRUDL, STRAP, ANSYS, LUSAS, etc.. A diferença entre as análises residirá não na forma de trabalho da estrutura em si, mas sim em outros aspectos, tais como: se a linearidade constitui uma hipótese adequada em ambas estruturas, ou se as forças inerciais ou a fluência do material podem ser importantes para certas categorias de cargas.

Em qualquer situação, exige-se o conhecimento completo das características da estrutura que se calcula: dimensões dos elementos constituintes e suas ligações, e as propriedades dos materiais que compõem a estrutura, isto é, a estrutura deve corresponder a uma obra real, já projetada, ou pelo menos prédimensionada. O papel do cálculo é comprovar e, às vezes, refinar a qualidade do projeto. O projeto se altera a partir das respostas obtidas em cada passo, e o cálculo se repete com uma nova estrutura modificada, conforme o caso. Esse esquema iterativo finaliza ao se alcançar um projeto cuja resposta estrutural é considerada satisfatória[QUIROGA (1983)].

\subsection{2- AS DIFICULDADES DA ANÁLISE ESTRUTURAL}

\subsubsection{1- Preliminares}

Com o advento e o contínuo aperfeiçoamento dos computadores eletrônicos, a análise das estruturas tem encontrado o respaldo necessário para o seu desenvolvimento quanto às suas metodologias. Um exemplo é a freqüente reorganização do método da rigidez, enquanto busca soluções cada vez mais precisas 


\section{Introdução}

para o comportamento das estruturas. Outro aspecto observado é a crescente sofisticação das técnicas construtivas e o arrojo, cada vez maior, das estruturas projetadas, obviamente amparadas pela disponibilidade dos métodos de análise, igualmente cada vez mais sofisticados.

O advento do Concreto de Alto Desempenho (CAD), possibilitando o projeto de estruturas cada vez mais esbeltas, está exigindo um enfoque analítico diferenciado, assim como a abordagem da questão da instabilidade da estrutura como um todo. Com o auxílio de computadores de grande capacidade, as teorias e métodos de difícil solução, como a análise não linear, estão tornando-se possíveis.

O comportamento não linear de uma estrutura pode estar relacionado a dois aspectos: a) a não linearidade geométrica (NLG) se refere às mudanças de geometria devido aos seus deslocamentos. Nesse caso, a matriz de rigidez $[\mathrm{K}]$ da estrutura é uma função dos seus deslocamentos $\{u\}$, isto é, ela se altera simultaneamente às alterações da forma da estrutura. As formulações da não linearidade geométrica com grandes deslocamentos, grandes deformações ou pequenas deformações são as mais freqüentes; b) a não linearidade física (NLF) se refere à resposta não linear do material constitutivo da estrutura. O Concreto Armado, assim como os materiais que o constituem, têm esse comportamento. Problemas, tais como caracterização do módulo de elasticidade, processo de fissuração sob solicitação ou não, ruptura frágil e deformações residuais são típicas do Concreto Armado.

\subsubsection{2- Módulo de Elasticidade do Concreto}

$\mathrm{Na}$ teoria convencional, presume-se que o módulo de elasticidade a tração seja igual ao da compressão para um material homogêneo. No concreto, por outro lado, algumas de suas características mecânicas são fortemente influenciadas pelo tipo e intensidade da solicitação, além de sofrerem alterações significativas ao longo do tempo. A ruptura frágil por deslizamentos internos, responsáveis pela indução de deformações permanentes que limitam o comportamento elástico do concreto, é fortemente influenciada pela natureza da solicitação. De fato, o limite elástico e a resistência a ruptura são da ordem de 10 vezes maiores na compressão do que na tração. Atingida a máxima tensão resistente, o concreto começa a 
experimentar um comportamento de regime de resposta instável com a crescente redução da solicitação necessária para produzir deformações adicionais. Em escala macroscópica, numa seção de concreto armado a fluência afeta significativamente o seu bloco comprimido. Mesmo para as cargas de curta duração, o módulo de elasticidade secante é consideravelmente mais variável do que a resistência a compressão $\mathrm{f}_{\mathrm{c}}$. Sobre o lado tracionado, existe a fissuração nas regiões de momentos fletores altos, enquanto que nas seções de momentos baixos o concreto pode permanecer íntegro, sem fissuração. O módulo secante a tração é essencialmente o mesmo da compressão quando a magnitude das tenções é baixa, mas o módulo reduz marcadamente para tensões próximas do nível da fissuração. Em ambos os casos, na tração e na compressão, o módulo de elasticidade real varia, não só com a magnitude das tensões entre as fibras extremas, mas também ao longo do vão de uma barra fletida. Além disso, a fluência e a retração reduzem o módulo de elasticidade a compressão, assim como amplificam os deslocamentos da barra significativamente ao longo de um período de tempo efetivo(Fig. 1.1).

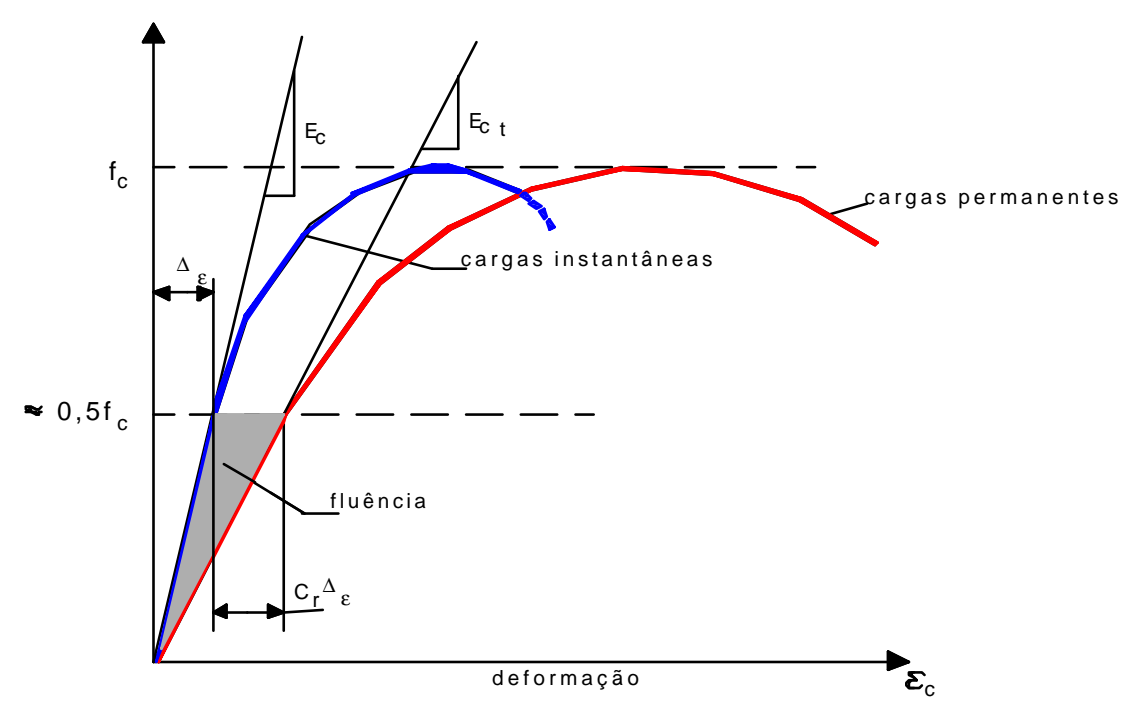

Fig. 1.1-Influência do Tempo em uma Curva Típica de $\sigma_{\mathrm{c}^{-}}-\varepsilon$

As observações relacionadas anteriormente sugerem o grau de complexidade enfrentado na modelagem do comportamento mecânico do concreto considerando-se o seu comportamento até a ruptura. Além do que foi exposto, há de se considerar também, a influência da armadura do Concreto Armado na alteração desse comportamento. No entanto, várias tentativas propõem simular tal 
Introdução

comportamento através de modelos constitutivos, alguns baseados em teorias, tais como elasticidade, plasticidade, mecânica da fratura, mecânica do dano, etc., e outros, até mesmo em modelos sugeridos por resultados experimentais.

\subsubsection{3-Rigidez à Flexão das Seções de Concreto}

Em complementação ao módulo de elasticidade, a rigidez à flexão $\mathrm{E}_{\mathrm{c}} \mathrm{I}$ depende do momento de inércia. O momento de inércia, mesmo onde as seções são constantes, varia consideravelmente ao longo do vão. Em análises, nas quais a avaliação dos deslocamentos ou nos casos onde a NLG é de interesse, os valores absolutos de $\mathrm{E}_{\mathrm{c}}$ e I devem ser bem determinados ou assumidos. O tema Momento de Inércia Efetivo para o cálculo dos deslocamentos, decorrentes das cargas de curta duração, tem merecido a atenção por parte de inúmeros pesquisadores. É sabido que a rigidez $\mathrm{E}_{\mathrm{c}} \mathrm{I}$ varia com a magnitude do momento fletor, em geral, da maneira mostrada na Fig. 1.2. A rigidez $\mathrm{E}_{\mathrm{c}} \mathrm{I}$ é maior para um nível baixo de carga, visto que a seção totalmente íntegra assume o maior momento de inércia efetivo possível. O momento de inércia da seção fissurada transformada cresce significativamente na proporção da taxa da armadura; seções com altas taxas de armadura ou submetidas simultaneamente a uma compressão axial alta, como é o caso dos pilares de pontes, devem exibir mudanças mais suaves na rigidez $\mathrm{E}_{\mathrm{c}} \mathrm{I}$ do que aquelas com baixas taxas de armadura ou submetidas apenas à flexão [BRANSON (1972)].

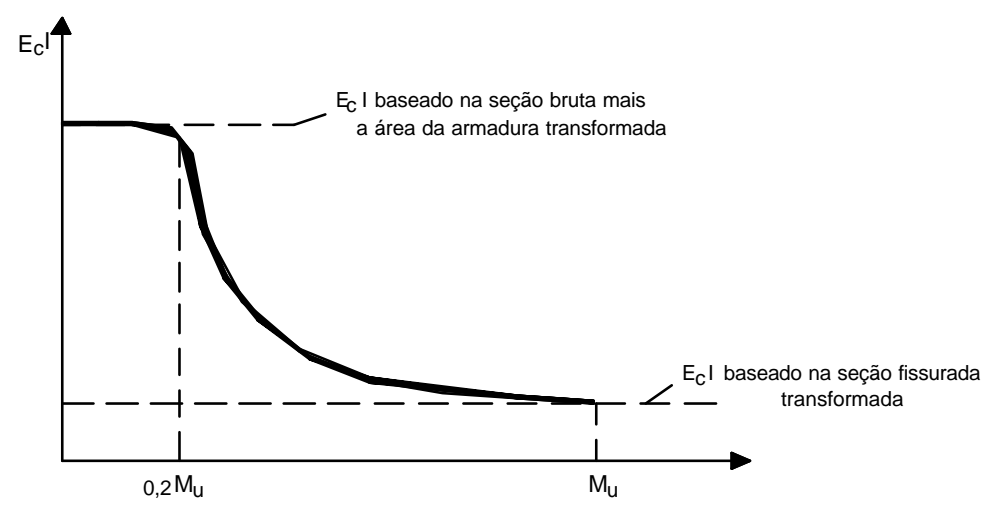

Fig. 1.2 - Variação Típica da Rigidez a Flexão $E_{\mathrm{c}} \mathrm{I}$

Para as cargas abaixo da carga de fissuração, os deslocamentos podem ser calculados com base na seção transversal bruta, com uma pequena diferença, quando se trata de se incluir ou não a influência da armadura no valor da rigidez (Fig. 
1.3). Entretanto, como a carga cresce acima da carga de fissuração, o momento de inércia se aproxima daquele da seção fissurada transformada, embora possa ser maior entre as fissuras [WANG \& SALMON (1985)].

A rigor, quando as peças de concreto armado são submetidas à flexão composta, o processo de fissuração e, consequentemente, a avaliação da rigidez depende da história do carregamento, isto é, da forma como são aplicados a força normal e os momentos fletores.

A maioria das normas técnicas trata o problema da esbeltez dos pilares considerando na análise não linear geométrica valores mais adequados da rigidez que, de uma forma ou outra, tentam refletir os efeitos da fissuração, armaduras e o efeito da duração do carregamento. Os códigos internacionais, American Concrete Institute (ACI), Comité Euro-Internacional du Beton (CEB) e as normas estruturais específicas da ABNT têm recomendado uma variedade de métodos para considerar o comportamento não linear do material nas estruturas de concreto armado.

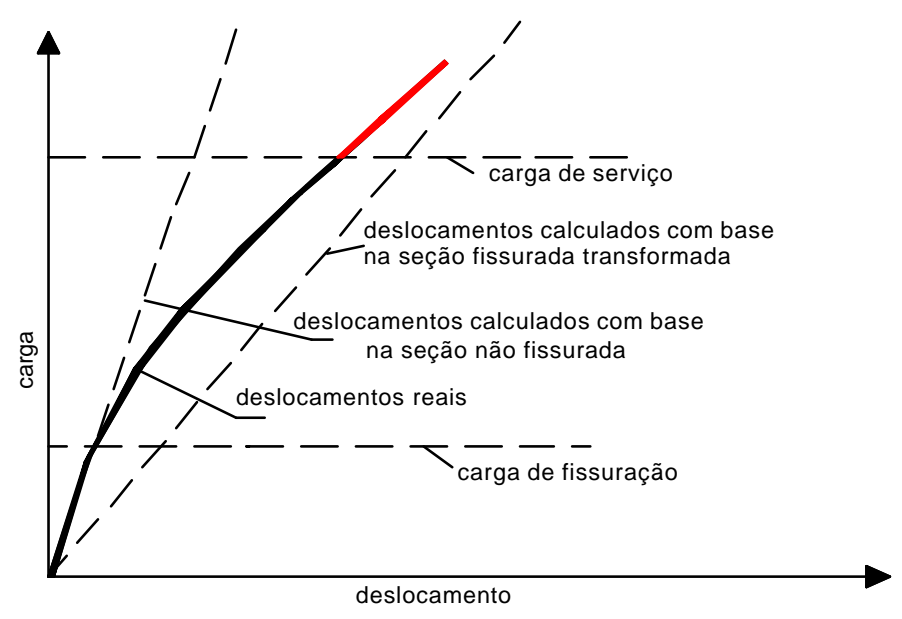

Fig. 1.3 - Curva Típica Carga vs. Deslocamento em Vigas de Concreto Armado

$\mathrm{Na}$ tentativa de possibilitar o uso dos Processos Simplificados para a avaliação dos efeitos de segunda ordem, alguns valores de $\mathrm{E}_{\mathrm{c}} \mathrm{I}$ são sugeridos pelas normas estruturais com a intenção de refletir o comportamento não linear do concreto e do aço, a quantidade de armadura, a extensão e distribuição da fissuração, os efeitos reológicos e a variação da rigidez ao longo da barra. Esses fatores são 
Introdução

difíceis de serem considerados nas análises aproximadas de sistemas estruturais mais complexos [SILVA (1996)].

MAcGREGOR \& HAGE (1977) recomendaram os valores de $0,4 \mathrm{E}_{\mathrm{c}} \mathrm{I}_{\mathrm{g}}$ nas vigas e $0,8 \mathrm{E}_{\mathrm{c}} \mathrm{I}_{\mathrm{g}}$ nos pilares para computar os efeitos não lineares. VASCONCELOS \& FRANCO (1991) sugeriram, da mesma forma, 0,5 $\mathrm{E}_{\mathrm{c}} \mathrm{I}_{\mathrm{g}} \mathrm{e}$ $0,8 \mathrm{E}_{\mathrm{c}} \mathrm{I}_{\mathrm{g}}$, respectivamente, para vigas e pilares, ou alternativamente $0,7 \mathrm{E}_{\mathrm{c}} \mathrm{I}_{\mathrm{g}}$ para a rigidez inicial na estrutura como um todo, sem fazer referência ao tipo de estrutura ou quaisquer outros fatores dos quais $E_{c} I_{g}$ depende. MAcGREGOR(1993) faz referência ao trabalho de FURLOG(1980) que sugeriu valores de rigidez para os pilares de edifícios em função da sua posição com relação aos andares. FURLOG(1980) sugere o valor de $\mathrm{EI}_{\mathrm{ef}}=0,6 \mathrm{EI}_{\mathrm{g}}$ para os pilares localizadas nos andares inferiores e $\mathrm{EI}_{\mathrm{ef}}=0,3 \mathrm{E}_{\mathrm{c}} \mathrm{I}_{\mathrm{g}}$ para os pilares dos andares superiores, evidenciando claramente que a rigidez $\mathrm{EI}_{\mathrm{ef}}$ é significativamente sensível ao nível de compressão atuante sobre elas. As normas ACI 318-89 (R 1992) e a NBR 7187 sugerem, em substituição aos processos mais rigorosos, expressões que fornecem o valor da rigidez efetiva em função da taxa geométrica da armadura:

$$
\begin{aligned}
& \text { ACI 318-89 } \rightarrow(\mathrm{EI})_{\mathrm{ef}}=\left(0,6+20 \rho_{\mathrm{t}}\right) \mathrm{E}_{\mathrm{c}} \mathrm{I}_{\mathrm{g}}, \\
& \text { NBR } 7187 \rightarrow(\mathrm{EI})_{\mathrm{ef}}=\left(0,7+4,2 \rho_{\mathrm{t}} \mathrm{E}_{\mathrm{s}} / \mathrm{E}_{\mathrm{c}}\right) \mathrm{E}_{\mathrm{c}} \mathrm{I}_{\mathrm{g}} \quad \text { onde, } \\
& \rho_{\mathrm{t}}=\text { taxa geométrica de armadura; } \\
& \mathrm{E}_{\mathrm{c}} \text { e } \mathrm{I}_{\mathrm{g}} \text { são, respectivamente, o módulo de elasticidade do concreto e }
\end{aligned}
$$
momento de inércia da seção bruta da barra. $\left[\mathrm{MPa}, \mathrm{cm}^{4}\right]$.

A pesquisa de um perfil de variação da rigidez EI nos pilares, especificamente no caso de pilares de pontes, segundo os históricos usuais de carregamento e demais fatores é relevante, e representa ainda uma lacuna. Essa avaliação é extremamente importante no sentido de propor a substituição dos modelos que consideram a não linearidade física por modelos equivalentes mais simples e menos onerosos em termos de projeto.

\subsubsection{4-Interação Solo-Estrutura}

O elemento solo, para onde todas as ações sobre a ponte são transferidas, representa um dos parâmetros mais importantes da análise da estrutura 
devido a sua forte influência no comportamento dos pilares. Pode-se imaginar o solo, juntamente com os elementos estruturais que constituem as fundações, representados por apoios flexíveis $K_{i}$; que no caso geral são em número de seis (Fig. 1.4). Esses apoios devem simular o solo, em termos de respostas mecânicas às ações provenientes da superestrutura. Sem dúvida, será conveniente e mais confiável proceder-se a um cálculo integrado da estrutura com as fundações de modo acoplado, sobretudo para avaliar a influência dessa interação no comportamento não linear dos pilares.

Segundo AOKI (1986), o estudo da interação solo-estrutura exige uma modelagem única do sistema, onde devem ser acoplados sob uma visão integrada os sistemas estrutural e geotécnico. É nesse acoplamento que se imporão os mecanismos de transferência de carga para o solo através de estacas ou tubulões isolados ou em grupo. Dentro desse enfoque, deve ser considerado um modelo de transferência de carga que considere o maciço de solos com comportamento não linear e as cargas ao longo e sob a base dos elementos estruturais de fundação, além dos movimentos decorrentes das deformações do maciço (Fig. 1.5).

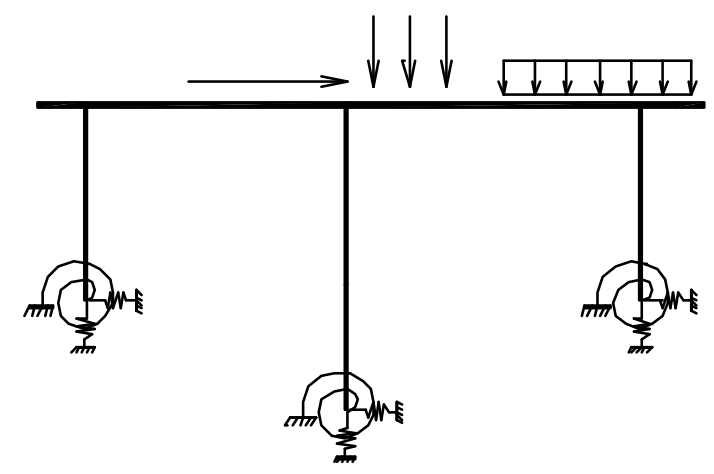

Fig. 1.4 - Sistema Solo-Estrutura: Modelo Desacoplado

A análise da estrutura deve ser feita com um modelo estrutural realista ou o mais próximo possível do modelo físico. Esta tendência fica cada vez mais clara nas recomendações contidas na maioria das normas de estruturas a medida que a pesquisa municia com recursos o campo de aplicação no sentido de viabilizar esta prática como rotineira. Não fugindo à regra, o próprio Projeto de Revisão da NB 1/1999 dá a seguinte indicação (item 14.1.2): 
“A análise deve ser feita com um modelo estrutural realista, que permita representar de maneira clara todos os caminhos percorridos pelas ações até os apoios da estrutura e que permita também representar a resposta não linear dos materiais. Em casos mais complexos a interação solo-estrutura deve ser contemplada pelo modelo"
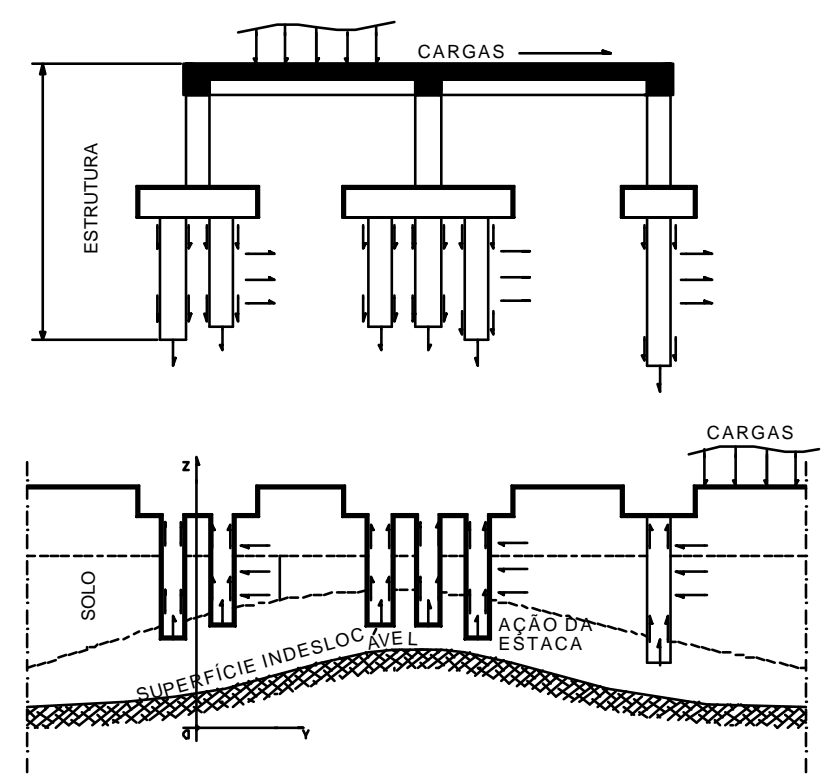

Fig. 1.5 - Sistema Solo-estrutura: Modelo Acoplado [adaptado de AOKI (1986)]

\section{2 - OBJETIVOS DESTE TRABALHO}

O objetivo principal deste trabalho é o de fornecer alguns subsídios para projeto de pilares de pontes de concreto armado tendo em vista o que recomendam as normas técnicas quanto à consideração das não-linearidades física e geométrica, além da consideração dos efeitos da interação solo-estrutura no comportamento dos pilares. Devido às particularidades e a grande diversificação das ações atuantes nesse tipo de estrutura, procura-se justificar a limitação da aplicabilidade dos Métodos Aproximados e as vantagens e necessidade da adoção da análise integrada para o cálculo de pilares de pontes. Objetiva-se também sugerir, para os pilares, uma rigidez equivalente em substituição à complexidade da nãolinearidade física do Concreto Armado. Com utilização de modelagens mais realistas na análise, onde a não-linearidade geométrica e uma rigidez equivalente estão associadas de forma integrada às fundações, visa fornecer ao projetista de pontes 


\section{Introdução}

indicações mais seguras para a análise das suas estruturas quanto aos seguintes aspectos:

- Avaliar a possibilidade, com base em análises numéricas de casos típicos de estruturas de pontes, de substituir a não-linearidade física do Concreto Armado por um modelo elástico linear simplificado aplicável aos pilares e aos elementos da infra-estrutura;

- Demonstrar a necessidade e as vantagens da adoção da análise integrada às fundações nos casos de estruturas deslocáveis esbeltas (Obs. Na presença de estacas inclinadas asituação é mais amena);

- Avaliar os efeitos da deformabilidade das fundações no comportamento dos pilares de pontes;

- Avaliar os efeitos da mudança de "status" da estrutura pela eliminação das juntas dos tabuleiros nas chamadas "Pontes Integrais".

\section{3 - JUSTIFICATIVA}

A maioria das normas estruturais impõe que o cálculo dos pilares deve ser baseado nos esforços (forças e momentos) obtidos da análise da estrutura. Neste cálculo, deverão ser considerados: a influência da força axial, a influência da variação do momento de inércia da seção transversal sobre a rigidez do pilar, a influência dos momentos e deslocamentos das extremidades do pilar, além dos efeitos da duração das cargas. Nesse caso, fica subentendido que devem ser considerados os efeitos da fluência e os efeitos dos movimentos das fundações e da estrutura na qual o pilar está inserido. Sem exceção, todas estas normas sugerem procedimentos aproximados alternativos para o cálculo de pilares em substituição aos métodos mais gerais e mais rigoroso [MC 90, ACI 31889 (R 1992), NB 1/1999 (PR), etc.].

Por conveniência de análise, a despeito da conceituação morfológica, as normas classificam, segundo um outro enfoque, as estruturas em deslocáveis e não deslocáveis. As estruturas onde os deslocamentos horizontais não são pequenos, e por conseqüência, os efeitos globais de $2^{-}$ordem são importantes (superiores a $10 \%$ 
Introdução

dos respectivos de $1^{\underline{a}}$ ordem), são denominadas estruturas deslocáveis. No dimensionamento dos pilares dessas estruturas devem ser obrigatoriamente considerados tanto os esforços de $2^{\underline{a}}$ ordem globais quanto os locais, além da não linearidade física do material. Por outro lado, quando os deslocamentos dos nós da estrutura são pequenos (com efeitos de segunda ordem inferiores a $10 \%$ dos respectivos de $1^{\text {a }}$ ordem), essas estruturas são consideradas não deslocáveis. Nelas é permitida a consideração somente dos efeitos da não-linearidade local, isto é, cada elemento comprimido é considerado isolado, como uma barra vinculada nas suas extremidades aos demais elementos estruturais que ali concorrem, onde se aplicam os esforços obtidos pela análise da estrutura efetuada segundo a teoria de $1^{\mathrm{a}}$ ordem.

Quando não for possível a utilização de um programa de análise ou métodos de análise que considerem a interação entre o carregamento e os deslocamentos, as normas sugerem a utilização de procedimentos aproximados, com aplicação restrita somente aos elementos comprimidos não deslocáveis. Esses métodos são todos baseados no comprimento efetivo do pilar $\left(\mathrm{kL}_{\mathrm{u}}\right)$, que no caso do ACI 31889 (R 1992) serve para determinar os fatores amplificadores de momento, ou os momentos adicionais de $2^{\mathrm{a}}$ ordem no caso do CEB/FIP. A análise de elementos isolados comprimidos, através dos Métodos Aproximados, é aplicável apenas àqueles de seção e armadura constantes ao longo de seu eixo quando submetidos à flexocompressão normal.

O ACI 318/89 (R 1992) dispensa a consideração dos efeitos de $2^{\mathrm{a}}$ ordem locais em elementos comprimidos não deslocáveis para índices de esbeltez $\lambda=$ $\mathrm{kL}_{\mathrm{u}} / \mathrm{r}<34-12 \mathrm{M}_{1 \mathrm{~A}} / \mathrm{M}_{1 \mathrm{~B}}$. Para os elementos comprimidos isolados deslocáveis, os efeitos de $2^{\mathrm{a}}$ ordem podem ser, do mesmo modo, desprezados para $\lambda=\mathrm{kL} / \mathrm{r} / \mathrm{r}<22$. Os valores $\mathrm{M}_{1 \mathrm{~A}}$ e $\mathrm{M}_{1 \mathrm{~B}}$ representam os momentos fletores de $1^{\mathrm{a}}$ ordem nas extremidades do pilar. Em quaisquer elementos comprimidos $\operatorname{com} \lambda=\mathrm{kL}_{\mathrm{u}} / \mathrm{r}>100$, uma análise geral mais rigorosa deve ser aplicada. A NB 1/1999 (PR) e o MC 90 sugerem, igualmente, limites para a dispensa dos efeitos de $2^{\mathrm{a}}$ ordem locais e os limites para a aplicabilidade dos Métodos Aproximados. Em nenhum caso é admitido pela NB 1/1999 (PR), a análise de pilares como isolados quando o índice de esbeltez $\lambda$ for superior a 200, obrigando-se que seja aplicado aos pilares com $\lambda>140$ um método 
geral mais rigoroso. Na NBR 7187 (ABNT), encontram-se também as seguintes referências com relação ao cálculo dos pilares de pontes: os efeitos de $2^{\mathrm{a}}$ ordem devem ser considerados para elementos com $\lambda>25$, e, do mesmo modo, restringe a aplicação dos Métodos Aproximados aos pilares com $\lambda \leq 140$. Nos casos em que $\lambda>140$, deve-se aplicar um método mais geral sem, no entanto, limitar a esbeltez dos pilares em qualquer caso.

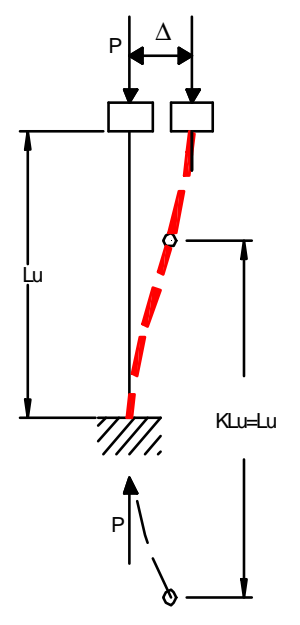

[a]

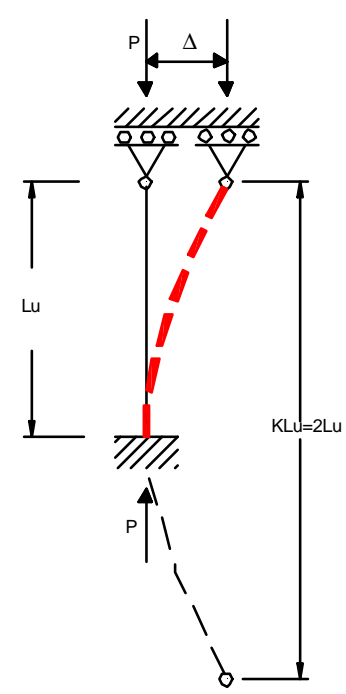

[b]

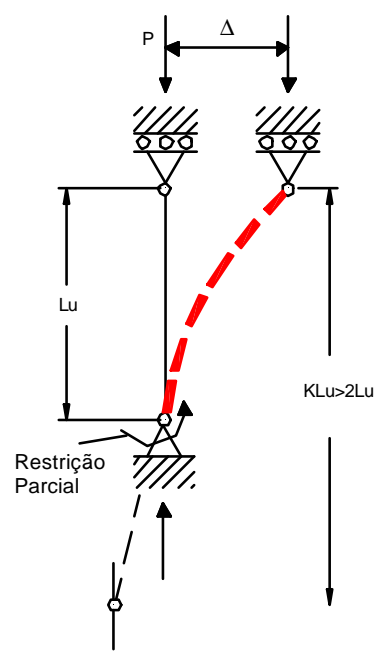

[c]

Fig. 1.6(a, b, c) - Influência das Condições de Apoio no Valor de $\mathrm{kL}_{\mathrm{u}}$

Uma das grandes dificuldades para caracterizar a deslocabilidade da estrutura de uma ponte, ou a esbeltez dos seus pilares, deve-se ao fato de que os procedimentos sugeridos pelas normas são, além de precários, direcionados freqüentemente aos casos de edifícios de andares múltiplos para um único plano de flexão e não levam em consideração a deslocabilidade das fundações ou o grau de restrição no topo dos pilares (Fig.1.6).

A determinação do fator $\mathrm{k}$, como se vê, depende das condições de mobilidade, tanto à rotação quanto à translação das extremidades do pilar.

Outro agravante é que os pilares de concreto armado, ao invés de serem elementos isolados, são em geral parte de grandes pórticos, devendo, portanto, 
serem tratados neste contexto, isto é, suscetíveis as suas características de deslocabilidade e combinação de esforços.

No tratamento racional correto de elementos esbeltos, em tais pórticos, deve-se levar em conta as reais condições de vinculação proporcionadas pelos membros contíguos ao pilar estudado, bem como se o pórtico é ou não deslocável como um todo. No caso dos pilares de pontes, essas condições são inerentes às características das fundações na sua base e às condições de sua ligação no seu topo com a superestrutura. Tradicionalmente, o cálculo de um pilar de um pórtico é feito através de uma analise elástica, onde a rigidez dos seus membros é obtida da seção transversal não fissurada, e os efeitos secundários decorrentes dos seus deslocamentos referentes ao esforço axial e a redução na rigidez são desprezados. Cada membro da estrutura é analisado e investigado usando as solicitações da análise nominal elástica.

Na ausência de uma análise conveniente de $2^{\mathrm{a}}$ ordem para a obtenção dos esforços mais exatos, um membro comprimido impedido por outros membros conectados nas suas extremidades pode ser considerado removido do seu pórtico e ser representado por um pilar simplesmente apoiada equivalente, cujo comprimento é igual ao comprimento efetivo $\mathrm{kL}_{\mathrm{u}}$, com uma carga axial de compressão igual ao do pilar real. Essa é a hipótese fundamental na qual os procedimentos simplificados se baseiam.

Outra dificuldade observada, quanto ao uso da análise nominal elástica em pórticos de concreto armado, se refere ao momento de inércia da seção não fissurada utilizado na rigidez das vigas. Neste caso, o efeito do grau da vinculação com os pilares é considerado superestimado. Se uma viga é fissurada sob carga de serviço, mas assumida não fissurada, o montante do momento transmitido para os pilares será subestimado; esta é uma situação comum. Uma outra dificuldade, talvez a mais restritiva à aplicação dos Métodos Aproximados, reside exatamente na avaliação do fator k do comprimento efetivo do pilar [PAGAY et al. (1970)]. Os ábacos sugeridos pelo Structural Stability Research Council Guide [JONSTON (1976)] dão uma noção da complexidade e o cuidado que a obtenção do comprimento de flambagem requer. Esses ábacos, constantes dos textos da NBR 
8800 (ABNT) e no ACI 31889 (R 1992), permitem a determinação do parâmetro k para alguns casos específicos, em função de dois fatores de restrição de extremidade $\psi_{\mathrm{A}}$ e $\psi_{\mathrm{B}}$ (Fig. 1.7). Para os nós do topo e da base de um pilar, $\psi_{\mathrm{A}}$ e $\psi_{\mathrm{B}}$ são ambos definidos como:

$$
\Psi=\frac{\sum \frac{\mathrm{EI}}{\mathrm{L}_{\mathrm{c}}}}{\sum \frac{\mathrm{EI}}{\mathrm{L}_{\mathrm{b}}}} \quad \text { onde, }
$$

os valores de $\frac{E I}{L_{c}}$ e $\frac{E I}{L_{b}}$ se referem respectivamente aos pilares e às vigas no plano de flexão.

Esses ábacos simulam, indiretamente, a flexibilidade à rotação nas extremidades do pilar por intermédio da rigidez EI/L de todas os elementos lineares que se conectam, tanto no topo como na base do pilar. Observa-se desses ábacos que os valores de k, variando entre zero e $\infty$, podem simular condições intermediárias de restrição de apoio entre a rótula e o engastamento teoricamente perfeitos. Na prática, algumas normas e autores tentam simular as condições reais de apoio através de valores mínimos de $\psi$ no intuito de simular a flexibilidade das fundações e da sua ligação na base dos pilares sem, no entanto, se referirem ao seu tipo e muito menos ao tipo do solo onde as mesmas se apoiam. Algumas outras condições restritivas ao uso desses ábacos são inerentes ao seu próprio desenvolvimento: 1) Todas os pilares atingem suas respectivas cargas críticas simultaneamente; 2) A estrutura é supostamente constituída por pórticos de formação simétrica e 3) As vigas são consideradas sem compressão.

Por meio desses ábacos, pode-se calcular o parâmetro k para um pilar de seção constante de um andar de um pórtico plano. Nos pórticos metálicos, onde o material é homogêneo e isotrópico, o módulo de elasticidade é constante em todos os membros da estrutura e o momento de inércia I é calculado para a seção bruta. No caso do concreto armado, o valor de $\mathrm{E}_{\mathrm{c}}$ varia com a resistência do concreto e a magnitude do carregamento, enquanto que I, além de depender da fissuração, também depende da porcentagem da armadura. O ACI 318/89 (10.11.2.2) preconiza 
que o parâmetro $\mathrm{k}$, do comprimento efetivo de flambagem para estruturas deslocáveis, seja obrigatoriamente avaliado com a devida consideração dos efeitos da fissuração e da armadura sobre a rigidez dos membros do pórtico.

Em resumo, duas dificuldades, além de outras, restringem a aplicação dos Métodos Simplificados ao cálculo de pilares esbeltos deslocáveis: a) a incerteza de uma avaliação segura da esbeltez do pilar $\left(0 \leq \lambda=\mathrm{kL}_{\mathrm{u}} / \mathrm{r} \leq \infty\right)$ necessária à aplicação desses métodos; b) a dificuldade de se aplicar um perfil de variação da rigidez EI, devido ao processo de fissuração ou devido à própria conformação geométrica do pilar. A essas dificuldades, soma-se outro aspecto bastante significativo: a necessidade de uma definição cuidadosa do grau de restrição aos deslocamentos, tanto no topo quanto na base dos pilares de uma ponte que, de certa forma, acentua a suspeita de que a utilização dos Métodos Simplificados, nesses casos, fica inviabilizada diante dessas incertezas.
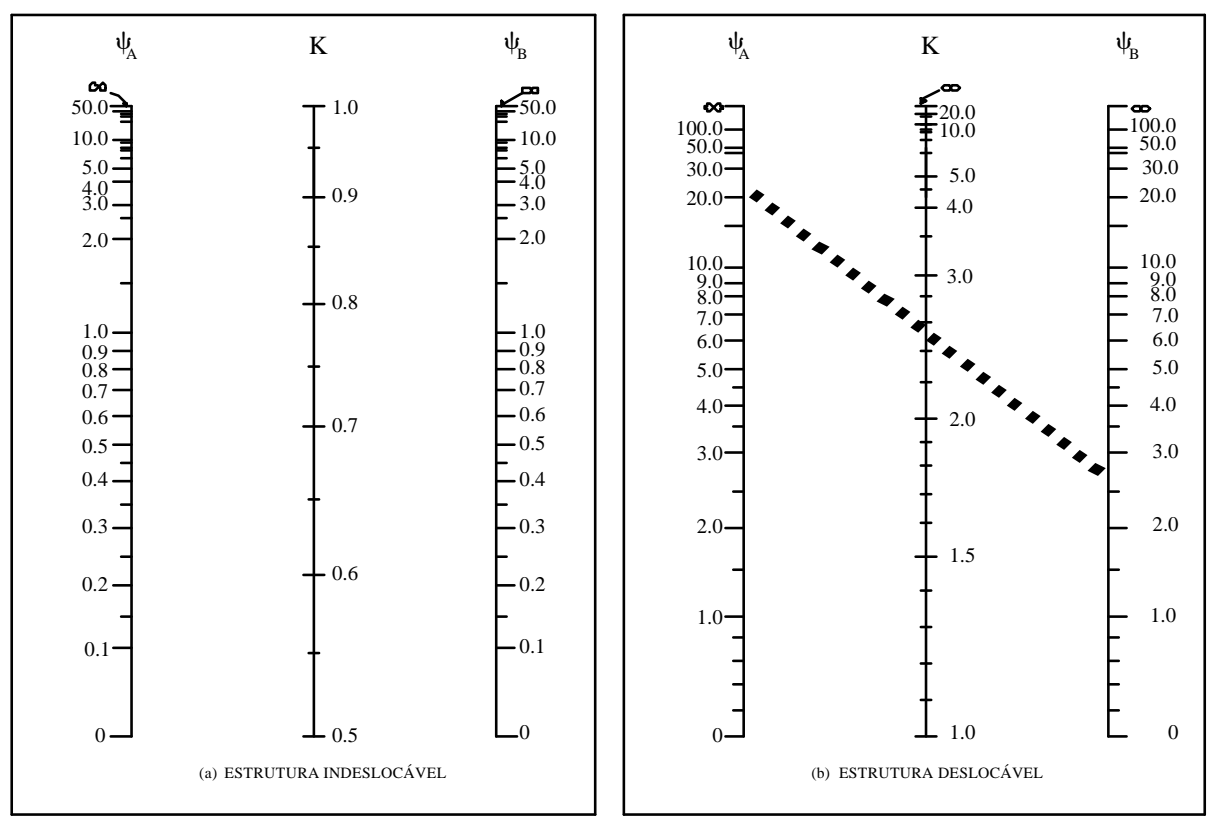

Fig. 1.7 - Ábacos para a Determinação do Parâmetro k (adaptado da NBR 8800 $\mathrm{ABNT})$

A crescente utilização de elementos comprimidos esbeltos de Concreto Armado nas estruturas de pontes e viadutos, associada à complexidade de sua análise, tem exigido dos projetistas de estrutura a necessidade de uma visão mais 
Introdução

criteriosa e realista quanto ao comportamento desses elementos. Outro fato, também restritivo à aplicabilidade dos Métodos Simplificados, se refere à tendência observada nos projetos quanto às formas estéticas arrojadas, utilizando, além de pilares esbeltos, formas prismáticas e não prismáticas, e formas curvilíneas ao longo da altura; além de uma gama considerável de tipos de seções transversais, que vão desde as seções retangulares e circulares maciças até seções vazadas de formatos diversos.

Questões como pilares sujeitos a grandes deslocamentos, forma arquitetônica e seções transversais mais complexas, não linearidade física e a própria interação da superestrutura com a infra-estrutura devem ser tratadas de forma geral e integrada no projeto. Um fato que pode perfeitamente justificar essa última afirmativa é a incerteza na determinação dos efeitos de segunda ordem das forças normais e a distribuição das ações horizontais (frenagem, vento, variação de temperatura, etc.) na estrutura de uma ponte sem se considerar a flexibilidade da infra-estrutura que a apoia.

É extremamente relevante que o perfil da variação da rigidez EI nos pilares, especificamente no caso de pontes, seja avaliado com relação às combinações das ações, taxas de armadura usuais, tipos de pilares, efeitos do tempo, etc., no sentido de propor a substituição da análise não linear física por modelos equivalentes mais simples e menos onerosos em termos de projeto.

\section{4 - METODOLOGIA}

A metodologia adotada nesse trabalho é fundamentada na análise numérica não linear de estruturas típicas de pontes, envolvendo a utilização do programa ANSYS para o processamento da não-linearidade geométrica com material em regime linear elástico. A consideração da não-linearidade física do Concreto Armado dos pilares e elementos da infra-estrutura é considerada através da calibragem dos parâmetros internos da matriz de rigidez elástica da estrutura para as combinações usuais das ações na estrutura. O fator motivador da adoção dessa estratégia reside na vantagem de se aproveitar todos os recursos e flexibilidade já implementados em um programa de grande porte, restando para a consecução dos objetivos a elaboração de um programa complementar que permita ajustar a rigidez 
Introdução

das seções através de um valor representativo para um determinado histórico de carregamento. A interação da estrutura com o maciço de solos é considerada através de elementos discretos acoplados às estacas ou tubulões calibrados por curvas de reação horizontal do solo. Para o que se propõe, foram realizadas seguintes etapas:

1- Revisão Bibliográfica

A obtenção de dados e informações em publicações científicas especializadas, dissertações e teses voltadas às áreas de interesse, segundo os objetivos mencionados, objetivou identificar e justificar a necessidade de aplicar procedimentos mais rigorosos no cálculo de pilares de pontes. Três foram as áreas de interesse na obtenção dessas informações: Análise Estrutural, Concreto Armado e Geotecnia.

Dentre os trabalhos, destacam-se as propostas de GALHI \& FAVRE (1994), COSENZA \& DEBERNARDI (1997) e do MC 90, onde estão embutidos na modelagem física do Concreto Armado os conceitos de valores médios representativos e efeitos diferidos. O trabalho desenvolvido por HOSHIKUMA et al. (1997), bastante significativo, avalia a influência da armadura transversal na ductilidade do bloco comprimido das seções tipicamente usadas em pilares de pontes e sugere uma relação constitutiva para o concreto comprimido. $O$ trabalho de POSTON et al. (1983) merece referência quanto à orientação e fornecimento de dados úteis à implementação do modelo físico para as peças axo-flexionadas de concreto armado.

A influência do solo no sistema é considerada através das curvas de reação horizontal sobre o fuste das estacas ou tubulões em cada profundidade, além das vinculações de extremidade em função do tipo do solo. Os trabalhos de interesse, para implementação, se referem aos modelos lineares com variação de $\mathrm{k}_{\mathrm{h}}$ constante, linear ou arbitrária com a profundidade, e os modelos não lineares representados pelas curvas $\mathrm{p}-\mathrm{y}$.

Com relação à não-linearidade geométrica, a bibliografia citada no capítulo 4 serve como orientação para a utilização do que foi implementado no programa ANSYS. 
Introdução

\section{2- Análise Numérica}

Foram analisadas estruturas típicas de pontes com superestrutura preferencialmente constituída por vigas e elementos de infra-estrutura verticais (Fig. $1.8)$.

Para cada estrutura analisada foram realizadas as seguintes fases:

Fase 1

Análise linear elástica preliminar com valores alternativos de rigidez $\mathrm{E}_{\mathrm{c}} \mathrm{I}$, sem a considerando da interação solo-estrutura. Ajustes dos detalhes da estrutura.

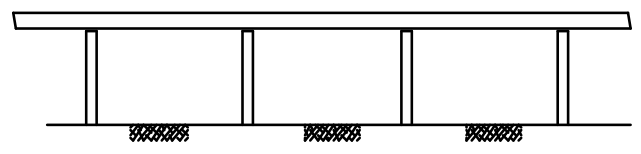

Fig. 1.8 - Estruturas Típicas objeto de análise

Fase 2

Modelagem da estrutura com consideração dos aparelhos de apoio, solo, e elementos da infraestrutura de forma integrada. Processamento dos exemplos para as combinações usuais das ações considerando as várias alternativas para a rigidez equivalente dos elementos da estrutura. A não-linearidade geométrica e a interação solo estrutura são considerados. Os desvios não intencionais do processo executivo são levados a efeito através de desaprumos dos pilares.

Fase 3

Avaliação da não-linearidade física que relaciona os esforços nas seções dos pilares, obtidos do processamento da Fase 2, com as deformações das respectivas seções. A obtenção da rigidez das seções objetivou a calibragem da rigidez equivalente adotada na fase 2. As informações e hipóteses do programa constam do capítulo 5 e Anexo.

Fase 4

Avaliação dos resultados: 
a) Análise da adequação dos valores alternativos de rigidez das seções;

b) Avaliação da influência da deformabilidade das fundações nos efeitos de segunda ordem (NLG);

c) Identificação da variação do perfil da rigidez das seções dos pilares, especificamente no caso de pontes, segundo uma determinada história do carregamento.

\section{5 - APRESENTAÇÃO DO TRABALHO}

CAPÍTULO 1 - Introdução: É feito um histórico sobre os aspectos do projeto e as dificuldades da modelagem do comportamento não linear das peças de concreto armado, e justifica-se a necessidade e a conveniência da adoção de métodos gerais de análise para o caso dos pilares de pontes. São relacionados também os motivos que delimitam a aplicação dos Métodos Aproximados no cálculo de pilares de pontes. Nesse capítulo é definida uma estratégia simples para contornar os problemas relacionados com o cálculo de pilares de pontes.

\section{CAPÍTULO 2 - Mesoestrutura}

Traça um histórico sobre os procedimentos habituais de análise utilizados nos projetos de pontes. Apresenta um levantamento da constituição e concepção mais utilizados nos elementos da mesoestrutura nas últimas décadas quanto aos arranjos, configurações, esbeltez, seções historicamente mais utilizadas e sua provável tendência.

\section{CAPÍTULO 3 - Interação Solo-Estrutura:}

No capítulo 3 são discutidas as alternativas para a modelagem do solo e sua parametrização. São estudados os modelos de resistência lateral para as argilas e areias tendo em vista a sua utilização como dispositivos discretos de Winkler. É apresentada uma alternativa para a correção das curvas de reação p-y tendo em vista a sua aplicação em estacas curtas. São fornecidas igualmente indicações para a consideração das restrições de base e efeito de grupo.

CAPÍTULO 4 - Não-linearidade Geométrica: 
Introdução

Neste capítulo são feitas considerações sobre os aspectos da formulação e aspectos históricos da Não-linearidade Geométrica. São fornecidas indicações de uma formulação consistente para um sistema conservativo baseado na Energia Potencial Total. São fornecidas indicações sobre a formalização do Método de Newton-Raphson na resolução de problemas não lineares. As formas de utilização desses conceitos em programas implementados de computador são também abordadas.

CAPÍTULO 5 - Não-linearidade Física:

No capítulo 5 é apresentada uma formulação para a obtenção da matriz de rigidez tangente para relacionar incrementos de esforços aos correspondentes incrementos de deformações em uma seção de pilar de pontes considerando uma só fibra. São considerados na implementação os efeitos médios das deformações em decorrência do bloco não fissurado nas peças de concreto armado e o efeito do confinamento da armadura transversal na ductilidade da seção. A fluência é implementada sem a consideração da influência da armadura.

CAPÍTULO 6 - Indicações para a análise numérica

Neste capítulo é feita a parametrização dos modelos para o solos utilizados nos exemplos numéricos, a parametrização e discretização dos aparelhos de apoio, efeito de grupo e consideração das excentricidades acidentais.

CAPÍTULO 7 - Exemplos numéricos

Neste capítulo são apresentados alguns exemplos numéricos seguida da análise dos resultados.

CAPÍTULO 8 - Conclusões

Finalmente as conclusões e as perspectivas futuras para continuidade deste estudo são apresentadas no capítulo 8. 


\section{CAPÍTULO 2}

\section{MESOESTRUTURA}

\section{1-GENERALIDADES}

Na divisão clássica da estrutura de uma ponte, normalmente aplicável ao cálculo dos sistemas constituídos por vigas, subentende-se considerada a hipótese do seu comportamento linear. Esse fracionamento, em grupos de elementos de comportamentos distintos, objetiva, de certa forma, tipificar a estrutura ou simplificar e organizar os procedimentos do seu cálculo. A divisão mais conhecida prevê três partes da estrutura: superestrutura, mesoestrutura e infraestrutura. Merece também referência um conjunto de detalhes, se não muito importantes do ponto de vista estrutural, fundamentais para o comportamento previamente definido para uma ponte: aparelhos de apoio, juntas, dispositivos de drenagem, rótulas, etc.. Por outro lado, quando a opção da não-linearidade é recomendada, qualquer que seja ela, alguns dos habituais procedimentos de cálculo ficam inviabilizados. Alguns deles podem ser mencionados:

- Procedimentos associados aos conceitos de superposição (Ex. linhas de influência);

- Cálculo fracionado segundo a divisão da estrutura mencionada anteriormente, principalmente no que se refere à infra-estrutura; 
- A combinação das ações na análise não linear não pode ser aplicada segundo a forma habitual, devendo-se prever, nesse caso, uma história de carregamento.

Os pilares de pontes, objeto desse trabalho, não apresentam dificuldades especiais do ponto de vista do cálculo quando tratados como elementos isolados. Tal afirmativa não é verdadeiramente clara quando na análise propõe-se considerar condições mais adequadas de sua vinculação com o contexto estrutural (infra-estrutura e superestrutura), comportamento não linear e formas geométricas especiais.

\section{2-MORFOLOGIA}

POSTON et al. (1983) obtiveram, através de questionários remetidos ao meio técnico envolvido, de uma forma ou de outra, com projetos de pontes, um panorama bastante significativo relativo à morfologia e considerações de projeto de pontes de concreto armado. A tendência, em termos de concepção de projeto de pilares de pontes, foi identificada através do estudo de 155.000 arranjos de pilares projetados e construídos no período de 1960-1980. Das informações obtidas, concluiu-se ainda que, na década seguinte (1980-1990), seriam construídos mais 60.000 arranjos de pilares adicionais com a expectativa de que poucas inovações, em termos de concepção, pudessem ocorrer relativamente ao período de 1960-1980. Algumas conclusões, aqui relacionadas, são baseadas nos estudos dos autores, POSTON et al. (1983). Como pode ser observado na Fig.2.1, o tipo predominante de solução, nos eixos das pontes, é em arranjos constituídos de múltiplos pilares, com arranjos simples ocorrendo na proporção de uma vez em seis casos.

De modo semelhante, é evidente a ocorrência do uso expressivo da seção sólida. A Fig. 2.1 indica, também, que a seção transversal nos arranjos de pilares múltiplos é predominantemente sólida, com uma alta porcentagem do uso de seções vazadas nos arranjos com pilar único.

A Fig. 2.2 indica que a seção sólida predomina nas aplicações em pilares de baixa altura e que o uso de seções vazadas é crescente com altura do pilar. 
O estudo mostra que $81 \%$ dos pilares construídos de 1960 a 1980 com altura maior que $34 \mathrm{~m}$ foram de seção transversal vazada.
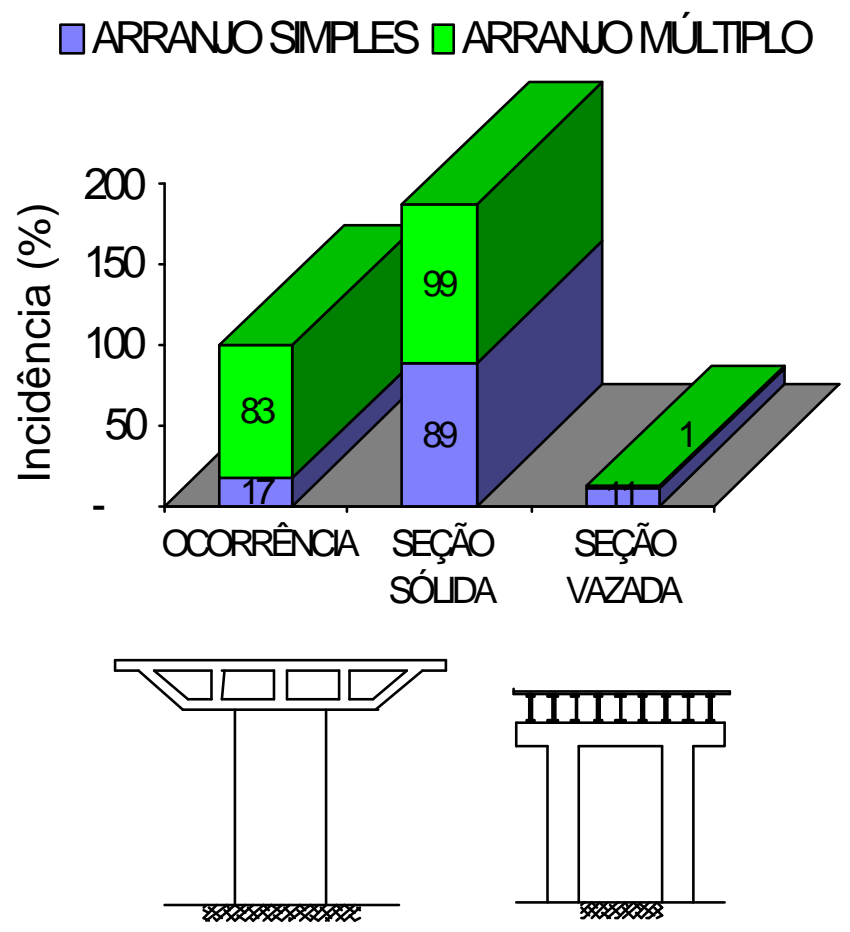

Fig. 2.1-Arranjos de Pilares em Pontes: Ocorrência

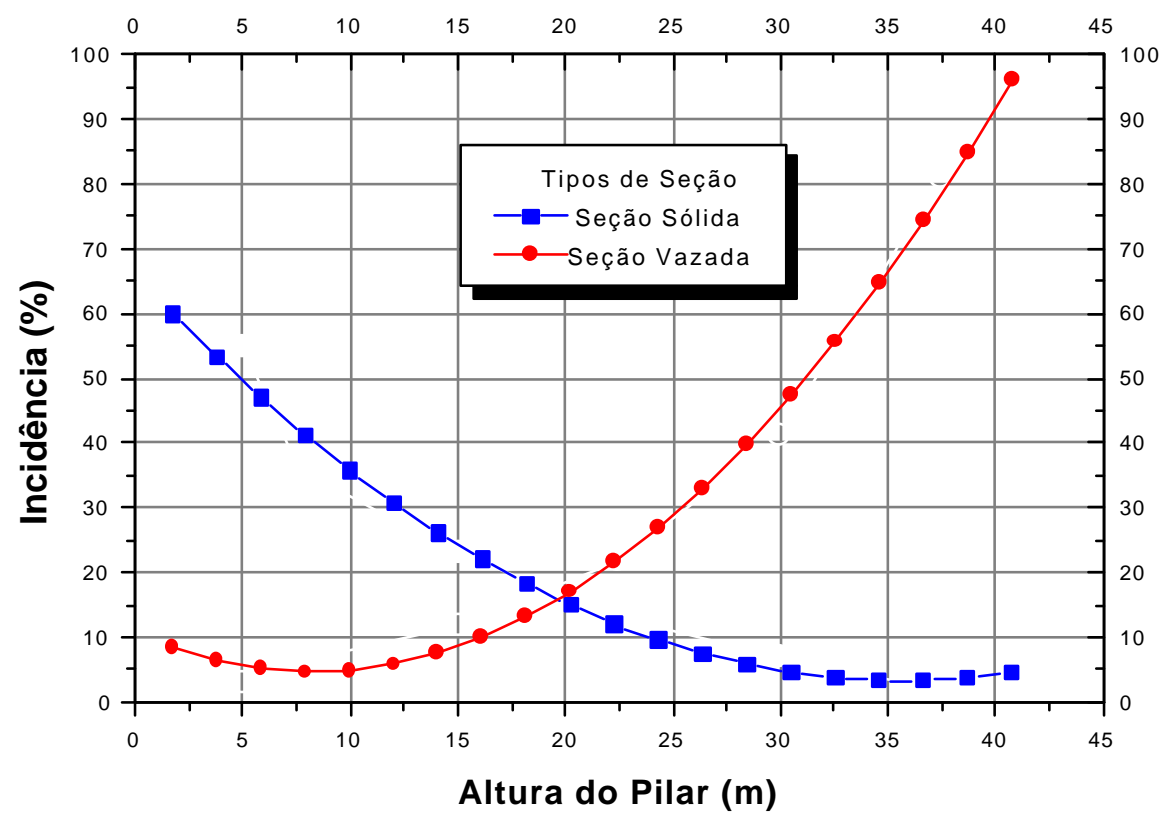

Fig. 2.2-Tipo de Seção vs. Altura do Pilar 


\section{Mesoestrutura}

A partir da distribuição geral dos tipos de seção transversal dos pilares para ambos os casos, arranjos com pilar único e arranjos com pilares múltiplos, novamente pode ser visto que a seção transversal vazada ocorre com mais freqüência em aplicações com arranjos em pilar único (Fig. 2.3).
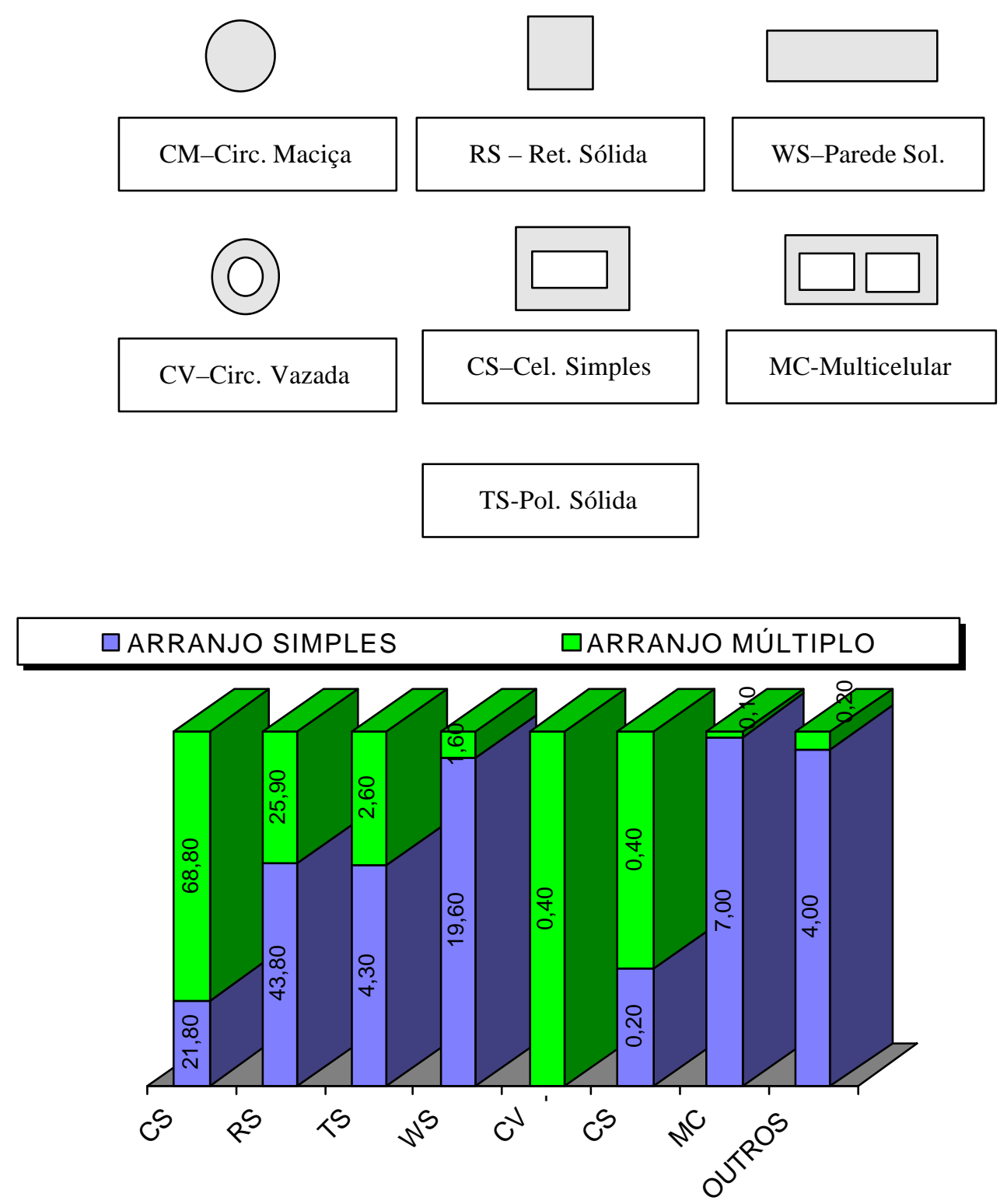

Fig. 2.3 - Seções Usuais em Pilares de Pontes (em \%) 
Uma grande variedade de configurações verticais de pilares foi relatada no estudo. Alguns tipos de pilares para arranjo simples são mostrados na Fig. 2.4. Nesta figura também é mostrada a distribuição, em porcentagem, das configurações dos pilares em função de sua altura. Por exemplo, observa-se desta figura que $82.3 \%$ de todos os arranjos de pilares simples, com menos de $10 \mathrm{~m}$ de altura e seção constante, são do tipo A. Semelhantemente, somente 3,5\% dos arranjos em pilares simples escalonados com menos de $10 \mathrm{~m}$ de altura são do tipo D. Observe que a soma de todas as porcentagens para as barras com $\mathrm{L}<10 \mathrm{~m}$ para os tipos de A até I constituem a totalidade de $100 \%$. Assim, os histogramas dão uma indicação do uso das várias configurações para as quatro diferentes categorias de altura. A configuração "outros" representa pilares que têm variação linear em ambas as dimensões, largura e profundidade. Para altura de pilares acima de $15 \mathrm{~m}$, somente uma pequena minoria de pilares tem dimensões constantes em elevação.

Para alturas moderadas de pilares $(15 \mathrm{~m}<\mathrm{L}<30 \mathrm{~m})$ quase $38 \%$ são do tipo $\mathrm{F}$ ou $\mathrm{H}$, tendo uma seção transversal variando linearmente, enquanto outros $16 \%$ são do tipo escalonado. Essa tendência é marcante para os pilares mais altos (L>30m). Acima de $70 \%$ dos pilares mais altos têm as dimensões da seção transversal variável (tipos F, H e outros), enquanto somente $20 \%$ são de seção constante. Um número relativamente pequeno $(6,7 \%)$ é de fuste escalonado.

A fig. 2.5 indica que os pilares mais curtos enfileirados nos arranjos múltiplos de pilares $(\mathrm{L}<10 \mathrm{~m}$ e $10 \mathrm{~m}<\mathrm{L}<15 \mathrm{~m})$ têm uma porcentagem mais alta de fuste de seção constante do que os pilares nos arranjos simples. Para L acima de $15 \mathrm{~m}$, o grupo $\mathrm{D}$ dos pilares escalonados representa a configuração mais predominante. Nota-se que o tipo D é usado na maioria dos casos para $15 \mathrm{~m}<\mathrm{L}$ $<30 \mathrm{~m}$, com 35\% dos casos para L>30m. Nos arranjos de pilares múltiplos com altura maior, relativamente poucos $(2 \%)$ têm variações na seção transversal dos pilares (tipo H) quando comparado com o significativo uso desse tipo nos arranjos de pilares simples (25\%). Quando as variações de seção transversal são usadas em arranjos múltiplos de pilares, a tendência é que elas ocorram na direção longitudinal da ponte (tipos E e F). Entretanto, os resultados dos estudos indicam claramente que se um programa de análise de pilares é limitado a membros de seções transversais constantes ou escalonadas com passos de variação somente nos pontos de conexão 
com as vigas de contraventamento, ele será capaz de manipular 52\% dos arranjos com altura entre $15 \mathrm{~m}$ e $30 \mathrm{~m}$ e $27 \%$ dos arranjos com pilares mais altos com $\mathrm{L}>30 \mathrm{~m}$.
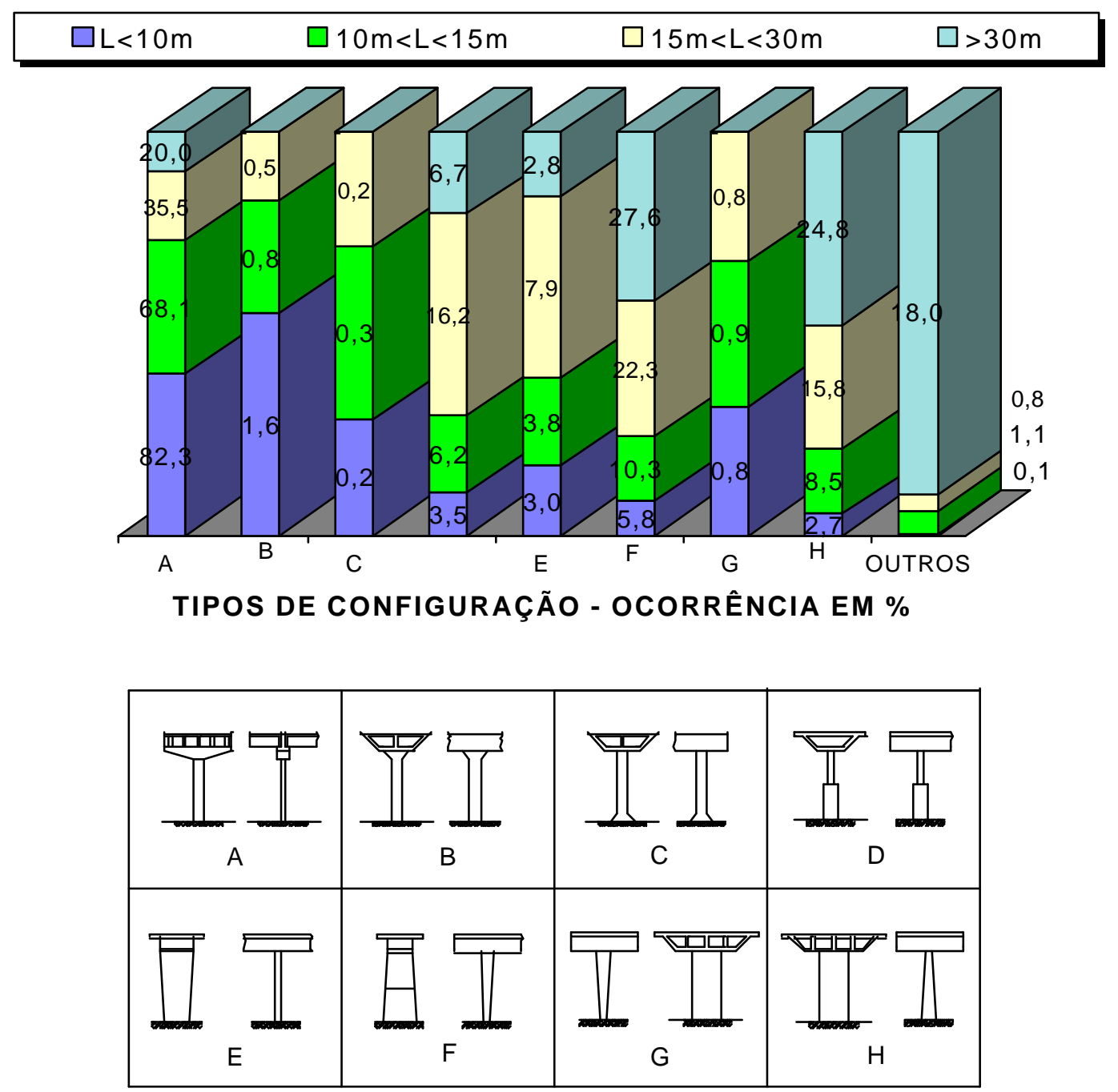

Fig.2.4-Configurações Verticais em Arranjos Simples de Pilares 

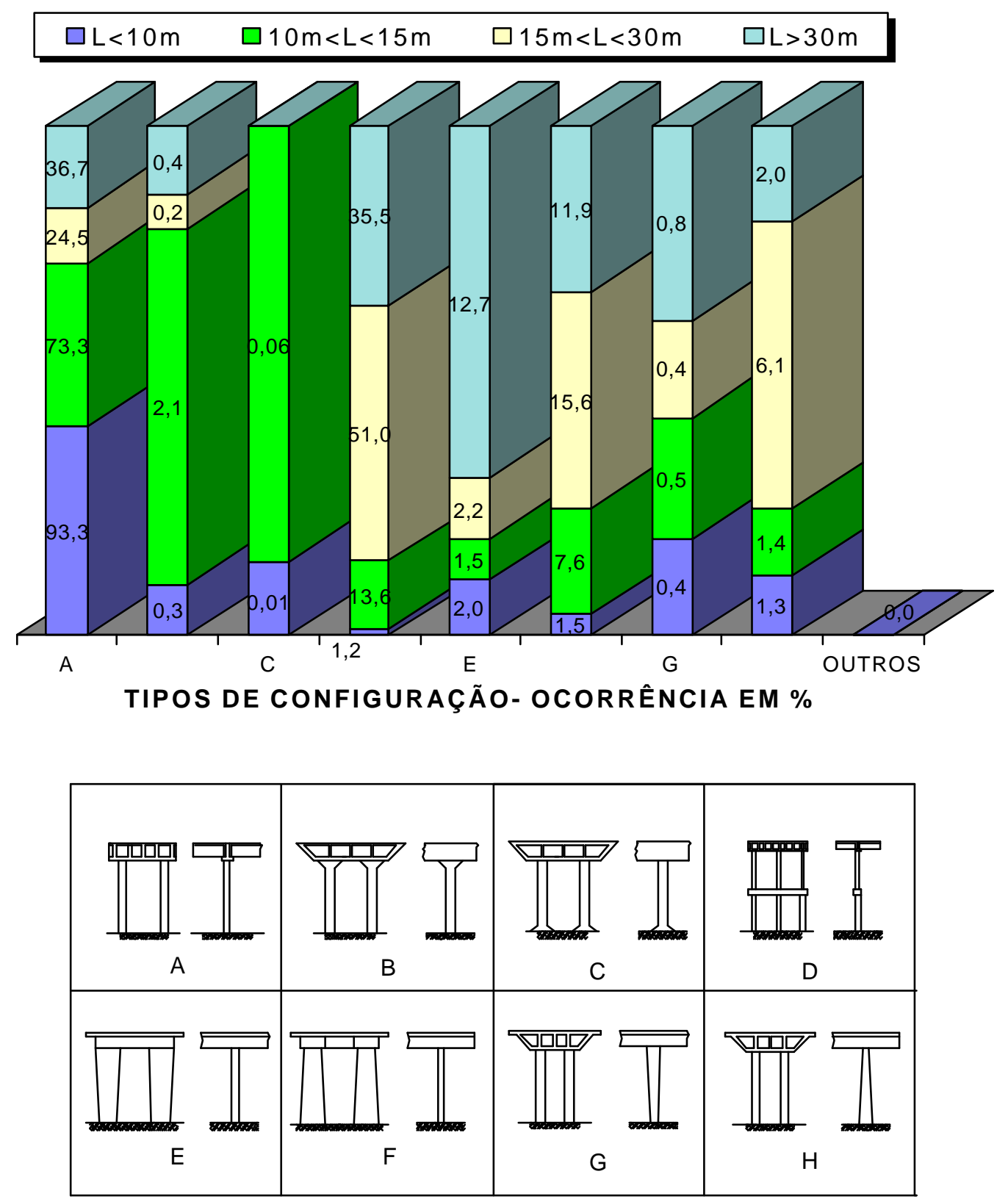

Fig.2.5-Configurações Verticais em Arranjos Múltiplos de Pilares

\section{3 - ESBELTEZ DOS PILARES}

No trabalho de POSTON et al. (1983) os pilares foram classificados de acordo com a altura total em quatro categorias: 0-10m, 10-15m, 15-30m e maiores do que $30 \mathrm{~m}$. Uma distribuição de ocorrência em função da altura, para todos os tipos de pilares, e separadamente para pilares sólidos e vazados é mostrada na Fig. 2.6. Como foi mencionado, a vasta maioria dos pilares se situa abaixo da categoria dos 
$10 \mathrm{~m}$ de altura. Observa-se que, para os pilares com altura abaixo de 10m, 73\% foram construídos com seção sólida e apenas $18 \%$ foram construídos em seção vazada. No outro extremo, isto é, para pilares com altura acima de $30 \mathrm{~m}, 52 \%$ foram construídos em seção vazada. Da totalidade dos pilares, $70 \%$ têm altura abaixo dos $10 \mathrm{~m}$ e apenas $3 \%$ têm altura acima dos $30 \mathrm{~m}$.

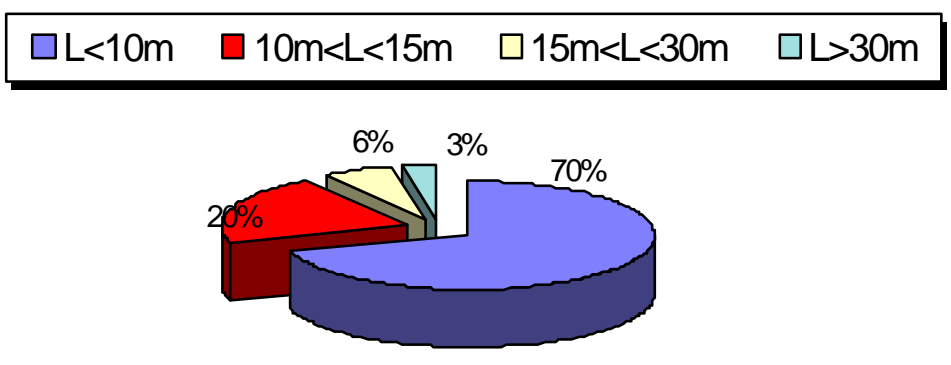

PILARES versus ALTURA

Fig.2.6(a)- Pilares Construídos vs. sua Altura L

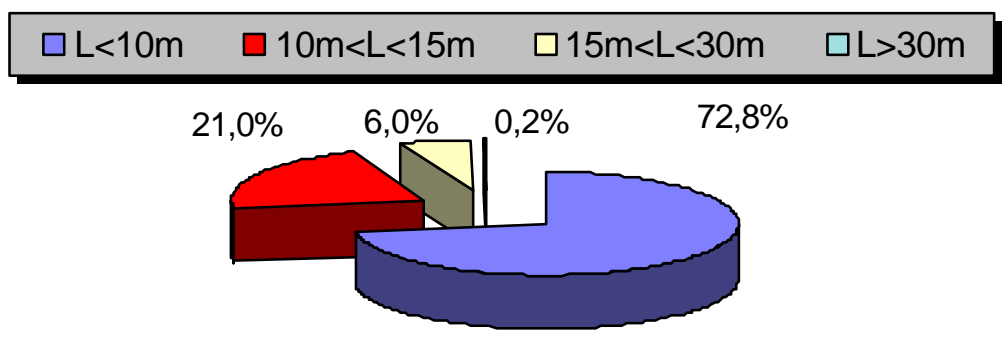

SEÇÃO SÓLIDA - OCORRÊNCIA EM \%

Fig. 2.6(b) - Pilares sólidos Construídos vs. sua Altura L

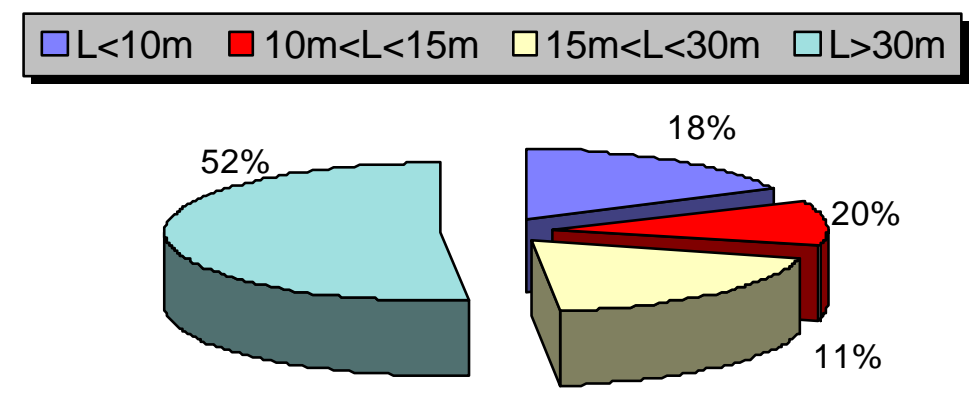

SEÇÃO VAZADA - OCORRÊNCIA EM \%

Fig. 2.6(c)- Pilares Construídos Vazados vs. sua Altura L 
A relação real de interesse para representar a esbeltez é a relação $k L_{\mathbb{u}} / \mathrm{r}$ , onde k é o parâmetro efetivo de altura que depende do grau de restrição nas extremidades do pilar, e $\mathrm{L}_{\mathrm{u}}$ é a altura livre entre os apoios de um segmento do pilar. Provavelmente, devido à grande dificuldade em se definir o parâmetro k, somente a relação $L / r$ foi relatada na pesquisa, onde $L$ é a altura do pilar e r o raio de giração da sua seção transversal. A relação L/r, embora grosseira, representa uma indicação de um parâmetro estrutural básico que governa as características do momento secundário e a instabilidade do pilar. Segundo POSTON et al.(1983), nas condições de restrição da maioria das pontes o valor de k pode variar entre 1,5 e 3,0. Assim, os valores de $\mathrm{L} / \mathrm{r}$ devem ser ajustados pelo valor de $\mathrm{k}$ no sentido de considerar as restrições nos extremos dos pilares e, consequentemente, delimitar o campo de aplicação dos Métodos Aproximados sugeridos pelas normas para avaliar os efeitos de $2^{-}$ordem. A aplicabilidade da análise aproximada preconizada pela AASHTO spec. ou o ACI 318-89 (R 1992) se refere ao intervalo $22<\mathrm{kL} / \mathrm{u} / \mathrm{r}<100$, para os pilares deslocáveis, sugerindo desprezar os efeitos de segunda ordem para $\mathrm{kL}_{\mathrm{u}} / \mathrm{r}<22$ (correspondendo ao valor de $\mathrm{L} / \mathrm{r}$ em torno de 10). Para todos os pilares com $\mathrm{kL}_{\mathrm{u}} / \mathrm{r}>100$ (isto é, para $\mathrm{L} / \mathrm{r}$ em torno de 40) impõe-se a avaliação dos efeitos da esbeltez por análise mais rigorosa.

A distribuição da relação $\mathrm{L} / \mathrm{r}$ relatada na pesquisa é mostrada nas figs. 2.7 e 2.8, respectivamente para arranjos simples e múltiplos de pilares. A Fig. 2.7 mostra vários aspectos interessantes sobre a esbeltez nos arranjos simples. Nota-se que $91 \%$ dos pilares vazadas se situam no intervalo de $\mathrm{L} / \mathrm{r}$ abaixo de 20 . Por outro lado, como mostrado na Fig. 2.6 os pilares vazados são freqüentemente aplicados para as maiores alturas, de onde se conclui, observando-se a distribuição de $\mathrm{L} / \mathrm{r}$ da Fig. 2.7, que tais seções são dimensionadas de modo conservador. Observa-se ainda que, em aplicações onde os arranjos são de pilares simples, cerca de um terço de todos os casos parece se situar acima do nível $\mathrm{L} / \mathrm{r}=40$, o que representa uma restrição para a aplicação dos Métodos Simplificados, indicando a necessidade de um procedimento geral de análise para um grande número de casos. 


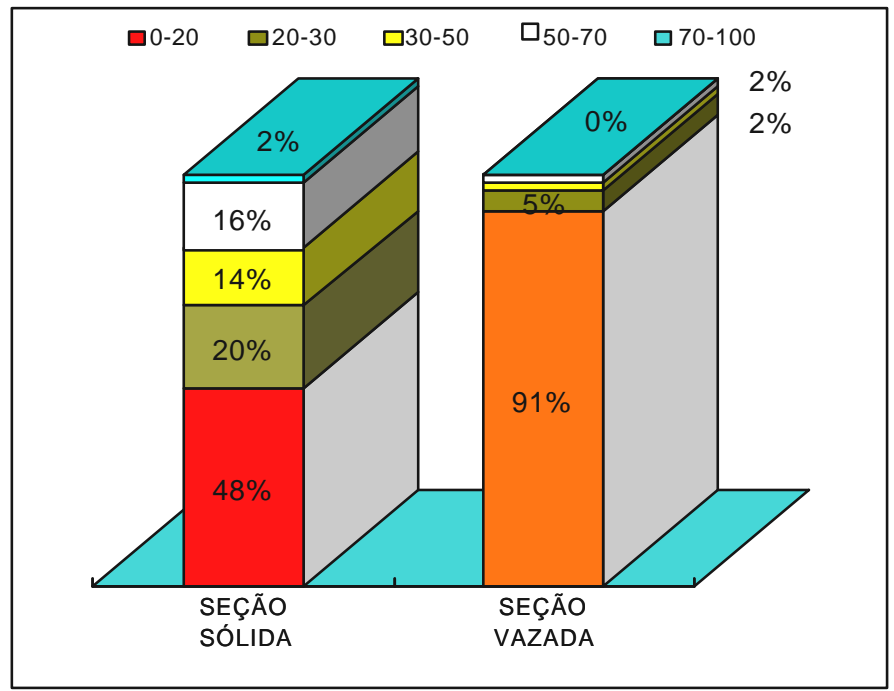

Fig. 2.7-Distribuição de L/r para Arranjos Simples de Pilares

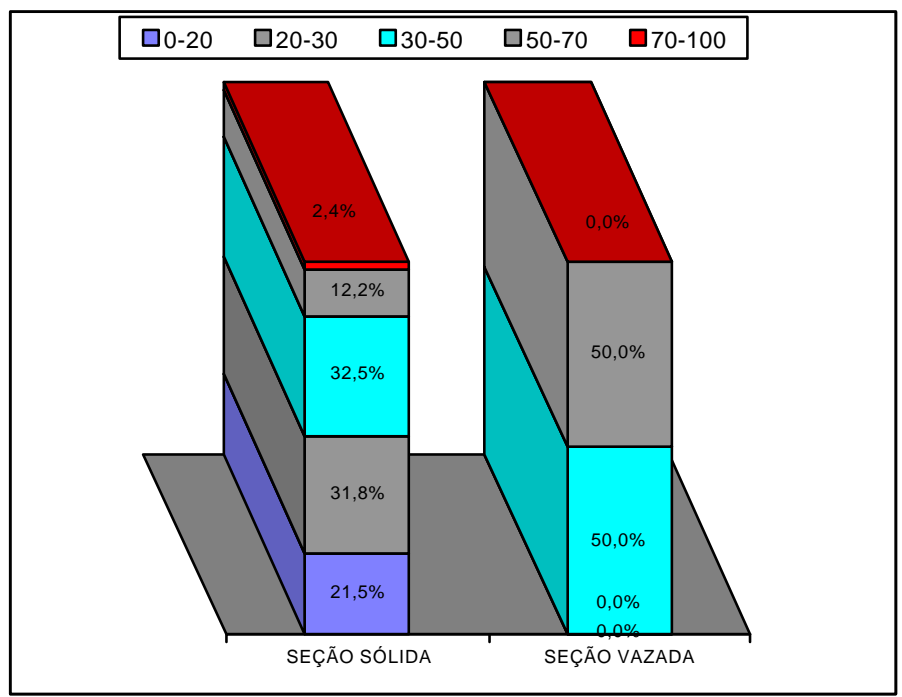

Fig. 2.8 - Distribuição de L/r para Arranjos de Pilares Múltiplos

\section{4 - ESBELTEZ E TIPO DE RUÍNA DOS PILARES}

Um pilar esbelto pode ruir de dois modos: a) o pilar pode entrar em colapso quando, por meio de uma combinação da carga normal $\mathrm{P}_{\mathrm{n}}$ e momento fletor $\mathrm{M}_{\mathrm{n}}$, a resistência natural ou convencional da seção é alcançada; ou b) também pode ruir por instabilidade, quando um acréscimo infinitesimal da carga normal resulta um deslocamento adicional, de tal modo que o equilíbrio não seja mais possível. 
Nos trabalhos de PFRANG (1966) e MAcGREGOR et al.(1970), encontra-se vasta discussão sobre os efeitos da esbeltez nos diagramas de interação (P-M) das seções de concreto armado de pilares esbeltos, além de discutir os aspectos do colapso das mesmas.

Referindo-se à figura Fig. 2.9(a), um pilar com esbeltez alta, por exemplo, $\mathrm{kL} / \mathrm{r} \approx 100$, geralmente segue a trajetória de carregamento até o ponto $\mathrm{D}$, onde é esgotada a resistência do material. O ponto D se encontra na curva de interação do pilar virtualmente curta $\left(\mathrm{kL}_{\mathrm{u}} / \mathrm{r} \approx 0\right)$, correspondendo a uma carga $\mathrm{P}_{1}$ menor do que a carga $\mathrm{P}_{\text {curta }}$ caso o pilar fosse realmente curto $\left(\mathrm{kL}_{\mathrm{u}} / \mathrm{r} \approx 0\right)$. Se o pilar entrar em colapso por instabilidade, o carregamento seguirá a linha tracejada até o ponto E, sendo incapaz de alcançar o diagrama de interação da resistência pelo material [MAcGREGOR et al.(1970)].

Geralmente, os pilares de pórticos contraventados são capazes de alcançar o colapso por ruína do material, enquanto o colapso por instabilidade, embora raro, pode ocorrer em pórticos deslocáveis como nos casos de pontes. Na fig. 2.9(b) é mostrada a influência da esbeltez nos diagramas de interação (P-M).

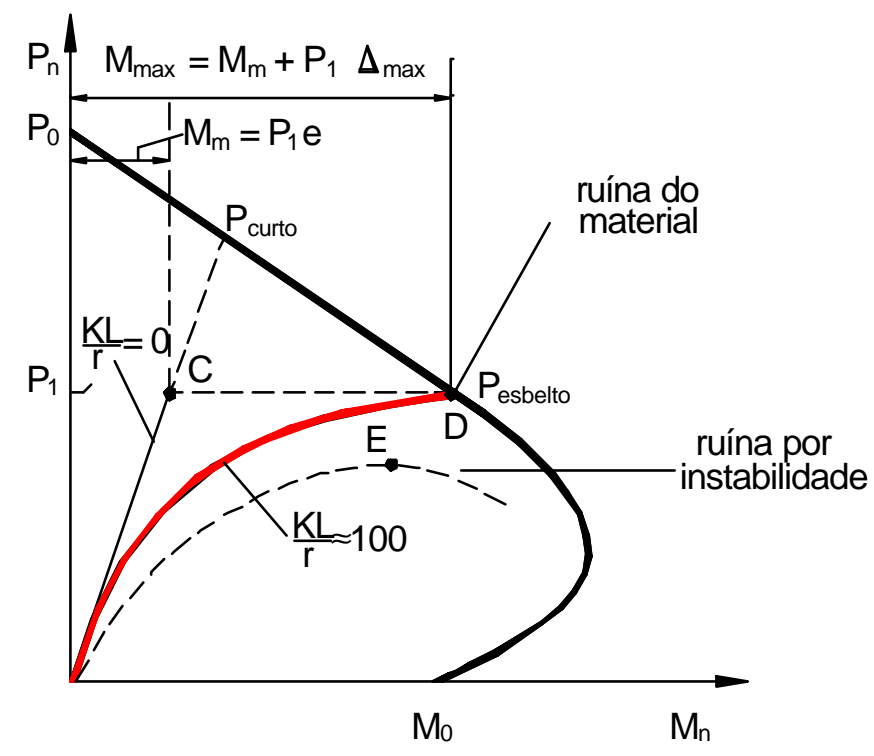

Fig. 2.9(a)- Modos de Ruína de Um Pilar 


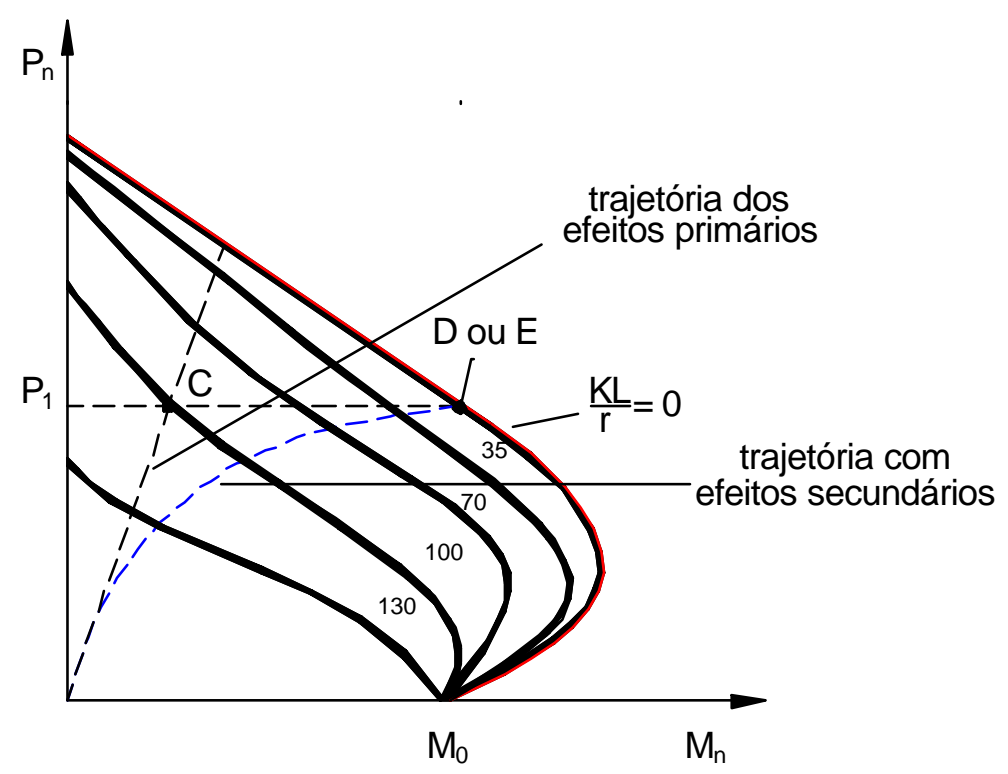

Fig. 2.9(b)- Modos de Ruína de Um Pilar [adaptado de MAcGREGOR et al. (1970)] 


\section{CAPÍTULO 3}

\section{INTERACÃO SOLO - ESTRUTURA}

\section{1-GENERALIDADES}

A função mais comum das estacas ou dos tubulões é a de transferir as cargas verticais para as camadas mais profundas do maciço de solos, onde uma capacidade adequada de suporte é disponível. Outra função, também muito comum em geotecnia, é a utilização de estacas como elementos redutores de recalques de fundações. Quando uma estaca atravessa um meio pobre e sua ponta penetra em um substrato de boa capacidade resistente, é geralmente denominada de estaca de ponta. Entretanto, quando a mesma é instalada num meio profundo de menor capacidade de suporte, ela desenvolve uma transferência de carga por atrito mobilizado na sua interface com o substrato. Neste caso, a estaca é denominada estaca de atrito. $\mathrm{Na}$ maioria das vezes a transferência de carga vertical para o substrato, através de uma estaca, resulta de uma combinação de resistência de ponta e atrito mobilizado ao longo do seu fuste. Em outros casos, estacas tracionadas podem ser usadas para impedir o tombamento de estruturas altas e resistir a forças de arrancamento. Os tubulões podem ser considerados, exceto quanto à técnica de sua execução, um caso particular de estaca, onde na sua ponta se executa um alargamento com a intenção de compatibilizar as condições de transferência das cargas com as condições de suporte do solo na cota de apoio. As estruturas de fundações, constituídas por estacas ou tubulões, quando utilizadas em determinadas estruturas, tais como pontes, torres e estruturas "offshore", submetidas também a cargas laterais significativas se comportam de modo bastante interativo com o maciço de solos. Devido a esta forte 
interação, principalmente quando as ações sobre as estruturas induzem deslocamentos laterais e recalques verticais no maciço de solos, a investigação sobre o comportamento das fundações profundas constitui um vasto campo de estudo e discussão.

Informações disponíveis na literatura sobre estacas indicam que estas podem ser classificadas em diferentes modos [CHELLIS (1961-1962), TOMLINSON (1977), VESIC (1977), FULLER (1983)]. Segundo PRAKASH \& SHARMA (1990) todos esses métodos de classificação podem ser agrupados em uma das seguintes categorias:

- Classificação quanto ao material;

- Estacas verticais ou inclinadas;

- Método de fabricação;

- Nível de perturbação no solo durante a instalação;

- Método de instalação no solo;

- Método de transferência de carga.

Dentre os vários aspectos, os mais relevantes aos objetivos desse trabalho são os métodos relacionados com o processo de transferência de cargas para o solo que direta ou indiretamente afetam o comportamento da estaca quando carregada.

Os métodos de análise da transferência de carga no sistema estacasolo podem ser agrupados em dois modelos básicos:

- Modelos que consideram a modelagem no contínuo;

- Modelo discreto de Winkler.

Os demais podem ser considerados variantes destes dois.

Os métodos do contínuo consideram e enfocam o sistema estaca-solo de modo integrado com base em algumas hipóteses simplificadoras. POULOS (1971), apresenta uma solução elástica para o problema de uma estaca carregada 
lateralmente assumindo um meio elástico e homogêneo em um espaço semi-infinito isotrópico com um módulo de elasticidade $\left(\mathrm{E}_{\mathrm{s}}\right)$ e um coeficiente de Poisson. A estaca modelada como uma chapa fina vertical retangular, com pressão constante ao longo da sua largura, foi analisada por Poulos através de um método baseado na equação de Mindlin para modelar o comportamento do solo em substituição à teoria da reação do subsolo fundamentada nas hipóteses de Winkler. Em complementação a este trabalho, Poulos assumiu a interação entre uma estaca sobre as demais de um mesmo grupo através de fatores de influência baseados na teoria linear elástica.

Outras abordagens como meio contínuo incluem a aplicação do método dos elementos de contorno [BANERJEE \& DAVIES (1980)] e elementos finitos. A principal limitação desses métodos reside, principalmente, na sua complexidade e na difícil tarefa de parametrizar adequadamente o solo, além, é claro, da considerável quantidade de dados e tempo de processamento exigido no procedimento numérico. Como exemplo da adoção do modelo contínuo cita-se, dentre muitos outros, o trabalho desenvolvido por FERRO (1993) na EESC-USP que combina o MEC com MEF para a análise de fundações enrijecidas por estacas.

O modelo de Winkler, por sua vez, considera a resposta do solo caracterizada por um conjunto de mecanismos discretos independentes entre si, isto é, indicam que a resposta do solo em um ponto não é dependente do deslocamento da estaca em outros pontos, o que de certo modo não modela perfeitamente o contínuo.

Dois são os problemas a serem resolvidos para a obtenção da resposta de uma estaca sujeita a um carregamento genérico:

- A resistência do solo deve ser conhecida em função da profundidade, dos deslocamentos da estaca, da geometria da estaca e da natureza da carga;

- Obtenção das respostas da estaca em termos de esforços e deslocamentos.

Um procedimento, relativamente simples, proposto por OOI \& DUCAN (1994) sugere a utilização dos modelos disponíveis para estaca isolada 
através do ajuste de seus deslocamentos laterais por fatores de amplificação que dependem do solo e do arranjo das estacas.

Embora não sendo regra geral, muitas vezes as bases das estacas ou tubulões se apoiam em um substrato quase que indeformável. Essa hipótese, razoavelmente aceitável para o caso de tubulões de base alargada, se adotada permite desprezar o atrito lateral despertado no fuste dos tubulões pelas cargas verticais aplicadas e o seu conseqüente efeito de grupo. Admitindo-se como desprezível os deslocamentos na base dos tubulões, o atrito lateral desenvolvido se torna pouco significativo, uma vez que depende somente do encurtamento elástico dos elementos da infraestrutura, o que pode ser considerado perfeitamente aceitável.

\section{1- ESTACAS VERTICAIS: RESPOSTA LATERAL DO SOLO}

\subsection{1 - BREVE REVISÃO BIBLIOGRÁFICA E COMENTÁRIOS}

Análises de interação entre o solo e as estacas, nas quais é usado o conceito da reação horizontal do solo para as cargas laterais, tiveram início nos trabalhos de GRANHOLM (1929), HETENYI (1946) e em um número enorme de outros trabalhos. Essas análises foram baseadas na hipótese da proporcionalidade entre a reação "p" do solo e o deslocamento horizontal "y" da estaca. A relação entre a reação do solo e o deslocamento da estaca foi denominado módulo de reação horizontal do solo $\left(\mathrm{k}_{\mathrm{s}}\right)$.

Soluções foram desenvolvidas para $\mathrm{k}_{\mathrm{s}}$ constante com a profundidade [GRANHOLM (1929), HETENYI (1946)], para $\mathrm{k}_{\mathrm{s}}$ variando linearmente com a profundidade [HETENYI (1946), REESE \& MATLOCK (1956 )], para K $\mathrm{s}_{\mathrm{s}}$ variando não linearmente com a profundidade [PALMER \& THOMPSON (1948), MATLOCK \& REESE (1960), DAVISSON \& PRAKASH (1963)], e para um sistema estratificado em camadas [DAVISSON \& GILL (1963), REDDY \& VALSANGKAR (1968), DIGIOIA et al. (1975), MATLOCK \& REESE (1961)]. Estas soluções mostram que esse tipo de análise pode ser usada como uma aproximação do comportamento não linear, por um processo iterativo, alterando e variando $\mathrm{K}_{\mathrm{s}}$ com a profundidade de acordo com os valores obtidos para os deslocamentos "y". 
Métodos de análise onde o solo circunvizinho à estaca é tratado como meio contínuo elástico foram desenvolvidos por DOUGLAS \& DAVIS (1964); SPILLERS \& STOLL (1964), POULOS (1971 e 1972), LENCI et al.(1968), BANERJEE \& DAVIES (1978). DOUGLAS \& DAVIS (1964) apresentaram soluções para o deslocamento e rotações de uma placa vertical rígida em um semiespaço elástico, carregada no seu topo por uma carga lateral mais um momento. POULOS (1971) apresentou essas soluções para elementos verticais flexíveis. Estas análises, que adotaram a modelam do solo vizinho à estaca como meio contínuo, foram consideradas úteis na avaliação da interação entre estacas agrupadas.

O método p-y desenvolvido por McCLELLAND \& FOCHT (1958) apresenta-se como o procedimento mais prático e útil para o cálculo de fundações profundas sob carga lateral. Como o método utiliza a análise numérica, pode ser usado para analisar condições onde as propriedades do solo ou da estaca variam de qualquer forma com a profundidade.

Métodos para estimar a forma da curva p-y, para vários tipos de solo e condições de carregamento (estático e dinâmico), foram desenvolvidos por MATLOCK (1970) para argila pouco rija, REESE et al. (1975) para argila rija abaixo do lençol freático, REESE \& WELCH (1975) para argila rija acima do lençol freático, REESE et al.(1984) para areia e SULLIVAN et al.(1979) para uma variedade de outras condições.

A aplicação do método p-y requer obviamente o uso de programas de computador. Vários deles foram desenvolvidos usando o Método das Diferenças Finitas: COM 622 (REESE-1977); COM 624 [REESE et al.(1984)], LPILE 1 [REESE (1985)] e muitos outros recentemente desenvolvidos. OOI \& DUCAN (1993) recomendam a amplificação dos deslocamentos laterais da estaca isolada para considerar o efeito de grupo. SWAN \& WRIGHT (1986) propõem ajustamentos nas curvas p-y para as estacas consideradas curtas.

A possibilidade que o critério $\mathrm{p}-\mathrm{y}$ tem de representar uma vasta variedade de solos e condições de carregamento de uma maneira realista, e devido à concordância dos seus resultados com muitos testes de campo, essa análise é 
perfeitamente adequada para observar o desempenho de estacas simples carregadas lateralmente. Informações complementares constam do capítulo 6.

\subsection{2 - MODELAGEM E PARÂMETROS DO SOLO}

\subsubsection{1 - Resposta Linear do Solo}

Genericamente, qualquer que seja o método de análise, as estacas e os tubulões podem ser submetidos, além da torção, às seguintes cargas:

- $\quad$ solicitações $H_{t}, V_{t}$ e $M_{t}$ aplicadas no seu topo devido às ações da superestrutura;

- resposta horizontal $\mathrm{p}_{\mathrm{h}}$ do solo aos deslocamentos laterais da estaca;

- atritos vertical e horizontal $\mathrm{p}_{\mathrm{x}}$ aplicados no fuste da estaca mobilizados pelo seu deslocamento vertical e pela distorção segundo o seu eixo;

- reações de base $\mathrm{H}_{\mathrm{b}}, \mathrm{V}_{\mathrm{b}}$ e $\mathrm{M}_{\mathrm{b}}$ (Fig. 3.1a).

Em uma análise de estacas sob cargas laterais, dois parâmetros de rigidez são necessários: a rigidez a flexão da estaca (EI) e a rigidez horizontal do solo $\mathrm{E}_{\mathrm{s}}, \mathrm{G}_{\mathrm{s}}$ ou $\mathrm{K}_{\mathrm{h}}$.Se a teoria da elasticidade é usada, a rigidez do solo é expressa em termos do módulo de elasticidade $\mathrm{E}_{\mathrm{s}}$ e o módulo de cisalhamento $\mathrm{G}_{\mathrm{s}}$. Entretanto, no modelo discreto de Winkler, a rigidez do solo pode ser definida pelo módulo de reação horizontal $\mathrm{K}_{\mathrm{h}}\left(\mathrm{FL}^{-2}\right)$ como (Fig. 3.1b):

$$
\begin{aligned}
& \mathrm{k}_{\mathrm{h}}=\frac{\mathrm{p}}{\mathrm{y}} \text { onde, } \\
& \mathrm{p}=\text { reação do solo em um ponto qualquer da estaca por unidade de }
\end{aligned}
$$
comprimento ao longo do seu fuste. Representa a resultante sobre a largura B de uma face carregada $\left(\mathrm{FL}^{-1}\right)$;

$$
\mathrm{y}=\text { deslocamento horizontal da estaca nesse ponto }(\mathrm{L}) \text {. }
$$




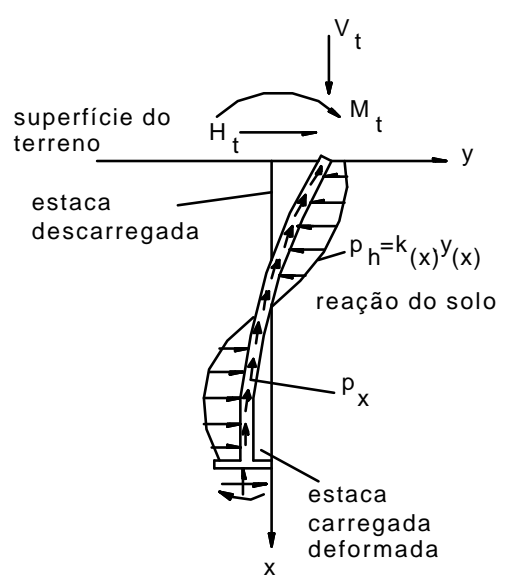

(a)

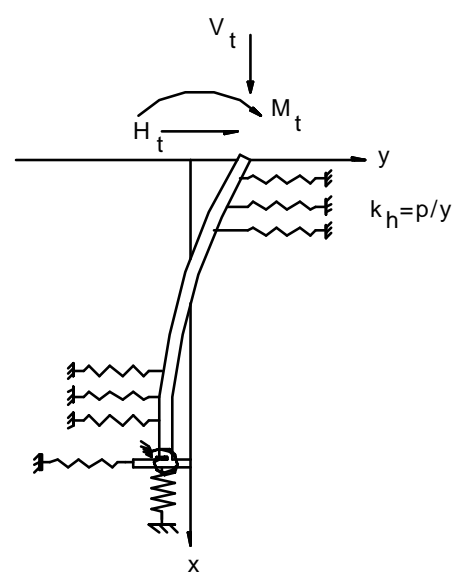

(b)

Fig. 3.1(a) - Cargas nas estacas e b) Discretização de Winkler

O problema das estacas verticais carregadas lateralmente pode ser visto como um caso especial do estudo da viga em apoio elástico [DINIZ (1972)]. Considerando-se que a reação do terreno "p" seja proporcional ao deslocamento y e sendo $K_{\mathrm{h}} \mathrm{o}$ módulo de proporcionalidade, também denominado de coeficiente de reação horizontal do solo, tem-se a equação diferencial da estaca:

$$
E I \frac{d^{4} y}{d x^{4}}=p=-k_{h} y
$$

Nessa equação, os parâmetros E e I são função do material e da geometria da seção transversal da estaca. Já o parâmetro $K_{h}$ é de natureza bastante complexa, não só no que se refere à sua variação ao longo da profundidade, como também do ponto de vista de sua determinação experimental.

A figura Fig. 3.2 mostra uma reação típica do solo circunvizinho a uma estaca carregada lateralmente em função do seu deslocamento y. Para reações do solo menores que $30 \%$ a $50 \%$ da sua reação última, a relação p-y pode ser expressa satisfatoriamente pelo módulo tangente. A inclinação da linha tangente representa o coeficiente de reação horizontal $\mathrm{K}_{\mathrm{h}}$ do solo para a estaca. Para reações do solo aproximadamente acima daqueles limites o módulo secante pode ser considerado, e, neste caso, o módulo se torna função do deslocamento da estaca [PRAKASH \& SHARMA (1990)]. A variação real do módulo de reação horizontal 
com a profundidade é mostrada na Fig. 3.3. As linhas tracejadas ilustram uma tendência provável da variação do módulo de reação horizontal com a profundidade.

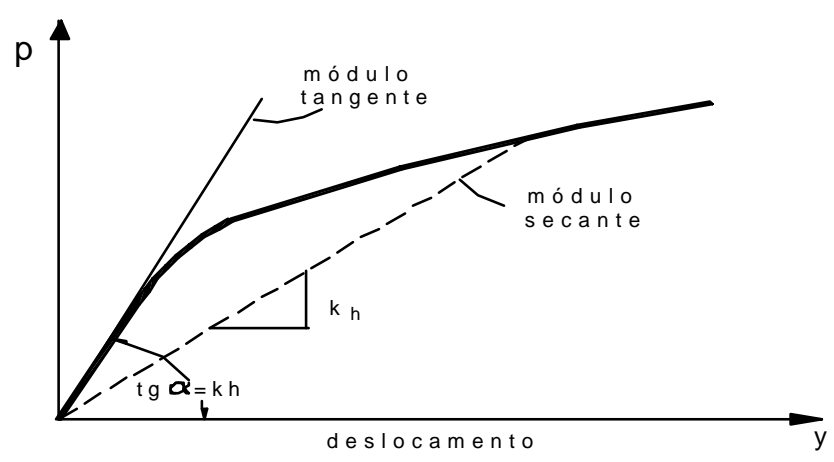

Fig. 3.2-Reação do solo vs. deslocamento da estaca

Uma variação mais realista do modulo de reação horizontal com a profundidade é recomendada por TERZAGHI (1955) para solos coesivos préadensados ( $\mathrm{K}_{\mathrm{h}}$ constante). Para solos granulares Tersaghi recomenda a adoção de $\mathrm{k}_{\mathrm{h}}$ diretamente proporcional com a profundidade (Fig. 3.3).

DAVISSON (1963) apud PRAKASH \& SHARMA (1990) estende a variação linear de $\mathrm{k}_{\mathrm{h}}$ para os siltes normalmente adensados e as argilas.

O trabalho mais difundido e considerado de importância fundamental para o entendimento sobre o módulo de reação horizontal do solo foi o apresentado por TERZAGHI em 1955. Este trabalho veio contribuir de forma decisiva para melhor conceituação do coeficiente de reação do solo. De um modo geral, a análise da estaca em meio elástico restringia-se ao âmbito da pesquisa matemática que resolvia a equação diferencial (3.2) da viga em apoio elástico sem, contudo, se preocupar com a determinação do coeficiente $\mathrm{k}_{\mathrm{h}}$, considerando simplesmente uma constante do solo. O notável trabalho de HETENYI (1946), apesar de tratar com detalhes a resolução do problema da viga em apoio elástico, não faz menção à determinação do módulo de reação para caracterizar o solo de apoio [DINIZ (1972)]. 


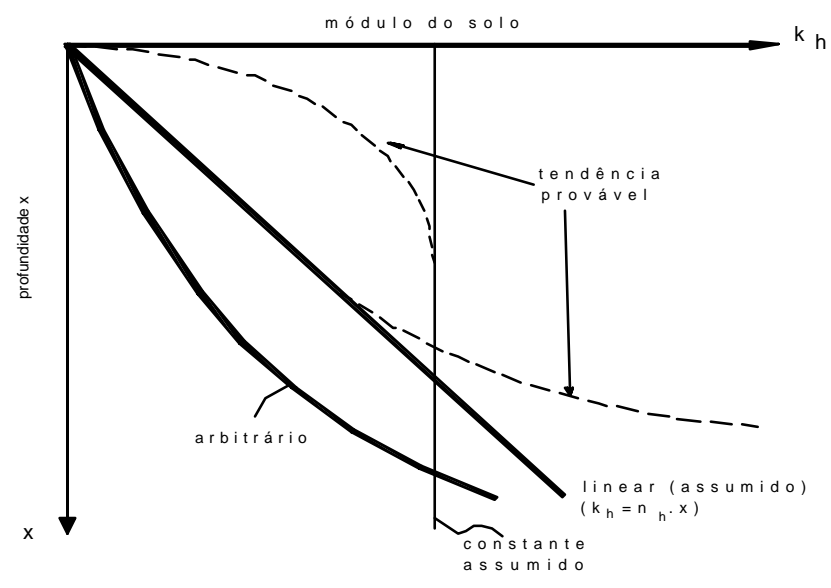

FIG. 3.3 - Variação do Módulo de Reação Horizontal: a)Solos coesivos préadensados: $\mathrm{K}_{\mathrm{h}}$ constante, b) Solos granulares, siltes normalmente carregados, e argilas: . $\mathrm{K}_{\mathrm{h}}$ linear

\subsubsection{2 - RESPOSTA NÃO LINEAR DO SOLO}

Como já mencionado, a resposta do solo pode ser caracterizada por um conjunto de mecanismos discretos, como foi sugerido por WINKLER (1897).

No caso geral, são necessárias três propriedades para um dado ponto da estaca. A primeira delas, na direção lateral, relaciona a força por unidade de comprimento "p" e o deslocamento lateral "y" do ponto da estaca. Esta relação é usualmente denominada curva p-y. De modo análogo, neste mesmo ponto uma curva relacionando a força axial "p" por unidade de comprimento da estaca e o deslocamento axial definirá as propriedades na direção axial. Esta curva é denominada curva $\mathrm{p}$-x. Finalmente, uma outra curva $\mathrm{p}$-xt pode ser definida para a torção, relacionando o torque por unidade de comprimento e o ângulo de distorção. Considerada a hipótese restritiva da não deslocabilidade da base dos tubulões e estacas, somente as curvas p-y serão objeto de estudo. A consideração, também, do comportamento isotrópico do solo implica em assumir que as curvas p-y sejam válidas para todas as direções horizontais. Com relação às cargas laterais, elas podem não se localizar em um plano, como por exemplo, quando uma estaca é solicitada no seu topo por duas forças horizontais e dois momentos ortogonais. Neste caso, se a resposta p-y for linear o problema pode ser superado pela superposição de duas soluções planares. Por outro lado, para um solo de resposta não linear, a 
superposição, obviamente, não pode ser aplicada e o problema deve ser tratado como um problema verdadeiramente tridimensional [SAYBH \& TSO (1988)].

Esses mecanismos discretos indicam que a resposta do solo em um ponto não é dependente do deslocamento da estaca em outros pontos. Deste modo, o contínuo não é considerado perfeitamente modelado. Entretanto, o contínuo pode ser modelado aproximadamente se as informações relativas aos efeitos da interação de uma camada do solo sobre a próxima forem disponíveis. Cada mecanismo discreto, então, pode simbolizar uma família de curvas, com cada curva apropriada para um determinado ponto selecionado refletindo os efeitos do solo abaixo ou acima desse ponto. O presente estado da arte relativamente à resposta do solo decorrente do deslocamento da estaca, não permite, ou justifica, uma abordagem mais sofisticada do que a sugerida por um conjunto desses mecanismos.

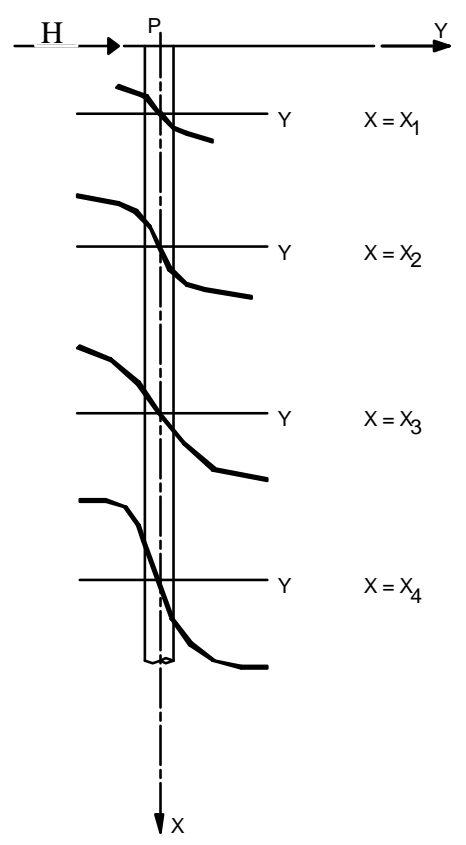

Fig. 3.4 - Família de Curvas p-y

Uma discussão mais específica sobre o significado físico de um desses mecanismos é extremamente útil e auxilia no entendimento da sua origem e limitações. A Fig. 3.5(a) representa uma estaca em elevação após ter sido instalada e antes que qualquer carga lateral fosse nela aplicada. $\mathrm{O}$ comportamento do solo na profundidade $\mathrm{x}_{1}$ é considerado e a distribuição das tensões contra a estaca, antes da aplicação de qualquer carga lateral, é mostrada na Fig. 3.5(b). A hipótese contida na 
figura se refere à cravação da estaca sem qualquer deformação residual ou momento fletor. Deste modo, nenhuma força lateral ocorre contra a estaca na profundidade $\mathrm{x}_{1}$ ou em qualquer outro ponto. É assumido que a carga lateral é agora aplicada na estaca e que ela causa um deslocamento igual a $\mathrm{y}_{1}$ na profundidade $\mathrm{x}_{1}$. A distribuição de tensões alterada é mostrada na Fig. 3.5(c).

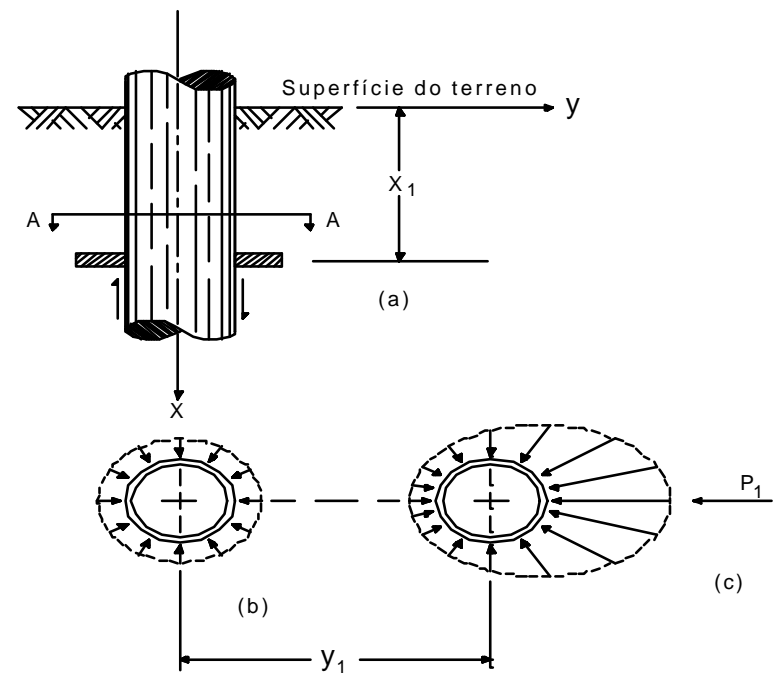

Fig. 3.5-Definição de "p" e "y"

A integração da nova distribuição de tensões indicada na Fig. 3.5(c) resultará em uma força $\mathrm{p}_{1}$ por unidade de comprimento ao longo da estaca. A quantidade $\mathrm{p}_{1}$ é definida como reação do solo ou resistência do solo. Ela age em sentido oposto ao deslocamento y, sendo, portanto, de sinal oposto. Se for possível prever a distribuição de tensões para um campo de deslocamento, integrações sucessivas resultarão em valores de $\mathrm{p}$ correspondentes a valores de $\mathrm{y}$, permitindo que uma curva $\mathrm{p}-\mathrm{y}$ para a profundidade $\mathrm{x}_{1}$ seja obtida. $\mathrm{O}$ mesmo pode ser feito para outros pontos, resultando em uma família de curvas p-y para toda a estaca [REESE (1983)].

Com respeito às curvas p-y, algumas hipóteses são adotadas:

1) Não existe tensão tangencial na superfície da estaca paralela ao seu eixo (a direção da resistência do solo é ortogonal ao eixo da estaca);

2) Qualquer resistência lateral ou momento na base da estaca podem ser considerados por uma curva p-y na face da mesma, próximo à sua base. 
3) Quaisquer erros devido a essas hipóteses são supostamente desprezíveis.

Para se obter a solução completa do problema de uma estaca carregada lateralmente, um critério para a formulação das curvas p-y, para um perfil particular de solo, deve ser obtido. O critério deve ser geral o suficiente de tal modo que os parâmetros de resistência do solo possam ser usados para estabelecer a família completa de curvas p-y. Os critérios são usualmente separados em duas categorias: aqueles para solos puramente coesivos e outros para solos arenosos. Para solos puramente coesivos, $\phi=0$ (ângulo de atrito interno nulo), geralmente assume-se que as deformações do sistema solo-estaca ocorrem sob condições não-drenadas. Para solos não coesivos, os parâmetros efetivos de resistência utilizados são os obtidos sob condições drenadas do solo.

Historicamente, o primeiro critério $\mathrm{p}-\mathrm{y}$ foi estabelecido por McCLELLAND \& FOCHT (1958). Visando obter valores para o coeficiente de reação horizontal, esses autores realizaram um trabalho teórico experimental em terreno argiloso do Golfo do México. Analisando os resultados de testes em protótipos de estacas tubulares de aço instrumentadas em tamanho real, McClelland e Focht observaram a semelhança entre as curvas tensão-deformação do solo, obtidas em laboratório, com as curvas reação-deslocamento lateral da estaca quando desenhadas em escala logarítmica. Estabeleceram assim uma correlação entre os dados obtidos em laboratório e os obtidos no campo. Fazendo atuar sobre a estaca instrumentada duas séries de cargas, uma estática e outra dinâmica, foram obtidos dados relativos às reações do solo e os deslocamentos nos pontos correspondentes à localização dos extensômetros. Traçadas as curvas p-y para esses pontos, e uma vez definido o módulo secante para cada ponto da curva, concluíram o seguinte [SWAN \& WRIGHT (1986)]:

- Devido à grande variação das relações p/y, a fixação de um único valor de $\mathrm{K}_{\mathrm{h}}=\mathrm{p} / \mathrm{y}$ para um determinado solo demonstrou ser incompatível com os resultados da análise; 
- Mesmo para uma determinada profundidade, representada por uma das curvas, a adoção de um único valor para $K_{h}$ já constitui uma aproximação grosseira.

Os dados disponíveis não permitiram a McClelland e Focht o desenvolvimento de uma família completa de curvas experimentais p-y e as propriedades $\sigma-\varepsilon$ da argila. Apesar disso, este trabalho se reveste de uma importância fundamental na medida que apontou o caminho para outros trabalhos que se seguiram no campo experimental de estacas instrumentadas com o objetivo de estabelecer as curvas p-y.

Baseados em testes de estacas, GILL \& DEMARS (1970) estabeleceram um procedimento empírico completo para determinar a variação da resistência última do solo com a profundidade.

Destacam-se pela sua importância, na obtenção das curvas p-y, os critérios de MATLOCK (1970), REESE \& WELCH (1975), REESE et al. (1975) e SULLIVAN (1977). REESE et al. (1974) apresentaram um critério para determinação das curvas p-y para estacas em solo não coesivo considerando os efeitos de carga cíclica.

\subsection{3 - ESTACAS CURTAS: AJUSTAMENTO DAS CURVAS P-Y}

Segundo SWAN \& WRIGHT (1986), uma estaca carregada lateralmente é considerada longa se a sua forma deformada experimenta deslocamentos nulos em pelo menos dois pontos do seu fuste. Se por outro lado, a deformada da estaca tem somente um ponto do seu eixo com deslocamento nulo ela é considerada uma estaca curta (Fig. 3.6). Três diferentes casos são examinados para determinar o comprimento do fuste necessário para que ele experimente dois pontos de deslocamentos nulos. Esses casos são diferenciados pelo módulo de reação do solo: 1) Módulo constante; 2) Módulo com variação linear com a profundidade e 3) Variação arbitrária com a profundidade. Para todos os casos, a força lateral é assumida aplicada no topo do fuste, o qual é assumido livre à rotação (Fig. 3.6). O comprimento mínimo do fuste necessário para que sua deformada tenha dois deslocamentos nulos é designado por $\mathrm{L}_{\mathrm{e}}$. 

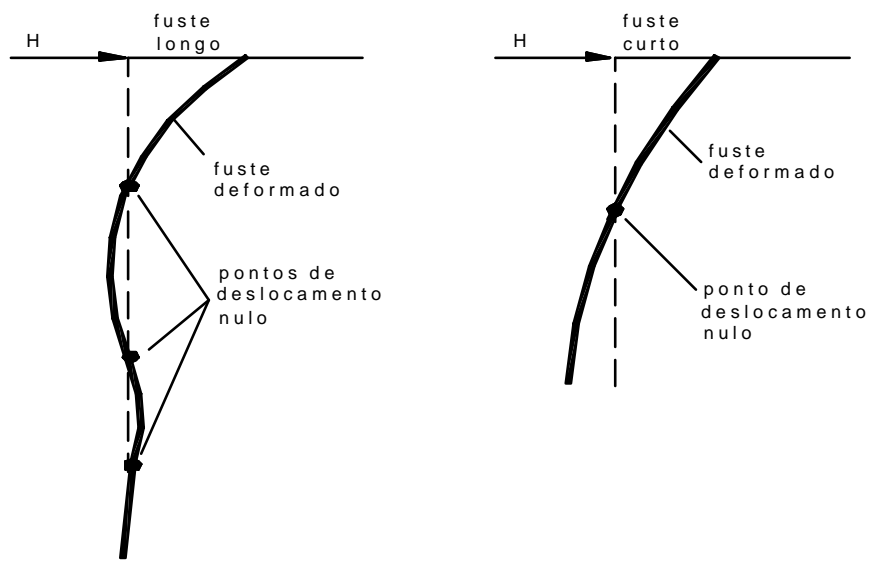

Fig. 3.6-Estacas Longas e Curtas

$\mathrm{O}$ comprimento $\mathrm{L}_{\mathrm{e}}$ é determinado baseado na hipótese de que a base do fuste não experimenta nem cortante e nem momento. Essa hipótese, entretanto, é válida para fustes com comprimento $\mathrm{L}_{\mathrm{e}}$, uma vez que os movimentos no segundo ponto de deslocamento nulo, ou abaixo dele, são muito pequenos. Assim, somente uma pequena quantidade desprezível de cortante e momento são desenvolvidos no segundo ponto de deslocamento nulo (base de um fuste com comprimento $\mathrm{L}_{\mathrm{e}}$ ).

O caso mais simples é o de um solo com módulo constante, estudado por TIMOSHENKO (1941) e HETENYI (1946), conforme citam SWAN \& WRIGHT (1986). O comprimento mínimo $L_{e}$ para que um fuste alcance dois pontos de deslocamentos nulos, pode ser expresso como:

$$
\mathrm{L}_{\mathrm{e}}=\frac{4.8}{\beta} \text { onde, }
$$

$\beta$ é denominado de "fator relativo de rigidez (1/L)" e relaciona a rigidez do fuste com a rigidez do solo:

$$
\beta=\left(\frac{\mathrm{K}_{\mathrm{s}}}{4 \mathrm{EI}}\right)^{0.25}
$$

$\mathrm{EI}=$ rigidez a flexão da estaca e $\mathrm{K}_{\mathrm{s}}=$ módulo de reação do solo.

Para muitos solos, o módulo pode ser considerado variando linearmente com a profundidade (Fig.3.3). MATLOCK \& REESE (1962) realizaram uma análise adimensional usando o Método das Diferenças Finitas, para desenvolver 
a solução da resposta de um fuste onde o módulo do solo varia linearmente com a profundidade. $\mathrm{O}$ comprimento mínimo $\left(\mathrm{L}_{\mathrm{e}}\right)$ de um fuste, necessário para alcançar dois pontos de deslocamentos nulos, pode ser expresso por:

$$
\begin{aligned}
& \mathrm{L}_{\mathrm{e}}=4,8 \mathrm{~T} \text { onde, } \\
& \mathrm{T}=\left(\frac{\mathrm{E}_{\mathrm{p}} \mathrm{I}_{\mathrm{p}}}{\mathrm{m}_{\mathrm{h}}}\right)^{0.2}
\end{aligned}
$$

onde $\mathrm{K}_{\mathrm{s}}=\mathrm{m}_{\mathrm{h}} \mathrm{x}$, sendo $\mathrm{m}_{\mathrm{h}}$ a taxa de variação do módulo com a profundidade e $\mathrm{T}=$ fator de rigidez relativa.

O terceiro caso considerado examina o solo que varia não linearmente com o deslocamento do fuste e, consequentemente, varia não linearmente com a profundidade. O comprimento mínimo do fuste, necessário para alcançar dois pontos de deslocamentos nulos, pode ser obtido por tentativa e erro usando as curvas não lineares p-y e algum procedimento de análise numérica.

A comparação feita por SWAN \& WRIGHT (1986) entre as respostas de inúmeros testes de campo com as respostas calculadas, usando as curvas convencionais $\mathrm{p}-\mathrm{y}$, revelaram uma concordância relativamente pobre entre esses valores e algumas deficiências envolvendo os procedimentos de análise. No sentido de melhorar a previsão do comportamento de fustes curtos, os autores sugeriram três modificações nos procedimentos convencionais. As duas primeiras modificações recomendadas envolvem alterações das curvas p-y. A primeira modificação se refere à redução do deslocamento característico ( $\left.\mathrm{y}_{50}\right)$ usado no critério das curvas p-y para as argilas, e a segunda o aumento da resistência última $\mathrm{p}_{\mathrm{u}}$ nas profundidades abaixo do ponto de deslocamento nulo. A terceira modificação consiste em introduzir as restrições de base, principalmente o esforço horizontal na base do fuste.

\footnotetext{
Alterações nas Curvas p-y:

O critério das curvas $\mathrm{p}-\mathrm{y}$, correntemente empregado, usa uma
} resistência última do solo cujo valor é baseado em um dos dois modos de ruptura assumidos: ruptura por formação de cunha e escoamento do solo em torno da estaca 
(Fig. 3.7). Ambos os parâmetros, $\mathrm{y}_{50}$ e $\mathrm{p}_{\mathrm{u}}$, na sua forma corrente, foram desenvolvidos para fustes escavado longos. Para a análise de fustes escavados curtos, os métodos correntes para o cálculo do deslocamento característico y50 e a resistência última do solo $\mathrm{p}_{\mathrm{u}}$ necessitam ser modificados.

a ) Deslocamento Característico y50:

O deslocamento característico y50 para o critério da curva p-y para a argila mole e argila dura submersa é calculado pela expressão (MALOCK-1970):

$$
\mathrm{y}_{50}=2,5 \varepsilon_{50} \mathrm{~B}
$$

onde o coeficiente 2,5 da expressão provém de ajustamentos relacionados ao diâmetro e o comprimento $\mathrm{L}$ do fuste e mais $\varepsilon_{50}$. Segundo SWAN \& WRIGHT (1986) a equação (3.6) para determinação de $\mathrm{y}_{50}$ foi derivada de uma equação desenvolvida por SKEMPTON (1951) para analisar o deslocamento de uma fundação em argila. A equação de Skempton envolve o produto da largura da fundação, a deformação do solo suporte e um coeficiente adimensional. Esse coeficiente depende da relação entre a largura e o comprimento da fundação, com o valor de 2,5 correspondendo à relação entre a largura e o comprimento igual ou maior que 10. Valores desenvolvidos por Skempton são apresentados na tabela (3.1). $\mathrm{O}$ valor $\mathrm{B} / \mathrm{L}$ representa a relação entre a largura e o comprimento da fundação. Quando o critério da curva p-y foi originalmente desenvolvido, a equação de Skempton foi adaptada para uso em tubulões ou estacas. O critério corrente da curva p-y foi desenvolvido usando dados obtidos de testes de carga reais em estacas instrumentadas com relação comprimento enterrado e diâmetro maior ou igual a 10. A sugestão de SWAN \& WRIGHT (1986) de ajustamento das curvas p-y para utilização em tubulões curtos se baseia na redução de y50 pela troca do coeficiente 2,5 da expressão (3.6) por um dos coeficientes da tabela (3.1).

No caso da curva p-y para uma argila dura submersa, onde o coeficiente " 2,5 " é tomado igual à unidade, o cálculo do deslocamento característico y50 é mantido conforme a expressão (3.7):

$$
\mathrm{y}_{50}=\varepsilon_{50} \mathrm{~B}
$$


O ajustamento da expressão (3.6) para tubulões curtos é sugerido pela redução do seu coeficiente:

$$
\mathrm{y}_{50}=\frac{\mathrm{c}}{2,5} \varepsilon_{50} \mathrm{~B} \quad \text { onde c é o coeficiente da tabela (3.1). }
$$

Tabela 3.1 - Coeficiente deAjustamento C

\begin{tabular}{|c|c|}
\hline$\frac{\mathrm{B}}{\mathrm{L}}$ & Coeficiente(c) \\
\hline Círculo & 1,7 \\
$1: 1$ & 1,9 \\
$1: 2$ & 2,1 \\
$1: 5$ & 2,4 \\
$1: 10$ & 2,5 \\
\hline
\end{tabular}

b) Resistência Última do Solo:

$\mathrm{O}$ valor da resistência última $\mathrm{p}_{\mathrm{u}}$ depende do modo como a ruptura do solo é idealizada ao longo do fuste da estaca. A ruptura do solo é assumida de um dos dois modos (Fig. 3.7):

- ruína tipo cunha;

- ruína por escoamento do solo em torno do fuste.

A ruptura ocorrerá segundo um modelo ou outro em função de vários fatores( tipo do solo, profundidade, histórico de tensões, etc.), mas principalmente em função da compressibilidade do solo. A ocorrência da ruptura tipo cunha é considerada quando o solo se move para frente comprimindo uma cunha para cima. O solo atrás do fuste forma uma cunha ativa fluindo em uma direção para baixo (Fig.6.7a). A ruína por escoamento em torno do fuste ocorre quando a resistência da ruína tipo cunha é maior e, desse modo, o solo tende a escoar pela lateral em torno do fuste em um plano horizontal (Fig. 3.7b).

As equações obtidas para uma determinada curva p-y são derivadas do cálculo da resistência última do solo para os dois modos de ruína. Os valores da resistência última são calculados para ambos os tipos de ruína e comparados nas 
profundidades onde as curvas p-y são formadas. Em cada profundidade, o menor valor de $\mathrm{p}_{\mathrm{u}}$ é considerado como predominante e é usado para construir a curva p-y para essa profundidade.

É assumido que um fuste curto permaneça essencialmente reto, com o fuste girando em torno de um ponto de deslocamento nulo (Fig. 3.6).

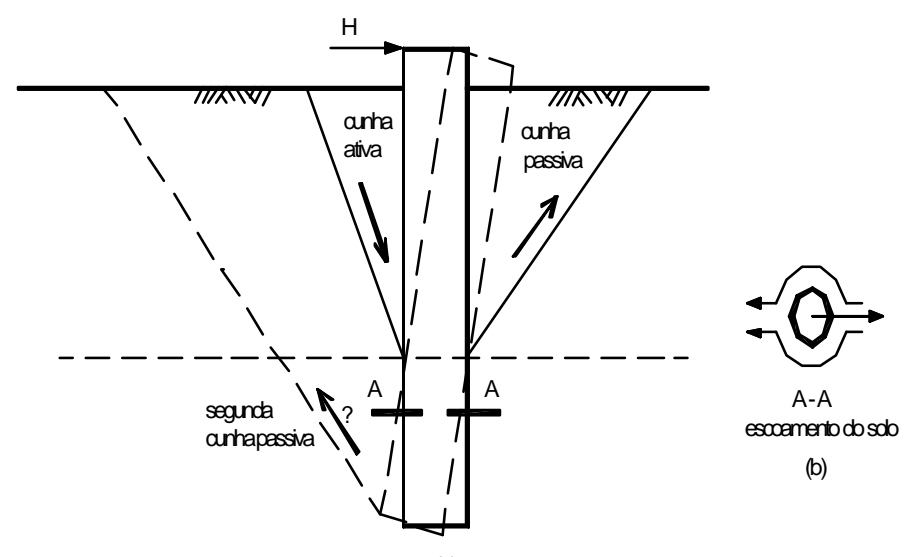

(a)

Fig. 3.7-Modos de Ruptura: a) formação de cunhas e b) por escoamento do solo.

O solo acima do ponto de deslocamento nulo segue o modo de ruína tipo cunha, entretanto é questionável se abaixo desse ponto o mesmo modo de ruína possa ocorrer.

Como uma aproximação, a resistência última do solo abaixo do ponto de deslocamento nulo para um fuste curto, como aquele da Fig. 3.6, é calculada usando as equações para o modo de ruína por escoamento em torno do fuste. Consequentemente, a resistência do solo para um dado deslocamento é aumentada.

\section{2 - RESISTÊNCIA DE BASE}

Os procedimentos convencionais de análise de fustes escavados consideram o esforço cortante e o momento fletor nulos na base do fuste. No caso de fustes longos essa hipótese é razoável, uma vez que, a base do fuste sofre pequenos movimentos durante o carregamento. Entretanto, movimentos significativos podem ocorrer na base de um fuste curto. Tais movimentos são capazes de produzir um esforço cortante e um momento entre a base e o solo. A terceira modificação, 
aplicada aos procedimentos convencionais, se refere à introdução de esforços de restrição na base do tubulão. Uma força horizontal na forma de uma relação bilinear $\left(\mathrm{H}_{\mathrm{B}}\right.$ - y) aplicada ao longo da base é mostrada na Fig. 3.8. Essa curva começa na origem e cresce linearmente até uma força limite $\mathrm{H}_{\mathrm{B}, \max }$, correspondente ao deslocamento de 2,5mm ( pol/10), valor este usado em curvas de transferência de carga nos estudos de COYLE et al. (1973) apud SWAN \& WRIGHT (1986). Essa curva permanece horizontal para uma força igual à força última $\left(\mathrm{H}_{\mathrm{B}, \max }\right)$ para todos os deslocamentos maiores que $2,5 \mathrm{~mm}$.

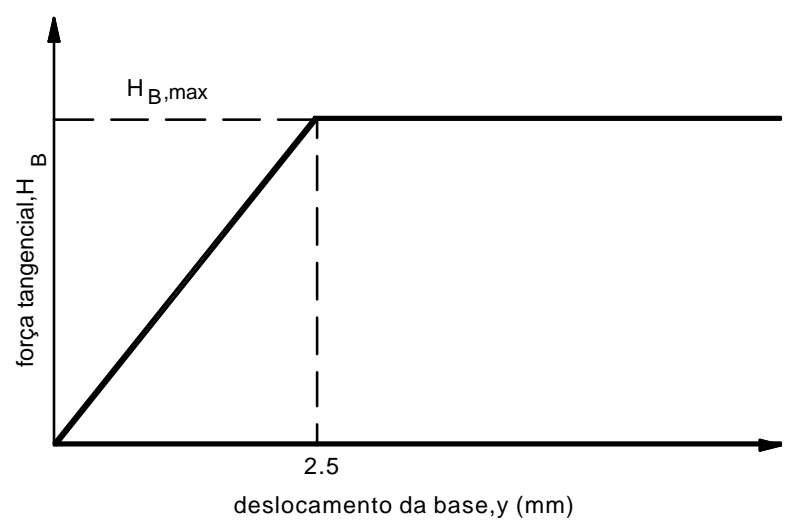

Fig. 3.8-Curva $\mathrm{H}_{\mathrm{B}}-\mathrm{y}$

$\mathrm{O}$ valor de $\mathrm{H}_{\mathrm{B} \text {,max }}$ é determinado usando o produto da resistência ao cisalhamento do solo pela área da base $\left(\mathrm{H}_{\mathrm{B}, \max }=\mathrm{cA}_{\mathrm{B}}\right)$. Para os solos coesivos, a resistência ao cisalhamento é tomada igual à resistência não drenada. Para os solos arenosos, a resistência ao cisalhamento pode ser calculada multiplicando-se a pressão de sobrecarga efetiva pela tangente do ângulo efetivo de atrito interno do solo $\left[\mathrm{H}_{\mathrm{B}, \max }=\mathrm{q} \mathrm{A}_{\mathrm{B}} \tan (\phi)\right]$. Como alternativa, pode-se usar a resistência ao atrito na interface solo-concreto.

A restrição às rotações na base do fuste, quando esse é considerado curto ou de base alargada, pode afetar significativamente o seu comportamento. Em complementação à terceira modificação dos critérios convencionais, é aceitável a consideração de uma relação linear momento-rotação na base do fuste:

$$
\mathrm{M}_{\mathrm{z}}=\overline{\mathrm{k}}_{\mathrm{s}} \mathrm{I}_{\mathrm{z}} \phi_{\mathrm{z}} \text { e } \mathrm{M}_{\mathrm{y}}=\overline{\mathrm{k}}_{\mathrm{s}} \mathrm{I}_{\mathrm{y}} \phi_{\mathrm{y}}
$$


$\mathrm{M}_{\mathrm{z}}$ e $\mathrm{M}_{\mathrm{y}}$ = são os momentos reativos na base da estaca;

$\phi_{\mathrm{z}}$ e $\phi_{\mathrm{y}}=$ são as rotações da base em torno de z e y;

$\mathrm{I}_{\mathrm{z}}$ e $\mathrm{I}_{\mathrm{y}}=$ momentos de inércia da área da base de apoio relativamente aos eixos z e y;

$\overline{\mathrm{k}}_{\mathrm{s}}=$ coeficiente de recalque vertical.

Adicionalmente, para o deslocamento vertical da base pode-se adotar uma relação, também linear, para o recalque vertical:

$$
\begin{aligned}
& \mathrm{F}_{\mathrm{x}}=\overline{\mathrm{k}}_{\mathrm{s}} \mathrm{A}_{\mathrm{b}} \mathrm{u}_{\mathrm{x}} \\
& \mathrm{u}_{\mathrm{x}}=\text { recalque vertical da base. }
\end{aligned}
$$

\section{3 - EFEITO DE GRUPO}

Um grupo de estacas se desloca mais que uma estaca isolada sujeita a uma carga $H_{s}$, quando ele é submetido, em média, a mesma $H_{s}$ por estaca. Isso se deve ao fato de que, cada estaca no grupo causa deslocamento no solo circunvizinho, induzindo deslocamentos adicionais nas demais estacas e, consequentemente, nos seus esforços. O procedimento, proposto por OOI \& DUCAN (1994) para considerar esse efeito, sugere a majoração dos deslocamentos da estaca isolada através de fatores de ampliação. Desta forma tem-se:

$$
\begin{aligned}
& \mathrm{y}_{\mathrm{g}}=\mathrm{C}_{\mathrm{y}} \mathrm{y}_{\mathrm{s}} \text { onde, } \\
& \mathrm{y}_{\mathrm{g}}=\text { deslocamento do grupo de estacas }(\mathrm{L}) ; \\
& \mathrm{C}_{\mathrm{y}}=\text { fator de amplificação de deslocamento }(\geq 1) ; \\
& \mathrm{y}_{\mathrm{s}}=\text { deslocamento da estaca isolada (L). } \\
& \text { Ao estudo paramétrico realizado por OOI (1991) apud OOI \& }
\end{aligned}
$$
DUCAN (1994) se seguiu a seguinte proposta para a expressão do fator $\mathrm{C}_{\mathrm{y}}$ :

$$
\mathrm{C}_{\mathrm{y}}=\frac{\mathrm{A}+\mathrm{n}_{\mathrm{p}}}{\mathrm{D}\left(\frac{\mathrm{S}}{\mathrm{B}}+\frac{\mathrm{H}_{\mathrm{s}}}{\mathrm{CP}_{\mathrm{N}}}\right)^{0.5}}, \quad \text { onde, }
$$


$\mathrm{A}=16$ para argila e $\mathrm{A}=9$ para areia;

$\mathrm{n}_{\mathrm{p}}=$ número de estacas no grupo;

$\mathrm{D}=5.5$ para argila e $\mathrm{D}=3.0$ para areia;

$\mathrm{S}=$ espaçamento médio entre as estacas (L);

$\mathrm{B}=$ diâmetro da estaca isolada $(\mathrm{L})$;

$\mathrm{H}_{\mathrm{s}}=$ carga lateral média por estaca $\left(\mathrm{H}_{\mathrm{tg}} / \mathrm{n}_{\mathrm{p}}\right)$;

$\mathrm{H}_{\mathrm{tg}}=$ carga lateral total aplicada no grupo $(\mathrm{F}) ;$

$\mathrm{C}=3$ para argila e $\mathrm{C}=16$ para areia;

$\mathrm{P}_{\mathrm{N}}=\mathrm{S}_{\mathrm{u}} \mathrm{D}^{2}$ para argila $(\mathrm{F}), \mathrm{K}_{\mathrm{p}} \gamma \mathrm{D}^{3}$ para areia $(\mathrm{F})$;

$\gamma=$ peso específico médio para a areia nos $8 \mathrm{D}$ superiores do solo

$\left(\mathrm{F} / \mathrm{L}^{3}\right)$

$K_{p}=\tan ^{2}(45+\phi / 2)$ : coeficiente de empuxo passivo;

$\phi=$ ângulo de atrito interno médio da areia nos $8 \mathrm{D}$ superiores do solo (graus);

$\mathrm{S}_{\mathrm{u}}=$ resistência média ao cisalhamento da argila não drenada nos 8D superiores do solo $\left(\mathrm{F} / \mathrm{L}^{2}\right)$.

A resposta lateral do solo é obtida nas curvas $\mathrm{p}-\mathrm{y}_{\mathrm{g}}$, onde somente o deslocamento y é ajustado pelo fator de ampliação $\mathrm{C}_{\mathrm{y}}$. 


\section{CAPÍTULO 4}

\section{NÃO-LINEARIDADE GEOMÉTRICA}

\section{1 - GENERALIDADES}

Quando em uma análise estrutural os efeitos da mudança de geometria da estrutura são considerados, a relação carga-deslocamento deixa de ser linear. Esta não-linearidade, denominada de geométrica, em geral pode ser desconsiderada nos casos em que a hipótese dos pequenos deslocamentos é considerada válida. Entretanto, a não-linearidade geométrica passa a ser relevante nos casos em que os deslocamentos, relativamente significativos, podem acentuar os problemas de instabilidade ou a interação entre o esforço axial e os momentos fletores. Nesses casos, devido à grandeza dos deslocamentos, surge a necessidade de se escrever as equações de equilíbrio em relação à configuração deformada da estrutura. Mesmo que com deslocamentos relativamente pequenos, combinados com certas disposições de cargas na estrutura podem ocorrer situações de instabilidade ou o surgimento de esforços adicionais.

Quando os efeitos não lineares implicarem em enrijecimento da estrutura, a utilização de uma análise linear pode conduzir a estruturas mais seguras, porém antieconômicas. Por outro lado, se o comportamento não linear implicar em perda de rigidez ou de estabilidade, a utilização de uma análise linear pode resultar ou induzir a uma falsa noção de segurança estrutural [BENJAMIN (1982)].

Seguindo essa linha, objetiva-se com este trabalho abordar o comportamento não linear dos pilares de pontes de concreto armado para as suas 
seções usuais e conformação arbitrária segundo o seu eixo, assim como a consideração da deformabilidade das fundações e os efeitos advindos do tempo.

Será usado como elemento básico o "BEAM4 3D Elastic Beam" da biblioteca interna do ANSYS disponível para a análise não linear geométrica. $\mathrm{O}$ efeito da não-linearidade física pode ser considerado pela atualização dos parâmetros internos da matriz de rigidez elástica para cada etapa de carregamento da estrutura (Fig. 4.1).

No caso de uma barra de concreto armado, as grandezas afetadas pela não-linearidade física são a rigidez axial (EA), a rigidez a flexão $\left(\mathrm{EI}_{\mathrm{y}} \mathrm{e} \mathrm{EI}_{\mathrm{z}}\right)$ e a rigidez a torção $\left(\mathrm{GI}_{\mathrm{x}}\right)$, todas dependentes do estado de solicitação para cada etapa de carregamento. No caso específico de pilares, serão desprezadas as alterações de rigidez a torção.

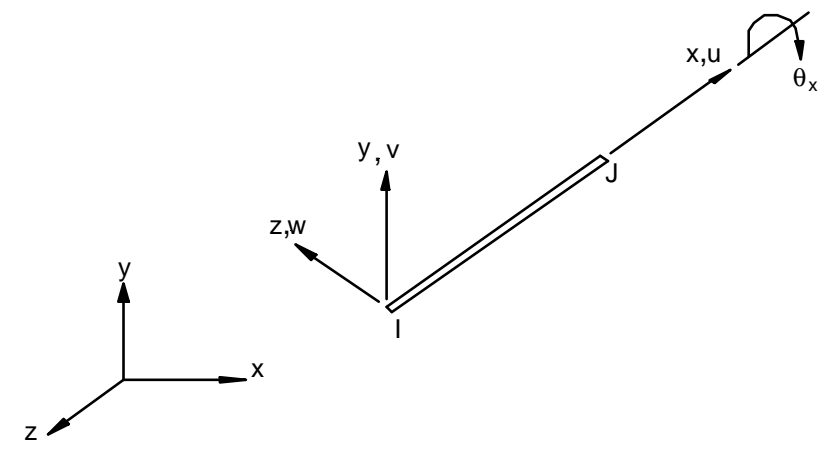

Fig.4.1-Elemento“BEAM4 3D Elastic

A análise não linear geométrica se fundamenta teoricamente na elasticidade não linear da Mecânica do Contínuo. A característica genérica dos conceitos e equações da Mecânica do Contínuo permite abranger, além da teoria da elasticidade, outras teorias como a visco-elasticidade ou a plasticidade [FUNG (1975)].

A não-linearidade geométrica tem origem na teoria da elasticidade, onde as equações de equilíbrio são escritas utilizando-se a configuração deformada da estrutura e as relações deformações vs. deslocamentos, incluindo-se nelas termos não lineares. 
Uma estrutura, quando submetida a ações de qualquer natureza, muda de configuração, sofrendo alterações na sua forma e no seu volume.

Como em cada configuração a posição das partículas da estrutura é diferente, é necessário que se estabeleça uma forma única de determiná-las. Isto é feito escolhendo-se uma configuração de referência a qual todas as outras são referenciadas.

O movimento de uma estrutura, descrito dessa maneira, é chamado de Descrição Material ou Lagrangeana. Nesta forma de descrição do movimento, todo o comportamento é descrito em termos das coordenadas iniciais da estrutura no tempo $\mathrm{t}=0$. Outra forma de descrição do movimento é a descrição Espacial ou Euleriana que se ocupa em descrever o movimento em termos da posição corrente ocupada pela estrutura em um determinado instante $\mathrm{t}$.

A maioria das formulações em elementos finitos, que permitem considerar a não-linearidade geométrica, é baseada em alguma forma de Descrição Lagrangeana do equilíbrio. Em uma Formulação Lagrangeana Total, todas as integrais são calculadas com relação à configuração não deformada da estrutura no instante inicial $t=0$. Como outra alternativa, qualquer configuração deformada, desde que conhecida, pode ser tomada como estado inicial e continuamente atualizada ao longo da análise. Esta forma de descrição é denominada Formulação Lagrangeana Atualizada.

\section{2 - BREVE REVISÃO BIBLIOGRÁFICA}

A pesquisa sobre a análise estrutural não-linear, de certa forma estimulada pela necessidade em otimizar melhor as estruturas segundo uma modelagem mais realista, procura satisfazer ou suprir como objetivo final as orientações cada vez mais exigentes das prescrições normativas.

Historicamente, as primeiras contribuições ao estudo e aplicação do MEF se devem aos trabalhos de ARGIRIS \& KELSEY por volta de 1955. Logo em seguida em 1956, uma contribuição adicional foi realizada através dos trabalhos de TURNER et al.(1956) e CLOUGH em 1960. Mais tarde vieram as contribuições do próprio ARGIRIS em 1965 e ZIENKIEWICZ \& CHEUN (1967). TURNER et al. 
(1960) publicaram o primeiro artigo em que a não linearidade geométrica é tratada pelo MEF usando um processo incremental em conjunto com o conceito da rigidez tangente. GALLAGHER \& PADLOG (1963) iniciaram a introdução da não linearidade física (NLF) no modelo de elementos finitos. ARGIRIS (1965) estudou os problemas não-lineares. MALLET \& MARCAL (1968) desenvolveram formalmente as matrizes incrementais de forma apropriada para deslocamentos finitos, grandes deslocamentos e análise de estabilidade. Em 1968 JENNING empregou as coordenadas eulerianas na formulação da matriz de rigidez tangente. ORAN em 1973 apresentou uma matriz tangente consistente com a teoria convencional de viga-pilar, utilizando as coordenadas eulerianas. No Brasil, inúmeros trabalhos foram desenvolvidos na COPPE/UFRJ, PUC/RJ, EESC/USP e EP/USP. MANTILLA (1974) desenvolveu um método iterativo para a análise da NLG, utilizando o conceito de funções de estabilidade. ANTUNES (1978) estudou a instabilidade da estrutura tridimensional de edifícios altos. Na década de 80 GATTASS \& ABEL e PIMENTA (1986-1989) trabalharam na linha da formulação Lagrangeana Atualizada, utilizando graus de liberdade naturais. Em particular, PIMENTA apresentou uma teoria que permite a consideração de barras não homogêneas e sem restrição à grandeza dos deslocamentos. KRÜGER (1989) apresentou uma metodologia para a análise física e geométrica não lineares de pórticos planos de concreto armado a partir de uma formulação incremental do princípio da energia potencial total estacionária. PAULA (1997) apresentou um estudo conceptual relativo à modelagem mecânico-geométrico para a descrição do comportamento estrutural geometricamente não linear. SILVA em 1989 utilizou o método P- $\Delta$ para avaliar os efeitos da NLG em estruturas tridimensionais de edifícios altos. MARTINS em 1979 estudou o comportamento não-linear de estruturas reticuladas espaciais de concreto armado com o objetivo de pesquisar a sua estabilidade e capacidade de carga. BATHE (1975) et al. apresentaram uma formulação de Lagrange aplicada à análise dinâmica utilizando o MEF. Em 1979 ARGYRIS et al. introduziram o conceito de graus de liberdade naturais na formulação Lagrangeana Atualizada. MEEK et al. (1990) estudaram o comportamento NLFG (não-linearidades física e geométrica) de pórticos espaciais, utilizando elementos vigas-pilar. CORRÊA (1991) desenvolveu um programa para 
análise não linear de estruturas tridimensionais para edifícios altos incluindo a NLF nas lajes de concreto armado. PIMENTA \& YOJO (1992-1993) desenvolveram um modelo de barra totalmente não linear, usando formulações variacionais para a obtenção das equações de equilíbrio. Contribuíram também na elaboração de algoritmos para solução de problemas não lineares CRISFIELD (1981), OWEN \& GOMES (1984), BATHE \& CIMENTO (1980) e PROENÇA (1989). SILVA (1996) estudou a modelagem das não-linearidades em pórticos planos de concreto armado e avaliou os Métodos Aproximados. BENJAMIN (1982) apresentou duas formulações consistentes de elementos finitos para a análise não linear geométrica de pórticos tridimensionais. SOLER (1985) estudou os problemas típicos de pórticos planos de concreto armado e em 1995 estendeu o estudo para os pórticos tridimensionais. CADAMURO JÚNIOR (1997) apresentou um estudo geral sobre o dimensionamento e verificação de pilares esbeltos de concreto armado solicitados por flexão oblíqua, e em 1998 SANCHES JÚNIOR apresentou um estudo para a análise estrutural de pavimentos de edifícios de concreto armado implementando os modelos de DEBERNARDI e de GHALI \& FAVRE. PINTO (1997) abordou os problemas das não-linearidades física e geométricas em edifícios de múltiplos andares.

\section{3 - MÉTODOS DE ANÁLISE}

Os métodos de análise estrutural surgiram dos esforços para superar a complexidade das estruturas e, principalmente, a dificuldade de resolução das equações diferenciais.

A racionalização, unificação e a caracterização dos elementos só foram conseguidas a partir dos princípios variacionais da Mecânica do Contínuo, reconhecidos a partir de então como base para o Método dos Elementos Finitos MEF [MARTIN \& CAREY (1973), NORRIE \& DE VRIES (1973)], resultando no desenvolvimento das chamadas Formulações Consistentes.

Após o êxito obtido com as estruturas de comportamento linear, as atenções se voltaram para a solução dos problemas do comportamento não linear, cada vez mais freqüentes com a crescente complexidade apresentadas pelas estruturas. Em decorrência disto, muitas formulações foram propostas. "No caso de 
elementos unidimensionais de comportamento linear, inexistem diferenças entre a matriz de rigidez obtida pela formulação consistente que utiliza um princípio variacional e outras formulações que utilizam outros princípios ou outras soluções para a equação diferencial em termos dos deslocamentos [PRZEMIENIECKI (1968) ]“

Quanto à solução de problemas de comportamento não linear, apenas a utilização de uma formulação consistente garante a inclusão de todos os termos não lineares na expressão da energia do problema.

Várias formulações têm sido apresentadas, diferenciando-se basicamente no modo da transformação das coordenadas e na consideração ou não dos termos de ordem superior [(BENJAMIN (1982), SILVA (1996), MARTINS (1979), PIMENTA(1986-1989), SOLER(1985-1995), PAULA(1997), KRÜGER(1989), etc.)].

Além das formulações consistentes, outras formulações utilizam-se do Método da Viga-pilar para representar o comportamento não linear dos pórticos. Esse método foi desenvolvido paralelamente à formulação do MEF para a análise não linear geométrica, e pode ser considerado como uma formulação não consistente do MEF.

A formulação variacional do Método dos Deslocamentos, ou modelo compatível com o MEF, pode ser feita a partir do Princípio dos Trabalhos Virtuais ou do Princípio da Energia Potencial Estacionária [BREBBIA \& FERRANTE (1975)].

A primeira opção é considerada geral, permitindo a utilização de qualquer tipo de relação constitutiva, enquanto a segunda é válida apenas para o comportamento elástico do material [DYM \& SHAMES (1973)]. A matriz de rigidez da estrutura pode ser obtida através dos princípios variacionais, e por meio de métodos numéricos é possível a obtenção das respostas da estrutura para uma determinada configuração de equilíbrio.

Para um sistema conservativo, a Energia Potencial Total é escrita como a soma da energia de deformação interna (U) e o potencial (W) das forças externas [KRÜGER (1989)]. 
$\Pi=\mathrm{U}+\mathrm{W}$

onde

$$
\begin{aligned}
& \mathrm{U}=\int_{\mathrm{V}} \mathrm{U}_{0}(\varepsilon) \mathrm{dV} \quad \mathrm{e} \\
& \mathrm{W}=-\int_{\mathrm{V}}\{\overline{\mathrm{F}}\}^{\top} \cdot\{\mathrm{u}\} \mathrm{dV}-\int_{\mathrm{S}_{\boldsymbol{\sigma}}}\{\overline{\mathrm{T}}\}^{\top} \cdot\{\mathrm{u}\} \mathrm{dS}+\mathrm{C}
\end{aligned}
$$

$\{u\}=$ vetor dos deslocamentos que permite descrever a configuração deformada e o estado de tensão da estrutura;

$\mathrm{U}_{0}=$ energia específica de deformação;

$\{\bar{F}\}=$ vetor das forças de corpo que atua no volume $V$ do elemento;

$\{\bar{T}\}=$ vetor das forças externas aplicadas no contorno $S_{\sigma}$ do elemento;

$\mathrm{C}=$ constante arbitrária.

A expressão da energia potencial total toma a seguinte forma:

$$
\Pi=\int_{\mathrm{V}} \mathrm{U}_{0}(\varepsilon) \mathrm{dV}-\int_{\mathrm{V}}\{\overline{\overline{\mathrm{F}}}\}^{\mathrm{T}} \cdot\{\mathrm{u}\} \mathrm{dV}-\int_{\mathrm{S}_{\sigma}}\{\overline{\mathrm{T}}\}^{\mathrm{T}} \cdot\{\mathrm{u}\} \mathrm{d} \mathrm{S}+\mathrm{C}
$$

A condição de equilíbrio das forças que agem em um sistema é encontrada para um deslocamento $\{u\}$ que torna a energia potencial total estacionária, ou seja, torna nula a sua primeira variação:

$$
\delta \Pi=\int_{\mathrm{V}} \delta \mathrm{U}_{0}(\varepsilon) \mathrm{dV}-\int_{\mathrm{V}}\{\overline{\bar{F}}\}^{\mathrm{T}} \cdot\{\delta \mathrm{u}\} \mathrm{dV}-\int_{\mathrm{S}_{\sigma}}\{\overline{\mathrm{T}}\}^{\mathrm{T}} \cdot\{\delta \mathrm{u}\} \mathrm{dS}=0
$$

Para uma determinada configuração de equilíbrio relacionada a um nível de carga $\bar{F}$, pretende-se obter o valor dos seus correspondentes deslocamentos $\{u\}$. Como a obtenção de $\{u\}$ não pode ser determinada diretamente a partir da equação (4.5), a qual é não linear em $\{u\}$, parte-se de uma configuração de equilíbrio (ponto A) próxima à configuração desejada (Fig.4.2). A configuração de equilíbrio no ponto $\mathrm{A}$ é descrita em função dos deslocamentos $\left\{\mathrm{u}_{0}\right\}$, que não corresponde necessariamente à trajetória de equilíbrio, mas para os quais se têm 
forças em equilíbrio $\mathrm{F}\left(\mathrm{u}_{\mathrm{o}}\right)$ no domínio $\mathrm{V}$ e $\mathrm{T}\left(\mathrm{u}_{\mathrm{o}}\right)$ no contorno $\mathrm{S}_{\sigma}$, função destes deslocamentos.

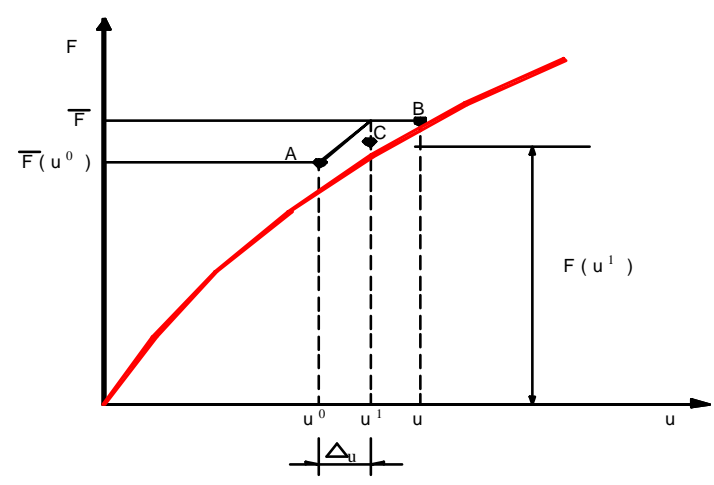

Fig. 4.2 - Configuração Genérica em Equilíbrio - Unidimensional (Adaptado de KRÜGER - 1989).

Estando a configuração de equilíbrio "A" suficientemente próxima da configuração "B", pode-se tentar chegar a uma configuração ainda mais próxima (ponto C) com a utilização de relações incrementais lineares entre os deslocamentos $\{\Delta u\}$ e acréscimos $\{\Delta \bar{F}\}$ das forças. Isto se consegue pela nova variação da expressão (4.5) agora em função de $\left\{u_{0}\right\}$, que resulta em:

$$
\delta^{2} \Pi=\int_{\mathrm{V}} \delta^{2} \mathrm{U}_{0}(\varepsilon) \mathrm{dV}-\int_{\mathrm{V}}\{\overline{\delta \mathrm{FF}}\}^{\mathrm{T}} \cdot\{\delta \mathrm{u}\} \mathrm{dV}-\int_{\mathrm{S}_{\sigma}}\{\overline{\delta \mathrm{T}}\}^{\mathrm{T}} \cdot\{\delta \mathrm{u}\} \mathrm{dS}=0
$$

As variações incrementais $\{\delta \overline{\mathrm{F}}\}$ e $\{\delta \overline{\mathrm{T}}\}$ são interpretadas do seguinte modo:

$$
\{\delta \overline{\mathrm{F}}\}=\{\overline{\mathrm{F}}(\overline{\mathrm{u}})\}-\{\mathrm{F}(\mathrm{u})\} \text { e }\{\delta \overline{\mathrm{T}}\}=\{\overline{\mathrm{T}}(\overline{\mathrm{u}})\}-\{\mathrm{T}(\mathrm{u})\}
$$

Com este procedimento, obtêm-se um incremento de deslocamento $\{\Delta \mathrm{u}\}$ e, consequentemente, uma solução melhor do problema em termos de deslocamento:

$$
\left\{u^{1}\right\}=\left\{u^{0}\right\}+\{\Delta u\}
$$

aos quais corresponde uma nova configuração de equilíbrio associada às forças $\left\{F\left(u^{1}\right)\right\}$ e $\left\{T\left(u^{1}\right)\right\}$, se bem que, ainda, afastadas da trajetória de equilíbrio. Aplica-se esse procedimento repetidas vezes até que se tenha uma 
precisão dos resultados dentro de uma tolerância preestabelecida. Esse procedimento constitui a base de todos os métodos numéricos de resolução de sistemas de equações não lineares [KRÜGER (1989), PAULA (1997)].

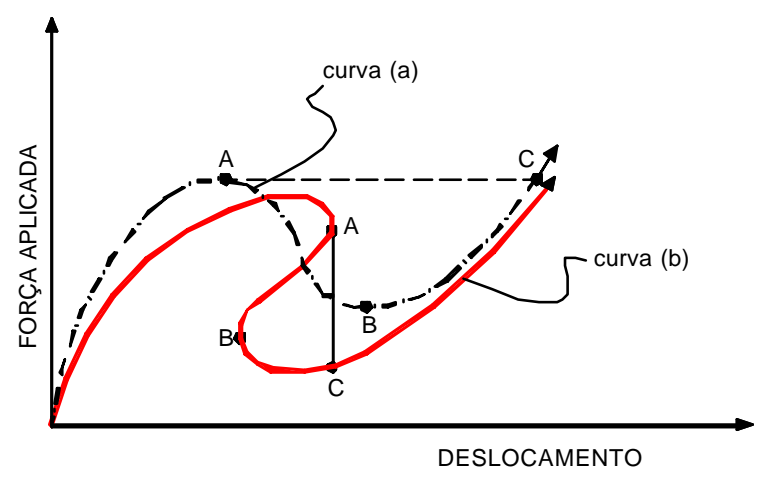

Fig. 4.3-Curva (a): "snap-through", curva (b): "snap-back"

Um sistema de equações não lineares pode ser positivo definido, singular ou indefinido, e podem ocorrer na sua resolução fenômenos tais como o "snap-through" e o "snap-back" (Fig.4.3).

O primeiro fenômeno ocorre quando, para se atingir o equilíbrio, é necessário que as forças aplicadas diminuam de intensidade à medida que os deslocamentos vão aumentando (Fig. 4.3 curva a). Por sua vez, no segundo fenômeno (Fig. 4.3.curva b), tanto os deslocamentos quanto as forças devem diminuir de intensidade para que o equilíbrio seja alcançado (KRÜGER-1989).

Um método mais geral deve ser capaz de superar todas estas dificuldades. Os principais métodos partem da formulação matemática incremental definida na equação (4.6). O método de Newton-Raphson, um método relativamente simples, serve de suporte para os demais.

A partir desses conceitos, o Método de Newton-Raphson é formalizado através de um estado de equilíbrio correspondente a um determinado nível de carregamento $\{p\}$ associado a um deslocamento $\{u\}$, isto é:

$$
\{\mathrm{p}(\mathrm{u})\}=\overline{\mathrm{p}}
$$

onde $\overline{\mathrm{p}}$ são as forças correspondentes ao deslocamento $\{u\}$. 
Como a equação (4.9) é não linear em $\{u\}$, esses deslocamentos não podem ser obtidos diretamente. Usa-se, portanto, um processo iterativo em que os deslocamentos aproximados $\left\{\mathrm{u}^{\mathrm{i}}\right\}$, correspondentes a i-ésima iteração, definem uma função de erro correspondente ao equilíbrio dada por:

$$
\left\{R\left(u^{i}\right)\right\}=\left\{-\{\}-\left\{p\left(u^{i}\right)\right\}\right.
$$

que deve ser tornada nula. Para tanto, expande-se essa função de erro em uma série de Taylor em torno da configuração de deslocamentos correspondentes à iteração i-1

$$
\left\{\mathrm{R}\left(\mathrm{u}^{\mathrm{i}}\right)\right\}=\mathrm{R}\left(\mathrm{u}^{\mathrm{i}-1}\right)+\left[\frac{\partial \mathrm{R}}{\partial \mathrm{u}}\right]_{\mathrm{i}-1} . \Delta\left\{\mathrm{u}^{\mathrm{i}}\right\}+\mathrm{O}\left\{(\Delta \mathrm{u})^{2}\right\}
$$

Este procedimento, em que se retêm somente os dois primeiros termos da série, corresponde ao método de Newton- Raphson:

$$
\begin{aligned}
& {\left[\mathrm{K}\left(\mathrm{u}^{\mathrm{i}-1}\right)\right] \Delta\left\{\mathrm{u}^{\mathrm{i}}\right\}=\left\{\mathrm{R}\left(\mathrm{u}^{\mathrm{i}-1}\right)\right\}, \text { onde }} \\
& {\left[\mathrm{K}\left(\mathrm{u}^{\mathrm{i}-1}\right)\right]=-\left[\frac{\partial \mathrm{R}}{\partial \mathrm{u}}\right]_{\mathrm{u}^{\mathrm{i}-1}}}
\end{aligned}
$$

representa a matriz de rigidez tangente da estrutura, função dos deslocamentos $\left(\mathrm{u}^{\mathrm{i}-1}\right)$, que também pode ser obtida pela segunda variação da energia de deformação U da equação (4.5)

Das equações (4.12 e 4.13) obtêm-se o seguinte sistema:

$$
\left[K\left(\mathrm{u}^{\mathrm{i}-1}\right)\right] \Delta\left\{\mathrm{u}^{\mathrm{i}}\right\}=\left\{\mathrm{R}\left(\mathrm{u}^{\mathrm{i}-1}\right)\right\}=\overline{\mathrm{p}}-\left\{\mathrm{p}\left(\mathrm{u}^{\mathrm{i}-1}\right)\right\}
$$

que é resolvido em termos do incremento de deslocamento $\left\{\Delta\left(\mathrm{u}^{\mathrm{i}}\right)\right\}$. Esse incremento é então utilizado para se determinar um vetor atualizado de deslocamentos $\left\{u^{i}\right\}$, de tal forma que:

$$
\left\{u^{i}\right\}=\left\{u^{i-1}\right\}+\Delta\left\{u^{i}\right\}
$$

As equações (4.14) e (4.15) constituem o procedimento iterativo de Newton-Raphson, tomando-se $i=1,2, \ldots . . .$. , até que um critério de convergência previamente estabelecido seja satisfeito. 
A Fig. 4.4 ilustra esse procedimento para um sistema com um grau de liberdade.

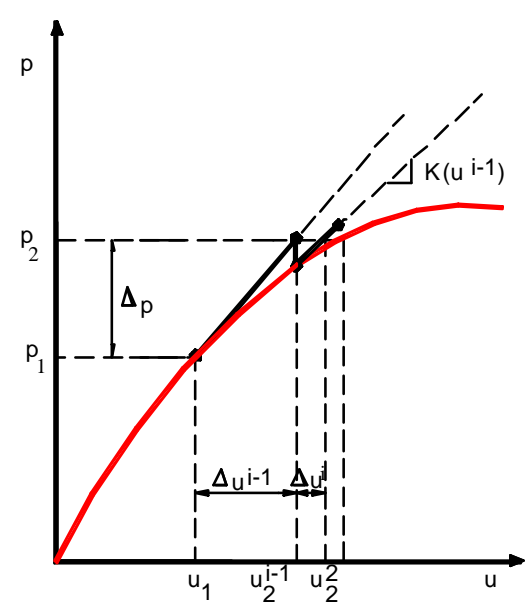

Fig.4.4-Procedimento Geral de Newton- Raphson

Como foi observado, a matriz de rigidez tangente resulta de uma análise incremental, ou seja, da linearização da equação de equilíbrio. Nota-se que a matriz de rigidez tangente relaciona os acréscimos de deslocamentos com as variações do carregamento aplicado

Dessa forma é possível transformar o cálculo não linear em uma sucessão de etapas lineares, com os parâmetros de que depende o problema sendo mantidos constantes ao longo de cada etapa. Nesse caso, se faz uma contínua atualização da configuração de referência [PAULA (1997)].

A composição da matriz de rigidez tangente dependerá da formulação adotada na sua obtenção, se Lagrangeana Total ou Lagrangeana Atualizada.

A Matriz de Rigidez Tangente resulta da soma de duas outras matrizes: a matriz de rigidez elástica e a matriz de rigidez não linear.

$$
\mathrm{K}_{\mathrm{T}}=\mathrm{K}_{\mathrm{L}}+\mathrm{K}_{\mathrm{NL}}
$$

Se o referencial adotado for a configuração indeformada, e se assim for mantido (Lagrangeana Total), a Matriz de Rigidez Não linear $\left(\mathrm{K}_{\mathrm{NL}}\right)$ será composta por duas outras matrizes, a Matriz das Correções de Coordenadas $\left(K_{u}\right)$ e uma outra denominada Matriz de Rigidez Geométrica $\left(\mathrm{K}_{\mathrm{N}}\right)$ : 


$$
\mathrm{K}_{\mathrm{NL}}=\mathrm{K}_{\mathrm{U}}+\mathrm{K}_{\mathrm{N}}
$$

A Matriz das Correções $\left(\mathrm{K}_{\mathrm{U}}\right)$ é função dos deslocamentos nodais $\{\mathrm{u}\}$ e determina a configuração corrente relativamente à configuração inicial não deformada, para cada etapa de carga, devido à mudança das coordenadas nodais. A Matriz de Rigidez Geométrica $\left(\mathrm{K}_{\mathrm{N}}\right)$ leva em consideração o efeito do esforço axial. Quando da adoção da atualização contínua da configuração de referência (Lagrangeana Atualizada), essa atualização é feita de tal modo que, ao se atingir o equilíbrio, a configuração de referência praticamente coincide com a configuração final. Neste caso, $\mathrm{K}_{\mathrm{NL}}=\mathrm{K}_{\mathrm{N}}$. Essas formulações se encontram implementadas na maioria dos programas em elementos finitos.

$\mathrm{Na}$ prática, na maior parte das estruturas, mesmo na presença de grandes deslocamentos e rotações relativamente grandes, os alongamentos $\left(\varepsilon_{\mathrm{i}}\right)$ e as distorções $\left(\phi_{\mathrm{ij}}\right)$ são pequenos em relação à unidade [ORAN (1973)]. Nesses casos, o estudo do comportamento da estrutura pode ser efetuado aplicando-se a hipótese das pequenas deformações à teoria geral.

A adoção da hipótese das pequenas deformações com grandes translações e rotações permite, em decorrência, admitir que as seções transversais inicialmente planas mantenham-se planas para qualquer configuração deformada. Pode-se supor também que um elemento esteja sujeito aos movimentos de rotações de corpo rígido, mantendo-se o eixo reto e as seções transversais e comprimentos constantes, tal como na configuração inicial. É possível então relacionar através de transformações lineares as configurações deformadas com a deformação inicial.

Em decorrência da aplicação dos métodos de análise estrutural aos problemas não lineares, alguns processos são sugeridos para a resolução dos sistemas de equações algébricas não lineares advindas das formulações. Os processos incrementais, iterativos, e incrementais-iterativos são os mais utilizados [MATTHIES \& STRANG (1979) ].

No processo incremental, supõe-se que a estrutura seja carregada por etapas, correspondendo a cada uma delas uma das configurações de equilíbrio dentre aquelas de uma sucessão. Seja uma série de configurações indicadas por: $\Omega^{0}, \Omega^{1}$, 
$\Omega^{2}, \Omega^{3}, \Omega^{\mathrm{n}-1}, \Omega^{\mathrm{n}}, \Omega^{\mathrm{n}+1}, \ldots \ldots \ldots, \Omega^{\mathrm{f}}$, onde $\Omega^{0}$ e $\Omega^{\mathrm{f}}$ são, respectivamente, os estados de deformação inicial e final, e $\Omega^{\mathrm{n}}$ uma configuração genérica intermediária. Propõese determinar a solução para a etapa $(n+1)$, conhecidas as soluções anteriores até a etapa (n) através da repetição do mesmo processo de solução. Isto é possível desde que, a configuração $(n+1)$ seja suficientemente próxima da configuração (n), e que as equações do problema possam ser linearizadas em relação às incógnitas incrementais. Desse modo, um problema não linear é transformado numa série de problemas lineares [BENJAMIN (1982)].

No processo iterativo [VENÂNCIO (1975)] uma ação ou uma combinação de ações é aplicada numa etapa única, na sua totalidade, e com isso obtêm-se uma solução inicial. Calculam-se, em seguida as forças nodais para a geometria dada por essa solução. Como o comportamento da estrutura é não linear, as forças nodais não se equilibram com as forças externas aplicadas, o que gera um carregamento residual não equilibrado igual às forças externas menos as forças nodais internas. Esse carregamento é então aplicado com os parâmetros da estrutura atualizados, segundo a geometria dada pela última solução. Obtém-se, assim, uma nova solução calculando-se novas forças nodais para uma geometria atualizada. Com estas forças nodais e o carregamento externo, calcula-se um novo carregamento residual e inicia-se todo o processo até que os carregamentos não equilibrados sejam menores que uma tolerância previamente adotada.

No procedimento incremental iterativo uma determinada etapa do carregamento, por exemplo, uma ação ou combinação de ações é efetuado por incrementos, sendo efetuadas iterações dentro de cada incremento até a obtenção da configuração de equilíbrio dentro de uma tolerância previamente estabelecida (Fig. 4.5)

Uma determinada etapa de carregamento pode ser constituída por uma simples ação de um histórico de carregamento ou quaisquer combinações de ações para o Estado Limite de Utilização ou Estado Limite Último aplicadas de uma só vez em uma única etapa 
Não-Linearidade Geométrica

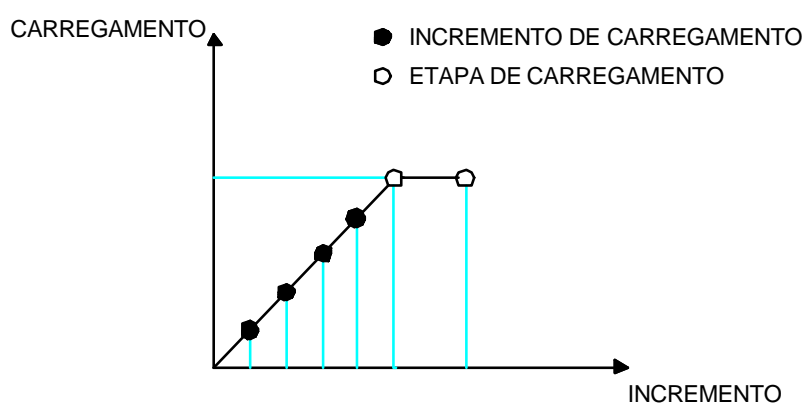

Fig. 4.5 - Procedimento Incremental iterativo de Carregamento 


\section{CAPÍtULO 5}

\section{NÃO-LINEARIDADE FÍSICA}

\section{1- GENERALIDADES}

A modelagem de um elemento de concreto armado esbarra no problema da generalização, quanto à compreensão e quantificação do seu comportamento, e quanto aos estados de tensão e deformação instalados na ligação aço-concreto após o aparecimento das fissuras. Dentre os inúmeros aspectos relevantes da modelagem do Concreto Armado, três deles podem ser considerados significativos na avaliação do comportamento de elementos lineares fletidos. $\mathrm{O}$ primeiro aspecto considerado na modelagem reside no princípio de que na realidade as tensões no aço se encontram numa situação intermediária relativamente aos comportamentos dos estádios I e II das seções. Dessa forma, devem ser feitos ajustes adequados nas relações constitutivas do aço da armadura, objetivando a consideração desse fenômeno.

Os outros dois efeitos, também muito importantes, estão relacionados ao concreto sob regime de compressão. Um desses efeitos se relaciona à influência da armadura transversal (estribos) no confinamento do concreto, advindo daí, a conceituação do concreto confinado ou não. $\mathrm{O}$ outro aspecto se refere à resposta das peças de concreto ao longo do tempo. Esses três efeitos podem convenientemente ser considerados nas relações constitutivas do concreto e do aço.

A modelagem do comportamento físico do Concreto Armado fissurado, utilizando-se do método geral da rigidez através dos elementos finitos, 
sugere, apesar de ter um campo de aplicação mais amplo, alguns inconvenientes quando uma formulação geral tridimensional de rigidez é utilizada. Nesse caso, as relações constitutivas para o concreto nas três direções, além da interação com a armadura, necessitam ser conhecidas, o que no estágio atual não são bem definidas ou adequadamente conhecidas. O principal problema do uso desse método geral é a inconveniência da vasta quantidade de dados e o tempo de processamento necessários para solucionar problemas, mesmo que pouco complexos. Uma outra alternativa, aplicável a determinados problemas mais específicos, é mais adequada do ponto de vista operacional, uma vez que elimina algumas dessas dificuldades, resultando em uma formulação mais simples sem, no entanto, se incorrer em perda de qualidade. Pelo que se conhece da literatura, esses métodos são perfeitamente satisfatórios, desde que ajustados e aplicados a problemas particulares. A utilização do método do diagrama momento x curvatura, por exemplo, pode ser aplicado na resolução dos problemas de flexão em vigas e pilares com grandes vantagens. Nesse caso, a minimização de memória e esforço computacional do modelo são conseguidos pela utilização de uma só fibra ativa (a fibra na direção axial), a definição da relação tensão x deformação do concreto segundo a direção axial e a consideração de algumas hipóteses. A primeira das hipóteses se refere à teoria clássica da flexão (hipótese de Navier): as seções planas permanecem planas após a deformação; a segunda hipótese considera desprezíveis as distorções dos esforços cortantes e torção. Esta última hipótese é considerada válida para as seções sólidas e perfeitamente aplicável às seções vazadas de espessuras moderadas de parede.

\section{2 - RELAÇÃO CONSTITUTIVA DO CONCRETO}

Segundo KENT \& PARK (1971), no cálculo de pórticos de concreto armado, tendendo para situações limites, se faz necessária a consideração da ductilidade disponível nos membros de concreto armado fora do campo elástico na distribuição dos momentos no pórtico. Se a zona comprimida do concreto sofrer algum processo de confinamento, e, por conseqüência, induzir um acréscimo de ductilidade na peça de concreto armado, obviamente ocorrerá uma alteração sensível nas suas relações momento-curvatura e uma conseqüente alteração nas respostas da não-linearidade geométrica da estrutura. 
Relatos experimentais têm revelado, quantitativa e qualitativamente, os efeitos benéficos da armadura transversal (estribos ou espirais) sobre a ductilidade do concreto armado. Outros pesquisadores têm se empenhado na determinação teórica das relações momento-curvatura de peças fletidas com zonas comprimidas confinadas no campo das grandes curvaturas.

Várias relações constitutivas para a curva $\sigma-\varepsilon$ do concreto sob compressão axial têm sido propostas. Provavelmente, a mais amplamente aceita é a curva proposta por HOGNESTAD (1951) apud KENT (1971). Essa curva foi obtida de ensaios de pilares curtas excentricamente carregadas e é constituída por dois trechos, um trecho parabólico do $2^{\underline{0}}$ grau que vai até um ponto de tensão máxima $\left(\mathrm{f}_{\mathrm{c}}\right.$, $\boldsymbol{\varepsilon}_{0}$ ) associado a um trecho reto descendente. Os parâmetros e a deformação na fibra mais comprimida determinados por Hognestad e outros pesquisadores foram relacionados com a resistência cilíndrica $\mathrm{f}_{\mathrm{cc}}$.

Vez ou outra, questionamentos, tais como influência do gradiente de deformação na forma da curva $\sigma-\varepsilon$ do concreto sob compressão e os efeitos do confinamento, não são pouco freqüentes. Por exemplo, STURMAN et al. (1964), em testes conduzidos em protótipos carregados excentricamente, concluíram que o pico da curva $f_{c}-\varepsilon_{c}$, para carregamentos excêntricos, ocorre $20 \%$ maior na tensão e $50 \%$ maior na deformação do que nos casos ensaiados com carga centrada. Isso, de certa forma conflita com o que fora sugerido por HOGNESTAD et al.(1955), onde foi observada estreita semelhança entre as curvas $\sigma-\varepsilon$ de protótipos prismáticos carregados excentricamente com as curvas de cilindros carregados concentricamente. Conclui-se assim como sendo pouco significativo o efeito do gradiente de deformações sobre a forma da curva $\sigma-\varepsilon$ do bloco de compressão em peças fletidas.

$\mathrm{O}$ concreto restringido na direção perpendicular à tensão de compressão é denominado concreto confinado. Na prática, o concreto pode ser confinado pela colocação de armadura na forma de estribos ou espiras. Tal confinamento é considerado passivo para baixos níveis de tensão axial, onde a armadura transversal é simplesmente tracionada sem que o efeito de confinamento seja despertado. O efeito do confinamento começa aparecer quando, para tensões próximas da resistência uniaxial, o concreto começa crescer de volume devido ao 
Não-Linearidade Física

progressivo fraturamento interno e se deforma para fora contra a armadura transversal, que por sua vez aplica uma reação de confinamento no mesmo. Baseado na evidência das experiências existentes PARK et al.(1971) propuseram uma curva considerada uma boa representação da relação $f_{c}-\varepsilon$ para o concreto confinado e não confinado. Nesse modelo, somente o aumento da ductilidade é reconhecida devido ao confinamento.

Uma versão modificada desse modelo, proposta por PARK et al.(1982), permitiu considerar o acréscimo do pico de resistência e deformação devido ao confinamento, assumindo que esse efeito era proporcional à taxa volumétrica e a tensão de escoamento da armadura transversal. Entretanto, esse novo modelo não leva em consideração o efeito do arranjo da armadura longitudinal no comportamento do concreto confinado. SHEIKH \& UZUMERI (1982) propuseram um modelo, para a relação tensão-deformação, que reflete o efeito do confinamento através do ajuste da tensão de pico e um coeficiente efetivo de confinamento. A inclinação do trecho reto descendente, denominada de taxa de deterioração, é semelhante à adotada no modelo de PARK et al.(1982). O modelo proposto por MANDER et al.(1988a, b) utiliza uma expressão matemática fracionada para representar ambos os ramos, ascendente e descendente, da curva tensão-deformação. Para avaliar o pico de tensão da curva foi introduzido um coeficiente de confinamento efetivo para as seções do tipo circular, quadrado e tipo parede, similar ao adotado por SHEIKH \& UZUMERI (1982). SAATCIOGLU \& RAZVI (1992) propuseram uma expressão parabólica para o ramo ascendente da curva seguido de uma linha reta para o ramo descendente definido pela deformação correspondente à uma tensão igual $85 \%$ da tensão de pico. Dos trabalhos relacionados à instituição de modelos para a curva tensão-deformação do concreto em protótipos de pilares, os trabalhos de MANDER et al. (1988) e SAATCIOGLU \& RAZVI-1992 podem ser diretamente aplicados aos pilares de pontes com seções transversais do tipo parede.

A proposta de HOSHIKUMA et al.(1997) de um modelo para a curva tensão-deformação de compressão de pilares foi baseado nos resultados de testes de protótipos com seções tipicamente utilizadas em pilares de pontes. Nestes testes foram considerados como parâmetros variáveis o tipo de seção (circular, quadrada e parede), a configuração dos estribos, seu espaçamento, e a sua taxa volumétrica. Nos 
testes realizados por HOSHIKUMA et al.(1997) foram identificadas três partes nas curvas tensão-deformação, isto é, um ramo ascendente tipicamente curvo, um descendente com conformação linear e um terceiro ramo com tensão mantida constante:

a) Primeiro ramo: assume que a tensão no concreto seja representada por uma função do tipo

$$
\mathrm{f}_{\mathrm{c}}=\mathrm{C}_{1} \boldsymbol{\varepsilon}_{\mathrm{c}}^{\mathrm{n}}+\mathrm{C}_{2} \boldsymbol{\varepsilon}_{\mathrm{c}}+\mathrm{C}_{3}
$$

onde:

- as constantes $\mathrm{C}_{1}, \mathrm{C}_{2}, \mathrm{C}_{3}$ e $\mathrm{n}$ são determinadas das seguintes condições de contorno:

- condição inicial: $\mathrm{f}_{\mathrm{c}}=0$ em $\varepsilon_{\mathrm{c}}=0$;

- condição de rigidez inicial: $\frac{\mathrm{df}_{\mathrm{c}}}{\mathrm{d} \boldsymbol{\varepsilon}_{\mathrm{c}}}=\mathrm{E}_{\mathrm{c}}$ em $\varepsilon_{\mathrm{c}}=0$;

- condição no pico de tensão : $\mathrm{f}_{\mathrm{c}}=\mathrm{f}_{\mathrm{cc}}$ em $\varepsilon_{\mathrm{c}}=\varepsilon_{\mathrm{cc}}$;

- condição de rigidez no pico de tensão: $\frac{\mathrm{df}_{\mathrm{c}}}{\mathrm{d} \varepsilon_{\mathrm{c}}}=0$

Aplicando as condições de contorno na expressão (5.1 ) tem-se:

$$
\begin{aligned}
& \mathrm{f}_{\mathrm{c}}=\mathrm{E}_{\mathrm{c}} \boldsymbol{\varepsilon}_{\mathrm{c}}\left[1-\frac{1}{\mathrm{n}}\left(\frac{\boldsymbol{\varepsilon}_{\mathrm{c}}}{\boldsymbol{\varepsilon}_{\mathrm{cc}}}\right)^{\mathrm{n}-1}\right], \text { onde } \\
& \mathrm{n}=\frac{\mathrm{E}_{\mathrm{c}} \boldsymbol{\varepsilon}_{\mathrm{cc}}}{\mathrm{E}_{\mathrm{c}} \boldsymbol{\varepsilon}_{\mathrm{cc}}-\mathrm{f}_{\mathrm{cc}}}
\end{aligned}
$$

$\mathrm{E}_{\mathrm{c}}=$ módulo de elasticidade tangente na origem

b) Ramo descendente: idealizado por uma linha reta expressa pela seguinte função:

$$
\mathrm{f}_{\mathrm{c}}=\mathrm{f}_{\mathrm{cc}}-\mathrm{E}_{\mathrm{des}}\left(\boldsymbol{\varepsilon}_{\mathrm{c}}-\boldsymbol{\varepsilon}_{\mathrm{cc}}\right)
$$


onde $\mathrm{E}_{\text {des }}$ é denominada taxa de deterioração determinada através de análise de regressão dos dados experimentais no intervalo de $\varepsilon_{\mathrm{cc}}$ até $\varepsilon_{\mathrm{cu}}$.

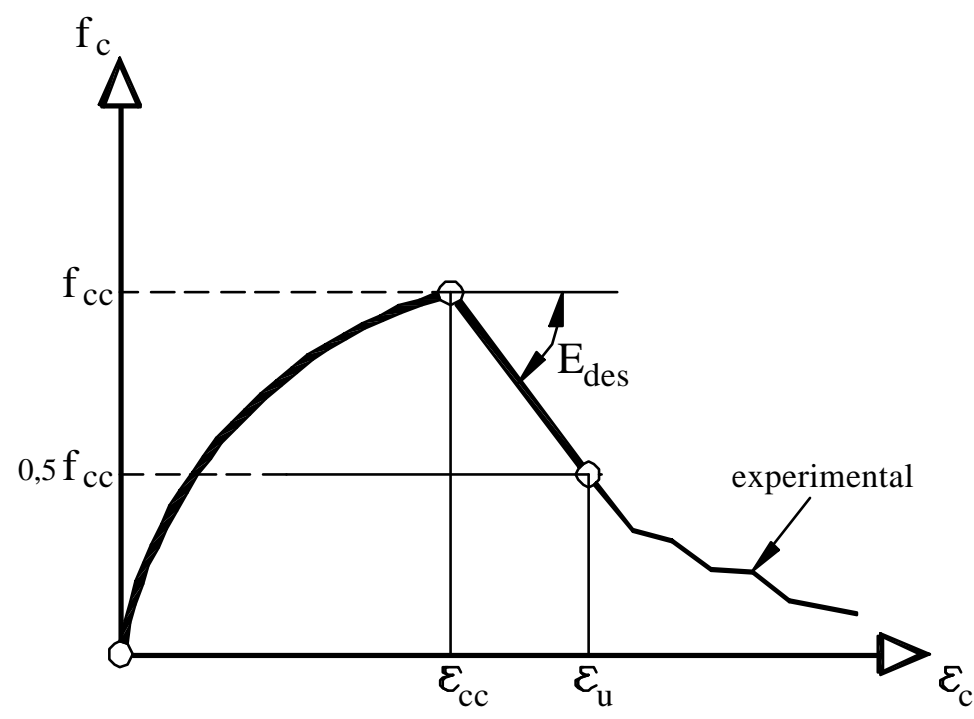

Fig. 5.1 - Deformação Última e Taxa de Deterioração

(HOSHIKUMA et al.(1997)

De acordo com os resultados dos testes apresentados por HOSHIKUMA et al.(1997), o esmagamento do concreto do núcleo da seção e a flambagem das barras longitudinais foram observados quando a tensão de compressão se situou abaixo de $0.5 f_{\text {cc }}$. Devido aos excessivos danos, impossíveis de serem reparados, adotou-se a deformação correspondente a $50 \%$ da tensão de pico $\mathrm{f}_{\mathrm{cc}}$ como a deformação limite $\varepsilon_{\mathrm{cu}}$.

KENT \& PARK (1971), SAATCIOGLU \& RAZVI (1992) e SHEIKH \& UZUMERI (1982) consideram nos seus modelos um terceiro ramo horizontal logo após o ramo descendente da curva. Este ramo corresponde a uma tensão sustentada de 20 a $30 \%$ da tensão de pico.

Os parâmetros que provavelmente mais afetam o efeito do confinamento são: a taxa volumétrica dos estribos, o espaçamento entre eles, sua configuração, a tensão de escoamento do aço do estribo, forma do núcleo de concreto e a resistência do concreto não confinado. HOSHIKUMA et al.(1997) observaram que a forma e o espaçamento entre os estribos são menos significativos para o efeito 
do confinamento se colocados com a configuração e espaçamento adequados, como os recomendados para os pilares de pontes projetados para efeitos sísmicos.

A tensão de pico e a deformação correspondente são obtidas por análise de regressão dos dados experimentais:

$$
\begin{aligned}
& \frac{\mathrm{f}_{\mathrm{cc}}}{\mathrm{f}_{\mathrm{co}}}=1.0+3.8 \alpha \frac{\rho_{\mathrm{s}} \mathrm{f}_{\mathrm{yk}}}{\mathrm{f}_{\mathrm{co}}} \\
& \varepsilon_{\mathrm{cc}}=0.002+0.033 \beta \frac{\rho_{\mathrm{s}} \mathrm{f}_{\mathrm{yh}}}{\mathrm{f}_{\mathrm{co}}} \\
& \mathrm{E}_{\mathrm{des}}=11.2 \frac{\mathrm{f}_{\mathrm{co}}^{2}}{\rho_{\mathrm{s}} \mathrm{f}_{\mathrm{yh}}} \quad, \text { onde }
\end{aligned}
$$

1) $\alpha$ e $\beta$ são fatores modificadores dependentes da forma da seção confinada: para seção circular $\alpha=1.0$ e $\beta=1.0$; para seções com forma retangular ou quadrada $\alpha=0.2$ e $\beta=0.4$.

2) $\rho_{\mathrm{s}}=$ taxa volumétrica de armadura de estribos;

3) $\mathrm{f}_{\text {co }}=$ resistência a compressão do concreto não confinado. Pode-se tomar, como valor representativo, a resistência média do concreto não confinado: $\mathrm{f}_{\mathrm{cm}}=\mathrm{f}_{\mathrm{ck}}+8 \mathrm{MPa}$;

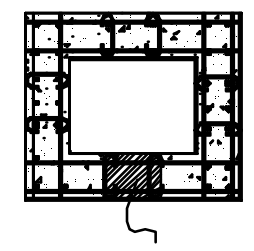

seção confinada seção confin
equivalente

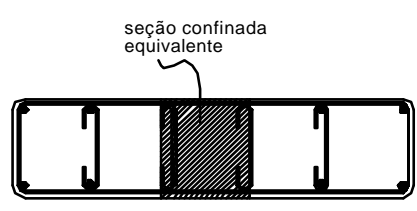

Fig. 5.2 - Confinamentos Típicos em Seções de Pilares

\section{3 - AÇO (CLASSE A DA ABNT)}

Aço laminado a quente, caracterizado pelo patamar de escoamento no diagrama $\sigma-\varepsilon .($ Fig. 5.3). 


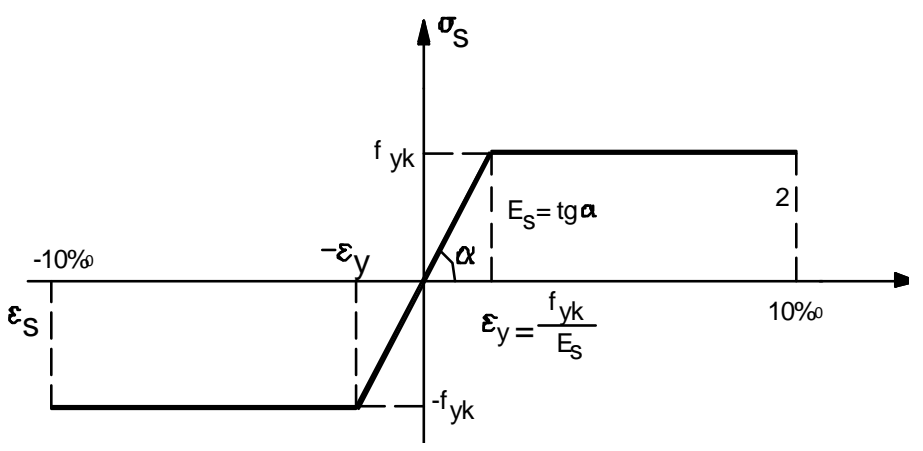

Fig. 5.3 - Aço tipo Classe A

Naturalmente, também podem ser implementados os aços da classe B

$$
\begin{aligned}
& \varepsilon_{\mathrm{yk}}=\frac{\mathrm{f}_{\mathrm{yk}}}{\mathrm{E}_{\mathrm{s}}} \\
& \sigma_{\mathrm{s}}=\varepsilon_{\mathrm{sm}} \mathrm{E}_{\mathrm{s}} \\
& \mathrm{E}_{\mathrm{s}}=\operatorname{tg} \beta=21.000 \frac{\mathrm{kN}}{\mathrm{cm}^{2}} \\
& \boldsymbol{\varepsilon}_{\mathrm{sm}}=\text { deformação média na armadura tracionada; } \\
& \boldsymbol{\varepsilon}_{\mathrm{s}}=\text { deformação na armadura comprimida; } \\
& \left|\boldsymbol{\varepsilon}_{\mathrm{ym}}\right|>\boldsymbol{\varepsilon}_{\mathrm{yk}} \quad \boldsymbol{\sigma}_{\mathrm{s}}=\mathrm{f}_{\mathrm{yk}} \quad, \quad \mathrm{E}_{\mathrm{s}}=0 \\
& \mathrm{E}_{\mathrm{s}}=\text { módulo elasticidade tangente }
\end{aligned}
$$

\section{4 - ELEMENTO LINEAR DE CONCRETO ARMADO}

\subsection{1 - DEFORMAÇÕES PARA CARGAS DE CURTA DURAÇÃO}

O comportamento não linear do Concreto Armado impõe que as relações entre o esforço normal e a deformação axial no centróide da seção, entre o momento fletor e a curvatura que lhe é associada, e entre o momento de torção e a rotação relativa por unidade de comprimento sejam também não lineares. Com isso, as rigidezas a flexão, à deformação axial e à torção de uma seção transversal passam a ser dependentes do estado de solicitação da mesma [MARTINS (1979)].

O problema da análise de pilares ou quaisquer outros elementos estruturais de concreto armado é, geralmente, conduzida usando técnicas numéricas. 
Essencialmente, a maioria das técnicas numéricas começa com uma distribuição assumida (valores da curvatura, inclinações ou deslocamentos), e a obtenção da solução desejada é conseguida com essa distribuição inicial através de um refinamento usando um processo iterativo. Em algumas técnicas a solução é desenvolvida incrementalmente, e para todo incremento de carga uma solução independente é obtida com vários ciclos de iteração. Praticamente, a solução é alcançada por um certo grau de convergência, daí uma pequena porção numérica é desprezada em função da precisão adotada. Portanto, esses métodos são perfeitamente aceitáveis, apesar do esforço computacional [AL-METWALLY (1994)].

Na Fig 5.4 está esquematizada uma alternativa para a consideração da não-linearidade física do concreto armado na estrutura de uma ponte em substituição às formulações consistentes. Os parâmetros da matriz de rigidez linear elástica podem ser atualizados a cada incremento de carregamento de uma determinada combinação de ações em decorrência da alteração da rigidez das seções pelo processo de fissuração. Quando a interação solo-estrutura é envolvida na análise a atualização das reações do solo devem ser também efetuadas a medida que o comportamento não linear do solo também é levado em consideração.

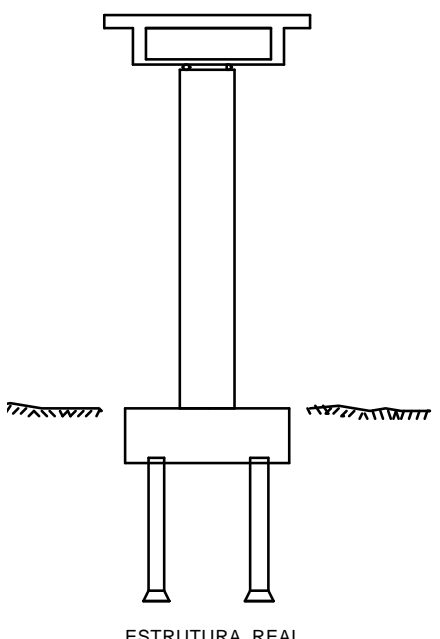

ESTRUTURA REAL

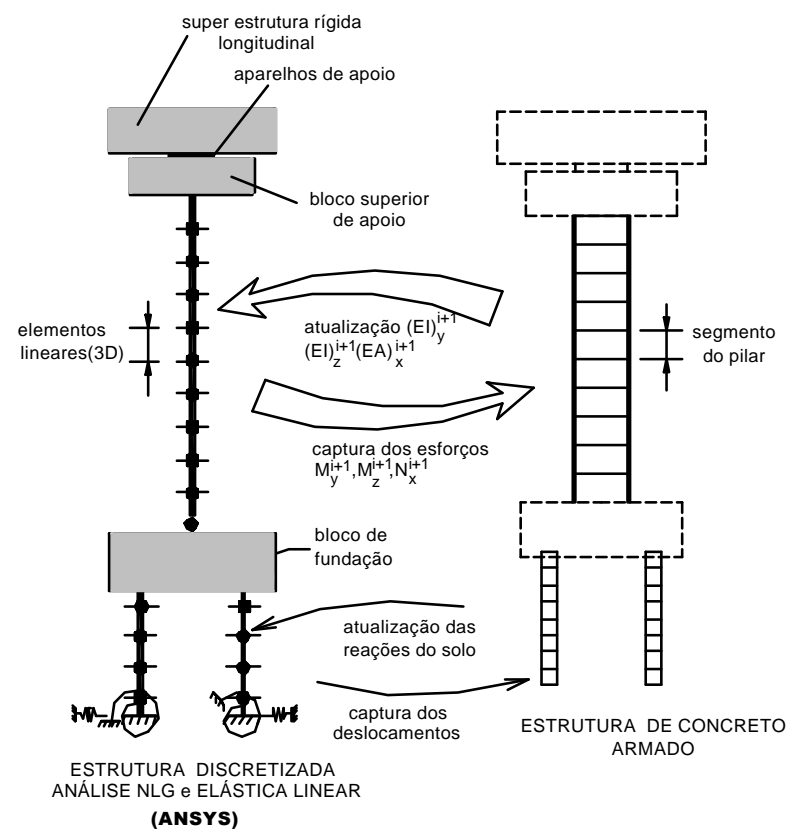

Fig. 5.4 - Atualização dos Parâmetros da Estrutura 
Apesar desta simplificação, a rotina de projeto em pontes passa por uma modelagem exaustiva e por um processo de otimização que exige o conhecimento prévio da quantificação e arranjo da armadura em todas as seções da estrutura, além de outros detalhes. Esta situação se agrava consideravelmente em termos de esforço de projeto, uma vez que, na maioria dos casos, o estudo de diversas alternativas de projeto é inevitável. A vantagem de se conhecer o perfil de variação da rigidez das seções dos pilares de uma ponte, segundo as combinações usuais das ações, é a de permitir a adoção de uma rigidez equivalente para os pilares em substituição aos processos mais onerosos e exaustivos. Deste modo, o cálculo para diferentes valores de rigidez permitirá uma avaliação da sensibilidade da estrutura quanto às suas respostas em função da alteração da rigidez dos seus elementos.

O modelo analítico básico selecionado para calibrar a não-linearidade física na estrutura usa um processo incremental iterativo através de uma formulação de rigidez tangente para uma só fibra ativa, àquela correspondente a tensão normal axial. As ações ou combinações das ações são aplicadas na estrutura para obtenção das respostas estruturais (deslocamentos e esforços) para determinados valores de rigidez. A partir dos esforços nas seções obtidos da análise é efetuada uma verificação da validade ou não do perfil de rigidez ensaiado através de um processo incremental iterativo, onde as deformações incrementais na seção são calculadas e adicionadas aos valores prévios da última configuração de equilíbrio. O método dos deslocamentos, adotado pelo programa ANSYS é utilizado para considerar a nãolinearidade geométrica e a interação solo-estrutura.

$\mathrm{Na}$ análise, os pilares de uma ponte, sejam prismáticos ou não, podem ser discretizados como um arranjo de segmentos prismáticos ou não, conectados entre si [ POSTON et al. (1983), fig. (5.5)]. 


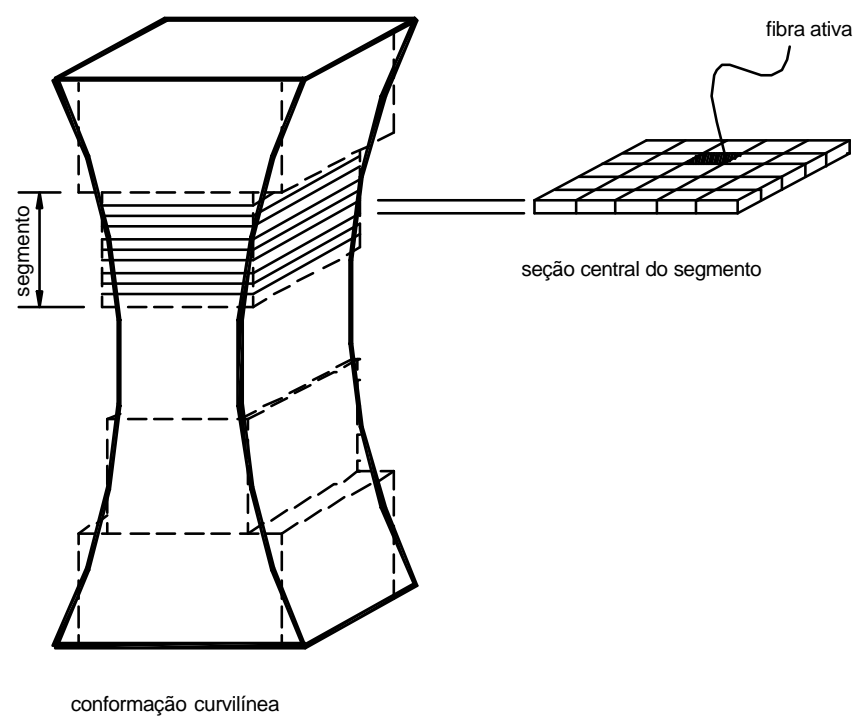

Fig. 5.5(a) - Discretização: Conformação Curvilínea

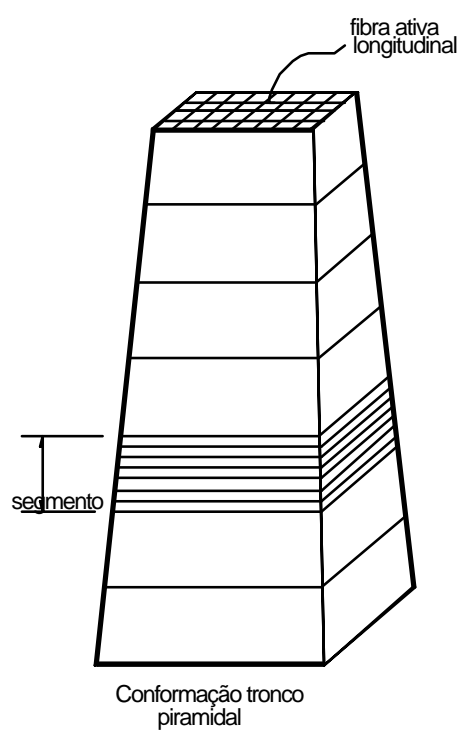

Fig. 5.5(b) - Discretização: Conformação Tronco - piramidal

Para a obtenção das relações incrementais entre esforços e as deformações para seção fissurada são adotadas as seguintes hipóteses:

- As seções planas são consideradas planas após a deformação;

- As pequenas variações nas deformações podem ser relacionadas linearmente a pequenas variações nos esforços em um segmento do pilar.

- As tensões de tração no concreto são desprezadas; 
- Os segmentos do pilar são considerados sem carregamento no seu interior.

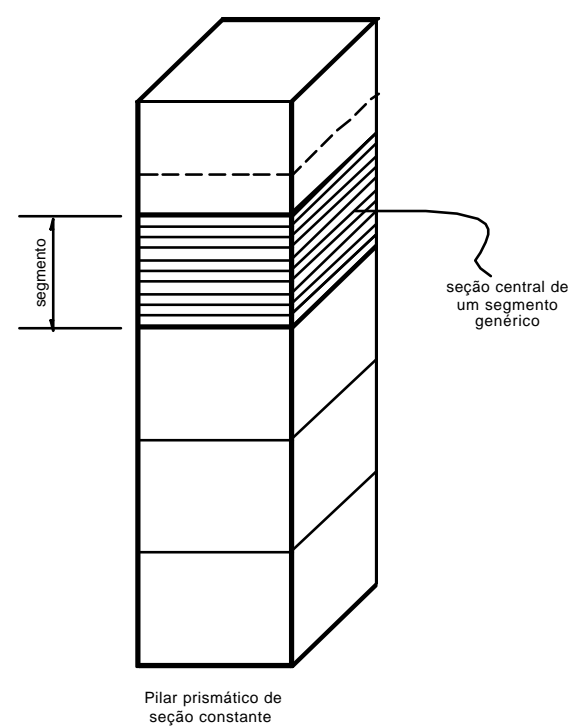

Fig. 5.5(c) - Discretização: Conformação Prismática

Nestas condições as seguintes relações podem ser asseguradas:

$$
\begin{aligned}
& \delta \mathrm{N}=\int_{\mathrm{A}} \mathrm{E}_{\mathrm{t}} \delta \varepsilon \mathrm{dA} \\
& \delta \mathrm{M}_{\mathrm{z}}=\int_{\mathrm{A}} \mathrm{yE}_{\mathrm{t}} \delta \varepsilon \mathrm{dA} \\
& \delta \mathrm{M}_{\mathrm{y}}=-\int_{\mathrm{A}} \mathrm{zE}_{\mathrm{t}} \delta \varepsilon \mathrm{dA} ;
\end{aligned}
$$

onde:

$\delta \mathrm{N}=$ incremento no esforço axial,

$\delta \mathrm{M}_{\mathrm{y}}=$ incremento no momento fletor em torno do eixo y;

$\delta \mathrm{M}_{\mathrm{z}}=$ incremento no memento fletor em torno do eixo $\mathrm{z}$;

$\delta \varepsilon=$ incremento na deformação de uma fibra na direção do eixo do segmento;

$\mathrm{E}_{\mathrm{t}}=$ módulo tangente em uma fibra genérica ativa da seção transversal A (fibra comprimida de concreto ou qualquer fibra da armadura - fig.4.10); 


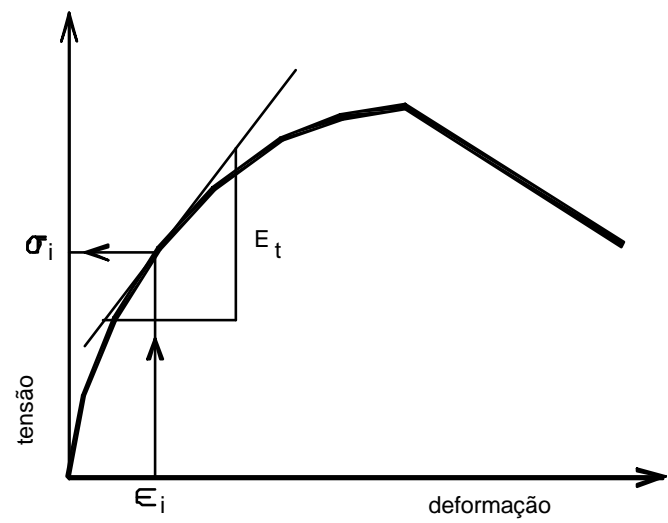

Fig. 5.6 - Módulo Tangente em uma Fibra Genérica Ativa.

$\mathrm{z}=$ distância do elemento diferencial dA do aço ou do concreto na direção z (fig. 5.6);

$\mathrm{y}=$ distância do elemento diferencial dA do aço ou do concreto na direção do eixo y;

$\mathrm{A}=$ seção transversal do segmento composta de concreto $\left(\mathrm{A}_{\mathrm{c}}\right) \mathrm{e}$ $\operatorname{armadura}\left(\mathrm{A}_{\mathrm{s}}\right)$.

A cada incremento de carga aplicado na estrutura corresponde uma variação na seção deformada. A variação na deformação na direção do eixo do segmento pode ser expressa pela equação do plano deformado:

$$
\begin{aligned}
& \delta \varepsilon(y, z)=\delta \varepsilon_{\mathrm{g}}+\mathrm{y} \delta \psi_{\mathrm{z}}-\mathrm{z} \delta \psi_{\mathrm{y}} \\
& \varepsilon^{\mathrm{i}}(\mathrm{y}, \mathrm{z})=\varepsilon_{\mathrm{g}}^{\mathrm{i}}-\mathrm{z} \psi_{\mathrm{y}}^{\mathrm{i}}+\mathrm{y} \psi_{\mathrm{z}}^{\mathrm{i}} \\
& \varepsilon^{\mathrm{i}+1}(\mathrm{y}, \mathrm{z})=\varepsilon^{\mathrm{i}}(\mathrm{y}, \mathrm{z})+\delta \varepsilon(\mathrm{y}, \mathrm{z}) \\
& \varepsilon^{\mathrm{i}+1}(\mathrm{y}, \mathrm{z})=\left(\varepsilon_{\mathrm{g}}^{\mathrm{i}}+\delta \varepsilon_{\mathrm{g}}\right)+\mathrm{y}\left(\psi_{\mathrm{z}}^{\mathrm{i}}+\delta \psi_{\mathrm{z}}\right)-\mathrm{z}\left(\psi_{\mathrm{y}}^{\mathrm{i}}+\delta \psi_{\mathrm{y}}\right) \\
& \varepsilon_{\mathrm{g}}^{\mathrm{i}}, \psi_{\mathrm{z}}^{\mathrm{i}}, \psi_{\mathrm{y}}^{\mathrm{i}} \text { são respectivamente, a deformação no eixo e as curvaturas }
\end{aligned}
$$

em uma seção genérica do segmento, para uma configuração de equilíbrio "i”;

$\delta \varepsilon_{\mathrm{g}}=$ incremento de deformação axial;

$\delta \psi_{z}=$ incremento na curvatura da seção em torno do eixo z 
$\delta \psi_{y}=$ incremento na curvatura da seção em torno do eixo y;

Substituindo (5.5) nas expressões (5.2), (5.3) e (5.4) os incrementos dos esforços podem ser expressos como:

$$
\begin{aligned}
& \delta \mathrm{N}=\int_{\mathrm{A}} \mathrm{E}_{\mathrm{t}}\left(\delta \varepsilon_{\mathrm{g}}+\mathrm{y} \delta \psi_{\mathrm{z}}-\mathrm{z} \delta \psi_{\mathrm{y}}\right) \mathrm{dA} \\
& \delta \mathrm{M}_{\mathrm{y}}=-\int_{\mathrm{A}} \mathrm{zE}_{\mathrm{t}}\left(\delta \varepsilon_{\mathrm{g}}+\mathrm{y} \delta \psi_{\mathrm{z}}-\mathrm{z} \delta \psi_{\mathrm{y}}\right) \mathrm{dA} \\
& \delta \mathrm{M}_{\mathrm{z}}=\int_{\mathrm{A}} \mathrm{yE}_{\mathrm{t}}\left(\delta \varepsilon_{\mathrm{g}}+\mathrm{y} \delta \psi_{\mathrm{z}}-\mathrm{z} \delta \psi_{\mathrm{y}}\right) \mathrm{dA}
\end{aligned}
$$

Dividindo-se a seção transversal em um número finito de "fibras", as integrais (5.6), (5.7) e (5.8) podem ser representadas na forma discreta (fig. 5.7):

$$
\begin{aligned}
& \delta \mathrm{N}=\sum_{\mathrm{n}} \mathrm{E}_{\mathrm{t}}\left(\delta \varepsilon_{\mathrm{g}}+\mathrm{y} \delta \psi_{\mathrm{z}}-\mathrm{z} \delta \psi_{\mathrm{y}}\right) \delta \mathrm{A} \\
& \delta \mathrm{N}=\sum_{\mathrm{j}=1}^{\mathrm{n} c} \frac{\mathrm{d} \sigma_{\mathrm{c}}}{\mathrm{d} \varepsilon_{\mathrm{j}}^{\mathrm{i}}} \delta \varepsilon \delta \mathrm{A}+\sum_{\mathrm{k}=1}^{\mathrm{n}} \frac{\mathrm{d} \sigma_{\mathrm{s}}}{\mathrm{d} \varepsilon_{\mathrm{k}}^{\mathrm{i}}} \delta \varepsilon \delta \mathrm{A} \\
& \delta \mathrm{M}_{\mathrm{z}}=\sum_{\mathrm{n}} \mathrm{yE}_{\mathrm{t}}\left(\delta \varepsilon_{\mathrm{g}}+\mathrm{y} \delta \psi_{\mathrm{z}}-\mathrm{z} \delta \psi_{\mathrm{y}}\right) \delta \mathrm{A} \\
& \delta \mathrm{M}_{\mathrm{z}}=\left(\sum_{\mathrm{j}=1}^{\mathrm{n}_{\mathrm{c}}} \mathrm{y}_{\mathrm{j}} \frac{\mathrm{d} \sigma_{\mathrm{c}}}{\mathrm{d} \varepsilon_{\mathrm{j}}^{\mathrm{i}}} \delta \varepsilon \delta \mathrm{A}_{\mathrm{c}}+\sum_{\mathrm{k}=1}^{\mathrm{n}_{\mathrm{s}}} \mathrm{y}_{\mathrm{k}} \frac{\mathrm{d} \sigma_{\mathrm{s}}}{\mathrm{d} \varepsilon_{\mathrm{k}}^{\mathrm{i}}} \delta \varepsilon \delta \mathrm{A}_{\mathrm{s}}\right) \\
& \delta \mathrm{M}_{\mathrm{y}}=-\sum_{\mathrm{n}} \mathrm{zE}_{\mathrm{t}}\left(\delta \varepsilon_{\mathrm{g}}+\mathrm{y} \delta \psi_{\mathrm{z}}-\mathrm{z} \delta \psi_{\mathrm{y}}\right) \delta \mathrm{A} \\
& \delta \mathrm{M}_{\mathrm{y}}=-\left[\sum_{\mathrm{j}=1}^{\mathrm{n}_{\mathrm{c}}} \mathrm{z}_{\mathrm{j}} \frac{\mathrm{d} \sigma_{\mathrm{c}}}{\mathrm{d} \varepsilon_{\mathrm{j}}^{\mathrm{i}}} \delta \varepsilon \delta \mathrm{A}+\sum_{\mathrm{k}=1}^{\mathrm{n}_{\mathrm{s}}} \mathrm{z}_{\mathrm{k}} \frac{\mathrm{d} \sigma_{\mathrm{s}}^{\mathrm{i}} \delta \varepsilon \delta \mathrm{A}}{\mathrm{d} \varepsilon_{\mathrm{k}}}\right.
\end{aligned}
$$

$\mathrm{n}_{\mathrm{c}}=$ número de elementos discretos de concreto;

$\mathrm{n}_{\mathrm{s}}=$ número de elementos discretos da armadura;

$\mathrm{y}_{\mathrm{j}}=$ distância de um elemento discreto de concreto ao eixo z;

$\mathrm{y}_{\mathrm{k}}=$ distância de um elemento discreto da armadura ao eixo z;

Reorganizando as equações 5.9, 5.10 e 5.11 tem-se: 
Não-Linearidade Física

$$
\begin{aligned}
& \{\delta \overline{\mathrm{F}}\}=\left[\mathrm{B}_{\mathrm{ij}}\right]\{\delta \bar{\varepsilon}\} \\
& \{\delta \overline{\mathrm{F}}\}^{\mathrm{T}}=\left\{\delta \mathrm{N}, \delta \mathrm{M}_{\mathrm{z}}, \delta \mathrm{M}_{\mathrm{y}}\right\}
\end{aligned}
$$

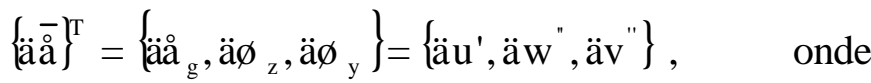

$$
\begin{aligned}
& \delta u^{\prime}=\text { incremento na deformação axial; } \\
& \delta v^{\prime \prime}=\text { incremento na curvatura em torno do eixo y; } \\
& \delta w^{\prime \prime}=\text { incremento na curvatura em torno do eixo z; } \\
& \mathrm{B}_{11}=\sum_{\mathrm{n}} \mathrm{E}_{\mathrm{t}} \delta \mathrm{A} \quad, \quad \mathrm{B}_{12}=\sum_{\mathrm{n}} \mathrm{yE}_{\mathrm{t}} \delta \mathrm{A} \quad, \quad \mathrm{B}_{13}=-\sum_{\mathrm{n}} \mathrm{zE}_{\mathrm{t}} \delta \mathrm{A} \\
& \mathrm{B}_{21}=\sum_{\mathrm{n}} \mathrm{yE}_{\mathrm{t}} \delta \mathrm{A}, \quad \mathrm{B}_{22}=\sum_{\mathrm{n}} \mathrm{y}^{2} \mathrm{E}_{\mathrm{t}} \delta \mathrm{A}, \mathrm{B}_{23}=-\sum_{\mathrm{n}} \mathrm{yz}_{\mathrm{t}} \delta \mathrm{A} \\
& \mathrm{B}_{31}=-\sum_{\mathrm{n}} \mathrm{zE}_{\mathrm{t}} \delta \mathrm{A} \quad, \quad \mathrm{B}_{32}=-\sum_{\mathrm{n}} \mathrm{zyE}_{\mathrm{t}} \boldsymbol{\delta} \mathrm{A}, \quad \mathrm{B}_{33}=\sum_{\mathrm{n}} \mathrm{z}^{2} \mathrm{E}_{\mathrm{t}} \delta \mathrm{A}
\end{aligned}
$$

resolvendo 5.12 tem-se:

$$
\{\delta \bar{\varepsilon}\}=\left[\mathrm{B}_{\mathrm{ij}}{ }^{-1}\{\delta \overline{\mathrm{F}}\}\right.
$$
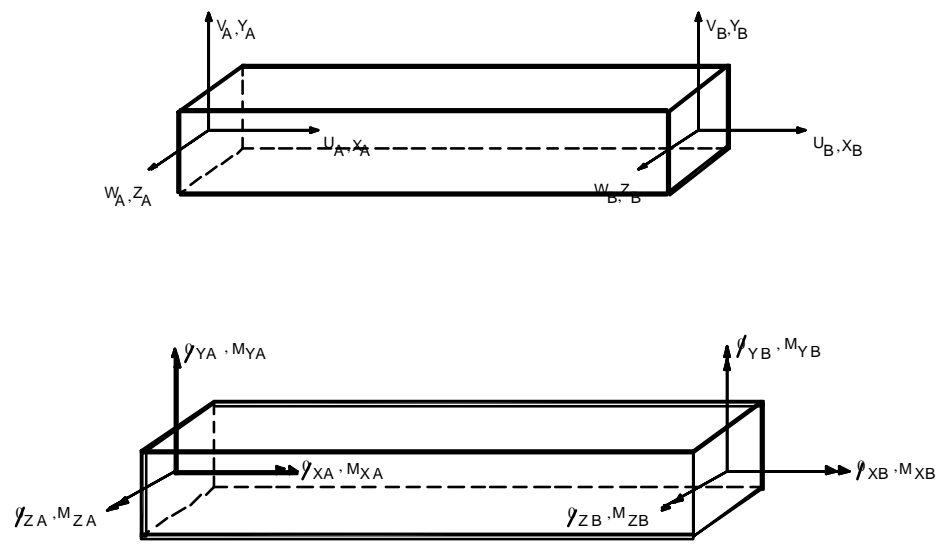

Fig. 5.6(a) - Segmento Genérico do Pilar 


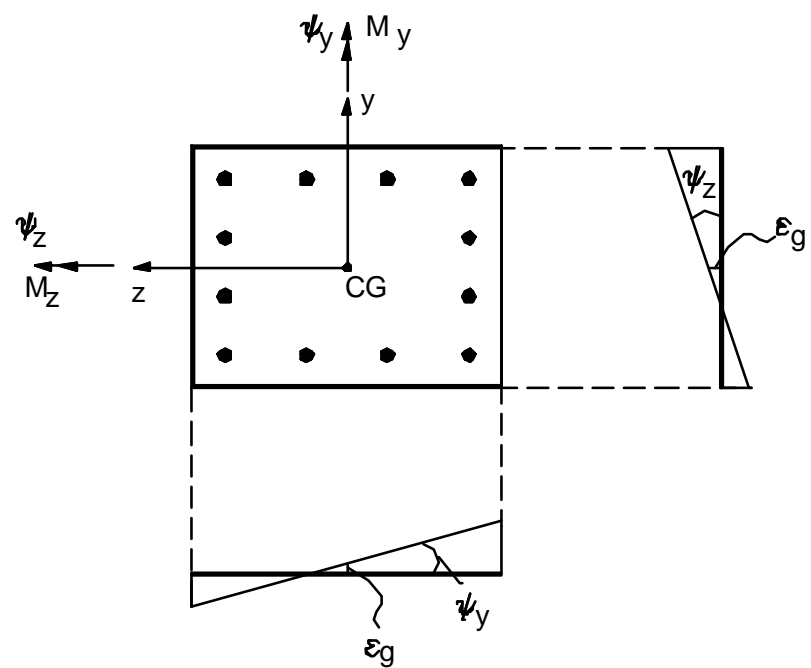

Seção real de concreto armado

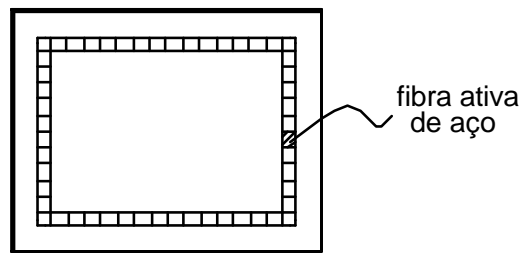

Discretização da armadura

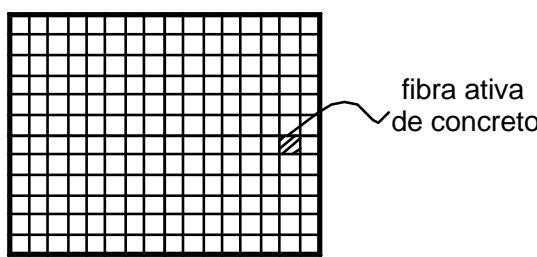

Discretização da seção de concreto

Fig. 5.7 - Discretização da Seção de Concreto Armado

Todas as seções dos pilares de uma ponte são, na maioria dos casos, submetidas a uma força axial inicial elevada e de aplicação rápida. Esta força axial de compressão inicial é decorrente do peso da superestrutura e do processo construtivo. Este "status" inicial de compressão está previsto nas análises conforme mostra o fluxograma.(Fig 5.10). 
Não-Linearidade Física

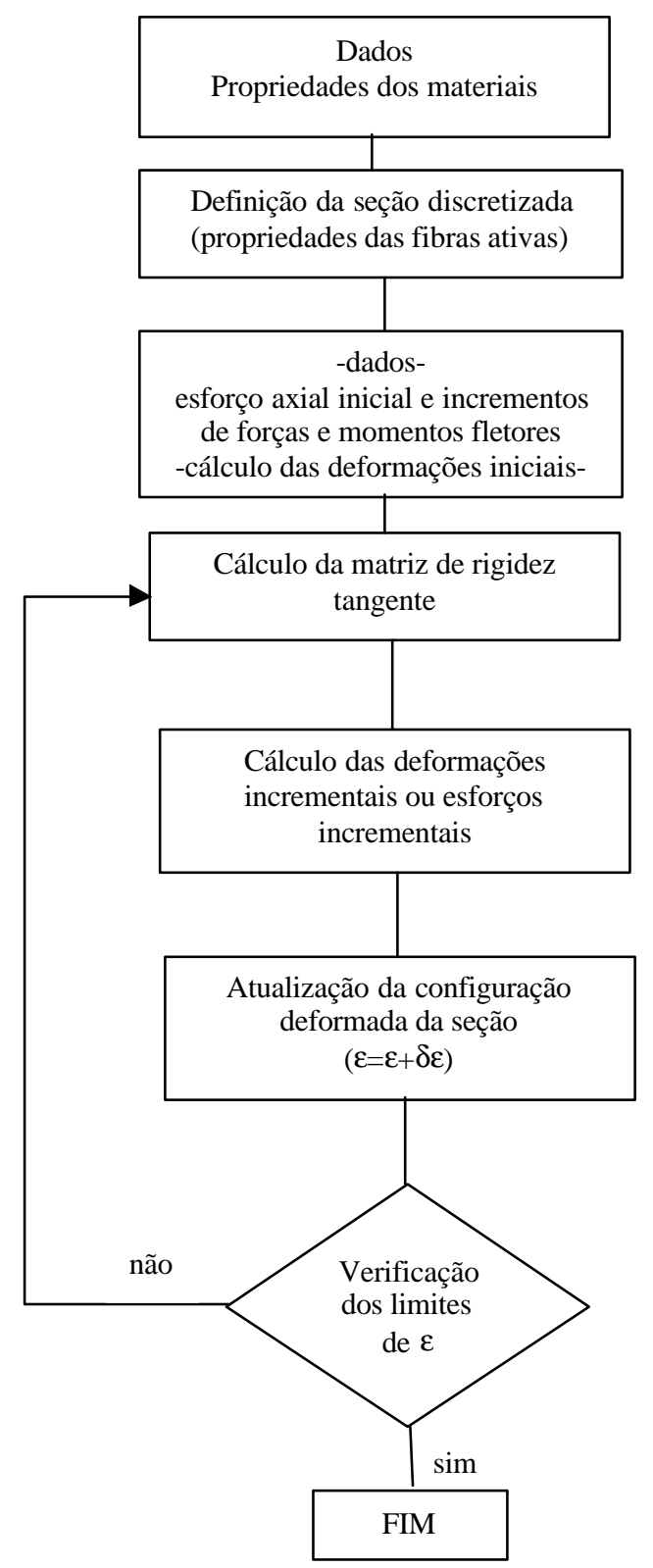

Fig.5.10 - Fluxograma Esquemático do Programa NLF

\section{A - DEFORMAÇÕES NO SEGMENTO NO ESTÁDIO II}

A.1 - Deformação axial atualizada no estádio II em uma seção genérica S:

$$
\left(\varepsilon_{\mathrm{g} 2}^{\mathrm{i}+1}\right)_{\mathrm{S}}=\left(\varepsilon_{\mathrm{g} 2}^{\mathrm{i}}\right)_{\mathrm{S}}+\left(\delta \varepsilon_{\mathrm{g}}\right)_{\mathrm{S}}
$$

A 2 - Curvaturas atualizadas no estágio 2: 


$$
\begin{aligned}
& \left(\psi_{y 2}^{i+1}\right)_{\mathrm{s}}=\left(\psi_{\mathrm{y}}^{\mathrm{i}}\right)_{\mathrm{s}}+\left(\delta \psi_{\mathrm{y}}\right)_{\mathrm{s}} \\
& \left(\psi_{\mathrm{z} 2}^{\mathrm{i}+1}\right)_{\mathrm{s}}=\left(\psi_{\mathrm{z} 2}^{\mathrm{i}}\right)_{\mathrm{s}}+\left(\delta \psi_{\mathrm{z} 2}\right)_{\mathrm{S}}
\end{aligned}
$$

\section{B - VALORES MÉDIOS DE DEFORMAÇÃO NA SEÇÃO S:}

A rigidez de um segmento de concreto armado e a deformação da sua armadura dependem do estado de fissuração instalado ao longo do seu comprimento. Sabe-se que, ao longo de um trecho de uma barra de concreto armado, existem seções fissuradas no estádio II, e entre as fissuras existem blocos íntegros de concreto isentos de fissuras comportando-se, portanto, no estádio I. Esse bloco não fissurado enrijece o segmento, induzindo, em média, reduções das tensões na armadura e nas curvaturas do segmento. Muitas das recomendações existentes nas normas se referem à transferência das tensões da armadura em uma seção fissurada para o concreto entre as fissuras, introduzindo a noção de curvatura média [CEB-FIP MC 90, Eurocode 2], ou através do conceito de momento de inércia médio [ACI Committee 435]. Por esta razão, o problema do vínculo entre o aço e o concreto não é analisado com detalhes. Essa simplificação possibilita a avaliação das condições da seção somente como fissurada ou não fissurada. GHALI \& FAVRE (1994) e o MC 90 (CEB) sugerem, para considerar esse enrijecimento, modelos alternativos para a determinação da curvatura média representativa das seções de um segmento de concreto armado e a deformação média de sua armadura.

$$
\text { Sejam } \mathrm{N}^{\mathrm{i}+1}, \mathrm{M}_{\mathrm{z}}^{\mathrm{i}+1}, \mathrm{M}_{\mathrm{y}}^{\mathrm{i}+1} \text { respectivamente } \mathrm{o} \text { esforço normal e os }
$$

momentos fletores de uma seção qualquer de um segmento genérico do pilar para a configuração de equilíbrio “i+1". Supõe-se também, para simplificação, que esses esforços sejam aplicados na seção simultaneamente, a partir de zero gradativamente, de modo proporcional até a ocorrência da fissuração. Adotada essa hipótese, as excentricidades $e_{z}$ e $e_{y}$ são mantidas constantes para quaisquer pares $\left(\mathrm{N}^{\mathrm{i}+1}, \mathrm{M}^{\mathrm{i}+1}\right)$. Deste modo, tem-se:

$$
e_{z}=-\frac{M_{y}^{i+1}}{N^{i+1}} ; \quad e_{y}=+\frac{M_{z}^{i+1}}{N^{i+1}}
$$




$$
\begin{aligned}
& \sigma_{\text {max }}=\frac{\mathrm{N}^{\mathrm{i}+1}}{\mathrm{~A}_{1}}+\frac{\mathrm{M}_{\mathrm{y}}^{\mathrm{i}+1}}{\mathrm{~W}_{1 \mathrm{y}}}+\frac{\mathrm{M}_{\mathrm{z}}^{\mathrm{i}+1}}{\mathrm{~W}_{1 \mathrm{z}}} ; \text { ou } \\
& \mathrm{N}^{\mathrm{i}+1}=\sigma_{\max }\left[\frac{1}{\mathrm{~A}_{1}}-\frac{\mathrm{e}_{\mathrm{z}}}{\mathrm{W}_{1 \mathrm{y}}}+\frac{\mathrm{e}_{\mathrm{y}}}{\mathrm{W}_{1 \mathrm{z}}}\right]^{-1} ;
\end{aligned}
$$

$\mathrm{A}_{1}$ = área da seção transversal homogeneizada;

$\mathrm{W}_{1 \mathrm{y}}, \mathrm{W}_{1 \mathrm{z}}=$ são os módulos resistentes da seção homogeneizada referidos aos eixos y e $\mathrm{z}$ respectivamente.

Considerando inalteradas as excentricidades, pode-se determinar o valor de $\mathrm{N}_{c r}^{i+1}$ e seus correspondentes momentos fletores $M_{c r y}^{i+1}$ e $M_{c r z}^{i+1}$ que produzem, na fibra mais tracionada, uma tensão igual à resistência média a tração do concreto $\left(f_{c t m}\right)$. Substituindo-se na expressão $5.15 \sigma_{\max }$ por $f_{c t m}$ tem-se o valor:

$$
N_{c r}^{i+1}=f_{c t m}\left[\frac{1}{A_{1}}+\frac{e_{z}}{W_{1 y}}-\frac{e_{y}}{W_{1 z}}\right]^{-1} ;
$$

A expressão (5.16) só se aplica quando a resultante da força normal $\mathrm{N}^{\mathrm{i}+1}$ atuar fora do núcleo central de inércia da seção homogeneizada no estádio I. Quando $\mathrm{N}^{i+1}>\mathrm{N}_{\mathrm{cr}}^{\mathrm{i}+1}$, inicia-se a fissuração. Neste caso, a deformação média em um elemento tracionado da armadura pode ser calculada pela expressão:

$$
\begin{aligned}
& \varepsilon_{\mathrm{km}}^{\mathrm{i}+1}=(1-\xi) \varepsilon_{\mathrm{s} 1}^{\mathrm{i}+1}+\xi \varepsilon_{\mathrm{s} 2}^{\mathrm{i}+1} \\
& \boldsymbol{\varepsilon}_{\mathrm{km}}^{\mathrm{i}+1}=\text { deformação média em uma fibra ativa " } k \text { " da armadura da seção }
\end{aligned}
$$
para a configuração de equilíbrio " $i+1$ ”. As tensões em uma fibra tracionada devem ser calculadas para esta deformação média;

$$
\varepsilon_{\mathrm{s} 1}^{\mathrm{i}+1}=\text { deformação no mesmo elemento } \mathrm{k} \text { da armadura supondo estádio }
$$
1 na configuração de equilíbrio 'i+1';

$$
\varepsilon_{\mathrm{s} 2}^{\mathrm{i}+1}=\text { deformação no elemento } \mathrm{k} \text { da armadura no estádio } 2 \text { para a }
$$
configuração de equilíbrio 'i+1'; 
$\xi=$ coeficiente de ponderação definido no modelo de GHALI \& FAVRE (1994) pela seguinte expressão:

$$
\xi=1-\beta_{1} \beta_{2}\left(\frac{\mathrm{N}_{\mathrm{cr}}^{\mathrm{i}+1}}{\mathrm{~N}_{\mathrm{c}}^{\mathrm{i}+1}}\right)^{2}
$$

$\beta_{1}$ e $\beta_{2}$ são coeficientes que consideram as condições de aderência e o tipo de carregamento respectivamente:

$$
\begin{aligned}
& \beta_{1}=1,0 \text { para barras de alta aderência }\left(\eta_{\mathrm{b}} \geq 1,5\right) ; \\
& \beta_{1}=0,5 \text { para barras lisas }\left(\eta_{\mathrm{b}} \geq 1,0\right) ; \\
& \beta_{2}=1,0 \text { ou } 0,5 . \mathrm{O} \text { valor } 1,0 \text { é usado para o primeiro carregamento ou }
\end{aligned}
$$
cargas pouco repetitivas não permanentes e 0,5 para as cargas permanentes ou para cargas com grande número de repetição.

$$
\begin{aligned}
& \text { Se } \sigma_{\max }<\mathrm{f}_{\mathrm{cmt}} \rightarrow \xi=0 \rightarrow \text { estádio I (seção não fissurada);(5.17) } \\
& \sigma_{\max }>\mathrm{f}_{\mathrm{cmt}} \rightarrow 0<\xi<1 \rightarrow \text { estádio II ( seção fissurada). }
\end{aligned}
$$

Para um elemento da armadura, eventualmente comprimido ou que a condição (5.17) se verifica, o valor de $\xi$ deve ser tomado igual a zero; portanto $\boldsymbol{\varepsilon}_{\mathrm{km}}^{\mathrm{i}+1}=\boldsymbol{\varepsilon}_{\mathrm{s} 1}^{\mathrm{i}+1}$. Neste caso, a deformação de qualquer elemento da armadura pode ser calculado pela seguinte expressão:

$$
\begin{aligned}
& \left(\varepsilon_{\mathrm{s} 1}^{\mathrm{i}+1}\right)_{\mathrm{k}}=\varepsilon_{\mathrm{g} 1}^{\mathrm{i}+1}-\mathrm{z}_{\mathrm{k}} \psi_{\mathrm{y} 1}^{\mathrm{i}+1}+\mathrm{y}_{\mathrm{k}} \psi_{\mathrm{z} 1}^{\mathrm{i}+1}, \quad \text { onde } \\
& \mathrm{z}_{\mathrm{k}}, \mathrm{y}_{\mathrm{k}}=\text { coordenadas que definem a posição de uma fibra " } \mathrm{k} \text { " da }
\end{aligned}
$$

armadura;

$$
\begin{aligned}
& \varepsilon_{\mathrm{g} 1}^{\mathrm{i}+1}=\frac{N^{\mathrm{i}+1}}{\mathrm{E}_{\mathrm{c}} \mathrm{A}_{1}}=\text { deformação no eixo do segmento no estádio I; } \\
& \psi_{\mathrm{z} 1}^{\mathrm{i}}, \psi_{\mathrm{y} 1}^{\mathrm{i}} \text { são as curvaturas da seção no estádio I, respectivamente em }
\end{aligned}
$$
torno de $\mathrm{z}$ e y ;

$$
\psi_{z 1}^{i+1}=\frac{M_{z}^{i+1}}{E_{c} I_{1 z}}, \psi_{y 1}^{i+1}=\frac{M_{y}^{i+1}}{E_{c} l_{1 y}}
$$


Curvatura média em uma seção do segmento:

$\psi_{\mathrm{m}}^{\mathrm{i}+1}=(1-\xi) \psi_{1}^{\mathrm{i}+1}+\xi \psi_{2}^{\mathrm{i}+1}$

$\emptyset_{1}^{i+1}=$ curvatura genérica na seção homogeneizada não fissurada;

$$
\emptyset_{1}^{i+1}=\frac{M^{i+1}}{E_{c} I_{1}}
$$

$\emptyset_{2}^{i+1}=$ curvatura genérica para a seção fissurada no estádio 2, determinada no item 5.4;

$$
\begin{aligned}
& \left(\psi_{\mathrm{m}}^{\mathrm{i}+1}\right)_{\mathrm{y}}=(1-\xi)\left(\psi_{1}^{\mathrm{i}}\right)_{\mathrm{y}}+\xi\left(\psi_{2}^{\mathrm{i}+1}\right)_{\mathrm{y}}: \text { curvatura média em torno de } \mathrm{y} \\
& \left(\psi_{\mathrm{m}}^{\mathrm{i}+1}\right)_{\mathrm{z}}=(1-\xi)\left(\psi_{1}^{\mathrm{i}}\right)_{\mathrm{z}}+\xi\left(\psi_{2}^{\mathrm{i}+1}\right)_{\mathrm{z}}: \text { curvatura média em torno de } \mathrm{z} .
\end{aligned}
$$

Deformação média axial na mesma seção do segmento:

$$
\varepsilon_{\mathrm{gm}}^{\mathrm{i}+1}=(1-\xi) \varepsilon_{\mathrm{g} 1}^{\mathrm{i}+1}+\xi \varepsilon_{\mathrm{g} 2}^{\mathrm{i}+1}
$$

Atualização da rigidez da seção para a etapa de equilíbrio “i+1":

$(E I)_{m y}^{i+1}=\frac{M_{y}^{i+1}}{\left(\emptyset_{m}^{i+1}\right)_{y}}$, rigidez média atualizada em torno de $y$;

$(E I)_{m z}^{i+1}=\frac{M_{z}^{i+1}}{\left(\emptyset_{m}^{i+1}\right)_{z}}$, rigidez média atualizada em torno de $z ;$

$(E A)_{m}^{i+1}=\frac{N^{i+1}}{a_{g m}^{i+1}}$, rigidez média axial.

\subsection{2 - EFEITOS DEPENDENTES DO TEMPO}

No caso de estruturas de pontes os efeitos da fluência devem ser de algum modo considerados. A seguir são apresentados alguns modelos que tentam avaliar o efeito da fluência no concreto.

\subsubsection{1 - Modelo de COSENZA \& DEBERNARDI:}

Considera a interação da armadura na determinação dos efeito do tempo. Nesta análise, a dificuldade da consideração do tempo na modelagem do 
concreto armado reside na complexa interação da fluência e da retração nas seções fissuradas.

O método, denominado AAEM (Age Adjusted Effective Modulus) [BAZANT (1972), CEB BI № 142 (1984)], constitui uma abordagem teórica mais meticulosa do ponto de vista conceptual. O método EM (Effective Modulus) representa uma variante simplificada do método AAEM, onde a fluência é modelada de uma forma mais simples. Uma simplificação adicional é também freqüentemente adotada em combinação com este método, isto é, usando a superposição dos efeitos da fluência e da retração que em termos rigorosos não seria admitido, tendo em vista a fissuração da seção e o deslocamento do eixo neutro com o tempo. O método proposto por GHALI \& FAVRE (1994) avalia de modo aproximado os efeitos da fluência e da retração adotando coeficientes corretivos e a superposição dos efeitos [COSENZA \& DEBERNARDI (1997)].

Além das hipóteses gerais assumidas por esses métodos, as hipóteses tradicionais de superposição e linearidade da fluência são aplicadas. Nas condições de serviço pode-se adotar as seguintes hipóteses:

- $\mathrm{O}$ aço tem um comportamento linear caracterizado pelo seu módulo de elasticidade $\mathrm{E}_{\mathrm{s}}$.

- O diagrama tensão-deformação do concreto na seção não fissurada pode ser considerado linear.

\section{A - Seção Não Fissurada - Estádio I}

Considere-se uma seção genérica de um pilar (fig.5.8), totalmente simétrica, submetida a uma força normal $N_{x}$ e os momentos fletores $M_{z}$ e $M_{y}$, tal que, nenhuma fissura seja produzida $\left(\sigma_{\max }<\mathrm{f}_{\mathrm{cmt}}\right)$.

Pretende-se determinar as variações da deformação axial $\delta \varepsilon_{\mathrm{g}} \mathrm{e}$ as variações das curvaturas $\delta \psi_{z} \mathrm{e} \delta \psi_{\mathrm{y}}$ devido à fluência e à retração, durante um determinado período $\Delta \mathrm{t}=\mathrm{t}-\mathrm{t}_{0}$, onde $\mathrm{t}>\mathrm{t}_{0}$; sendo $\mathrm{t}_{0}$ a idade do concreto na data da aplicação dos esforços $N_{x}, M_{z}$ e $M_{y}$. 

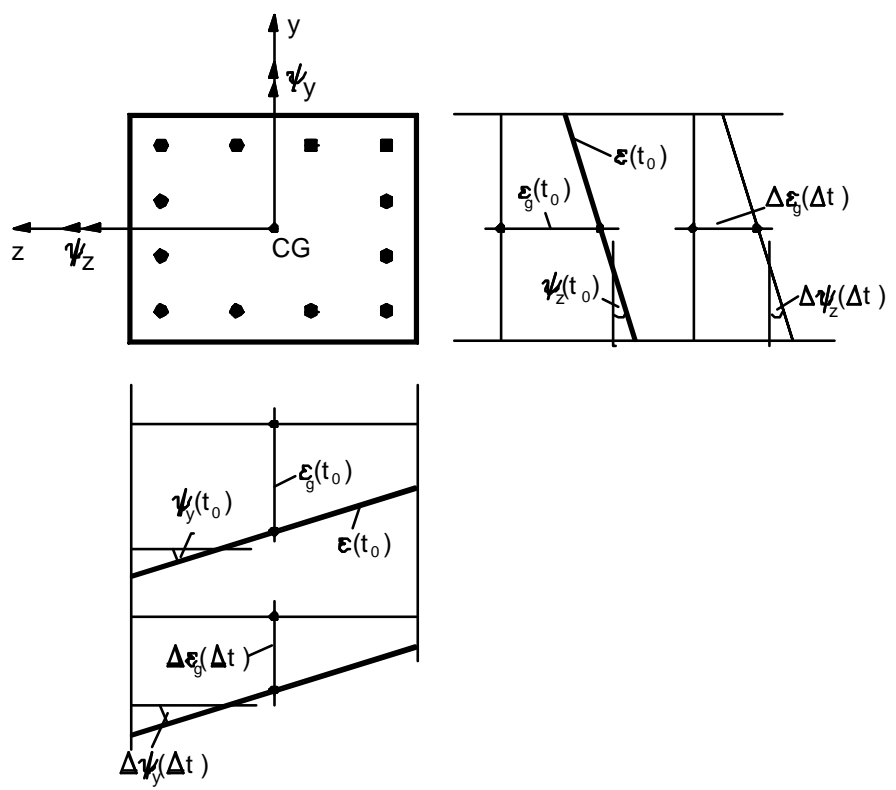

Fig. 5.8 - Deformações na Seção Não Fissurada.

Sendo as seções dos pilares simétricas, o centro da área de concreto coincide com o centro geométrico da área transformada ajustada à idade.

$\overline{\mathrm{A}}=\mathrm{A}_{\mathrm{c}}+\bar{\alpha}\left(\mathrm{t}, \mathrm{t}_{0}\right) \mathrm{A}_{\mathrm{s}} \rightarrow$ área transformada ajustada à idade $\mathrm{t} ;$ (5.18)

onde:

$\mathrm{A}_{\mathrm{s}}=$ área total da armadura,

$\mathrm{A}_{\mathrm{c}}=$ área de concreto

$\bar{\alpha}\left(\mathrm{t}, \mathrm{t}_{0}\right)=$ fator de equivalência ajustado à idade $\mathrm{t}$;

$\bar{\alpha}\left(\mathrm{t}, \mathrm{t}_{0}\right)=\frac{\mathrm{E}_{\mathrm{s}}}{\overline{\mathrm{E}}_{\mathrm{c}}\left(\mathrm{t}, \mathrm{t}_{0}\right)} ;$

$\overline{\mathrm{E}}_{\mathrm{c}}\left(\mathrm{t}, \mathrm{t}_{0}\right)=\frac{\mathrm{E}_{\mathrm{c}}\left(\mathrm{t}_{0}\right)}{1+\chi \varphi\left(\mathrm{t}, \mathrm{t}_{0}\right)} \rightarrow$ módulo elástico ajustado (MC 90);

$E_{c}(t)=\beta_{E}(t) E_{c}(28)$

$\beta_{E}(t)=\sqrt{\beta_{c c}(t)}, \beta_{c c}(t)=\exp [s(1-\sqrt{28 / t})] ; \quad($ MC 90) 
$\mathrm{s}=$ coeficiente que depende do tipo do cimento ;

$\mathrm{E}_{\mathrm{c}}(28)=21500\left[\left(\mathrm{f}_{\mathrm{ck}}+\Delta \mathrm{f}\right) / \mathrm{f}_{\mathrm{cmo}}\right]^{\frac{1}{3}} \mathrm{MPa}, \Delta \mathrm{f}=8 \mathrm{MPa}$,

$\mathrm{f}_{\mathrm{cmo}}=10 \mathrm{MPa} \quad(\mathrm{MC} 90)$

$\varphi\left(t, t_{0}\right)$ coeficiente de fluência: representa a deformação devido a fluência em relação à deformação inicial,

$$
\begin{aligned}
& \varepsilon_{\mathrm{c}}(\mathrm{t})=\frac{\sigma_{\mathrm{c}}\left(\mathrm{t}_{0}\right)}{\mathrm{E}_{\mathrm{c}}\left(\mathrm{t}_{0}\right)}\left[1+\chi \varphi\left(\mathrm{t}, \mathrm{t}_{0}\right)\right] \rightarrow \text { deformação total até a data " } \mathrm{t} ; \\
& \varepsilon_{\mathrm{c}}\left(\mathrm{t}_{0}\right)=\frac{\sigma_{\mathrm{c}}\left(\mathrm{t}_{0}\right)}{\mathrm{E}_{\mathrm{c}}\left(\mathrm{t}_{0}\right)} \rightarrow \text { deformação elástica inicial do concreto para }
\end{aligned}
$$

$\boldsymbol{\sigma}_{\mathrm{c}}\left(\mathrm{t}_{0}\right)$ introduzida em $\mathrm{t}_{0}$

$$
\varepsilon_{\mathrm{cc}}\left(\mathrm{t}_{0}\right)=\frac{\sigma_{\mathrm{c}}\left(\mathrm{t}_{0}\right)}{\mathrm{E}_{\mathrm{c}}\left(\mathrm{t}_{0}\right)} \varphi\left(\mathrm{t}, \mathrm{t}_{0}\right) \rightarrow \text { deformação desenvolvida pela fluência no }
$$

período $\left(\mathrm{t}-\mathrm{t}_{0}\right)$;

MC-90 define a deformação total com a seguinte expressão:

$$
\begin{aligned}
& \varepsilon_{\mathrm{c}}(\mathrm{t})=\frac{\sigma_{\mathrm{c}}\left(\mathrm{t}_{0}\right)}{\mathrm{E}_{\mathrm{c}}\left(\mathrm{t}_{0}\right)}\left[1+\frac{\mathrm{E}_{\mathrm{c}}\left(\mathrm{t}_{0}\right)}{\mathrm{E}_{\mathrm{c}}(28)} \varphi_{28}\left(\mathrm{t}, \mathrm{t}_{0}\right)\right] ; \\
& \left.\varphi_{28}\left(\mathrm{t}, \mathrm{t}_{0}\right)\right] \rightarrow \text { coeficiente de fluência relativamente à deformação aos }
\end{aligned}
$$

28 dias;

$\chi=\chi\left(\mathrm{t}, \mathrm{t}_{0}\right) \rightarrow$ coeficiente de envelhecimento, geralmente varia entre 0,6 e 0,9 (GHALI \& FAVRE -1994).

Considerando-se que, as seções típicas utilizadas nos pilares de pontes são, na sua maioria, totalmente simétricas; o centro geométrico da área de concreto, obrigatoriamente, coincide com o centro geométrico da seção transformada ajustada. Para esses casos, [GHALI \& FAVRE (1994)] sugerem o cálculo das variações $\delta \varepsilon_{\mathrm{g}}, \delta \psi_{\mathrm{z}}$ e $\delta \psi_{\mathrm{y}}$, devido a fluência e a retração no período $\left(\mathrm{t}-\mathrm{t}_{0}\right)$, de uma forma bem simples:

$$
\delta \varepsilon_{\mathrm{g}}=\eta\left\lfloor\varphi\left(\mathrm{t}, \mathrm{t}_{0}\right) \varepsilon_{\mathrm{g}}\left(\mathrm{t}_{0}\right)+\varepsilon_{\mathrm{cs}}\left(\mathrm{t}, \mathrm{t}_{0}\right)\right\rfloor
$$




$$
\begin{aligned}
& \delta \psi_{\mathrm{z}}=\kappa_{\mathrm{z}}\left[\varphi\left(\mathrm{t}, \mathrm{t}_{0}\right) \psi_{\mathrm{z}}\left(\mathrm{t}_{0}\right)\right] ; \\
& \delta \psi_{\mathrm{y}}=\kappa_{\mathrm{y}}\left[\varphi\left(\mathrm{t}, \mathrm{t}_{0}\right) \psi_{\mathrm{y}}\left(\mathrm{t}_{0}\right)\right] \text { onde, } \\
& \eta=\frac{\mathrm{A}_{\mathrm{c}}}{\overline{\mathrm{A}}}, \quad \kappa_{\mathrm{z}}=\frac{\mathrm{I}_{\mathrm{cz}}}{\mathrm{I}_{\mathrm{tz}}}, \quad \kappa_{\mathrm{y}}=\frac{\mathrm{I}_{\mathrm{cy}}}{\mathrm{I}_{\mathrm{ty}}} \\
& \overline{\mathrm{A}}=\text { área da seção transformada ajustada à idade } \mathrm{t} ; \\
& \mathrm{A}_{\mathrm{c}}=\text { área de concreto da seção; } \\
& \mathrm{I}_{\mathrm{cy}}, \mathrm{I}_{\mathrm{cz}}=\text { momentos de inércia da área de concreto, referidos }
\end{aligned}
$$
respectivamente aos eixos y e z;

$$
\mathrm{I}_{\mathrm{ty}}, \mathrm{I}_{\mathrm{tz}}=\text { momentos de inércia da seção transformada ajustada à idade, }
$$
referidos respectivamente aos eixos y e $\mathrm{z}$.

Após a aplicação das cargas de longa duração na idade $\mathrm{t}_{0}$ do concreto, as deformações da seção são atualizadas para a idade t do concreto:

$$
\begin{aligned}
& \left.\varepsilon_{1 \mathrm{~g}}(\mathrm{t})=\eta \mid \varphi\left(\mathrm{t}, \mathrm{t}_{0}\right) \varepsilon_{\mathrm{g}}\left(\mathrm{t}_{0}\right)+\varepsilon_{\mathrm{cs}}\left(\mathrm{t}, \mathrm{t}_{0}\right)\right]+\varepsilon_{1 \mathrm{~g}}\left(\mathrm{t}_{0}\right) \\
& \psi_{1 \mathrm{z}}(\mathrm{t})=\kappa_{\mathrm{z}}\left[\varphi\left(\mathrm{t}, \mathrm{t}_{0}\right) \psi_{\mathrm{z}}\left(\mathrm{t}_{0}\right)\right]+\psi_{1 \mathrm{z}}\left(\mathrm{t}_{0}\right) ; \\
& \psi_{1 \mathrm{y}}(\mathrm{t})=\kappa_{\mathrm{y}}\left[\varphi\left(\mathrm{t}, \mathrm{t}_{0}\right) \psi_{\mathrm{y}}\left(\mathrm{t}_{0}\right)\right]+\psi_{1 \mathrm{y}}\left(\mathrm{t}_{0}\right) \text { onde, } \\
& \varepsilon_{1 \mathrm{~g}}\left(\mathrm{t}_{0}\right), \quad \psi_{1 \mathrm{z}}\left(\mathrm{t}_{0}\right) \text { e } \psi_{1 \mathrm{y}}\left(\mathrm{t}_{0}\right) \text { são as deformações instantâneas no }
\end{aligned}
$$

estádio I devido às cargas de longa duração aplicadas na idade $t_{0}$.

\section{B - Seção fissurada - Estádio 2}

A configuração deformada da seção central do segmento no tempo $t_{0}$, para as ações de longa duração, é tomada como conhecida e definida pela expressão:

$$
\begin{aligned}
& \varepsilon\left(\mathrm{y}, \mathrm{z}, \mathrm{t}_{0}\right)=\varepsilon_{\mathrm{g}}\left(\mathrm{t}_{0}\right)+\mathrm{z} \psi_{\mathrm{y}}\left(\mathrm{t}_{0}\right)-\mathrm{y}_{\mathrm{z}}\left(\mathrm{t}_{0}\right)=\varepsilon\left(\mathrm{t}_{0}\right) \\
& \varepsilon_{\mathrm{g}}\left(\mathrm{t}_{0}\right)=\text { deformação axial instantânea na idade } \mathrm{t}_{0} ; \\
& \psi_{\mathrm{y}}\left(\mathrm{t}_{0}\right), \psi_{\mathrm{z}}\left(\mathrm{t}_{0}\right)=\text { curvaturas instantâneas na idade } \mathrm{t}_{0} ;
\end{aligned}
$$


$\varepsilon\left(t_{0}\right)=$ deformação de uma fibra ativa genérica na idade $t_{0}$.

Objetiva-se determinar a deformada da seção, no final de uma idade $\mathrm{t}$ no estádio 2, em decorrência dos efeitos da fluência e retração do concreto, mantido constante o carregamento externo. Define-se a nova configuração pela seguinte expressão (fig.4.15):

$$
\begin{aligned}
& \varepsilon_{2}(\mathrm{t})=\varepsilon_{2}\left(\mathrm{t}_{0}\right)+\delta \varepsilon_{2}(\Delta \mathrm{t}), \text { sendo } \Delta \mathrm{t}=\mathrm{t}-\mathrm{t}_{0} \\
& \delta \varepsilon_{2}(\Delta \mathrm{t})=\delta \varepsilon_{2 \mathrm{~g}}(\Delta \mathrm{t})+\mathrm{z} \delta \psi_{2 \mathrm{y}}(\Delta \mathrm{t})-\mathrm{y} \delta \psi_{2 \mathrm{z}}(\Delta \mathrm{t}), \quad \text { onde } \\
& \delta \varepsilon_{2 \mathrm{~g}}(\Delta \mathrm{t}), \delta \psi_{2 \mathrm{y}}(\Delta \mathrm{t}), \delta \psi_{2 \mathrm{z}}(\Delta \mathrm{t}) \text { são as variações no período de tempo }
\end{aligned}
$$

$\Delta \mathrm{t}$ na deformação axial e curvaturas, decorrentes da fluência e retração na seção fissurada.

$$
\varepsilon_{2}(\mathrm{y}, \mathrm{z}, \mathrm{t})=\varepsilon_{2 \mathrm{~g}}(\mathrm{t})+\mathrm{z} \psi_{2 \mathrm{y}}(\mathrm{t})-\mathrm{y} \psi_{2 \mathrm{z}}(\mathrm{t})=\varepsilon_{2}(\mathrm{t}), \quad \text { onde }
$$

A deformação do concreto, afetada pela fluência através do coeficiente $\varphi\left(t, t_{0}\right)$ e a retração pelo coeficiente $\varepsilon_{c s}\left(t, t_{0}\right)$, é calculada pelo método AAEM pela seguinte expressão (COSENZA \& DEBERNARDI (1997)] :
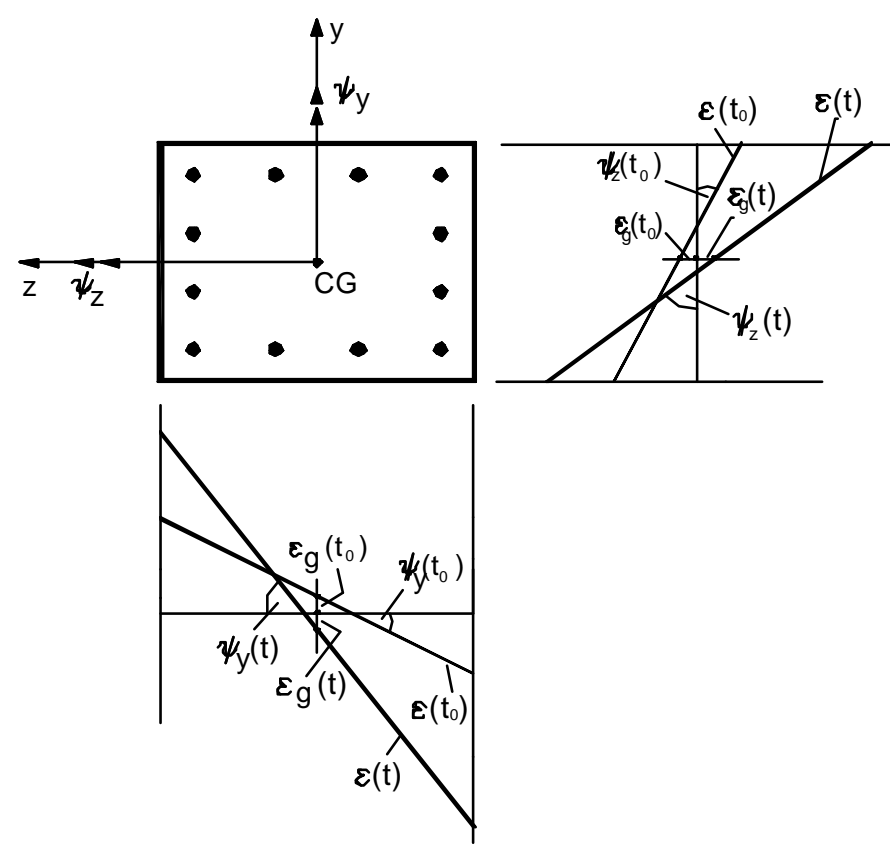

Fig. 5.9 - Deformações na Seção Fissurada na Idade t 


$$
\begin{aligned}
& \varepsilon(\mathrm{t})=\varepsilon\left(\mathrm{t}_{0}\right)+\sigma_{\mathrm{c}}\left(\mathrm{t}_{0}\right) \frac{\varphi\left(\mathrm{t}, \mathrm{t}_{0}\right)}{\mathrm{E}_{\mathrm{c}, 28}}+\left[\sigma_{\mathrm{c}}(\mathrm{t})-\sigma_{\mathrm{c}}\left(\mathrm{t}_{0}\right)\right]\left[\frac{1}{\mathrm{E}_{\mathrm{c}}\left(\mathrm{t}_{0}\right)}+\chi\left(\mathrm{t}, \mathrm{t}_{0}\right) \frac{\varphi\left(\mathrm{t}, \mathrm{t}_{0}\right)}{\mathrm{E}_{\mathrm{c}, 28}}\right]+\varepsilon_{\mathrm{cs}}\left(\mathrm{t}, \mathrm{t}_{0}\right) \\
& \delta \varepsilon(\Delta \mathrm{t})=\sigma_{\mathrm{c}}\left(\mathrm{t}_{0}\right) \overline{\mathrm{F}}+\mathrm{E}_{\mathrm{t}} \delta \varepsilon(\Delta \mathrm{t}) \overline{\mathrm{K}}+\varepsilon_{\mathrm{cs}}\left(\mathrm{t}, \mathrm{t}_{0}\right) \\
& \delta \varepsilon(\Delta \mathrm{t})=\left[\sigma_{\mathrm{c}}\left(\mathrm{t}_{0}\right) \overline{\mathrm{F}}+\varepsilon_{\mathrm{cs}}\left(\mathrm{t}, \mathrm{t}_{0}\right)\right]\left(1-\mathrm{E}_{\mathrm{t}} \overline{\mathrm{K}}\right)^{-1} \\
& \sigma_{\mathrm{s}}(\mathrm{y}, \mathrm{z}, \mathrm{t})=\sigma_{\mathrm{s}}\left(\mathrm{y}, \mathrm{z}, \mathrm{t}_{0}\right)+\mathrm{E}_{\mathrm{s}}\left[\varepsilon(\mathrm{y}, \mathrm{z}, \mathrm{t})-\varepsilon\left(\mathrm{y}, \mathrm{z}, \mathrm{t}_{0}\right)\right] \quad \text { ou } \\
& \sigma_{\mathrm{s}}(\mathrm{y}, \mathrm{z}, \mathrm{t})=\sigma_{\mathrm{s}}\left(\mathrm{y}, \mathrm{z}, \mathrm{t}_{0}\right)+\mathrm{E}_{\mathrm{s}} \delta \varepsilon(\mathrm{y}, \mathrm{z}, \Delta \mathrm{t}) \\
& \sigma_{\mathrm{s}}(\mathrm{y}, \mathrm{z}, \mathrm{t})=\text { tensão em uma fibra genérica da armadura na idade } \mathrm{t} .
\end{aligned}
$$

Supondo constantes os esforços inicialmente aplicados na seção, são válidas as seguintes equações de equilíbrio:

$$
\begin{aligned}
& \int_{A}\left[\sigma(t)-\sigma\left(t_{0}\right)\right] d A=\int_{A}\left[E_{t} \delta \varepsilon(\Delta t)\right] d A=\delta N=0 \\
& \int_{A}\left[\sigma(t)-\sigma\left(t_{0}\right)\right] y d A=\int_{A}\left[E_{t} \delta \varepsilon(\Delta t)\right] y d A=\delta M_{z}=0 \\
& -\int_{A}\left[\sigma(t)-\sigma\left(t_{0}\right)\right] z d A=-\int_{A}\left[E_{t} \delta \varepsilon(\Delta t)\right] z d A=\delta M_{z}=0
\end{aligned}
$$

Aplicando as condições 5.23, 5.24 e 5.25 em todas as fibras da seção é possível determinar a nova deformada da seção, decorrido o intervalo de tempo $\Delta \mathrm{t}=\mathrm{t}-\mathrm{t}_{\mathrm{o}}$, com a determinação das variações $\delta \varepsilon(\Delta \mathrm{t}), \delta \psi_{\mathrm{z}}(\Delta \mathrm{t})$ e $\delta \psi_{\mathrm{y}}(\Delta \mathrm{t})$.

\subsubsection{2 - Modelo Linear}

Nesta abordagem as deformações no concreto são determinadas independentemente da armadura existente e é considerada válida para baixos níveis de tensão. Nesse modelo a função $\varphi\left(t, t_{0}\right)$ de fluência é admitida independente das tensões aplicadas no concreto e a deformação final é determinada sem a interferência da armadura.

Supondo-se estas hipóteses, o incremento de deformação em uma fibra ativa do concreto da seção, correspondente a incrementos gradativos do 
carregamento aplicados de $t_{\mathrm{o}}$ até a idade " $\mathrm{t}$ " do concreto, pode ser determinada da seguinte forma para tensões abaixo de $\cong 0,5 \mathrm{f}_{\text {cc }}$ :

$$
\begin{aligned}
& \Delta \varepsilon_{\mathrm{c}}(\mathrm{t})=\frac{\Delta \sigma_{\mathrm{c}}(\mathrm{t})}{\mathrm{E}_{\mathrm{c}}(\mathrm{t})}, \text { como } \varepsilon_{\mathrm{c}}(\mathrm{t})=\frac{\sigma_{\mathrm{c}}\left(\mathrm{t}_{0}\right)}{\mathrm{E}_{\mathrm{c}}\left(\mathrm{t}_{0}\right)}\left[1+\chi \varphi\left(\mathrm{t}, \mathrm{t}_{0}\right)\right] \rightarrow \text { tem-se, } \\
& \Delta \varepsilon_{\mathrm{c}}(\mathrm{t})=\frac{\Delta \sigma_{\mathrm{c}}\left(\mathrm{t}_{\mathrm{o}}\right)}{\mathrm{E}_{\mathrm{c}}\left(\mathrm{t}_{\mathrm{o}}\right)}\left[1+\chi \varphi\left(\mathrm{t}, \mathrm{t}_{0}\right)\right] \text { ou }, \\
& \varepsilon_{\mathrm{c}}\left(\mathrm{t}, \mathrm{t}_{0}\right)=\left(1+\chi \varphi\left(\mathrm{t}, \mathrm{t}_{0}\right)\right) \varepsilon\left(\mathrm{t}_{0}\right) \Rightarrow \text { deformação final na idade } \mathrm{t} \text {; onde } \\
& \left.\varphi\left(\mathrm{t}, \mathrm{t}_{0}\right)\right) \varepsilon\left(\mathrm{t}_{0}\right)=\text { parcela decorrente do tempo; } \\
& \varepsilon\left(\mathrm{t}_{0}\right)=\text { deformação inicial na idade } \mathrm{t}_{0} \text { do concreto }
\end{aligned}
$$

Para considerar os efeitos do tempo segundo esse modelo, basta deslocar os valores do eixo das abscissas do digrama $\sigma_{\mathrm{c}} \mathrm{x} \varepsilon_{\mathrm{c}}$ do concreto de uma valor $\left[1+\chi \varphi\left(t, t_{0}\right)\right]$ (Fig. 5.10). Para a consideração da fluência foi implementado esse modelo

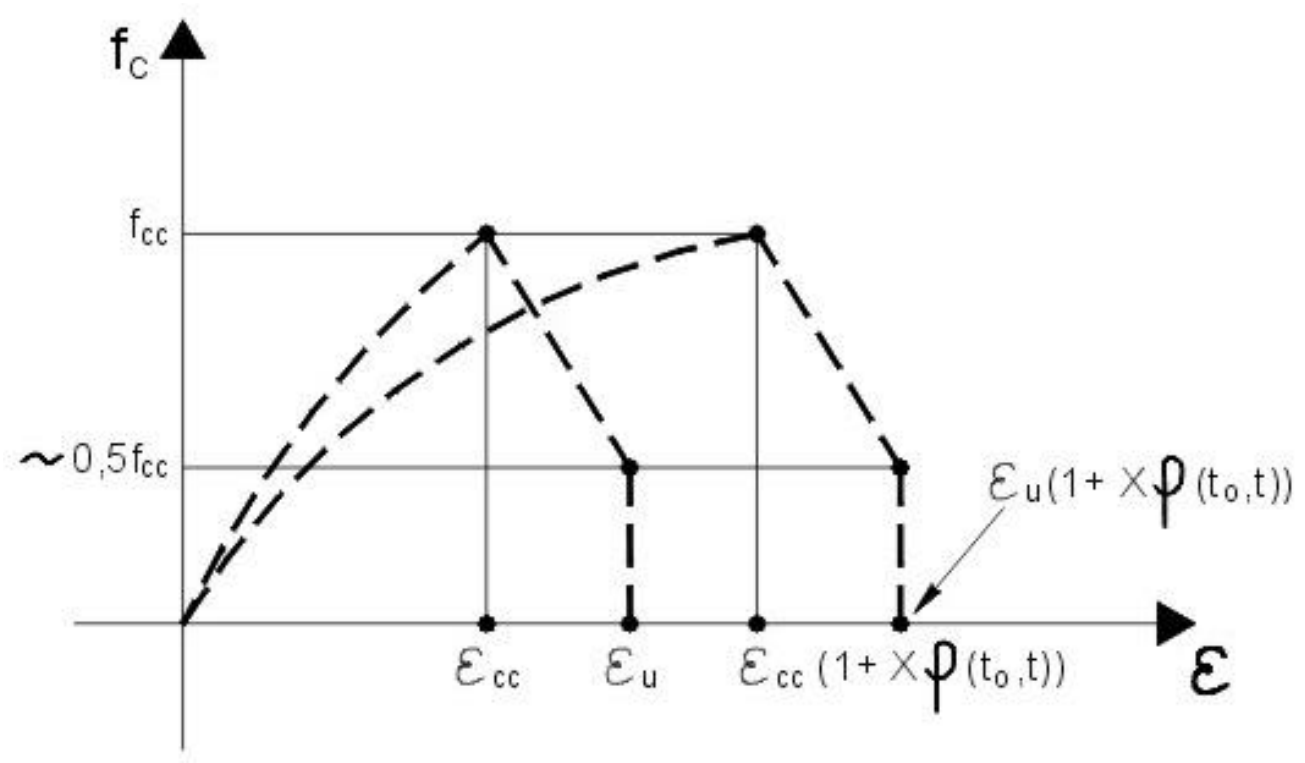

Fig. 5.10.- Consideração do efeito da fluência do concreto 


\section{CAPÍTULO 6}

\section{INDICACÕES PARA A ANÁLISE NUMÉRICA}

\subsection{INTRODUÇÃO}

As análises numéricas realizadas neste estudo são baseadas em projetos típicos de pontes projetadas e já executadas. Algumas adaptações foram efetuadas de modo a permitir algumas simulações quanto ao modelo físico do concreto armado e a interação solo-estrutura. Os testes numéricos foram conduzidos admitindo-se algumas hipóteses de rigidez dos pilares para uma determinada seqüência de carregamento, tendo como objetivo avaliar a sensibilidade dessas hipóteses quanto às respostas estruturais. Nos modelos utilizados para simular a resposta lateral do solo foi adotada a discretização de Winkler com dispositivos de comportamento linear elástico e elástico não linear. Os aparelhos de apoio são simulados por meio de dispositivos de contato.

\section{2 - SOLO: MODELOS UTILIZADOS}

\subsection{1 - MODELO DE BOWLES (1977)}

Independentemente dos parâmetros de um solo do tipo arenoso, BOWLES (1977) sugere um modelo elástico linear simplificado baseado nos valores de sondagem de reconhecimento SPT para determinar a resposta lateral do solo.

- Constante de reação horizontal do solo $\left(\mathrm{k}_{\mathrm{h}}\right)$ recomendados: 
Indicações para a análise numérica

Tabela 6.1 Constantes de Reação Horizontal k $\mathrm{h}$ BOWLES(1977)

\begin{tabular}{|l|l|}
\hline Para SPT $<10$ & $\mathrm{k}_{\mathrm{h}}=5000 \mathrm{kN} / \mathrm{m}^{3}$ \\
\hline Para $10 \leq \mathrm{SPT} \leq 30$ & $\mathrm{k}_{\mathrm{h}}=10000 \mathrm{kN} / \mathrm{m}^{3}$ \\
\hline Para SPT $\geq 30$ & $\mathrm{k}_{\mathrm{h}}=20000 \mathrm{kN} / \mathrm{m}^{3}$ \\
\hline
\end{tabular}

A constante do dispositivo elástico linear é obtida multiplicando a área frontal deformada do solo pela constante $\mathrm{m}_{\mathrm{h}}$. Assim sendo, para um trecho $\Delta \mathrm{H}$ do fuste de um tubulão com diâmetro $\mathrm{B}$, a constante elástica equivalente do solo no trecho $\Delta \mathrm{H}$ será tomada igual a $\mathrm{K}_{\mathrm{s}}=\mathrm{k}_{\mathrm{h}} \mathrm{B} \Delta \mathrm{H}$, e a correspondente reação horizontal nessa área frontal para uma deslocamento horizontal "y" será dada por $\mathrm{P}=\mathrm{k}_{\mathrm{h}} \mathrm{B} \Delta \mathrm{Hy}$.

\subsection{2 - MODELO DE MATLOCK (1970)}

- Resposta da Argila Submersa

O critério apresentado por Matlock para a obtenção das curvas p-y para cargas estáticas consiste de duas partes. Inicialmente começa pela obtenção de uma expressão para descrever a variação da resistência última $\mathrm{p}_{\mathrm{u}}$ do solo com a profundidade x. A segunda etapa visa obter uma expressão para descrever a resistência do solo em função dos deslocamentos laterais da estaca para uma profundidade particular. A diferença básica entre essas duas etapas é que a teoria pode geralmente ser usada para determinar a variação de $\mathrm{p}_{\mathrm{u}}$ com a profundidade, ao contrário da segunda fase, onde o empirismo predomina na determinação da forma real das curvas $\mathrm{p}-\mathrm{y}$. A resistência última do solo pode ser obtida usando a seguinte equação:

$$
\begin{aligned}
& \mathrm{p}_{\mathrm{u}}=\mathrm{N}_{\mathrm{p}} \mathrm{S}_{\mathrm{u}} \mathrm{B} \\
& \mathrm{N}_{\mathrm{p}}=\text { resistência última normalizada do solo; } \\
& \mathrm{S}_{\mathrm{u}}=\text { resistência ao cisalhamento do solo não drenado na profundidade }
\end{aligned}
$$

$\mathrm{x}$

$$
\mathrm{B}=\text { diâmetro da estaca. }
$$

$\mathrm{O}$ valor de $\mathrm{N}_{\mathrm{p}}$ é determinado em função da profundidade abaixo da superfície do terreno [MATLOCK (1970), REESE \& WELCH (1975), REESE et al. 


\section{Indicações para a análise numérica}

(1975), THOMPSON (1977)]. O valor de $\mathrm{N}_{\mathrm{p}}$ cresce com a profundidade até alcançar um valor limite em um determinado ponto, a partir do qual se mantêm constante para profundidades maiores.

A função geral que descreve a variação de $\mathrm{N}_{\mathrm{p}}$ para baixas profundidades, é dada por:

$$
\mathrm{N}_{\mathrm{p}}=\mathrm{A}_{0}+\frac{\bar{\sigma}_{\mathrm{x}}}{\mathrm{S}_{\mathrm{x}}}+\mathrm{J} \frac{\mathrm{x}}{\mathrm{B}} \quad \text { onde, }
$$

$\mathrm{A}_{0}=$ resistência última normalizada do solo na superfície do terreno;

$\bar{\sigma}_{\mathrm{x}}=$ tensão efetiva, devido a sobrecarga na profundidade $\mathrm{x}$;

$\mathrm{x}=$ profundidade abaixo da superfície do terreno

$\mathrm{J}=$ coeficiente empírico.

- Resposta da Argila Mole Submersa

Recomendações para a determinação das curvas p-y(carga estática):

1) Obtenção da melhor estimativa possível da variação de $S_{u}$ e o peso específico submerso $\gamma$ com a profundidade. Determinação do valor de $\varepsilon_{50}$ (deformação correspondente à metade da máxima diferença das tensões principais determinada no ensaio triaxial de compressão). Se não se dispõe de nenhuma curva $\sigma-\varepsilon$ do ensaio de compressão, alguns valores típicos de $\varepsilon_{50}$ indicados na tabela (6.2) podem ser utilizados;

Tabela 6.2 - Valores típicos de $\varepsilon_{50}$

\begin{tabular}{|l|l|}
\hline Consistência da Argila & $\varepsilon_{50}$ \\
\hline Mole & 0,020 \\
\hline Média & 0,010 \\
\hline Dura & 0,005 \\
\hline
\end{tabular}

2) Cálculo da resistência última por unidade de comprimento de estaca, usando o menor dos dois valores dados pelas expressões: 


$$
\begin{aligned}
& \mathrm{p}_{\mathrm{ul}}=\left(3+\frac{\gamma_{\mathrm{m}}}{\mathrm{S}_{\mathrm{u}}} \mathrm{x}+\frac{\mathrm{J}}{\mathrm{B}} \mathrm{x}\right) \mathrm{S}_{\mathrm{u}} \mathrm{B} \\
& \mathrm{p}_{\mathrm{u} 2}=9 \mathrm{~S}_{\mathrm{u}} \mathrm{B}
\end{aligned}
$$

Baseando-se em testes realizados, MATLOCK (1970) recomendou o valor 3 para $\mathrm{A}_{0}$. Para a argila mole o valor $\mathrm{J}=0,5$ e para a argila média o valor $\mathrm{J}=0.25$. Para profundidades maiores Matlock recomendou $\mathrm{N}_{\mathrm{p}}=9$. A profundidade na qual essa transição ocorre para um depósito com resistência ao cisalhamento uniforme pode ser obtida usando a seguinte expressão:

$$
\begin{aligned}
& \mathrm{X}_{\mathrm{r}}=\frac{6 \mathrm{~B}}{\frac{\mathrm{B} \gamma_{\mathrm{m}}}{\mathrm{S}_{\mathrm{u}}}+\mathrm{J}} \quad \text { onde, } \\
& \gamma_{\mathrm{m}}=\text { peso específico médio entre a superfície do terreno e a }
\end{aligned}
$$
profundidade $\mathrm{x}$ considerada.

$\mathrm{O}$ valor de $\mathrm{X}_{\mathrm{r}}$ representa a profundidade a partir da qual a ruína ocorre por escoamento do solo ao redor da estaca (expressão 6.3). Para as profundidades acima de $\mathrm{x}_{\mathrm{r}}$ a ruína é governada pela formação de cunhas[expressão (6.4)].

3) Cálculo do deslocamento $\mathrm{y}_{50}$, correspondente à metade da resistência última do solo:

$$
\mathrm{y}_{50}=2,5 \varepsilon_{50} \mathrm{~B}
$$

4) Descrição da curva p-y calculada pela seguinte relação:

$$
\frac{\mathrm{p}}{\mathrm{p}_{\mathrm{u}}}=0.5\left(\frac{\mathrm{y}}{\mathrm{y}_{50}}\right)^{\frac{1}{3}}
$$

$\mathrm{O}$ valor de $\mathrm{p}$ permanece constante para valores de y superiores a $8 \mathrm{y}_{50}$ (Fig. 6.1). 


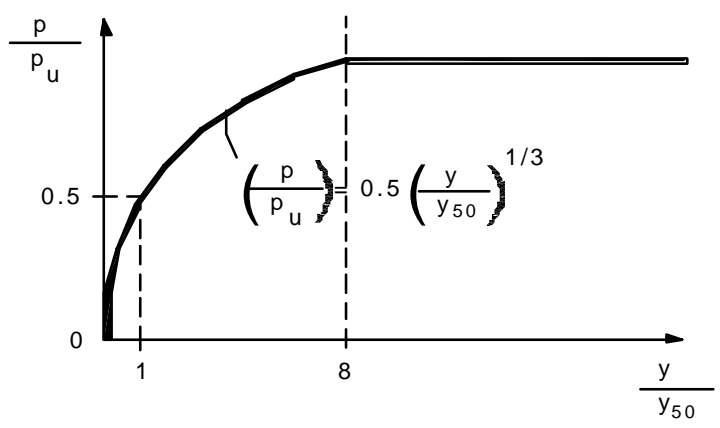

Fig. 6.1 - Curva p-y para Argila Mole - Carga Estática

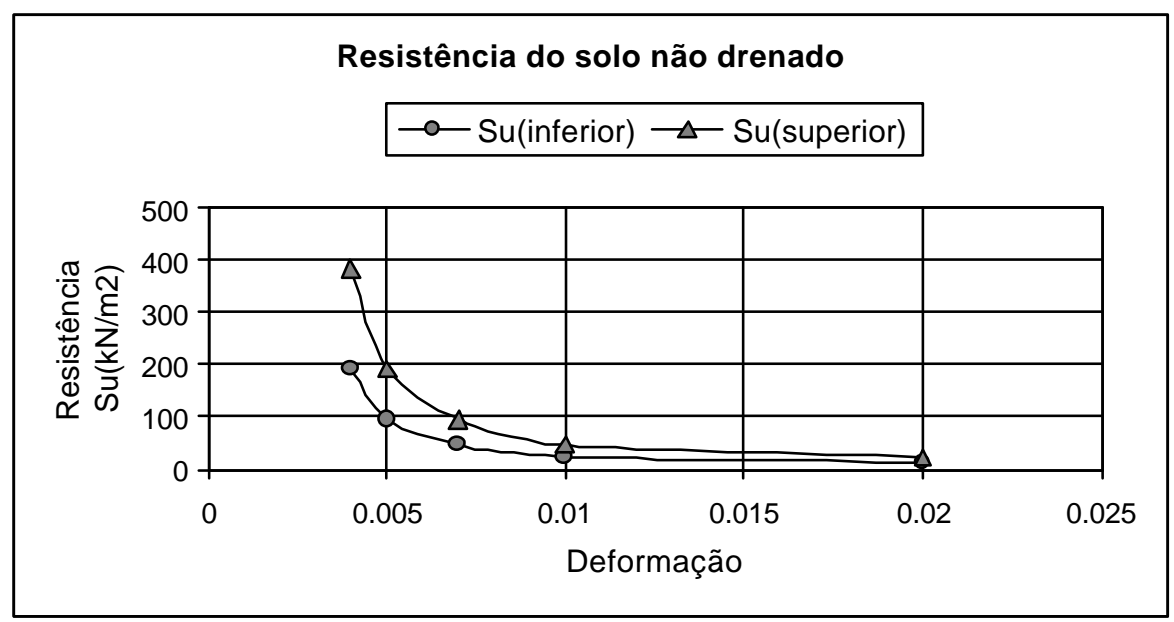

Fig. 6.2 - Resistência $S_{u}$ vs. $\varepsilon_{50}$

Tabela 6.3 -Valores médios de $\gamma_{\mathrm{m}}$ para a argila

\begin{tabular}{|l|l|}
\hline$\gamma_{\mathrm{m}}\left(\mathrm{kN} / \mathrm{m}^{3}\right)-$ submersa & $7-11$ \\
\hline$\gamma_{\mathrm{m}}\left(\mathrm{kN} / \mathrm{m}^{3}\right)-$ não submersa & $17-21$ \\
\hline
\end{tabular}

Para uma argila rija acima do lençol freático a curva p-y em uma profundidade qualquer, a menos dos parâmetros do solo e alguns ajuste na sua expressão, é semelhante à curva da fig.6.1. Para o caso do carregamento estático, o expoente da expressão (6.7) é tomado igual a $1 / 4$ no lugar de $1 / 3$, e o limite do deslocamento, a partir do qual a resistência se mantém constante, é tomado igual a $16 y_{50}$ em substituição ao limite $8 y_{50}$. 
Indicações para a análise numérica

Dispositivos de Winkler para uma argila média submersa

- Dados Adotados-

\begin{tabular}{lc}
\hline $\mathrm{S}_{\mathrm{u}}\left(\mathrm{kN} / \mathrm{m}^{2}\right)$ & 48,00 \\
Peso específico médio $\gamma_{\mathrm{m}}\left(\mathrm{kN} / \mathrm{m}^{3}\right)$ & 11,00 \\
$\mathrm{~J}$ (valor empírico) & 0,25 \\
Diâmetro do tubulão B(m) & 1,60 \\
$\varepsilon_{50}$ & 0,01 \\
$\mathrm{y}_{50}(\mathrm{~m})$ & 0,04 \\
$\mathrm{x}_{\mathrm{r}}(\mathrm{m})$ & 15,57 \\
\hline
\end{tabular}

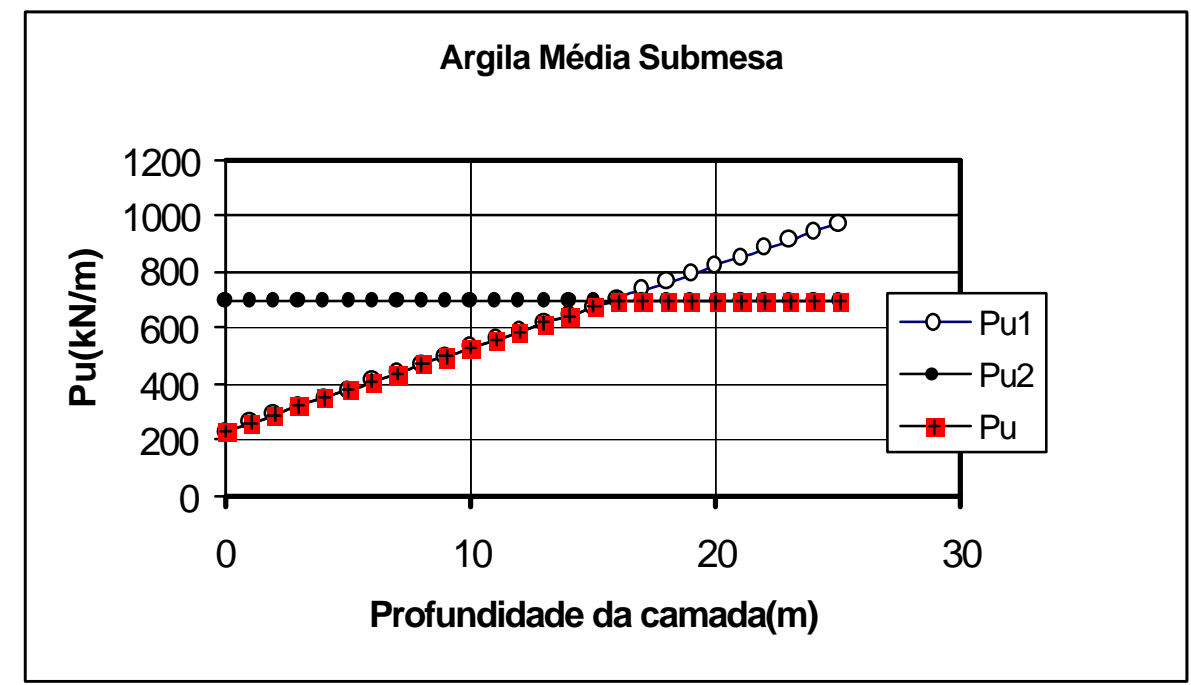

Fig. 6.3 - Resistência $p_{u}$ da Argila Média Submersa

Família de curvas de resistência lateral p-y para uma argila de consistência média abaixo do lençol freático: $\mathrm{p}_{\mathrm{xi}}$ representa uma curva de resistência lateral para uma profundidade genérica $\mathrm{x}_{\mathrm{i}}$. 


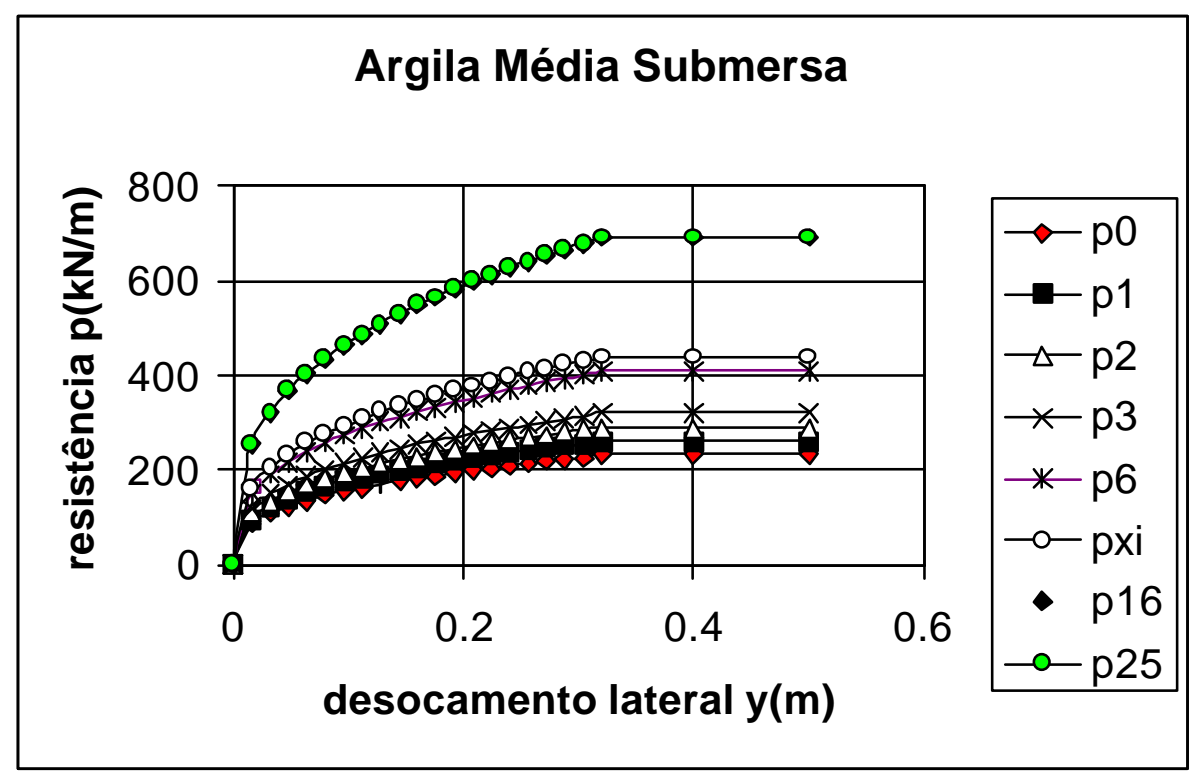

Fig. 6.4 Família de Curvas p-y da Argila Média Submersa

Dispositivos de Winkler para uma argila rija não submersa

- Dados adotados

$\mathrm{S}_{\mathrm{u}}\left(\mathrm{kN} / \mathrm{m}^{2}\right)$

192,00

Peso específico médio $\gamma_{\mathrm{m}}\left(\mathrm{kN} / \mathrm{m}^{3}\right)$

19,00

J (valor empírico)

0,50

Diâmetro do tubulão B(m)

1,60

$\varepsilon_{50}$

0,005

$\mathrm{y}_{50}(\mathrm{~m})$

0,02

$\mathrm{x}_{\mathrm{r}}(\mathrm{m})$

14,58 


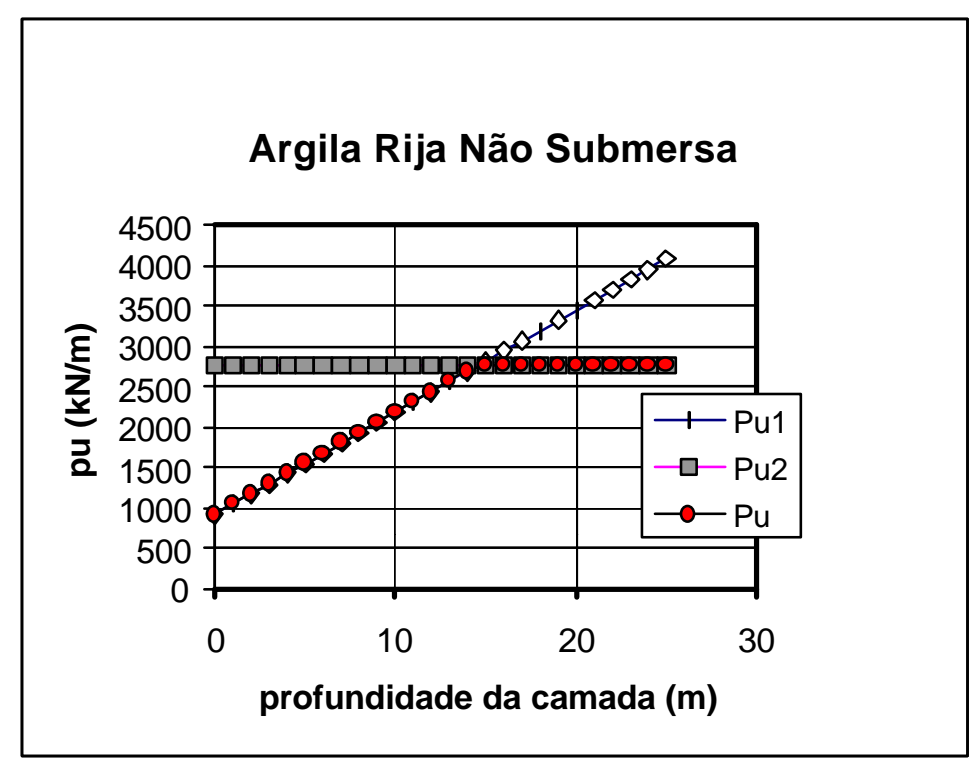

Fig. 6.5 - Resistência $p_{u}$ da Argila Rija Não Submersa

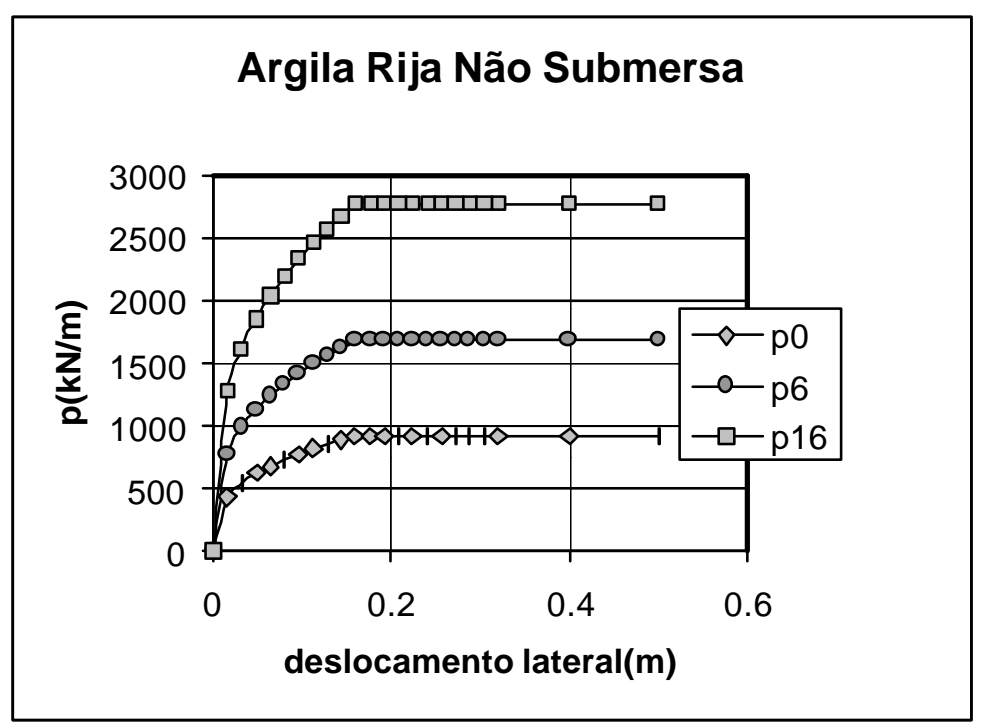

Fig. 6.6 - Família de Curvas p-y da Argila Rija Não Submersa (carga estática)

\subsection{3 - MODELO DE COX, REESE, \& GRUBBS (1974)}

- Resposta de uma Areia

Recomendações para a determinação das curvas p-y

1) Obtenção dos parâmetros necessários:

$\phi$ - ângulo de atrito interno da areia; 
$\gamma$ - peso específico da areia;

B - diâmetro do fuste da estaca;

$\mathrm{x}$ - profundidade abaixo da superfície do terreno.

2) Cálculo preliminar dos seguintes parâmetros:

$\alpha=\frac{\phi}{2} ; \quad \beta=45^{0}+\frac{\phi}{2} ; \quad \mathrm{k}_{0}=0,4 ; \quad \mathrm{k}_{\mathrm{a}}=\tan ^{2}\left(45^{0}-\frac{\phi}{2}\right)$

3) Cálculo da resistência última $\mathrm{p}_{u}$ do solo

Tomar o menor dos dois valores, $\mathrm{p}_{\mathrm{st}}$ ou $\mathrm{p}_{\mathrm{sd}}$.

$$
\begin{aligned}
& \mathrm{p}_{\mathrm{st}}=\gamma \mathrm{x}\left[\frac{\mathrm{k}_{0} \mathrm{x} \tan \phi \sin \beta}{\tan (\beta-\phi) \cos \alpha}+\frac{\tan \beta}{\tan (\beta-\phi)}(\mathrm{B}+\mathrm{x} \tan \beta \tan \alpha)+\right. \\
& \left.+\mathrm{k}_{0} \mathrm{x} \tan \beta(\tan \phi \sin \beta-\tan \alpha)-\mathrm{k}_{\mathrm{a}} \mathrm{B}\right] \\
& \mathrm{p}_{\mathrm{sd}}=\mathrm{k}_{\mathrm{a}} \mathrm{B} \gamma \mathrm{x}\left(\tan ^{8} \beta-1\right)+\mathrm{k}_{0} \mathrm{~B} \gamma \mathrm{x} \tan \phi \tan ^{4} \beta
\end{aligned}
$$

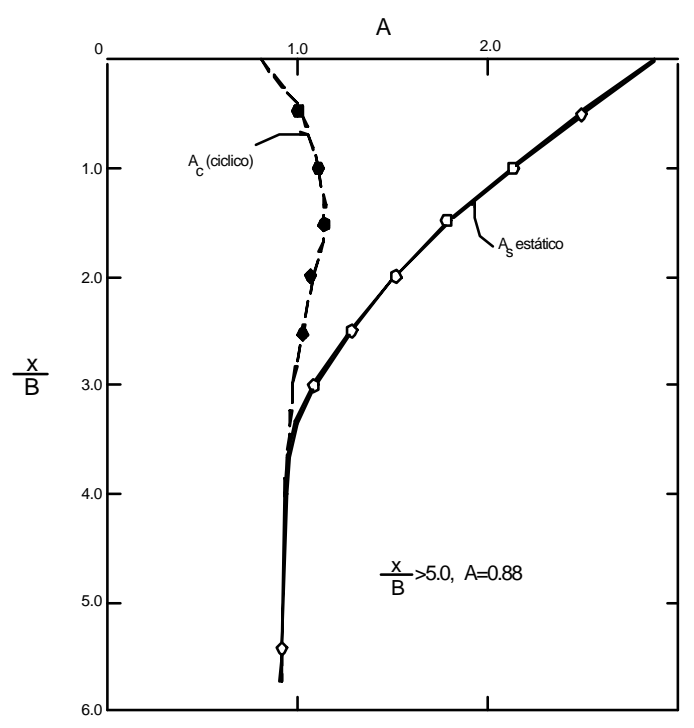

Fig. 6.7 - Valores de $A_{s}$ e $A_{c}$

Para areia submersa deve ser usado nas expressões o seu peso específico efetivo. 
4) Determinação de $x_{t}$

Para as camadas acima da profundidade $\mathrm{x}_{\mathrm{t}}$ são usados os valores de $\mathrm{p}_{\mathrm{st}}$, e para as profundidades abaixo de $\mathrm{x}_{\mathrm{t}}$ são utilizados os valores de $\mathrm{p}_{\mathrm{sd}}$.

5) Selecionar a profundidade " $x$ "onde se deseja a curva $p-y$;

6) Estabelecer o valor $y_{u}$ como 3B/80. Calcular $p_{u}$ pelas equações:

$\mathrm{p}_{\mathrm{u}}=\mathrm{A}_{\mathrm{s}} \mathrm{p}_{\mathrm{s}} \quad \mathrm{ou}$

$\mathrm{p}_{\mathrm{u}}=\mathrm{A}_{\mathrm{c}} \mathrm{p}_{\mathrm{s}} \quad$ onde,

$\mathrm{A}_{\mathrm{s}}$ e $\mathrm{A}_{\mathrm{c}}$ são fatores empíricos de ajustamento obtidos da Fig. 6.7 para uma profundidade particular $\mathrm{x}$.

7) Determinação do ponto $\left(\mathrm{y}_{\mathrm{m}}, \mathrm{p}_{\mathrm{m}}\right)$.

Define-se $\mathrm{y}_{\mathrm{m}}$ como B/60. Calcula-se $\mathrm{p}_{\mathrm{m}}$ pelas seguintes expressões:

$\mathrm{p}_{\mathrm{m}}=\mathrm{B}_{\mathrm{s}} \mathrm{p}_{\mathrm{s}} \quad \mathrm{ou}$

$\mathrm{p}_{\mathrm{m}}=\mathrm{B}_{\mathrm{c}} \mathrm{p}_{\mathrm{s}}$

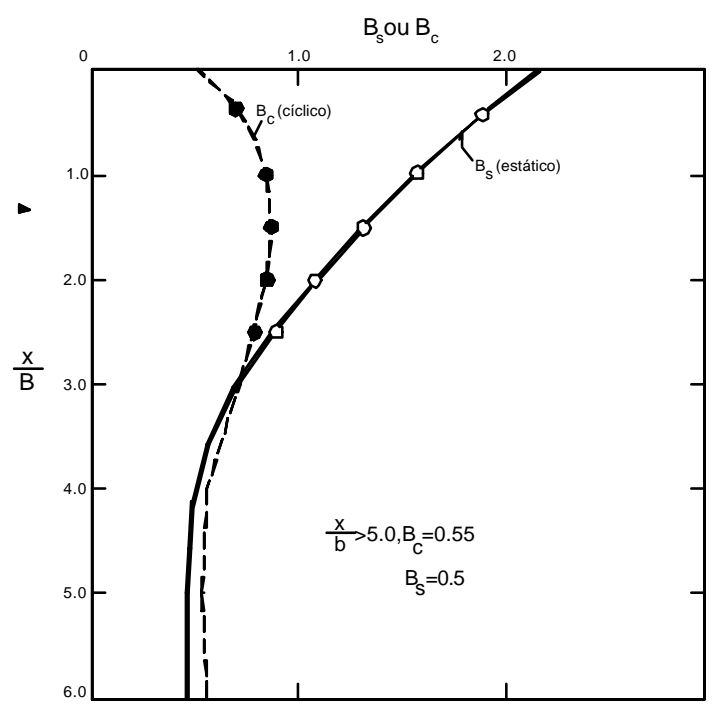

Fig. 6.8 - Valores de $\mathrm{B}_{\mathrm{s}}$ e $\mathrm{B}_{\mathrm{c}}$ 


\section{Indicações pa ra a análise numérica}

Os fatores de ajustamento $B_{s}$ e $B_{c}$ são obtidos da fig. 6.8 para uma determinada profundidade $\mathrm{x}$ a partir da superfície do terreno.

8) Definição do trecho linear inicial da curva p-y;

$$
\mathrm{p}=\left(\mathrm{k}_{\mathrm{s}} \mathrm{x}\right) \mathrm{y}
$$

Usar valores apropriados de $\mathrm{k}_{\mathrm{s}}$ das tabelas 6.4 para areia abaixo ou acima do lençol freático;

Tabela 6.4 - Valores Representativos de $\mathrm{k}_{\mathrm{s}}$ para Areia

\begin{tabular}{|l|c|c|c|}
\hline $\begin{array}{l}\text { Densidade relativa da } \\
\text { areia }\end{array}$ & Fofa & média & Densa \\
\hline $\begin{array}{l}\mathrm{K}_{\mathrm{s}}\left(\mathrm{N} / \mathrm{cm}^{3}\right) \\
(\text { areia submersa })\end{array}$ & $\mathbf{5}$ & $\mathbf{1 6}$ & $\mathbf{3 5}$ \\
\hline $\begin{array}{l}\mathrm{K}_{\mathrm{s}}\left(\mathrm{N} / \mathrm{cm}^{3}\right) \\
(\text { areia não submersa })\end{array}$ & $\mathbf{7}$ & $\mathbf{2 5}$ & $\mathbf{6 3}$ \\
\hline
\end{tabular}

10) Estabelecer o trecho não linear da curva p-y válido entre os pontos “m” e "k" como segue (fig. 4.5.C9):

$$
\mathrm{p}=\overline{\mathrm{cy}} \mathrm{1} / \mathrm{n}
$$

11) Cálculo da inclinação da linha reta entre os pontos "m" e "u" pela expressão:

$$
\mathrm{m}=\frac{\mathrm{p}_{\mathrm{u}}-\mathrm{p}_{\mathrm{m}}}{\mathrm{y}_{\mathrm{u}}-\mathrm{y}_{\mathrm{m}}}
$$

12) Potência do trecho não linear entre "k" e "m";

$$
\mathrm{n}=\frac{\mathrm{p}_{\mathrm{m}}}{\mathrm{my}_{\mathrm{m}}}
$$


13) Obtenção do coeficiente $\bar{c}$;

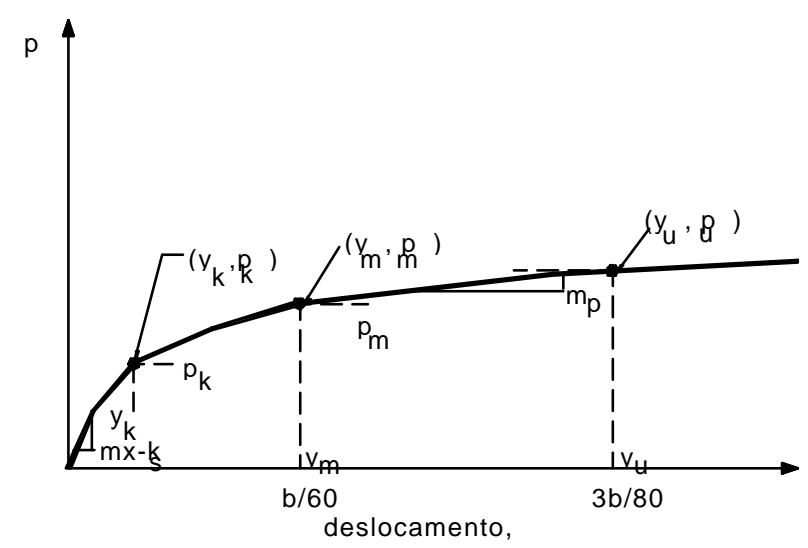

Fig. 6.9 - Características de uma Família de Curvas p-y para a Areia[COX, REESE, \& GRUBBS (1974)]

$$
\bar{c}=\frac{p_{m}}{\left(y_{m}\right)^{1 / n}}
$$

14) Determinação do ponto "k".

$$
\mathrm{y}_{\mathrm{k}}=\left(\frac{\overline{\mathrm{c}}}{\mathrm{k}_{\mathrm{s}} \mathrm{x}}\right)^{\frac{\mathrm{n}}{\mathrm{n}-1}} \quad ; \quad \mathrm{p}_{\mathrm{k}}=\left(\mathrm{k}_{\mathrm{s}} \mathrm{x}\right) \mathrm{y}_{\mathrm{k}}
$$

Curvas de reação horizontal para uma areia de consistência média

Dados adotados:

$\mathrm{K}_{0}=0,4$;

$\gamma_{\mathrm{m}}=1,10 \mathrm{E}+01\left(\mathrm{kN} / \mathrm{m}^{3}\right)$ - areia submersa;

$\mathrm{B}=1,60 \mathrm{~m}$ (diâmetro do tubulão);

$\mathrm{Ks}=16000\left(\mathrm{kN} / \mathrm{m}^{3}\right)$

Ângulo de atrito interno: $25^{\circ}$ a $30^{0}$

Na Fig.6.10 está indicada a resistência última para uma areia de consistência média abaixo do lençol freático. Na fig. 6.11 estão indicadas as curvas 


\section{Indicações para a análise numérica}

p-y $\mathrm{p}_{0}, \mathrm{p}_{5}, \mathrm{p}_{9}$ e $\mathrm{p}_{12}$, respectivamente, para as profundidades $0,5,9$ e $15 \mathrm{~m}$ abaixo do terreno. Na tabela 6.5 estão indicados os pontos $\left(\mathrm{p}_{\mathrm{k}}, \mathrm{y}_{\mathrm{k}}\right),\left(\mathrm{p}_{\mathrm{m}}, \mathrm{y}_{\mathrm{m}}\right)$ e $\left(\mathrm{p}_{\mathrm{u}}, \mathrm{y}_{\mathrm{u}}\right)$ até a profundidade $23 \mathrm{~m}$ abaixo do terreno.

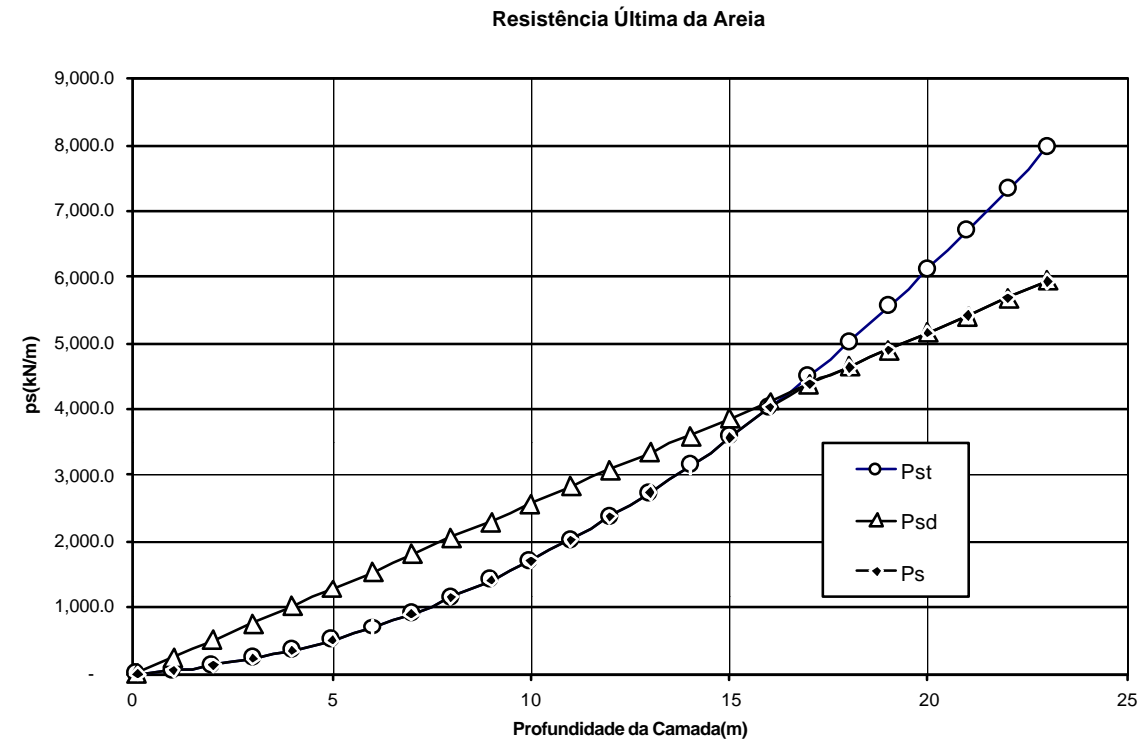

Fig. 6.10 - Resistência Última da Areia Média Submersa Adotada

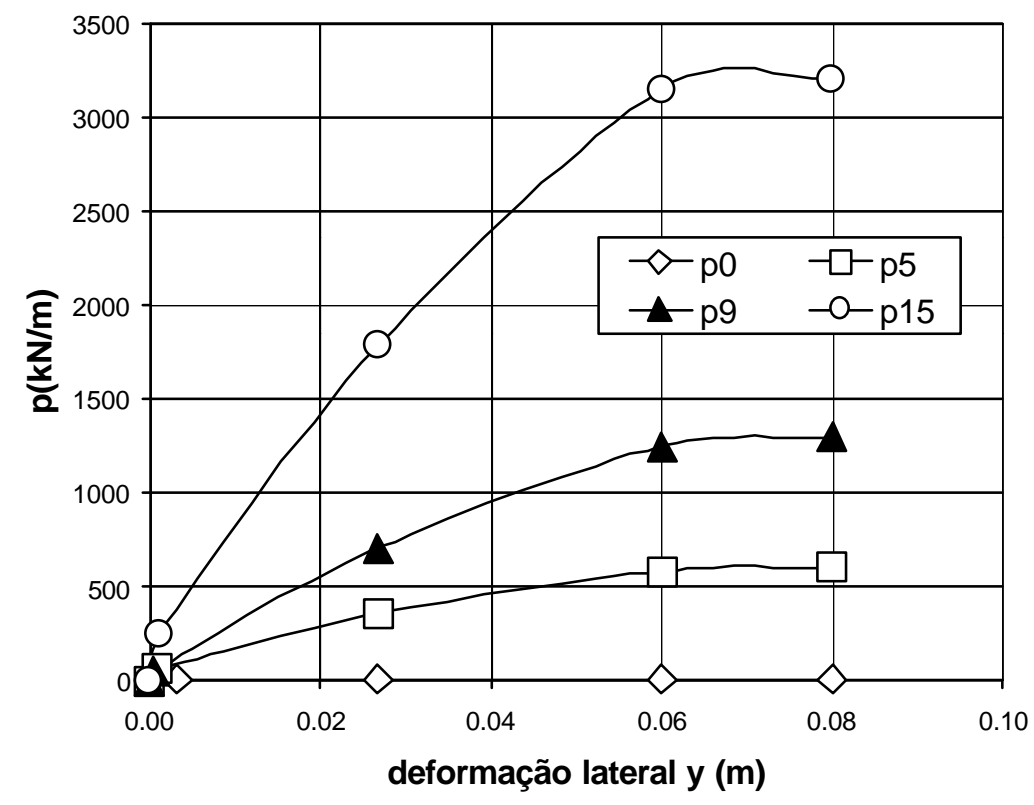

Fig. 6.11 Curvas p-y para uma areia submersa de compacidade média 
Indicações para a análise numérica

Tabela 6.5 - Curvas p-y para uma Areia Média Submersa

\begin{tabular}{|c|c|c|c|c|c|c|}
\hline $\mathrm{x}(\mathrm{m})$ & $\mathrm{y}_{\mathrm{k}(\mathrm{m})}$ & $\mathrm{p}_{\mathrm{k}}(\mathrm{m})$ & $\mathrm{Y}_{\mathrm{m}}(\mathrm{m})$ & $\mathrm{p}_{\mathrm{m}}(\mathrm{kN} / \mathrm{m})$ & $\mathrm{Y}_{\mathrm{u}}(\mathrm{m})$ & $\mathrm{p}_{\mathrm{u}}(\mathrm{kN} / \mathrm{m})$ \\
\hline 0.10 & 0.0032 & 5.0563 & 0.027 & 8.34 & 0.06 & 10.79 \\
\hline 1.00 & 0.0032 & 51.6194 & 0.027 & 89.59 & 0.06 & 118.82 \\
\hline 2.00 & 0.0029 & 92.0750 & 0.027 & 179.48 & 0.06 & 246.74 \\
\hline 3.00 & 0.0022 & 107.7022 & 0.027 & 256.54 & 0.06 & 368.98 \\
\hline 4.00 & 0.0015 & 96.1941 & 0.027 & 317.07 & 0.06 & 481.44 \\
\hline 5.00 & 0.0008 & 66.7848 & 0.027 & 364.71 & 0.06 & 588.13 \\
\hline 6.00 & 0.0004 & 36.2120 & 0.027 & 408.32 & 0.06 & 698.70 \\
\hline 7.00 & 0.0002 & 17.2212 & 0.027 & 459.83 & 0.06 & 826.01 \\
\hline 8.00 & 0.0003 & 36.2198 & 0.027 & 574.49 & 0.06 & 1011.10 \\
\hline 9.00 & 0.0004 & 51.2079 & 0.027 & 706.86 & 0.06 & 1244.07 \\
\hline 10.00 & 0.0004 & 70.1807 & 0.027 & 852.73 & 0.06 & 1500.80 \\
\hline 11.00 & 0.0005 & 93.7239 & 0.027 & 1012.11 & 0.06 & 1781.31 \\
\hline 12.00 & 0.0006 & 122.4519 & 0.027 & 1185.00 & 0.06 & 2085.60 \\
\hline 13.00 & 0.0008 & 157.0070 & 0.027 & 1371.42 & 0.06 & 2413.71 \\
\hline 14.00 & 0.0009 & 198.0592 & 0.027 & 1571.39 & 0.06 & 2765.64 \\
\hline 15.00 & 0.0010 & 246.3046 & 0.027 & 1784.90 & 0.06 & 3141.43 \\
\hline 16.00 & 0.0012 & 302.4656 & 0.027 & 2011.98 & 0.06 & 3541.09 \\
\hline 17.00 & 0.0013 & 341.7398 & 0.027 & 2189.86 & 0.06 & 3854.15 \\
\hline 18.00 & 0.0013 & 362.1742 & 0.027 & 2319.50 & 0.06 & 4082.33 \\
\hline 19.00 & 0.0013 & 382.6458 & 0.027 & 2449.25 & 0.06 & 4310.67 \\
\hline 20.00 & 0.0013 & 403.1546 & 0.027 & 2579.08 & 0.06 & 4539.18 \\
\hline 21.00 & 0.0013 & 423.7008 & 0.027 & 2709.01 & 0.06 & 4767.86 \\
\hline 22.00 & 0.0013 & 444.2843 & 0.027 & 2839.03 & 0.06 & 4996.69 \\
\hline 23.00 & 0.0013 & 464.9053 & 0.027 & 2969.14 & 0.06 & 5225.69 \\
\hline
\end{tabular}

O efeito de grupo na resposta lateral do solo é assim obtida deslocando-se os valores "y" das curvas p-y de um valor igual à constante $\mathrm{C}_{\mathrm{y}}$ (Capítulo 3). Essa medida se justifica uma vez que essas curvas foram obtidas em ensaios de espécimes isolados no campo. 


\section{3 - SIMULA ÇÃO DOS APARELHOS DE NEOPRENE}

Os aparelhos de apoio de neoprene podem ser modelados por um dispositivo de contato em 3D. O elemento de contato CONTAC52 (3-D Ponto a Ponto) pode ser utilizado para essa finalidade(Fig. 6.12). A parametrização deste elemento para simular o comportamento de um aparelho de apoio de neoprene é efetuada através de duas curvas. Uma delas simula o movimento tangencial do aparelho, isto é, ortogonal à linha I-J do seu eixo, e a outra simula a deformabilidade provocada pela força normal aplicada segundo a direção I-J do aparelho.

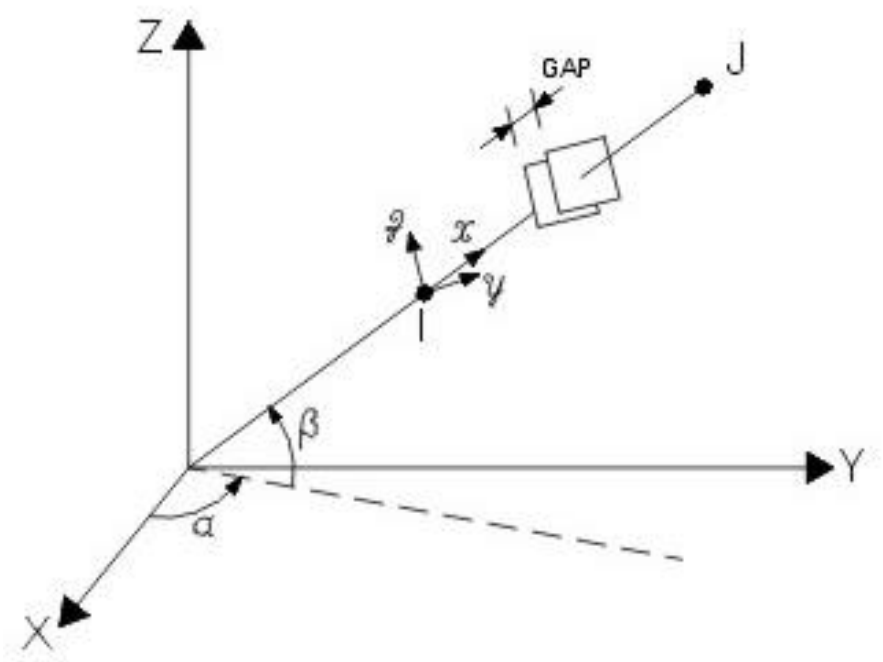

Fig. 6.12 - Elemento de contato CONTAC52 (Biblioteca do ANSYS)

- Rigidez a distorção dos aparelhos de apoio

$\mathrm{K}_{\mathrm{s}}=\mathrm{SG} / \mathrm{h}$

$\mathrm{S}=$ área de contato do aparelho,

G= módulo de distorção do neoprene;

$\mathrm{h}=$ altura total das almofadas de neoprene do aparelho;

O limite ao esforço tangencial do aparelho está relacionado com a possibilidade do seu escorregamento no topo do pilar(Fig.6.13). Este limite será calculado pela seguinte expressão: 


$$
\mathrm{Fs}(\text { máx. })=\left|\mathrm{F}_{\mathrm{N}}\right| \mu
$$

$\mathrm{F}_{\mathrm{N}}=$ força normal de compressão e $\mu$ é o coeficiente de atrito entre o concreto e o neoprene $(\mu \cong 0,20)$.

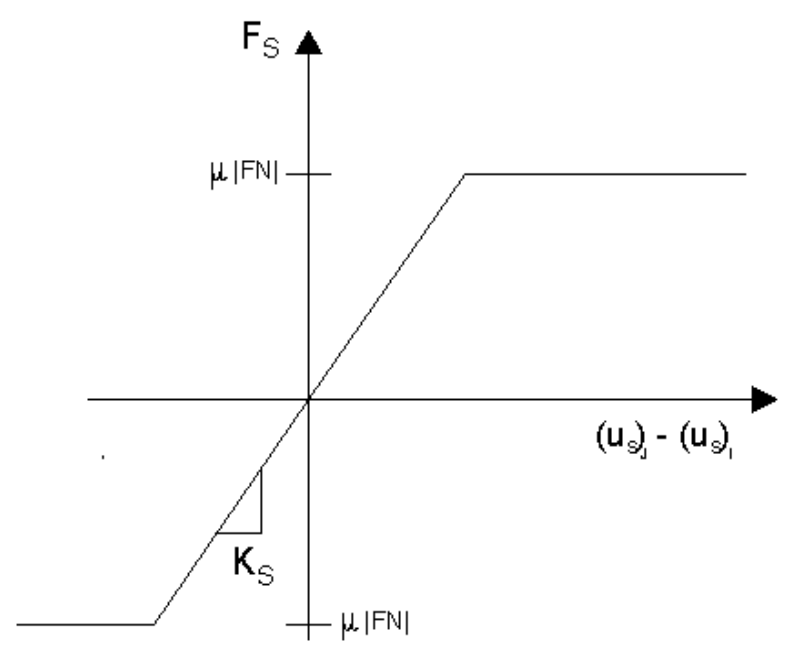

Fig. 6.13 Rigidez a distorção do aparelho

- Rigidez normal do aparelho de apoio

A rigidez normal está relacionada com a deformabilidade normal do aparelho e pode ser avaliada pela seguinte expressão:

$$
\mathrm{K}_{\mathrm{N}}=\mathrm{SE} / \mathrm{h} \text { onde, }
$$

S é a superfície do aparelho de apoio;

E é o módulo de deformação normal do aparelho e pode ser determinado pela seguinte expressão:

$$
\mathrm{E}=4 \mathrm{~B}^{2} \mathrm{G}+3 \sigma_{\mathrm{m}}
$$

$\sigma_{\mathrm{m}}$ : tensão normal máxima no aparelho de apoio. A título de simplificação será adotado, preliminarmente, o valor de $11 \mathrm{MPa}$;

B: denominado fator de forma, é calculado pela seguinte expressão:

$$
\mathrm{B}=\frac{\mathrm{S}}{2 \mathrm{~h}_{1}(\mathrm{a}+\mathrm{b})}
$$


$\mathrm{h}_{1:}$ espessura de uma camada de neoprene;

"a": largura do aparelho;

"b": comprimento do aparelho $(\mathrm{S}=\mathrm{ab})$

O parâmetro "GAP" representa a abertura inicial entre as faces de contato, que no caso específico dos casos analisados será tomado sempre como zero. (Fig.6.14).

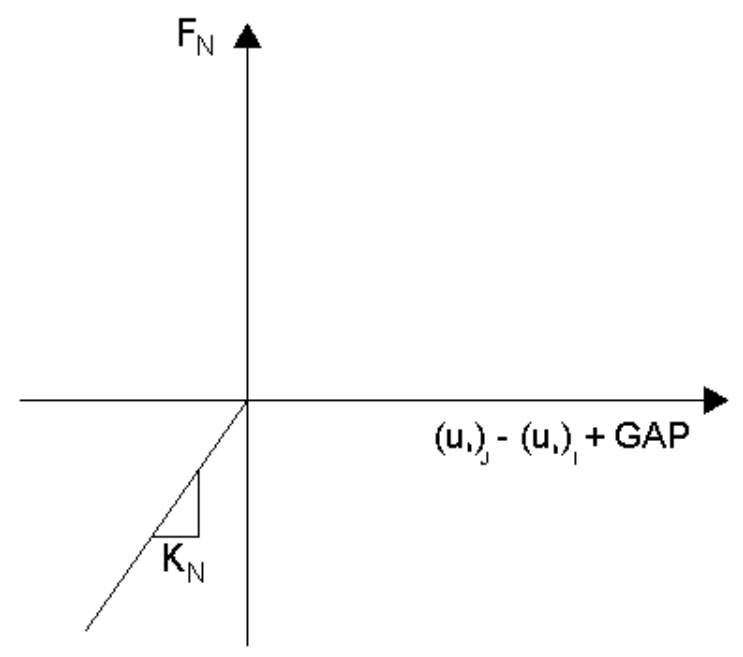

Fig.6.14 - Rigidez normal do aparelho de apoio

\section{4 - CARREGAMENTOS PREVISTOS}

\subsection{1 - AÇÕES TÍPICAS NAS PONTES}

a) Ações de longa duração

- Cargas Permanentes $\left(\mathrm{F}_{\mathrm{g}}\right)_{\mathrm{k}}$ : Peso próprio da estrutura, Defensas e passeios, Complementos: pavimento, lastro, dormentes, trilhos, dutos, postes de iluminação, sinalização, etc.;

- Deformações impostas: Variação média de temperatura na superestrutura $\left(\mathrm{F}_{\Delta \mathrm{t}}\right)_{\mathrm{k}}$, Encurtamento por retração $\left(\mathrm{F}_{\mathrm{cs}}\right)_{\mathrm{k}}$, Encurtamento por protensão posterior na superestrutura $\left(\mathrm{F}_{\mathrm{pk}}\right)$; Encurtamento por fluência $\left(\mathrm{F}_{\mathrm{cc}}\right)_{\mathrm{k}}$, Recalques $\left(\mathrm{F}_{\delta}\right)_{\mathrm{k}}$ etc.;

b) Ações de curta duração $\left(\mathrm{F}_{\mathrm{q}}\right)_{\mathrm{k}},\left(\mathrm{F}_{\varepsilon}\right)_{\mathrm{k}}$ 
Indicações para a análise numérica

- Carga móvel e sobrecargas $\left(\mathrm{F}_{\mathrm{q}}\right)_{\mathrm{k}}$, Ações devido ao vento $\left(\mathrm{F}_{\mathrm{w}}\right)_{\mathrm{k}}$, Variação de temperatura de curta duração $\left(\mathrm{F}_{\Delta \mathrm{t}}\right)_{\mathrm{k}}$, Empuxos (terra, correnteza, etc.).

\subsection{2 - COMBINAÇÕES DAS AÇÕES}

Os carregamentos sobre a estrutura na qual se prevê a análise não linear geométrica devem ser efetuados sob a forma de pilhas de ações com atuação seqüencial.

6.4.2.1 - Pilhas previstas para os Estados Limites de Utilização:

- Pilha 1: Seqüência Rara das Ações

$\mathrm{C}_{1} \rightarrow \mathrm{C}_{2} \rightarrow \mathrm{C}_{3} \rightarrow \mathrm{C}_{4} \rightarrow \mathrm{C}_{5} \rightarrow \mathrm{C}_{6} \rightarrow \mathrm{C}_{7} \rightarrow \mathrm{C}_{8} \rightarrow \mathrm{C}_{9} \rightarrow 0,7 \mathrm{C}_{10} \rightarrow 0,7 \mathrm{C}_{11} \rightarrow 0,7 \mathrm{C}_{12}$

\begin{tabular}{|cccc|}
\hline CARGA C & $\gamma_{\mathrm{j}} \mathrm{F}_{\mathrm{jk}}$ & $\gamma_{\mathrm{j}}$ & OBSERVAÇÃO \\
\hline \hline $\mathrm{C}_{1}$ & $\gamma_{\mathrm{j}} \mathrm{F}_{\mathrm{k}}$ & 1,0 & peso dos pilares e infra-estrutura \\
$\mathrm{C}_{2}$ & $\gamma_{\mathrm{j}} \mathrm{F}_{\mathrm{jk}}$ & 1,0 & peso da superestrutura \\
$\mathrm{C}_{3}$ & $\gamma_{\mathrm{j}} \mathrm{F}_{\mathrm{jk}}$ & 1,0 & permanente complementar \\
$\mathrm{C}_{4}$ & $\gamma_{\mathrm{j}} \mathrm{F}_{\mathrm{jk}}$ & 1,0 & pós-tensão na superestrutura \\
$\mathrm{C}_{5}$ & $\gamma_{\mathrm{j}} \mathrm{F}_{\mathrm{jk}}$ & 1,0 & retração do tabuleiro \\
$\mathrm{C}_{6}$ & $\gamma_{\mathrm{j}} \mathrm{F}_{\mathrm{jk}}$ & 1,0 & variação de temperatura ( longa dur.) \\
$\mathrm{C}$ & $\gamma_{\mathrm{j}} \mathrm{F}_{\mathrm{jk}}$ & 1,0 & sobrecargas na superestrutura \\
$\mathrm{C}_{8}$ & $\gamma_{\mathrm{j}} \mathrm{F}_{\mathrm{jk}}$ & 1,0 & carga móvel vertical \\
$\mathrm{C}_{9}$ & $\gamma_{\mathrm{j}} \mathrm{F}_{\mathrm{jk}}$ & 1,0 & carga móvel ( frenação ou empuxo da \\
& & sobrecarga no aterro de acesso) \\
$\mathrm{C}_{10}$ & $\gamma_{\mathrm{j}} \mathrm{F}_{\mathrm{jk}}$ & 0,7 & empuxo no aterro - \\
$\mathrm{C}_{11}$ & $\gamma_{\mathrm{j}} \mathrm{F}_{\mathrm{jk}}$ & 0,7 & pressão do vento \\
$\mathrm{C}_{12}$ & $\gamma_{\mathrm{j}} \mathrm{F}_{\mathrm{jk}}$ & 0,7 & pressão de correnteza \\
\hline
\end{tabular}

$\mathrm{C}_{1}$ a $\mathrm{C}_{6}$ são cargas de longa duração

$\mathrm{C}_{7}$ a $\mathrm{C}_{12}$ são cargas de curta duração, exceto o empuxo do aterro nos encontros $\left(\mathrm{C}_{10}\right)$

- Pilha 2: Sequiência Freqüente das Ações

$\mathrm{C}_{1} \rightarrow \mathrm{C}_{2} \rightarrow \mathrm{C}_{3} \rightarrow \mathrm{C}_{4} \rightarrow \mathrm{C}_{5} \rightarrow \mathrm{C}_{6} \rightarrow \mathrm{C}_{7} \rightarrow(1,0$ ou 0,8$) \mathrm{C}_{8} \rightarrow(1,0$ ou 0,8$) \mathrm{C}_{9}$ $\rightarrow 0,4 \mathrm{C}_{10} \rightarrow 0,4 \mathrm{C}_{11} \rightarrow 0,4 \mathrm{C}_{12}$ 
Indicações para a análise numérica

\begin{tabular}{|cccc|}
\hline CARGA C & $\gamma_{\mathrm{j}} \mathrm{F}_{\mathrm{jk}}$ & $\gamma_{\mathrm{j}}$ & OBSERVAÇÃO \\
\hline \hline $\mathrm{C}_{1}$ & $\gamma_{\mathrm{j}} \mathrm{F}_{\mathrm{k}}$ & 1,0 & peso dos pilares e infra-estrutura \\
$\mathrm{C}_{2}$ & $\gamma_{\mathrm{j}} \mathrm{F}_{\mathrm{jk}}$ & 1,0 & peso da superestrutura \\
$\mathrm{C}_{3}$ & $\gamma_{\mathrm{j}} \mathrm{F}_{\mathrm{jk}}$ & 1,0 & permanente complementar \\
$\mathrm{C}_{4}$ & $\gamma_{\mathrm{j}} \mathrm{F}_{\mathrm{jk}}$ & 1,0 & pós - tensão na superestrutura \\
$\mathrm{C}_{5}$ & $\gamma_{\mathrm{j}} \mathrm{F}_{\mathrm{jk}}$ & 1,0 & retração do tabuleiro \\
$\mathrm{C}_{6}$ & $\gamma_{\mathrm{j}} \mathrm{F}_{\mathrm{jk}}$ & 1,0 & variação de temperatura ( longa dur.) \\
$\mathrm{C}_{7}$ & $\gamma_{\mathrm{j}} \mathrm{F}_{\mathrm{jk}}$ & 1,0 & sobrecargas na superestrutura \\
$\mathrm{C}_{8}$ & $\gamma_{\mathrm{j}} \mathrm{F}_{\mathrm{jk}}$ & 1,0 & carga móvel vertical ferroviária \\
& & 0,8 & carga móvel vertical rodoviária \\
$\mathrm{C}_{9}$ & $\gamma_{\mathrm{j}} \mathrm{F}_{\mathrm{jk}}$ & 0,8 & carga móvel ( frenagem rodoviária) \\
& & 1,0 & carga móvel ( frenagem ferroviária) \\
$\mathrm{C}_{10}$ & $\gamma_{\mathrm{j}} \mathrm{F}_{\mathrm{jk}}$ & 0,4 & empuxo do aterro de acesso \\
$\mathrm{C}_{11}$ & $\gamma_{\mathrm{j}} \mathrm{F}_{\mathrm{jk}}$ & 0,4 & pressão do vento \\
$\mathrm{C}_{12}$ & $\gamma_{\mathrm{j}} \mathrm{F}_{\mathrm{jk}}$ & 0,4 & pressão de correnteza \\
\hline
\end{tabular}

- Pilha 3: Seqüência Quase Permanente das Ações

$\mathrm{C}_{1} \rightarrow \mathrm{C}_{2} \rightarrow \mathrm{C}_{3} \rightarrow \mathrm{C}_{4} \rightarrow \mathrm{C}_{5} \rightarrow \mathrm{C}_{6} \rightarrow 0,4 \mathrm{C}_{7} \rightarrow 0,4 \mathrm{C}_{8} \rightarrow 0,4 \mathrm{C}_{9} \rightarrow 0,4 \mathrm{C}_{10} \rightarrow 0,4 \mathrm{C}_{11}$ $\rightarrow 0,4 \mathrm{C}_{12}$

\begin{tabular}{|c|c|c|c|}
\hline CARGA $\mathrm{C}_{\mathrm{j}}$ & $\gamma_{\mathrm{j}} \mathrm{F}_{\mathrm{jk}}$ & $\gamma_{j}$ & OBSERVAÇÃO \\
\hline $\mathrm{C}_{1}$ & $\gamma_{\mathrm{j}} \mathrm{F}_{\mathrm{jk}}$ & 1,0 & peso dos pilares e infra-estrutura \\
\hline $\mathrm{C}_{2}$ & $\gamma_{\mathrm{j}} \mathrm{F}_{\mathrm{jk}}$ & 1,0 & peso da superestrutura \\
\hline $\mathrm{C}_{3}$ & $\gamma_{\mathrm{j}} \mathrm{F}_{\mathrm{jk}}$ & 1,0 & permanente complementar \\
\hline $\mathrm{C}_{4}$ & $\gamma_{\mathrm{j}} \mathrm{F}_{\mathrm{jk}}$ & 1,0 & pós - tensão na superestrutura \\
\hline $\mathrm{C}_{5}$ & $\gamma_{\mathrm{j}} \mathrm{F}_{\mathrm{jk}}$ & 1,0 & retração do tabuleiro \\
\hline $\mathrm{C}_{6}$ & $\gamma_{\mathrm{j}} \mathrm{F}_{\mathrm{jk}}$ & 1,0 & variação de temperatura ( longa dur.) \\
\hline $\mathrm{C} 7$ & $\gamma_{\mathrm{j}} \mathrm{F}_{\mathrm{jk}}$ & 0,4 & sobrecargas na superestrutura \\
\hline \multirow[t]{2}{*}{$\mathrm{C}_{8}$} & $\gamma_{\mathrm{j}} \mathrm{F}_{\mathrm{jk}}$ & 0,4 & carga móvel vertical ferroviária \\
\hline & & 0,4 & carga móvel vertical rodoviária \\
\hline \multirow[t]{2}{*}{$\mathrm{C}_{9}$} & $\gamma_{\mathrm{j}} \mathrm{F}_{\mathrm{jk}}$ & 0,4 & carga móvel ( frenagem rodoviária) \\
\hline & & 0,4 & carga móvel ( frenagem ferroviária) \\
\hline $\mathrm{C}_{10}$ & $\gamma_{\mathrm{j}} \mathrm{F}_{\mathrm{jk}}$ & 0,4 & empuxo do aterro de acesso \\
\hline $\mathrm{C}_{11}$ & $\gamma_{\mathrm{j}} \mathrm{F}_{\mathrm{jk}}$ & 0,4 & pressão do vento \\
\hline $\mathrm{C}_{12}$ & $\gamma_{\mathrm{j}} \mathrm{F}_{\mathrm{jk}}$ & 0,4 & pressão de correnteza \\
\hline
\end{tabular}


6.4.2.2 - Pilhas para os estados limites últimos(NBR 7187)

- Pilha 4 - Seqüências Normais

$$
\mathrm{F}_{\mathrm{gk}}\left\{\begin{array}{l}
1,35 \\
1,00
\end{array}\right\} \rightarrow \mathrm{F}_{\mathrm{pk}}\left\{\begin{array}{l}
1,2 \\
0,9
\end{array}\right\} \rightarrow \mathrm{F}_{(\mathrm{cc}, \mathrm{cs}, \Delta \mathrm{t}) \mathrm{k}}\{1,0\} \rightarrow \mathrm{F}_{\mathrm{q} 1 \mathrm{k}}\left\{\begin{array}{c}
1,5 \\
0
\end{array}\right\} \rightarrow \sum \mathrm{F}_{\mathrm{qik}}\left\{\begin{array}{c}
0,75 \\
0
\end{array}\right\}
$$

Os coeficientes de ponderação na parte superior das chaves correspondem às cargas cujos efeitos são considerados desfavoráveis na seqüência. Os coeficientes constantes da parte inferior das chaves devem ser usados quando a respectiva ação provocar efeitos favoráveis

$\mathrm{F}_{\mathrm{gk}}$ : representam quaisquer valores característicos da carga permanente;

$\mathrm{F}_{\mathrm{pk}}:$ representam valores característicos da força de protensão;

$\mathrm{F}_{\mathrm{q} 1 \mathrm{k}}$ : representa o valor da ação variável principal (móvel);

$\mathrm{F}_{\mathrm{qik}}$ : são as demais ações variáveis;

$\mathrm{F}_{(\mathrm{cc}, \mathrm{cs}, \Delta t) \mathrm{k}}$ : são as ações relacionadas às deformações impostas (fluência, retração, variação de temperatura, recalques, etc.).

A NBR 7187 prevê também uma combinação para o Estado Limite Último relacionado com a perda de equilíbrio global da estrutura como corpo rígido quando a mesma é passível de sofrer determinados tipos de movimentos, tais como deslizamento, tombamento. basculamento, deslocamento dos apoios, entre outros. A verificação deste estado limite consiste em satisfazer a seguinte expressão:

$$
\begin{aligned}
& 0,9 \mathrm{~F}_{\mathrm{gks}}-1,1 \mathrm{~F}_{\mathrm{gkn}}-1,5\left[\mathrm{~F}_{\mathrm{q} 1 \mathrm{kn}}+0,5 \sum_{\mathrm{i}>1} \mathrm{~F}_{\mathrm{qikn}}\right] \geq 0 \\
& \mathrm{~F}_{\mathrm{gks}}=\text { valor absoluto das ações permanentes estabilizantes; } \\
& \mathrm{F}_{\mathrm{gkn}}=\text { valor absoluto das ações permanentes não estabilizantes; } \\
& \mathrm{F}_{\text {qikn }}=\text { valor absoluto das ações variáveis não estabilizantes. }
\end{aligned}
$$

Esta verificação deve ser considerada como uma verificação adicional de estado limite último. 


\section{5 - DESVIOS CONSTRUTIVOS NÃO INTENCIONAIS}

Para estruturas de nós deslocáveis as normas sugerem a substituição da excentricidade adicional, que leva em consideração o desvio do ponto de aplicação das cargas nos pilares, por uma inclinação involuntária $\alpha$ dos pilares da estrutura em relação ao seu eixo teórico. Esta inclinação é determinada pela expressão tg $\alpha=1 / \mathrm{N}$. O valor de $\mathrm{N}$ depende da esbeltez do pilar e do grau de controle na sua execução. Supõe-se que esses desvios sejam crescentes com a esbeltez do pilar e com o precário controle na sua execução. A NBR 7187 sugere um valor de 150 para N, podendo ser alterado até o limite de 225 se o controle na execução do pilar for um controle especial. Apesar dos deslocamentos não ocorrerem na mesma ordem indicada, o esquema da fig. 6.15 mostra as considerações necessárias na análise de um pilar esbelto de concreto armado de uma ponte.

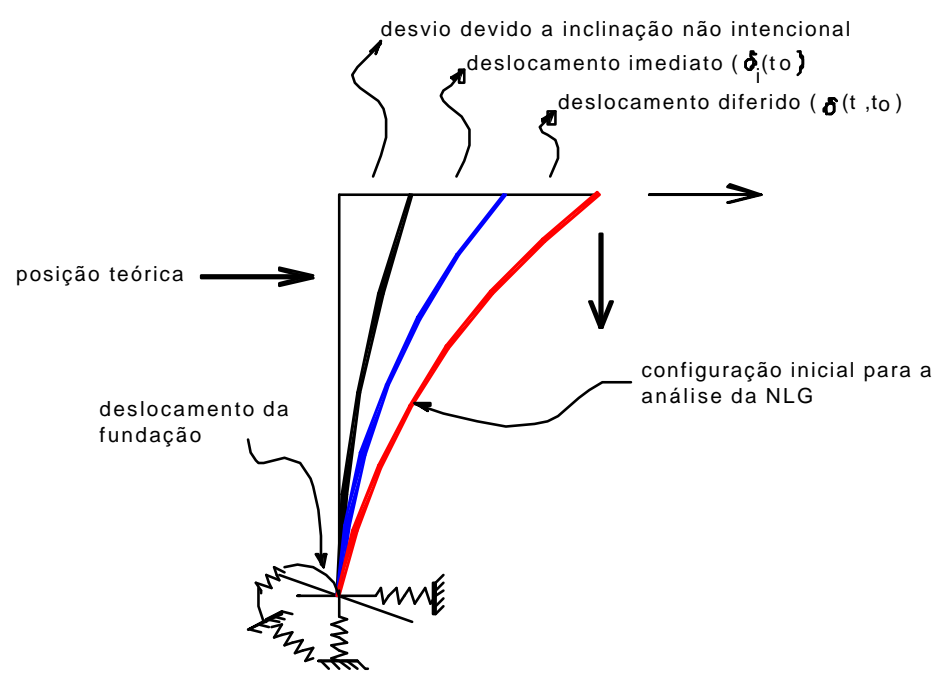

Fig. 6.15 - Esquema Geral para a Análise de um Pilar Esbelto 


\section{CAPÍTULO 7}

\section{EXEMPLOS NUMÉRICOS}

\section{1 - EXEMPLO 1: PILAR SIMPLES ISOLADO}

Os objetivos principais deste exemplo são: avaliar a influência do confinamento do tubulão em uma areia de consistência média submersa, e a influência da variação da rigidez da estrutura no comportamento do conjunto pilar tubulão. É feita uma simulação da extrapolação da ação de frenação da carga móvel.com o objetivo de observar os seus efeitos em uma estrutura previamente executada (Fig.7.1).

- Características Gerais: Pilar $\mathrm{P}_{1}$ do eixo 3 da Ponte sobre o Rio Mogi-Guaçu, trecho Ribeirão Preto-Bebedouro, estaca km 360 da SP 322.

- Altura do pilar a partir do topo do tubulão: $10 \mathrm{~m}$;

- Diâmetro do pilar: $1,30 \mathrm{~m}$

- Armadura longitudinal no pilar: $130 \mathrm{~cm}^{2}$ (26 \$25 mm, aço CA 50 classe A),

- $\quad$ Taxa da armadura: 0,98\%

- Armadura transversal no pilar: $\phi 8 \mathrm{c} / 20 \mathrm{~cm}$ (estribos circulares);

- Taxa volumétrica dos estribos: $0,0712 \%$ 


\section{Exemplos Numéricos}

- Concreto: C25 [fator redutor de 0,85, $\mathrm{f}_{\mathrm{cm}}=28,85 \mathrm{MPa}$, $\mathrm{E}_{\mathrm{cs}}=27279 \mathrm{MPa}$ (módulo de elasticidade secante)].

- Altura do tubulão: $15 \mathrm{~m}$ com trecho aéreo igual a $4 \mathrm{~m}$ e $11 \mathrm{~m}$ confinado no solo;

- Diâmetro: $1,60 \mathrm{~m}$ com base alargada de 3,5m apoiada no substrato rochoso;

- Armadura longitudinal no tubulão: $130 \mathrm{~cm}^{2}$ ( 26 ф25 mm, aço CA 50 classe A);

- Taxa da armadura: 0,65\%

- Armadura transversal no tubulão: $\phi 8 \mathrm{c} / 20 \mathrm{~cm}$ (estribos circulares);

- Taxa volumétrica dos estribos: 0,0585\%

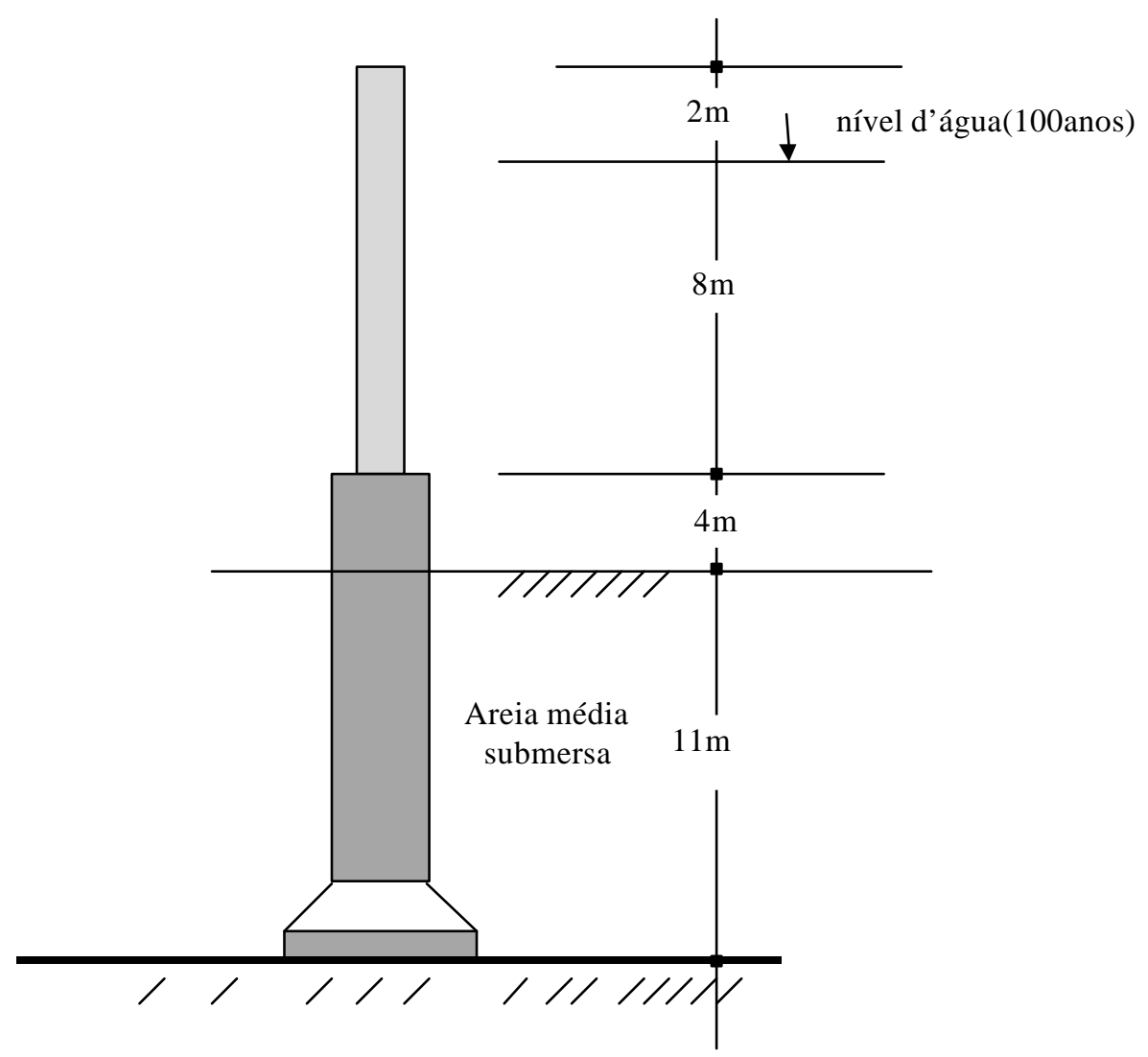

Fig. 7.1 - Esquema do pilar P1 do Eixo 3 


\section{Exemplos Numéricos}

Obs. A altura original do pilar de $4 \mathrm{~m}$ foi propositadamente alterada para $10 \mathrm{~m}$ com a intenção de simular um pilar presumivelmente esbelto com $\lambda$ acima de 80 .

- Seções transversais:

I- $\quad$ Pilar : $A=1,327 \mathrm{~m}^{2} ; \mathrm{I}=0,14 \mathrm{~m}^{4}$; núcleo central de inércia com raio igual $0,162 \mathrm{~m}, \mathrm{f}_{\mathrm{ck}}=25 \mathrm{Mpa}$

II- Tubulão : $\mathrm{A}=2,0 \mathrm{~m}^{2}, \mathrm{I}=0,3217 \mathrm{~m}^{4}$, núcleo central de inércia com raio igual $0,201 \mathrm{~m}$.

- Casos de rigidez analisados: $\mathrm{IE}_{\mathrm{cs}}, 0,8 \mathrm{IE}_{\mathrm{cs}}$, e (IE) $)_{\mathrm{ef}}=\mathrm{k} \mathrm{IE}_{\mathrm{cs}}$ com $\mathrm{k}$ igual a $\left(0,7+4,2 \rho_{\mathrm{t}} \mathrm{E}_{\mathrm{s}} / \mathrm{E}_{\mathrm{cs}}\right)$. Para o pilar $\mathrm{k}=1,016$ e para o tubulão $\mathrm{k}=0,91$.

- Ações consideradas:

Reação vertical de cálculo para a combinação mais desfavorável no Estado Limite Último: $\mathrm{R}_{\mathrm{d}}=7500 \mathrm{kN}$ ( superestrutura)

Peso próprio da infra-estrutura (pilar e tubulão);

Frenação de cálculo (distribuição do projeto original): $\mathrm{F}_{\mathrm{H}}=65 \mathrm{kN}$;

Ação transversal de cálculo do vento: $\mathrm{T}_{\mathrm{w}}=60 \mathrm{kN}$;

Ação da correnteza: $p_{a t}=0,34 \mathrm{~V}^{2}$ com $\mathrm{V}=2 \mathrm{~m} / \mathrm{seg}$; $\mathrm{p}_{\mathrm{at}}=1,36$ $\mathrm{kN} / \mathrm{m}^{2}$. Para o tubulão e pilar $\mathrm{q}_{\mathrm{t}}=2,17 \mathrm{kN} / \mathrm{m}$.

É previsto um desaprumo de $6 \mathrm{~cm}$ do topo do pilar com relação à sua base, equivalente a uma desvio angular não intencional do seu eixo igual a $\operatorname{tg} \alpha=1 / 225$.

Obs. A parcela da frenação absorvida pelo conjunto pilar-tubulão seguramente será menor, tendo em vista a alteração da altura do pilar de $4 \mathrm{~m}$ para $10 \mathrm{~m}$.

- Foram utilizados os seguintes elementos na modelagem :

BEAM4 [3-D ELASTIC BEAM(ANSYS)].para modelar o pilar e o tubulão; 
O solo é simulado de modo discreto pelo elemento de comportamento não linear denominado COMBIN39 (biblioteca do ANSYS).O Modelo de COX, REESE \& GRUBBS(1974), detalhado para a areia submersa no capítulo 6, é simulado através de três pontos principais para cada profundidade do solo(Fig.7.2).
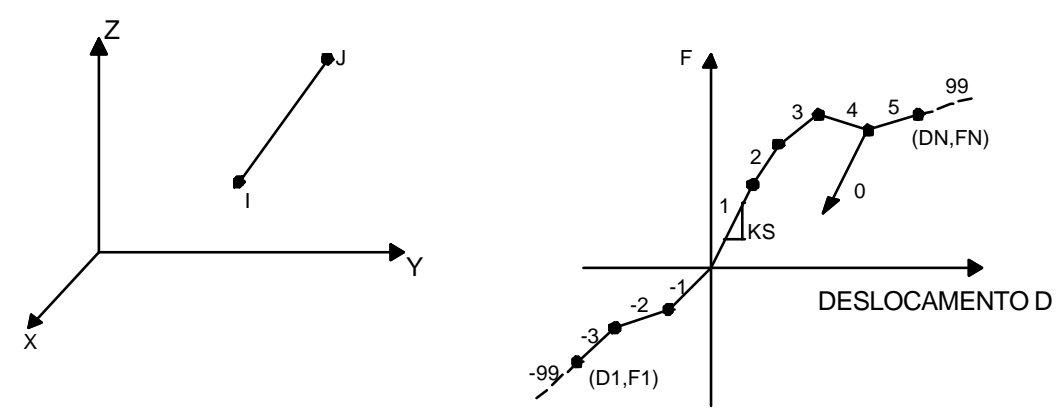

Fig. 7.2 - Elemento COMBIN39 (ANSYS)

$\underline{\text { Resultados da análise }}$

CASO 1: combinação da frenação, vento transversal, reação máxima da superestrutura, desvio acidental e correnteza. Hipóteses: Rigidez da seção bruta $\mathrm{E}_{\mathrm{cs}} \mathrm{I}$. Cálculo estático no regime linear elástico e com a consideração da nãolinearidade geométrica.
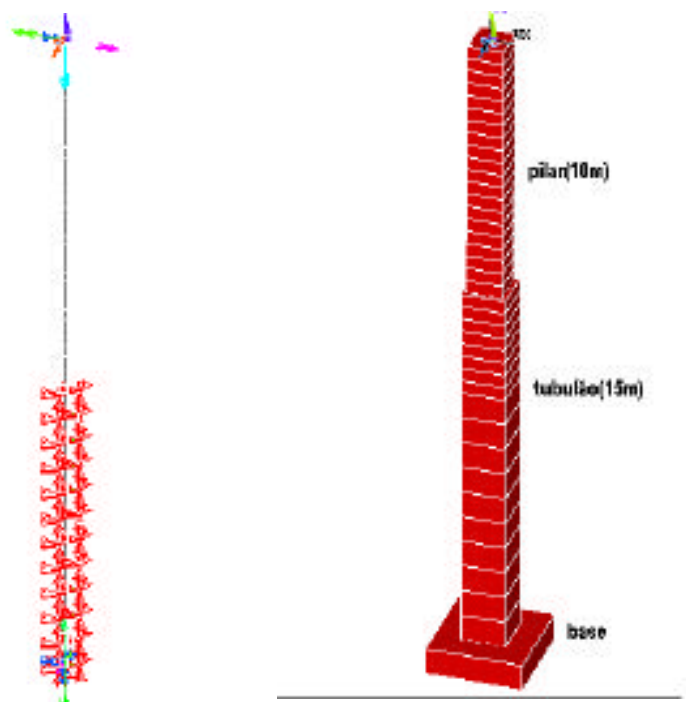

Fig. 7.3 - Discretização do solo e do conjunto pilar-tubulão

Resultados de deslocamentos : 
Exemplos Numéricos
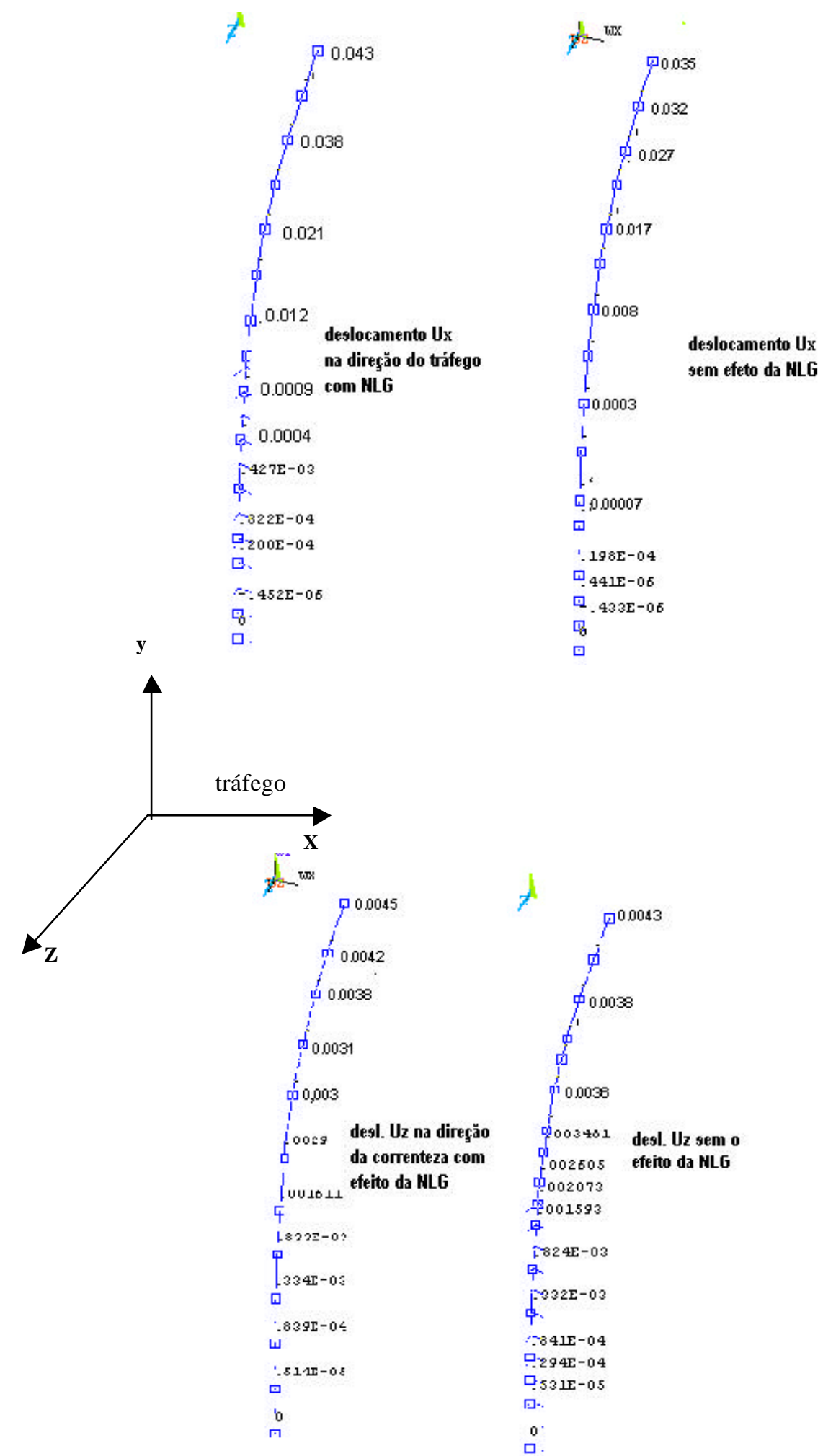

Fig.7.4 - Deslocamentos do conjunto nas direções x e z ( com e sem NLG)

Resultados de Momentos Fletores com NLG : 


\section{Exemplos Numéricos}
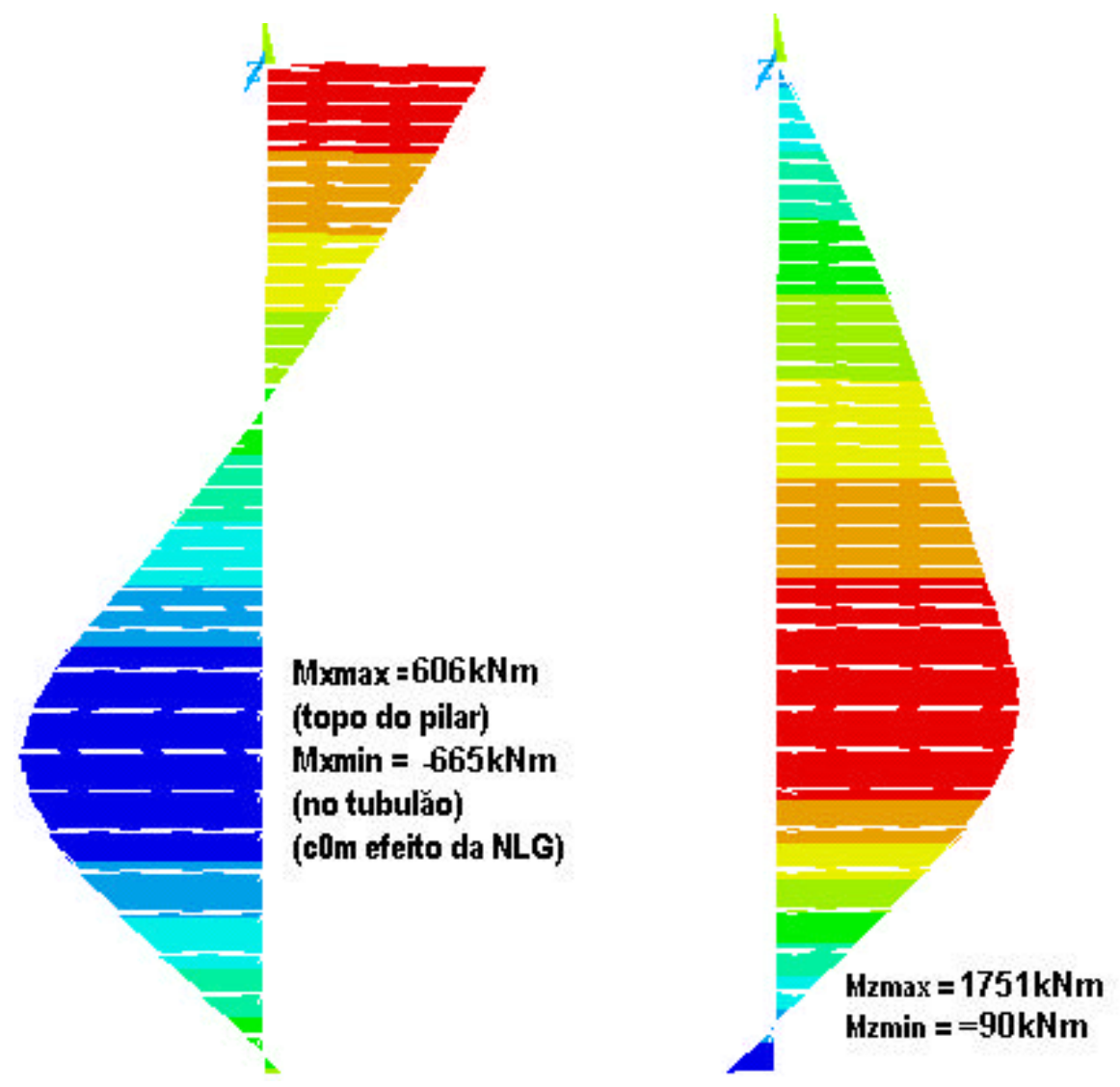

Fig. 7.5 - Momentos $\mathrm{M}_{\mathrm{z}}$ e $\mathrm{M}_{\mathrm{x}}$ com NLG

Na fig. 7.4 estão indicadas as elásticas do conjunto pilar - tubulão na direção do tráfego (eixo x) e nca direção transversal (eixo z). Na modelagem, o topo do pilar foi conderado com restrição a rotação na direção tranversal para simular o portico transversal.

Esforço normal de compressão na seção de momento fletor máximo: $\mathrm{N}=8300 \mathrm{kN}$. Na base do tubulão $\mathrm{N}=8550 \mathrm{kN}$.

Excentricidade do esforço normal na seção do máximo momento fletor no tubulão: 0,19m (dentro do núcleo central de inércia).

Excentricidade no topo do pilar: 0,077m (dentro do núcleo central de inércia)

Obs. Para as combinações de cálculo no estado limite último as seções não sofrem fissuração (pequena excentricidade) 


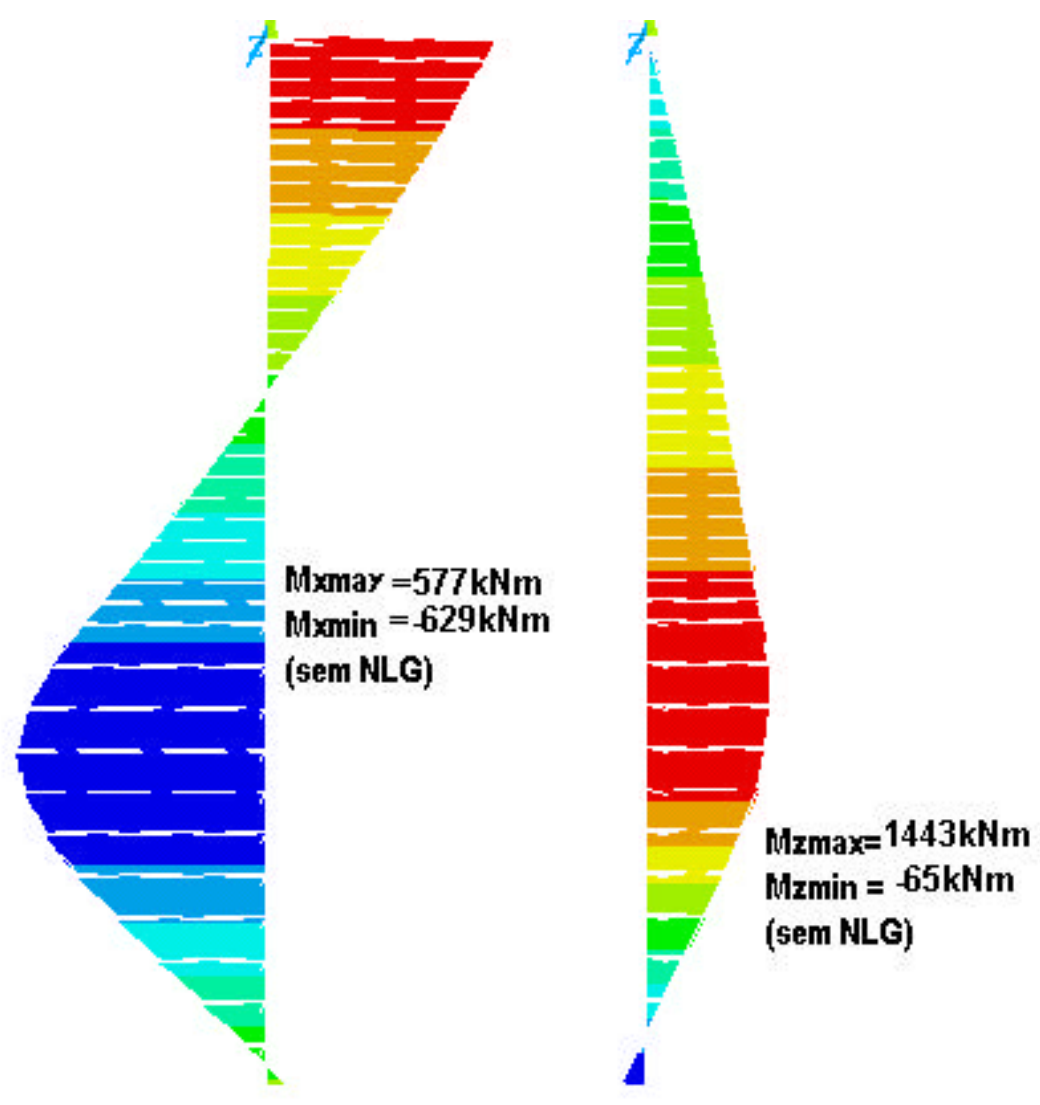

Fig. 7.6 - Momentos $\mathrm{M}_{\mathrm{x}}$ e $\mathrm{M}_{\mathrm{z}}$ sem NLG

Momento máximo Mz no fuste do tubulão: $\mathrm{M}_{\mathrm{z}}=1443 \mathrm{kN} . \mathrm{m}$;

Momento máximo Mx no topo do pilar: $\mathrm{M}_{\mathrm{x}}=577 \mathrm{kN}$.m;

Momento máximo Mx no fuste do tubulão: $M_{x}=-629 k N \cdot m$

Excentricidade da força normal : e $=0,182 \mathrm{~m}$ (dentro do núcleo central de inércia - pequena excentricidade)

CASO 2 : O mesmo carregamento do caso 1 porém com a rigidez reduzida para $0,8 \mathrm{E}_{\mathrm{cs}} \mathrm{I}$. 
Exemplos Numéricos

Resultados: deslocamentos (m)
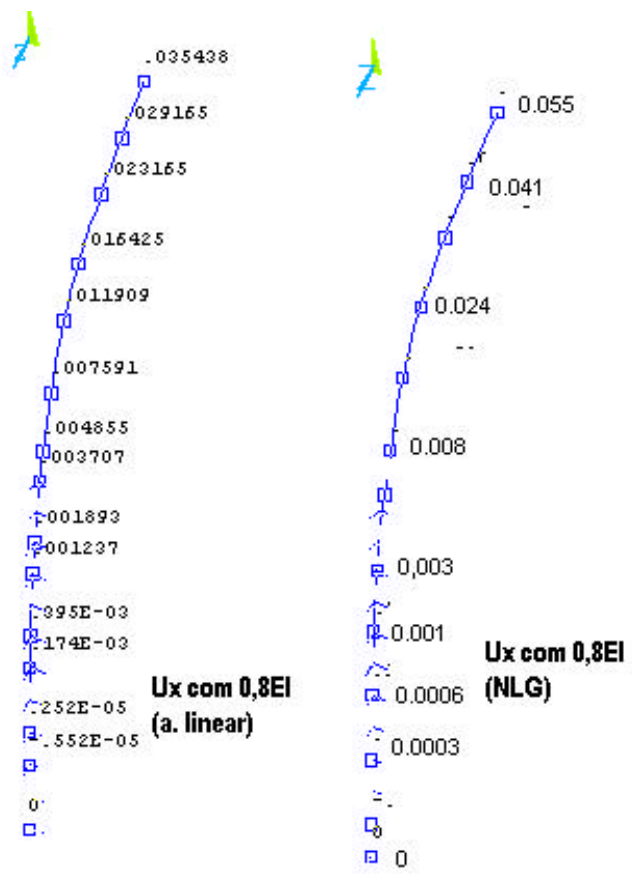

Fig. 7.7 Deslocamentos Ux para 0,80EI

Deslocamento máximo no topo do pilar = $55 \mathrm{~mm}(\mathrm{NLG})$;

Deslocamento máximo no topo do pilar $=35,4 \mathrm{~mm}$ (linear) 


\section{Exemplos Numéricos}
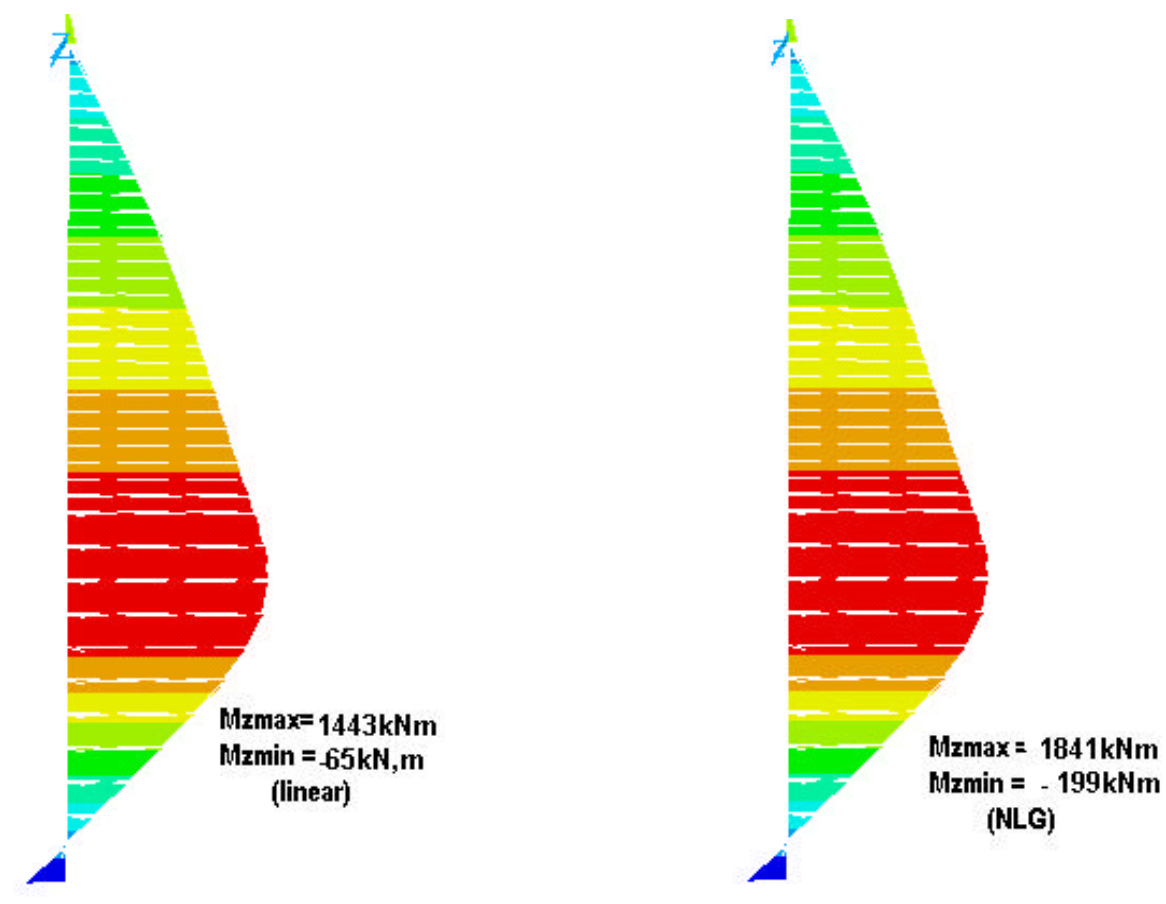

Fig. 7.8 Momento Fletor $M_{z}$ para a rigidez reduzida 0,8EI

A força normal é mantida no núcleo central de inércia apesar da redução da rigidez para $0,8 \mathrm{EI}$

Momento máximo no tubulão: $\mathrm{M}_{\mathrm{z}}=1841 \mathrm{kN}$.m (NLG)

Momento mínimo na base do tubulão $\mathrm{M}_{\mathrm{z}}=-199 \mathrm{kN} \cdot \mathrm{m}(\mathrm{NLG})$;

Momento máximo no tubulão: $\mathrm{M}_{\mathrm{z}}=1443 \mathrm{kN} \cdot \mathrm{m}$ (NLG)

Momento mínimo na base do tubulão: $\mathrm{M}_{\mathrm{z}}=-65 \mathrm{kN}$.m (NLG);

O efeito da não linearidade geométrica na seção de momento máximo é igual a 398 kN.m;

O deslocamento de segunda ordem no topo do pilar é igual a $20 \mathrm{~mm}$. 


\section{2 - EXEMPLO 2: PONTE FERROVIÁRIA}

- Características Gerais: Classe 32 (NB 7/43)

Superestrutura: Viga calha protendida invertida, simplesmente apoiada, com vão livre de $45 \mathrm{~m}$;

Aparelhos de apoio: neoprene fretado (dureza SHORE A 60), $80 \mathrm{x}$ $80 \mathrm{~cm}^{2}$ de base, com sete chapas de aço de $4 \mathrm{~mm}$ e 6 camadas intermediárias de $15 \mathrm{~mm}$ de neoprene;

Infraestrutura: constituída por tubulões com fuste de $120 \mathrm{~cm}$ de diâmetro e base alargada de $360 \mathrm{~cm}$ (fig. 7.9);

- Modelagem:

- Superestrutura: SHELL63 [ELASTIC SHELL(ANSYS)];

$\square$ tubulões e travessa dos tubulões: BEAM4 [3-D ELASTIC BEAM(ANSYS)];

neoprenes: CONTACT52 [3-D Point-to-Point (ANSYS)];

Solo: COMBIN14 [Spring - Damper (ANSYS)];

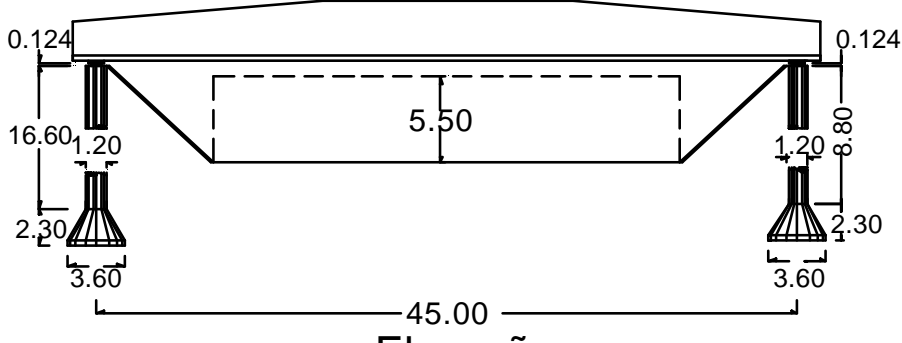

Elevação

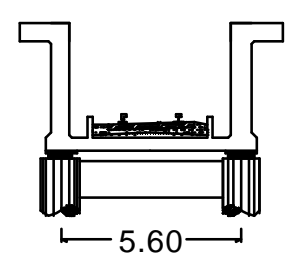

Seção Transversal

Fig. 7.9 - Esquema do Exemplo 2 
- Características Geométricas

tubulões $-\mathrm{A}=1,31 \mathrm{~m}^{2}, \mathrm{I}=0,102 \mathrm{~m}^{4}$, área da base: $\mathrm{A}_{\mathrm{b}}=10,18 \mathrm{~m}^{2}$, momento de inércia da base: $I_{b}=8,25 \mathrm{~m}^{4}$, concreto: $f_{c k}=18 \mathrm{MPa}, E_{c 28}=32 \times 10^{6}$ $\mathrm{kN} / \mathrm{m}^{2}$;

$\square \quad$ travessa dos tubulões $\left(40 \times 120 \mathrm{~cm}^{2}\right): A=0,48 \mathrm{~m}^{2} ; \mathrm{I}=0,058 \mathrm{~m}^{4}$;

- Constante de reação horizontal do solo:Areia

$\square$ para $\mathrm{SPT}<10 \Rightarrow \mathrm{m}_{\mathrm{h}}=5000 \mathrm{kN} / \mathrm{m}^{3}$, para $10 \leq \mathrm{SPT} \leq 30 \Rightarrow$ $\mathrm{m}_{\mathrm{h}}=10000 \mathrm{kN} / \mathrm{m}^{3}$, para SPT $\geq 30 \Rightarrow \mathrm{m}_{\mathrm{h}}=20000 \mathrm{kN} / \mathrm{m}^{3}$ [BOWLES (1977)];

\section{Eixo 1}

Camada superior: espessura - 12m (SPT <10)

Camada intermediária: espessura - 2m $(10 \leq \mathrm{SPT} \leq 30)$

Camada inferior: espessura - 4m (SPT $\geq 30)$

\section{Eixo 2}

Camada superior: espessura $-7,5 \mathrm{~m}(\mathrm{SPT}<10)$

Camada intermediária: espessura - 1m $(10 \leq \mathrm{SPT} \leq 30)$

Camada inferior: espessura - 2m (SPT $\geq 30)$

- Rigidez Horizontal do Solo: (comportamento linear elástico) :

camada superior $\Rightarrow \quad \mathrm{k}_{\mathrm{h}}=1 \mathrm{mx} 1,2 \mathrm{mx} 5000 \mathrm{kN} / \mathrm{m}^{3}=6000 \mathrm{kN} / \mathrm{m}$; camada intermediária $\Rightarrow \mathrm{k}_{\mathrm{h}}=1 \mathrm{mx} 1,2 \mathrm{mx} 10000 \mathrm{kN} / \mathrm{m}^{3}=12000 \mathrm{kN} / \mathrm{m}$; camada inferior $\Rightarrow \mathrm{k}_{\mathrm{h}}=1 \mathrm{mx} 1,2 \mathrm{mx} 20000 \mathrm{kN} / \mathrm{m}^{3}=24000 \mathrm{kN} / \mathrm{m}$ ( por metro de tubulão);

- Rigidez vertical do solo na base do tubulão:

Areia fina cinza compacta a muito compacta: $\mathrm{k}_{\mathrm{s}}=50000 \mathrm{kN} / \mathrm{m}^{3}$ (coef. de recalque vertical) $\Rightarrow \mathrm{k}_{\mathrm{v}}=\mathrm{A}_{\mathrm{b}} \mathrm{k}_{\mathrm{s}}=10,18 \mathrm{~m}^{2} \times 50000 \mathrm{kN} / \mathrm{m}^{3} \cong 509000 \mathrm{kN} / \mathrm{m}$; 


\section{Exemplos Numéricos}

- Rigidez a rotação do solo na base do tubulão:

$$
\mathrm{k} \phi=8,25 \mathrm{~m}^{4} \times 50000 \mathrm{kN} /\left(\mathrm{m}^{3} \mathrm{rd}\right)=412500 \mathrm{kNm} / \mathrm{rd}
$$

- Rigidez tangencial do solo na base do tubulão:

$$
\mathrm{k}_{\mathrm{H}}=\mathrm{A}_{\mathrm{b}} \mathrm{k}_{\mathrm{s}} \mu=10,18 \mathrm{~m} 2 \times 50000 \mathrm{kN} / \mathrm{m}^{3} \times 0,5 \cong 255000 \mathrm{kN} / \mathrm{m}(\mu=\text { coef. }
$$

de atrito solo/concreto);

- Aparelhos de Apoio deNeoprene

- Rigidez a distorção dos aparelhos de apoio: $S=0,64 \mathrm{~m}^{2}$, $\mathrm{G}=1000 \mathrm{kN} / \mathrm{m}^{2}, \mathrm{~h}=90 \times 10^{-3} \mathrm{~m} ; \mathrm{K}_{\mathrm{s}}=\mathrm{SG} / \mathrm{h}=7111 \mathrm{kN} / \mathrm{m}$; limite do esforço tangencial: $\mu\left|\mathrm{F}_{\mathrm{N}}\right| \mathrm{c} / \mu \approx 0,19$.

- Rigidez normal dos aparelhos de apoio: $B=13,33$ (fator de forma); $\mathrm{S}=0,64 \mathrm{~m}^{2} ; \quad \mathrm{G}=1000 \mathrm{kN} / \mathrm{m}^{2} ; \quad \mathrm{h}=90 \times 10^{-3} \mathrm{~m} ; \quad \mathrm{E}=4 \mathrm{~B}^{2} \mathrm{G}+3 \sigma_{\mathrm{m}} ; \quad \mathrm{E}=743756 \mathrm{kN} / \mathrm{m}^{2}, \quad \mathrm{p} /$ $\sigma_{\mathrm{m}}=11 \mathrm{Mpa} ;$ rigidez normal $-\mathrm{K}_{\mathrm{N}} \cong \mathrm{SE} / \mathrm{h}=5,0 \mathrm{E}+6 \mathrm{kN} / \mathrm{m}$.

- Carregamento:

\section{Verticais}

a) Cargas Permanentes

a.1) Peso: superestrutura $\mathrm{g}_{1}=177,50 \mathrm{kN} / \mathrm{m}$, ou $1996,90 \mathrm{kN} /$ neoprene a.2 ) Peso: lastro, dormentes, trilhos e pavimento $\mathrm{g}_{2}=45,20 \mathrm{kN} / \mathrm{m}$, ou $508,50 \mathrm{kN} /$ neoprene

a.3) Peso da infraestrutura $\left(\gamma=25 \mathrm{kN} / \mathrm{m}^{3}\right)$

b) Cargas Móveis - Trem-tipo TB-32

b.1) Trem-tipo sem impacto vertical

Eixo 1: $\mathrm{R}_{1 \max .}=1700 \mathrm{kN} /$ neoprene 


\section{Exemplos Numéricos}

Eixo 2: $\mathrm{R}_{2 \text { comp. }}=1220 \mathrm{kN} /$ neoprene $\left[\right.$ Compatível/ $\mathrm{R}_{1 \text { max.] }}$; impacto vertical: $\varphi=1,3$

b.2) Multidão nos passeios

$\mathrm{R}_{\mathrm{m}}=43,0 \mathrm{kN} /$ neoprene

Ações horizontais longitudinais:

a) Cargas aplicadas

a.1) Aceleração/Frenagem (NBR 7187 - 7.2.1.5);

$\mathrm{F}_{\mathrm{ac} .}=25 \%(8 \times 320)=640 \mathrm{kN}$;

$F_{\text {fren. }}=15 \%(160+8 \times 210+8 \times 320+13,80 \times 100)=891 \mathrm{kN}$;

$\mathrm{F}_{\text {fren. }}=222,75 \mathrm{kN} /$ neoprene.

a.2) Empuxo/Sobrecarga :Empuxo unilateral devido à sobrecarga no aterro:

$\mathrm{E}=70 \mathrm{kN}$ ou $\mathrm{E}=17,5 \mathrm{kN} /$ neoprene

b) Deformações impostas

b.1) Deformação inicial (pós-tensão)

$\mathrm{N}_{\mathrm{c} / \mathrm{p}}=-38470 \mathrm{kN}, \mathrm{A}_{\mathrm{c}}=7,10 \mathrm{~m}^{2}, \sigma_{\mathrm{cm}}=5419 \mathrm{kN} / \mathrm{m}^{2}, \mathrm{E}_{\mathrm{c}}=32 \mathrm{E}+6$ $\mathrm{kN} / \mathrm{m}^{2} ; \varepsilon_{\mathrm{i}}=-16,9 \mathrm{E}-5$, ou $\Delta \mathrm{t} \cong-17^{\circ} \mathrm{C}$

b.2) Variação de temperatura na superestrutura

$$
\Delta \mathrm{t} \cong \pm 15^{\circ} \mathrm{C}
$$

b.3) Retração do concreto na superestrutura

Período: 50 anos $\Rightarrow \varepsilon_{\mathrm{i}}=-23,7 \mathrm{E}-5$, ou $\Delta \mathrm{t} \cong-24{ }^{\circ} \mathrm{C}$; queda devido à retração: $3,9 \%$

b.4) Encurtamento da superestrutura devido à fluência

Período: 30 dias-50 anos $\Rightarrow \varepsilon_{\mathrm{i}}=-29,7 \mathrm{E}-5$, ou $\Delta \mathrm{t} \cong-30{ }^{\circ} \mathrm{C}$; queda devido à fluência: $4,7 \%$

Ações horizontais transversais: 


\section{Exemplos Numéricos}

a) Ação transversal do vento

$\mathrm{H}_{\mathrm{t}, \text { carregada }}=160 \mathrm{kN}$ ou $\mathrm{H}_{\mathrm{t}, \text { carregada }}=40 \mathrm{kN} /$ neoprene

b) Carga vertical (efeito do tombamento do vento)

$\mathrm{N}_{\mathrm{v}}= \pm 80 \mathrm{kN} /$ neoprene

c) Força Centrífuga - bitola larga $(\mathrm{R}<1200 \mathrm{~m})$

$\mathrm{H}_{\mathrm{c} 1}=0,15 \mathrm{R}_{1 \max }=0,15 \times 1700=255 \mathrm{kN} /$ neoprene; $\mathrm{H}_{\mathrm{c} 2}=0,15 \mathrm{R}_{2 \mathrm{comp}}=$ $0,15 \times 1220=183 \mathrm{kN} /$ neoprene;

d) Carga vertical (efeito do tombamento);

$\mathrm{V}_{\mathrm{c} 1}= \pm 242 \mathrm{kN} /$ neoprene, $\mathrm{V}_{\mathrm{c} 2}= \pm 173 \mathrm{kN} /$ neoprene.

- Combinações das cargas

A - condições de serviço

- Pilha 1: Caso da Seqüência Rara das Ações

$\mathrm{C}_{1} \rightarrow \mathrm{C}_{2} \rightarrow \mathrm{C}_{3} \rightarrow \mathrm{C}_{4} \rightarrow \mathrm{C}_{5} \rightarrow \mathrm{C}_{6} \rightarrow \mathrm{C}_{7} \rightarrow \mathrm{C}_{8} \rightarrow \mathrm{C}_{9} \rightarrow 0,7 \mathrm{C}_{10} \rightarrow \mathrm{C}_{11}$

\begin{tabular}{|c|c|c|c|}
\hline $\begin{array}{l}\text { CARGA } \\
\mathrm{C}_{\mathrm{j}} \\
\end{array}$ & $\gamma_{\mathrm{J}} \mathrm{F}_{\mathrm{jk}}$ & $\gamma_{j}$ & OBSERVAÇÃO \\
\hline $\mathrm{C}_{1}$ & $\gamma_{\mathrm{g}} \mathrm{F}_{\mathrm{gk}}$ & 1,0 & $\begin{array}{c}\text { Peso das colunas e infra-estrutura } \\
\text { Peso da superestrutura } \\
\text { (geração automática ) }\end{array}$ \\
\hline $\mathrm{C}_{2}$ & $\gamma_{\mathrm{g}} \mathbf{F}_{\mathrm{gk}}$ & 1,0 & Permanente complementar $\left(\mathrm{g}_{2}=45,20 \mathrm{kN} / \mathrm{m}\right)$ \\
\hline $\mathbf{C}_{3}$ & $\gamma_{\varepsilon} F_{\varepsilon k}$ & 1,0 & $\begin{array}{l}\text { Def. inicial - pós-tensão na superestrutura }(\Delta t= \\
\left.\qquad-17^{\circ} \mathrm{C}\right) \rightarrow \text { ação equivalente }\end{array}$ \\
\hline $\mathbf{C}_{4}$ & $\gamma_{\varepsilon} F_{\varepsilon k}$ & 1,0 & $\begin{array}{c}\text { Fluência na superestrutura }\left(\Delta t \cong-30^{\circ} \mathrm{C}\right) \rightarrow \text { ação } \\
\text { equivalente }\end{array}$ \\
\hline $\mathbf{C}_{5}$ & $\gamma_{\varepsilon} F_{\varepsilon k}$ & 1,0 & Retração do tabuleiro $\left(\Delta t \cong-24^{\circ} \mathrm{C}\right)$ \\
\hline $\mathrm{C}_{6}$ & $\gamma_{\varepsilon} \mathbf{F}_{\varepsilon k}$ & 1,0 & $\begin{array}{l}\text { Variação de temperatura (curta dur.) } \\
\qquad\left(\Delta t \cong \pm 15^{\circ} \mathrm{C}\right)\end{array}$ \\
\hline $\mathbf{C}_{7}$ & $\gamma_{q} F_{q k}$ & 0,7 & $\begin{array}{l}\text { Sobrecarga na superestrutura } \\
\qquad(\mathbf{q}=\mathbf{3 , 8} \mathbf{8 N} / \mathbf{m})\end{array}$ \\
\hline $\mathrm{C}_{8}$ & $\gamma_{\mathbf{q}} \mathbf{F}_{\mathbf{j k}}$ & 1,0 & $\begin{array}{l}\text { Carga móvel (frenagem e empuxo da } \\
\text { sobrecarga no aterro de acesso) }\end{array}$ \\
\hline
\end{tabular}


Exemplos Numéricos

\begin{tabular}{|c|c|c|c|}
\hline \multicolumn{3}{|l|}{ Cont....... } & $\mathrm{H}=891+70=961 \mathrm{kN}$ \\
\hline \multirow[t]{3}{*}{$\mathbf{C}_{9}$} & $\gamma_{q} F_{q k}$ & 1,0 & Eixo 1: $R_{1 \text { max. }}=1700 \mathrm{kN} /$ neoprene \\
\hline & & & $\begin{array}{c}\text { Eixo } 2 \text { : } \mathbf{R}_{2 \text { comp. }}=1220 \mathrm{kN} / \text { neoprene [Compatível } \\
\left.\mathrm{c} / \mathbf{R}_{1 \text { max. }}\right]\end{array}$ \\
\hline & & & Impacto vertical: $\varphi=1,3$ \\
\hline \multirow[t]{3}{*}{$\mathrm{C}_{10}$} & $\boldsymbol{\gamma}_{\mathbf{q}} \mathbf{F}_{\mathrm{qk}}$ & 0,7 & Vento - transversal \\
\hline & & & $H_{t, \text { carregada }}=40 \mathrm{kN} /$ neoprene \\
\hline & & & $N_{v}= \pm 80 \mathrm{kN} /$ neoprene \\
\hline \multirow[t]{7}{*}{$\mathrm{C}_{11}$} & $\gamma_{\mathbf{q}} \mathbf{F}_{\mathbf{j k}}$ & 1.0 & Força Centrífuga - bitola larga $(\mathrm{R}<1200 \mathrm{~m})$ \\
\hline & & & $H_{c 1}=0,15 R_{1 \max }=0,15 \times 1700$ \\
\hline & & & $=255 \mathrm{kN} /$ neoprene \\
\hline & & & $H_{c 2}=0,15 R_{2 c o m p}=0,15 \times 1220$ \\
\hline & & & $=183 \mathrm{kN} /$ neoprene \\
\hline & & & Carga vertical (efeito do tombamento) \\
\hline & & & $V_{c 1}= \pm 242 \mathrm{kN} /$ neoprene, $V_{c 2}= \pm 173 \mathrm{kN} /$ neoprene \\
\hline
\end{tabular}

Cargas de curta duração $\left(\mathrm{t}_{\mathrm{ji}} \cong \mathrm{t}_{\mathrm{j} f}\right)$

B - Pilha complementar: situação limite

- Pilha 2 : Sequiência Complementar Desfavorável.

$$
0,35 \mathrm{C}_{12} \rightarrow 0,35 \mathrm{C}_{13} \rightarrow 0,2 \mathrm{C}_{14} \rightarrow 0,05 \mathrm{C}_{15} \rightarrow 0,5 \mathrm{C}_{16} \rightarrow 0,5 \mathrm{C}_{17} \rightarrow 0,05 \mathrm{C}_{18}
$$
$\rightarrow 0,05 \mathrm{C}_{19} \rightarrow 0,50 \mathrm{C}_{20}$

\begin{tabular}{|cccc|}
\hline CARGA $C_{j}$ & $\gamma_{\mathbf{j}} \mathrm{F}_{\mathbf{j k}}$ & $\gamma_{j}$ & OBSERVAÇÃO \\
\hline \hline$C_{12}$ & $\boldsymbol{\gamma}_{\mathbf{j}} \mathbf{F}_{\mathbf{j k}}$ & $\mathbf{0 , 3 5}$ & Peso da superestrutura \\
& & & Peso da infra-estrutura \\
$C_{13}$ & $\boldsymbol{\gamma}_{\mathbf{j}} \mathbf{F}_{\mathbf{j k}}$ & $\mathbf{0 , 3 5}$ & Permanente complementar \\
$C_{14}$ & $\boldsymbol{\gamma}_{\mathbf{j}} \mathbf{F}_{\mathbf{j k}}$ & $\mathbf{0 , 2 0}$ & Def. inicial: pós - tensão na superestrutura \\
$C_{15}$ & $\boldsymbol{\gamma}_{\mathbf{j}} \mathbf{F}_{\mathbf{j k}}$ & $\mathbf{0 , 0 5}$ & Sobrecargas na superestrutura \\
$\mathrm{C}_{16}$ & $\boldsymbol{\gamma}_{\mathbf{j}} \mathbf{F}_{\mathbf{j k}}$ & $\mathbf{0 , 5 0}$ & Carga móvel vertical ferroviária \\
$\mathrm{C}_{17}$ & $\boldsymbol{\gamma}_{\mathbf{j}} \mathbf{F}_{\mathbf{j k}}$ & $\mathbf{0 , 5 0}$ & Carga móvel ( frenagem ferroviária) \\
$\mathrm{C}_{18}$ & $\boldsymbol{\gamma}_{\mathbf{j}} \mathbf{F}_{\mathbf{j k}}$ & $\mathbf{0 , 0 5}$ & Empuxo do aterro de acesso \\
$\mathrm{C}_{19}$ & $\boldsymbol{\gamma}_{\mathbf{j} \mathbf{j}} \mathbf{F}_{\mathbf{j k}}$ & $\mathbf{0 , 0 5}$ & Pressão do vento \\
$\mathbf{C}_{\mathbf{2 0}}$ & $\boldsymbol{\gamma}_{\mathbf{j}} \mathbf{F}_{\mathbf{j k}}$ & $\mathbf{0 , 5 0}$ & Força centrífuga \\
\hline
\end{tabular}




\section{Exemplos Numéricos}

Situação de carregamento crítico: Pilha $1 \rightarrow$ Pilha 2

\section{Modelagem}

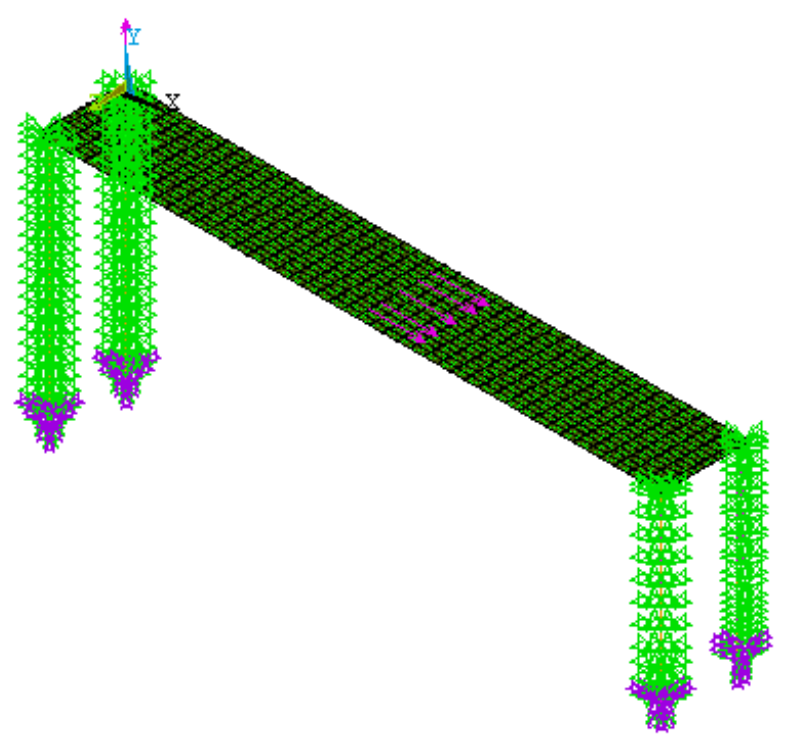

Fig. 7.10 - Detalhes do modelo - Exemplo 2 Discretização - vista geral e modelagem do solo

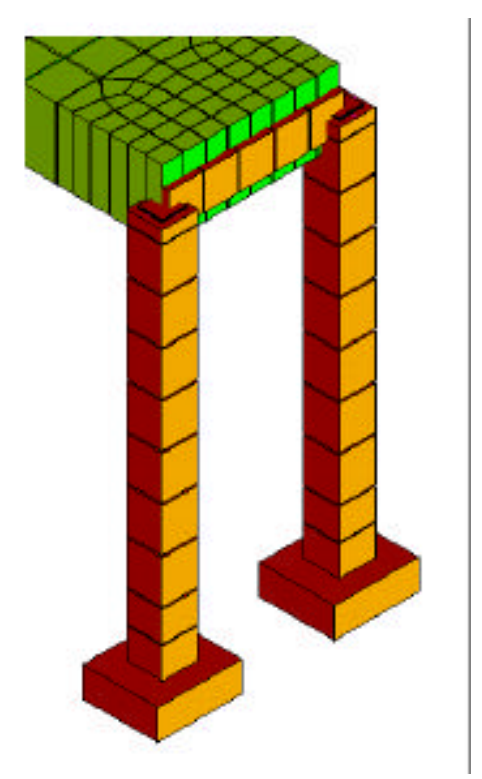

Fig. 7.11 - Pórtico de Apoio do Eixo 2 


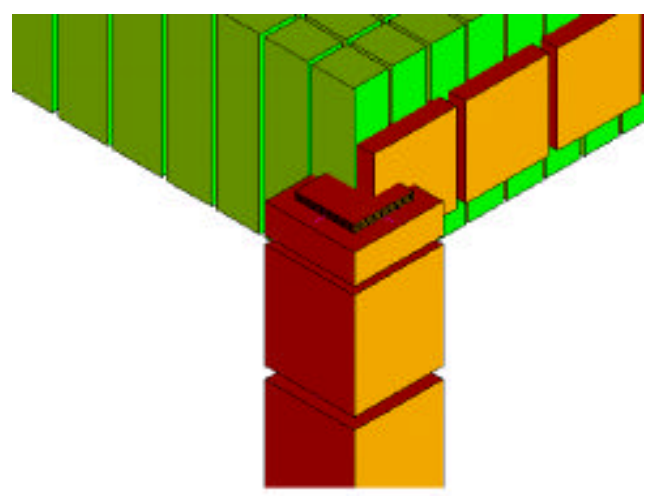

Fig. 7.12 - Detalhe do Aparelho de Apoio de Neoprene

- Casos de carregamento:
A) Pilha 3: $\mathrm{P}_{3}=\mathrm{C}_{1} \rightarrow \mathrm{C}_{2 \rightarrow} \mathrm{C}_{8 \rightarrow} \mathrm{C}_{9}$
$\mathrm{C}_{1}=$ peso próprio $\left(\mathrm{g}_{1}\right)$;
$\mathrm{C}_{2}=$ peso complementar $\left(\mathrm{g}_{2}\right)$;
$\mathrm{C}_{8}=$ frenagem;
$\mathrm{C}_{9}=$ carga móvel vertical

Momento Fletor $\mathrm{M}_{\mathrm{z}}$
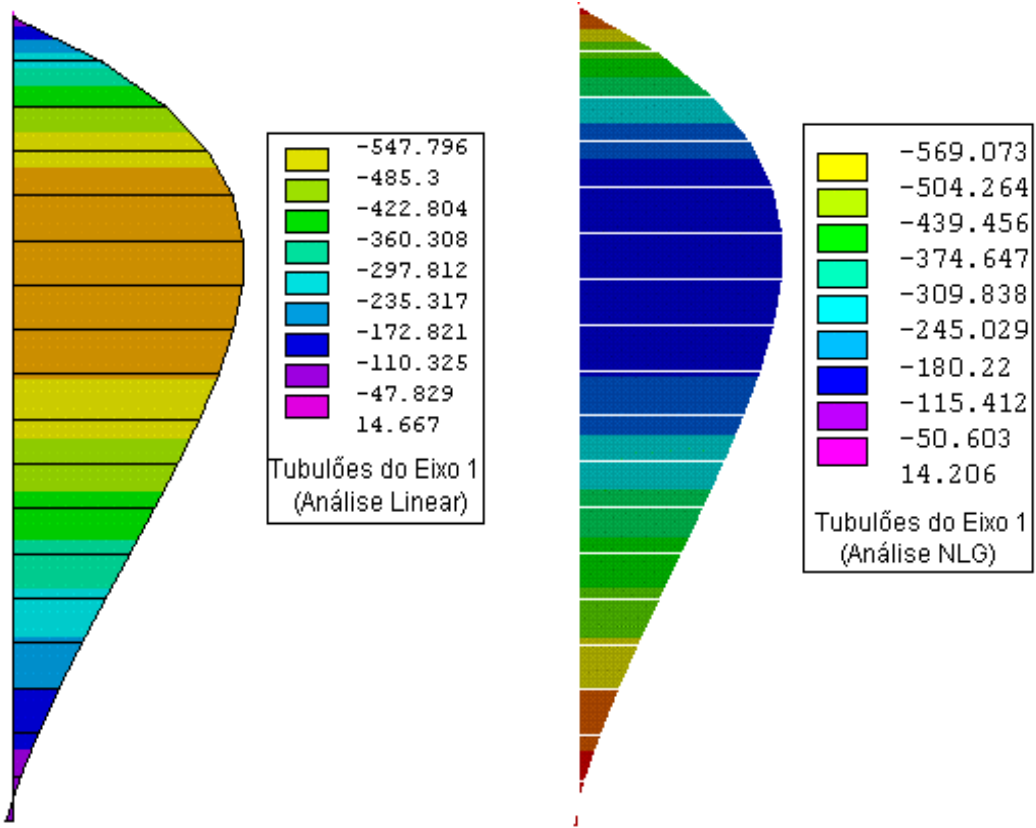

Fig. $7.13-\mathrm{M}_{\mathrm{Z}}$ no Tubulão T2 do Eixo 1 (Pilha 3) 


\section{Exemplos Numéricos}

- Esforços horizontais longitudinais nos aparelhos de apoio:

Analise linear

Eixo 1(T2): $F_{x}=248,82 \mathrm{kN}$

Eixo 2(T4): $F_{x}=232,09 \mathrm{kN}$

Analise NLG

Eixo 1(T2): $F_{x}=248,08 \mathrm{kN}$

Eixo 2(T4): $F_{x}=231,09 \mathrm{kN}$

Observações: Houve uma inversão de curvatura nos tubulões do eixo 1 com pequeno momento reativo na sua base. A alteração dos momentos fletores longitudinais é pouco significativa no que se refere a adoção ou não da análise com não linearidade geométrica $(\cong 4 \%)$.

Deslocamento Longitudinal $\mathrm{U}_{\mathrm{x}}$

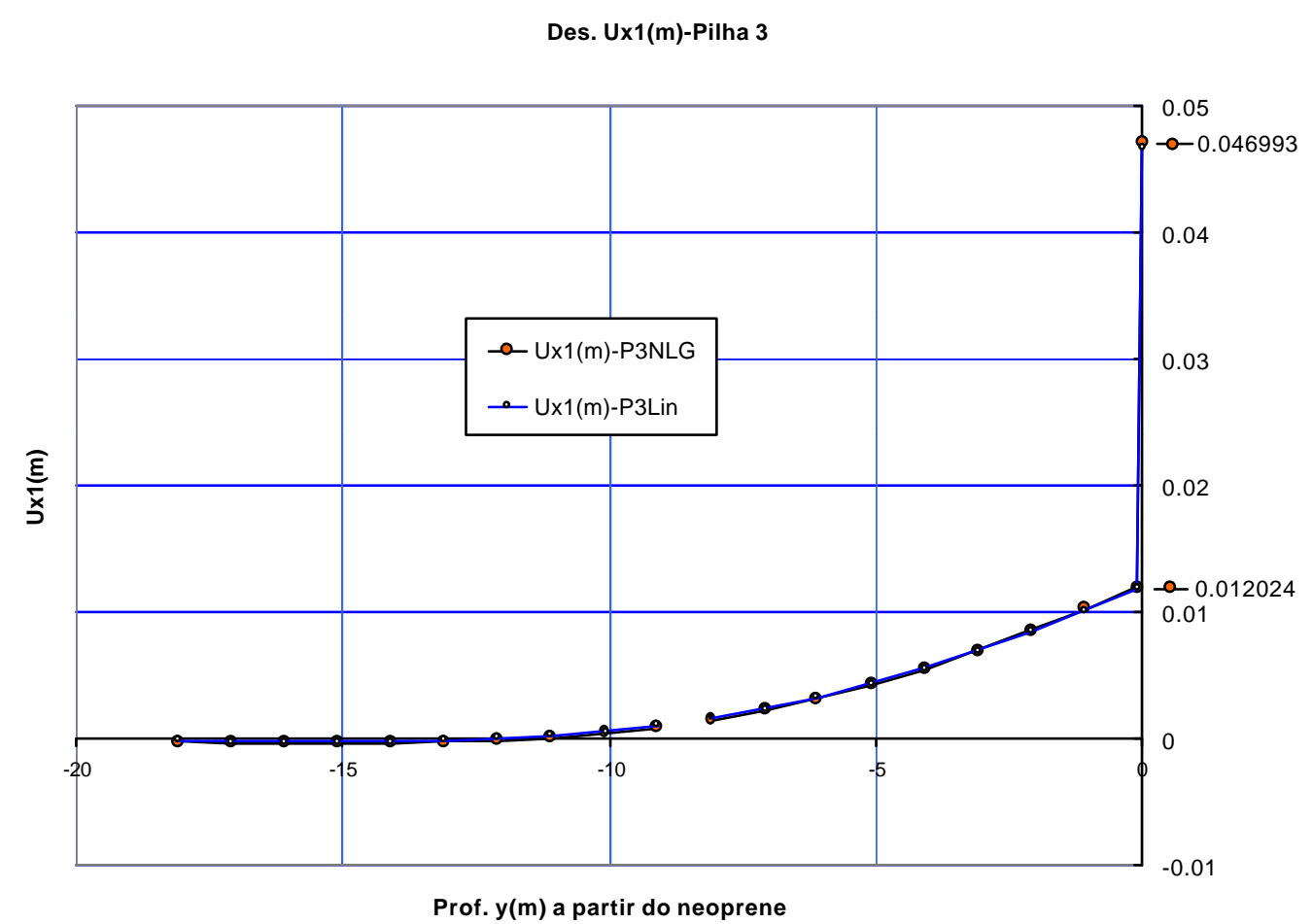

Fig. 7.14 - Deslocamentos $\mathrm{U}_{\mathrm{x}}(\mathrm{m})$ no Tubulão $\mathrm{T} 2$ do Eixo 1

Distorção do aparelho de apoio (NLG): $\operatorname{tg} \gamma=0.3885$ 
Exemplos Numéricos

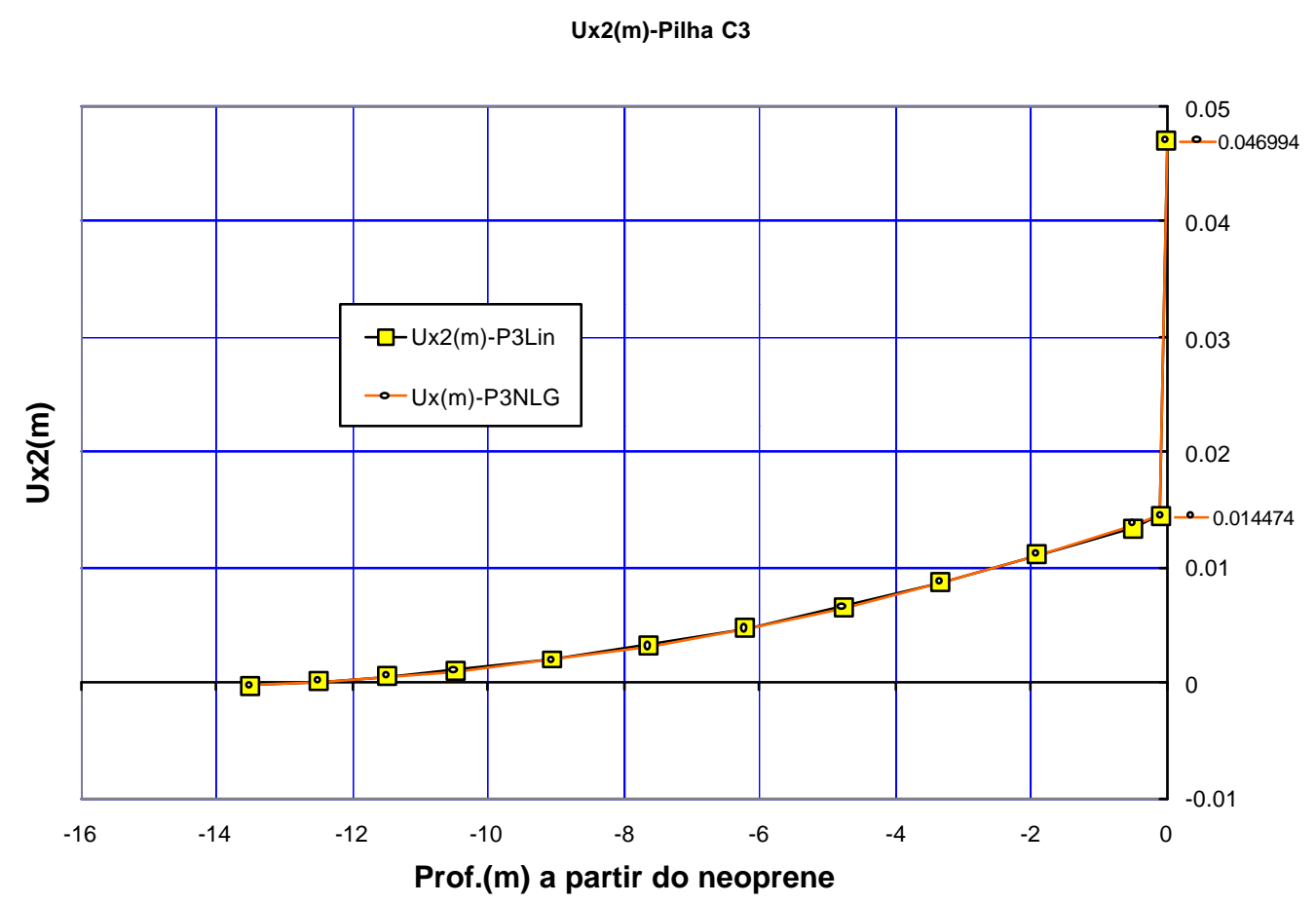

Fig. 7.15 - Deslocamentos $U_{\mathrm{x}}(\mathrm{m})$ no Tubulão T4 do Eixo 2

Distorção do aparelho de apoio (NLG): $\operatorname{tg} \gamma=0.3613$

B) Pilha 1 : Sequiência Rara das ações

$\underline{\text { Momento Fletor } \mathrm{M}_{\mathrm{z}}}$
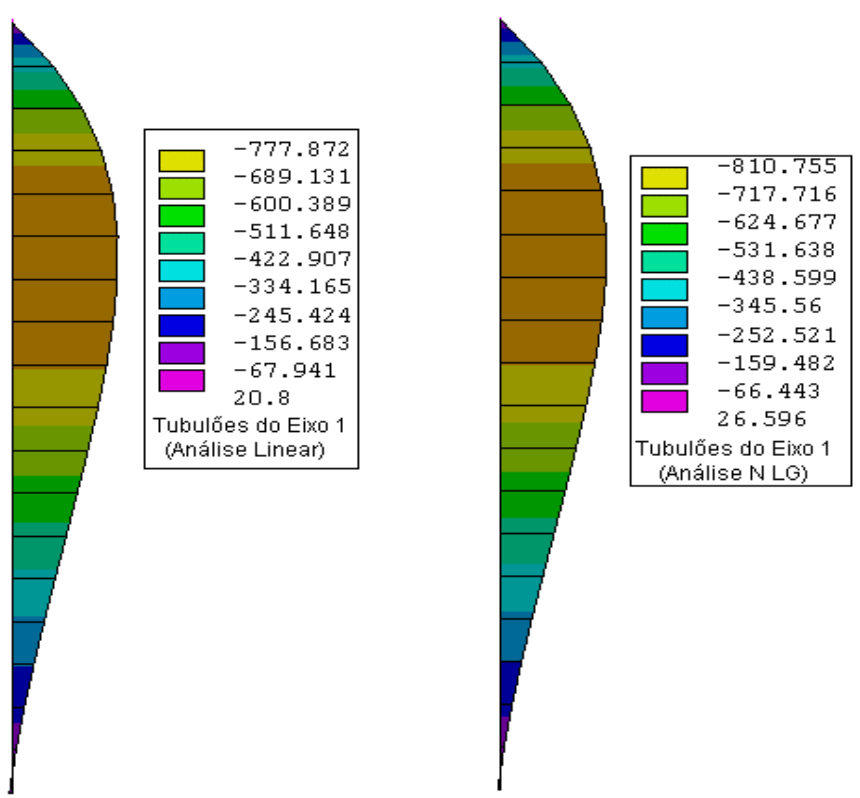

Fig. 7.16 $-\mathrm{M}_{\mathrm{z}}$ no Eixo 1(T2) para Pilha 1 de Ações 
Exemplos Numéricos

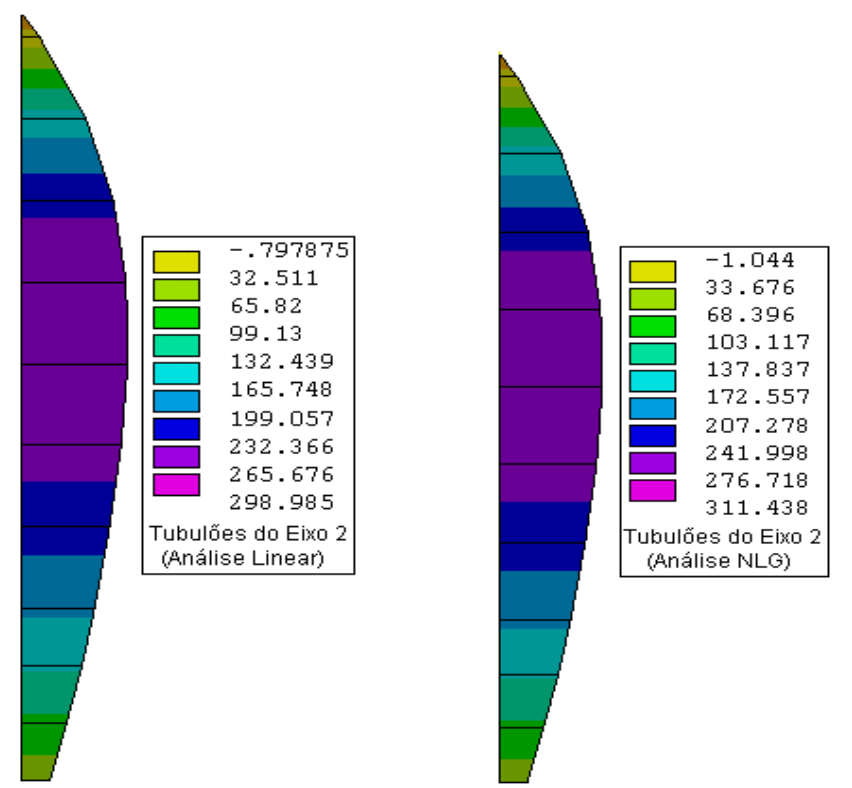

Fig. 7.17 $-\mathrm{M}_{\mathrm{z}}$ no Eixo 2(T4) para Pilha 1 de Ações

Deslocamento Longitudinal $\mathrm{U}_{\mathrm{x}}$

Ux1(m)-Pilha 1

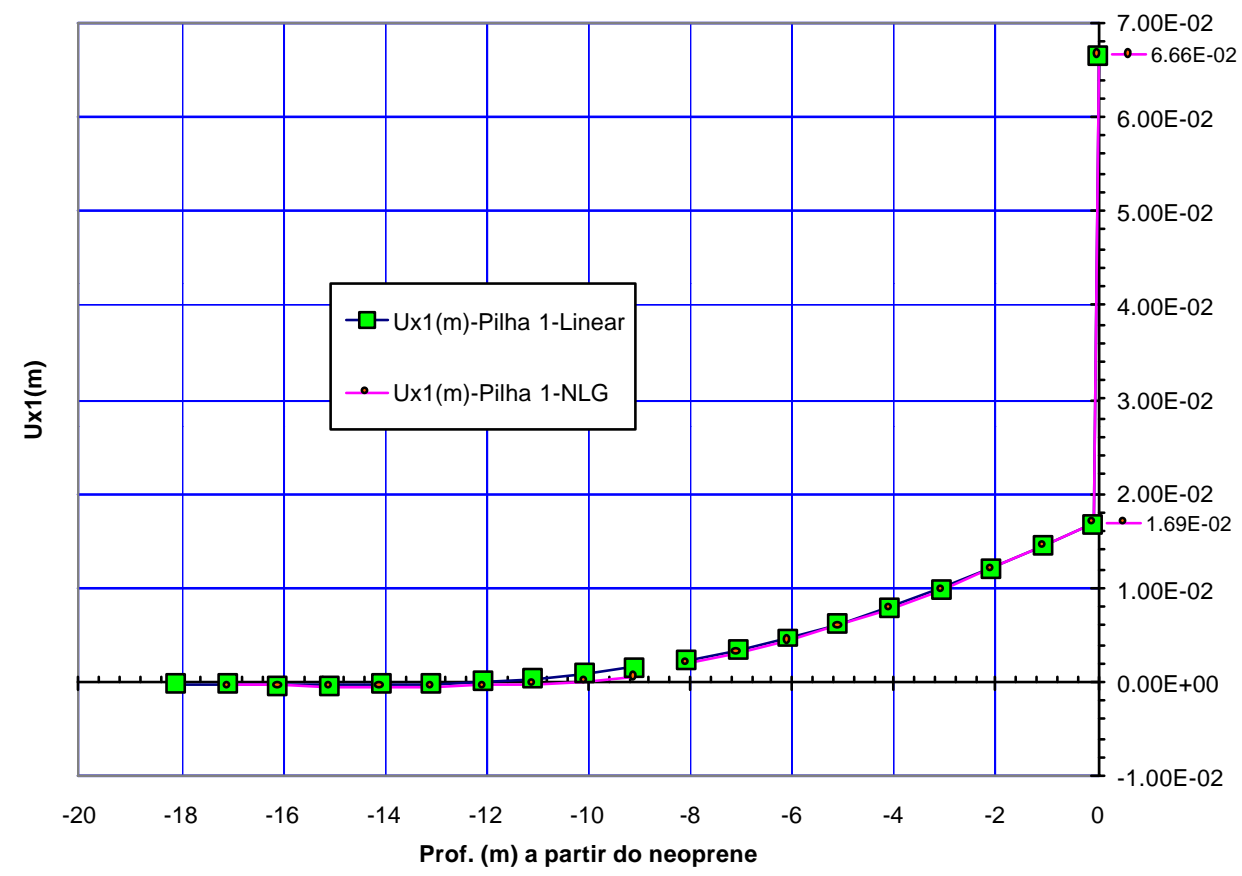

Fig. - 7.18 - Deslocamento $\mathrm{U}_{\mathrm{x}}$ nos Tubulões do Eixo 1(T2) 
Exemplos Numéricos

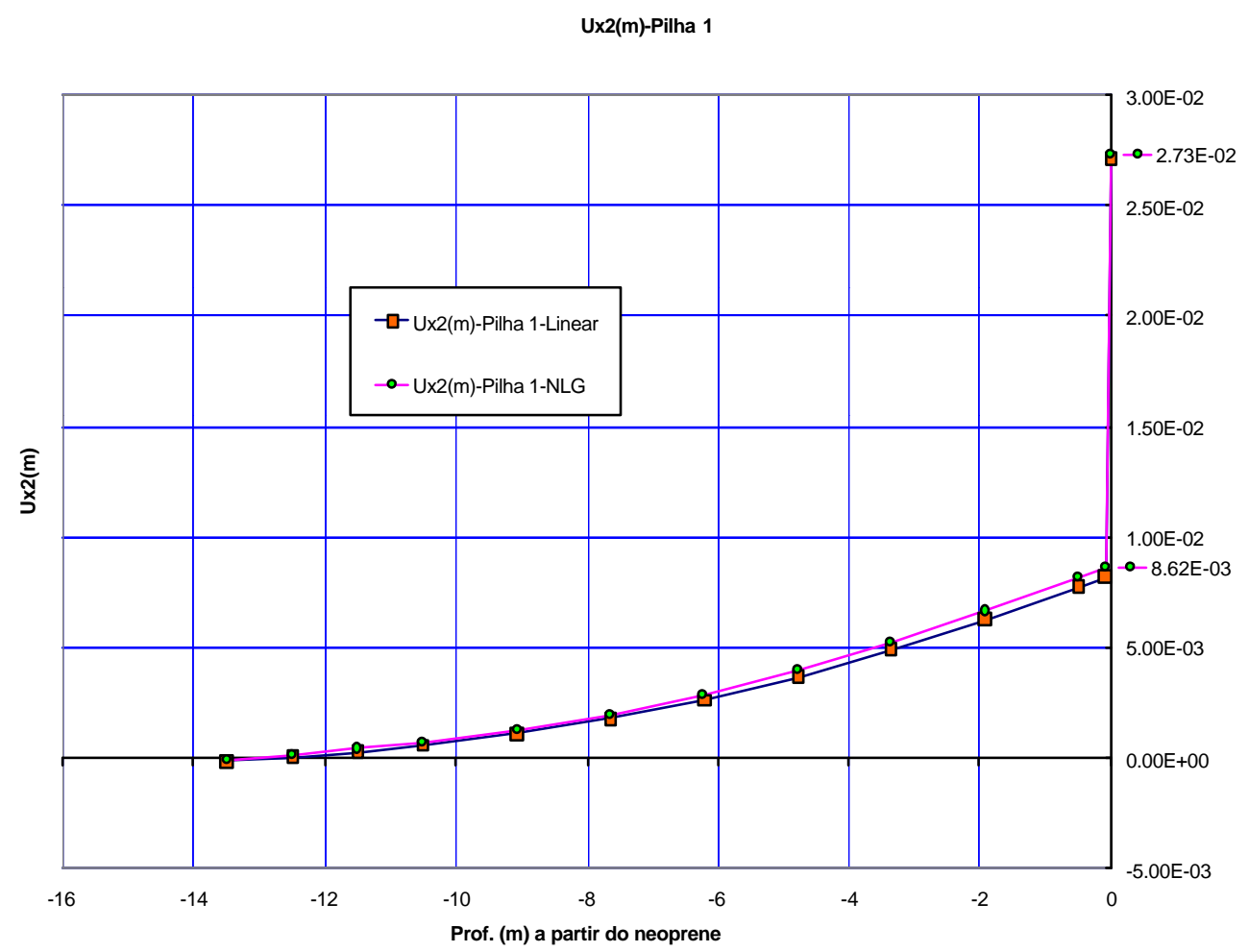

Fig. 7.19 - Deslocamento $\mathrm{U}_{\mathrm{x}}$ nos Tubulões do Eixo 2(T4)

- Esforços horizontais longitudinais nos aparelhos de apoio:

- Analise linear - Pilha 1

Eixo 1(T1): $F_{x}=345,74 \mathrm{kN}$

Eixo 1(T2): $F_{x}=352,53 \mathrm{kN}$

Eixo 2(T3): $F_{x}=128,26 \mathrm{kN}$

Eixo 2(T4): $F_{x}=134,64 \mathrm{kN}$

- Analise NLG - Pilha 1

Eixo 1(T1): $F_{x}=347,02 \mathrm{kN}$

Eixo 1(T2): $F_{x}=353,15 \mathrm{kN}$

Eixo 2(T3): $F_{x}=128,19 \mathrm{kN}$

Eixo 2(T4): $F_{x}=132,84 \mathrm{kN}$ 


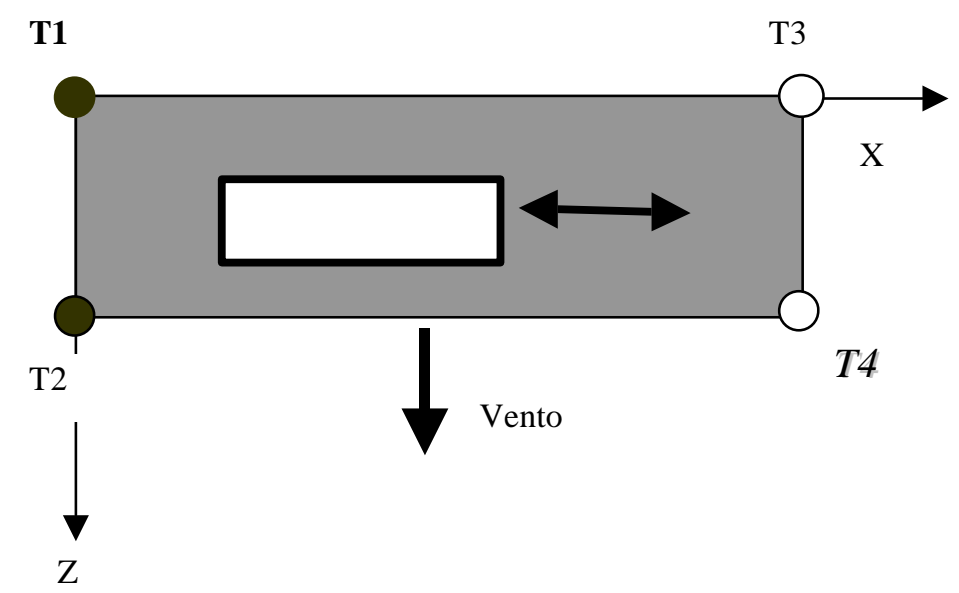

Distorção Máxima no aparelho de apoio do T2: $\operatorname{tg} \gamma=0,55$

- Comentários:

a) Para a pilha 3 de carregamento, os tubulões dos eixo1 e 2 absorveram, respectivamente, $51,7 \%$ e $48,3 \%$ da frenagem na análise linear. $\mathrm{Na}$ análise com não linearidade geométrica a redistribuição da frenagem pouco diferiu da análise linear, com $51,8 \%$ da frenagem para o eixo 1 e $48,2 \%$ para o eixo 2 ;

b) Os deslocamentos de $2^{\underline{a}}$ ordem, relativamente aos de $1^{\text {a }}$ ordem, apresentaram os seguintes valores:

\begin{tabular}{|l|l|l|}
\hline Eixo 1 & Pilha 3: $1,9 \%$ & Pilha 1: $0,6 \%$ \\
\hline Eixo 2 & Pilha 3: $-0,36 \%$ & Pilha 1: $5,4 \%$ \\
\hline
\end{tabular}

Obs. A estrutura do exemplo 2, aparentemente indeslocável, pode se tornar deslocável, em particular no seu eixo 2, se for adotado para o solo um modelo de comportamento não linear, com a conseqüente expansão do efeito do confinamento para as camadas inferiores do subsolo. 


\section{3 - EXEMPLO 3: PONTE FERROVIÁRIA}

- Características Gerais: Classe 32 (NB 7/43)

Superestrutura: Duas vigas protendidas de seção monocelular, simplesmente apoiadas com vão livre de $45 \mathrm{~m}$, instaladas por içamento;

Aparelhos de apoio: almofada de neoprene fretado (dureza SHORE A 60), 80x80 $\mathrm{cm}^{2}$ de base, com sete chapas de aço de $4 \mathrm{~mm}$ e 6 camadas intermediárias de $15 \mathrm{~mm}$ de neoprene;

Infra-estrutura: constituída por tubulões com fuste de $120 \mathrm{~cm}$ de diâmetro e base alargada de $360 \mathrm{~cm}$ (fig. 7.20);

- Modelagem

$\square \quad$ superestrutura- SHELL63 [ ELASTIC SHELL(ANSYS)];

- tubulões: BEAM4 [3-D ELASTIC BEAM(ANSYS)];

$\square$ blocos de transição do eixo central : SHELL63 [ELASTIC SHELL(ANSYS)];

$\square$ aparelhos de apoio de neoprene: CONTACT52 [3-D Point-toPoint(ANSYS)];

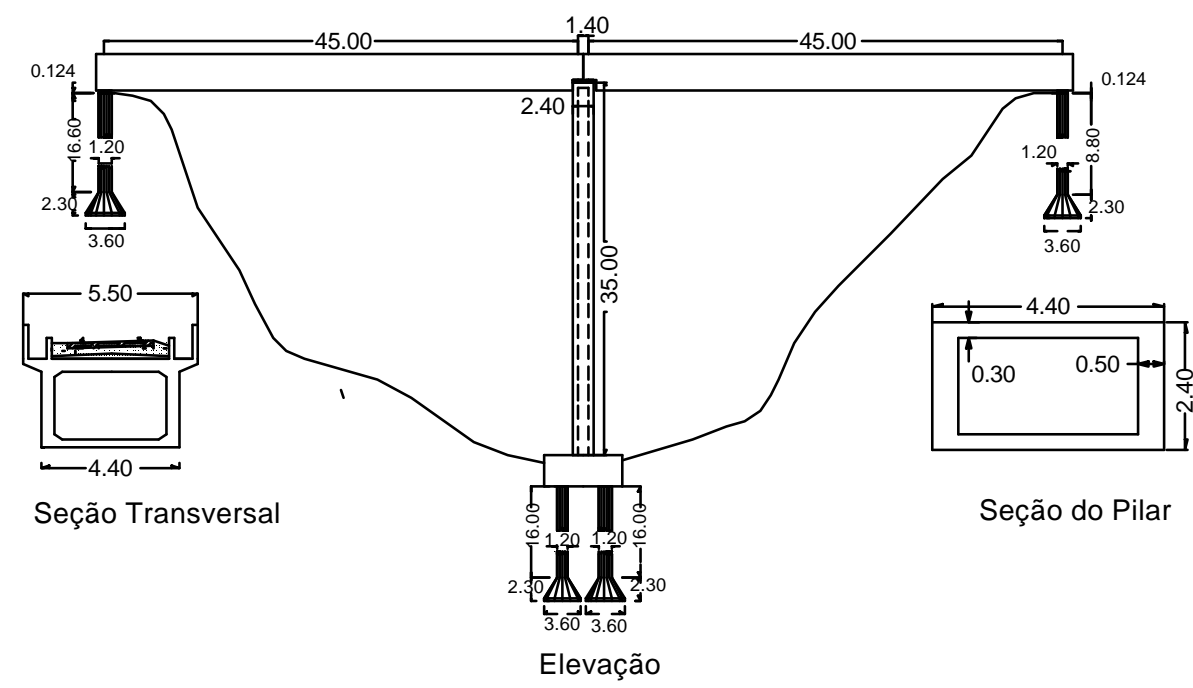

Fig. 7.20 - Esquema do Exemplo 3 
- solo: COMBIN14 [Spring Damper(ANSYS)]

- $\quad$ Perfil do Solo: constantes de reação horizontal do solo

Eixo 1 - igual ao perfil do eixo 1 do exemplo 1;

Eixo 2 - igual ao perfil do eixo 1 do exemplo 1;

Eixo 3 - igual ao perfil do eixo 2 do exemplo 1.

- $\quad$ Rigidez do aparelho de apoio:

$\mathrm{S}=0,64 \mathrm{~m}^{2}, \mathrm{G}=1000 \mathrm{kN} / \mathrm{m}^{2}, \mathrm{~h}=90 \times 10^{-3} \mathrm{~m}$

$E=4 B^{2} G+3 \sigma_{m}, B=13,33$ (fator de forma)

$\mathrm{E}=743756 \mathrm{kN} / \mathrm{m}^{2}$, para $\sigma_{\mathrm{m}}=11 \mathrm{MPa}$

Rigidez normal $-\mathrm{K}_{\mathrm{N}} \cong \mathrm{SE} / \mathrm{h}=5,0 \mathrm{E}+6 \mathrm{kN} / \mathrm{m}$

Rigidez a distorção dos aparelhos de apoio: $\mathrm{S}=0,64 \mathrm{~m}^{2}, \mathrm{G}=$ $1000 \mathrm{kN} / \mathrm{m}^{2}, \mathrm{~h}=90 \times 10^{-3} \mathrm{~m} ; \mathrm{K}_{\mathrm{s}}=\mathrm{SG} / \mathrm{h}=7111 \mathrm{kN} / \mathrm{m}$. Limite do esforço tangencial: $\mu\left|\mathrm{F}_{\mathrm{N}}\right| \operatorname{com} \mu \approx 0,19$.

- Carregamento

- Verticais

a) Cargas Permanentes

a.1) Superestrutura: $\mathrm{g}_{1}=150,00 \mathrm{kN} / \mathrm{m}$,

a.2) Lastro, dormentes, trilhos e pavimento: $\mathrm{g}_{2}=45,20 \mathrm{kN} / \mathrm{m}$

a.3) Infra-estrutura (tubulões, bloco e travessas)

b) Carga Móvel - Trem-tipo TB-32

Impacto vertical: $\varphi=1,3$ ( $\mathrm{R}_{2 \max }$ com o vão 2 carregado)

c) Multidão nos passeios

$\mathrm{R}_{\mathrm{m}}=43,0 \mathrm{kN} /$ neoprene

Ações horizontais longitudinais

a) Cargas aplicadas 
a.1) Aceleração/Frenagem (NBR $7187-7.2 .1 .5): F_{\text {fren. }}=891 \mathrm{kN}$

a.2) Empuxo/Sobrecarga: Empuxo devido à sobrecarga no aterro:

$\mathrm{Esc}=70 \mathrm{kN}$

Empuxo do aterro de acesso

$\mathrm{Ea}=20 \mathrm{kN}$

Deformações impostas

a) Deformação inicial nula (fase única de protensão e montagem por içamento)

b) Variação de temperatura na superestrutura: $\Delta \mathrm{t} \cong \pm 15^{\circ} \mathrm{C}$

c) Retração do concreto na superestrutura: Período: 60 dias - 50 anos $\Rightarrow \varepsilon_{\mathrm{i}}=-19,0 \mathrm{E}-5$ ou $\Delta \mathrm{t} \cong-19{ }^{\circ} \mathrm{C}$ (Queda devido à retração: 3,0\%)

d) Encurtamento devido à fluência: Período: 60 dias -50 anos $\Rightarrow \varepsilon_{\mathrm{i}}=$ $24,0 \mathrm{E}-5$ ou $\Delta \mathrm{t} \cong-24{ }^{\circ} \mathrm{C}$ (Queda devido à fluência: 3,8\%)

- Forças horizontais transversais

a) Ação transversal do vento

$\mathrm{H}_{\mathrm{t}, \text { carregada }}=89 \mathrm{kN} /$ neoprene

Carga vertical (efeito do tombamento do vento)

$\mathrm{N}_{\mathrm{v}}= \pm 163 \mathrm{kN} /$ neoprene

b) Choque lateral sobre os trilhos

$\mathrm{H}_{\mathrm{c} 1}=0,20 \mathrm{Q}_{\max }=0,20 \times 320=64 \mathrm{kN}($ no eixo 2$)$

Carga vertical (efeito do tombamento)

$\mathrm{V}_{\mathrm{c} 2}= \pm 40 \mathrm{kN} /$ neoprene (no eixo 2 )

- Inclinação involuntária

Desvio construtivo vertical no pilar do eixo 2: $15 \mathrm{~cm}$ (entre a base e o topo do pilar central). Inclinação adotada: $\operatorname{tg} \alpha=1 / 235$

- Combinações das cargas 


\section{Exemplos Numéricos}

\section{A - Estrutura em operação}

- Pilha 1: Caso da Seqüência Rara das Ações

$$
\mathrm{C}_{1} \rightarrow \mathrm{C}_{2} \rightarrow \mathrm{C}_{4} \rightarrow \mathrm{C}_{5} \rightarrow \mathrm{C}_{6} \rightarrow 0,7 \mathrm{C}_{7} \rightarrow \mathrm{C}_{8} \rightarrow \mathrm{C}_{9} \rightarrow 0,7 \mathrm{C}_{10} \rightarrow 0,7 \mathrm{C}_{11} \rightarrow \mathrm{C}_{12}
$$

\begin{tabular}{|c|c|c|c|}
\hline CARGA C $_{\mathrm{j}}$ & $\gamma_{\mathrm{J}} \mathrm{F}_{\mathrm{jk}}$ & $\gamma_{\mathrm{j}}$ & OBSERVAÇÃO \\
\hline $\mathbf{C}_{1}$ & $\gamma_{\mathrm{g}} \mathbf{F}_{\mathrm{gk}}$ & 1,0 & $\begin{array}{c}\text { Peso da estrutura } \\
\text { (geração automática ) }\end{array}$ \\
\hline $\mathbf{C}_{2}$ & $\gamma_{\mathrm{g}} \mathbf{F}_{\mathrm{gk}}$ & 1,0 & Permanente complementar $\left(\mathrm{g}_{2=} \mathbf{4 5 , 2 0} \mathrm{kN} / \mathrm{m}\right)$ \\
\hline $\mathbf{C}_{3}$ & $\boldsymbol{\gamma}_{\mathbf{\varepsilon}} \mathbf{F}_{\mathbf{\varepsilon k}}$ & 1,0 & $\begin{array}{l}\text { Def. inicial - pós-tensão na superestrutura } \\
\text { (não se aplica nesse caso) }\end{array}$ \\
\hline $\mathrm{C}_{4}$ & $\boldsymbol{\gamma}_{\boldsymbol{\varepsilon}} \mathbf{F}_{\mathbf{\varepsilon k}}$ & 1,0 & $\begin{array}{c}\text { Fluência na superestrutura }\left(\Delta t \cong-24^{\circ} \mathrm{C}\right) \\
\rightarrow \text { ação equivalente }\end{array}$ \\
\hline $\mathrm{C}_{5}$ & $\boldsymbol{\gamma}_{\varepsilon} \mathbf{F}_{\varepsilon k}$ & 1,0 & Retração do tabuleiro $\left(\Delta t \cong-19^{\circ} \mathrm{C}\right)$ \\
\hline $\mathbf{C}_{6}$ & $\boldsymbol{\gamma}_{\varepsilon} \mathbf{F}_{\varepsilon k}$ & 1,0 & $\begin{array}{l}\text { Variação de temperatura (curta dur.) } \\
\qquad\left(\Delta \mathrm{t} \cong \pm 15^{\circ} \mathrm{C}\right)\end{array}$ \\
\hline $\mathbf{C}_{7}$ & $\gamma_{q} F_{q k}$ & 0,7 & Sobrecarga na superestrutura \\
\hline $\mathrm{C}_{8}$ & $\boldsymbol{\gamma}_{\mathrm{q}} \mathbf{F}_{\mathbf{j k}}$ & 1,0 & $\begin{array}{l}\text { Carga móvel (frenagem e empuxo da } \\
\text { sobrecarga no aterro de acesso) } \\
\qquad \mathrm{H}=891+70=961 \mathrm{kN}\end{array}$ \\
\hline $\mathbf{C}_{9}$ & $\gamma_{q} F_{q k}$ & 1.0 & $\begin{array}{c}\text { Carga móvel: posição crítica } p / R_{2 \text { max. }} \text { c/ o vão } \\
2 \text { carregado } \\
\text { Impacto vertical: } \varphi=1,3\end{array}$ \\
\hline $\mathrm{C}_{10}$ & $\gamma_{\mathbf{q}} \mathbf{F}_{\mathbf{q k}}$ & $\mathbf{0 , 7}$ & Empuxo do aterro de acesso \\
\hline $\mathrm{C}_{11}$ & $\boldsymbol{\gamma}_{\mathbf{q}} \mathbf{F}_{\mathbf{q k}}$ & 0,7 & $\begin{array}{c}\text { Vento }- \text { transversal } \\
H_{t, \text { carregada }}=89 \mathrm{kN} / \text { neoprene } \\
\mathbf{N}_{v}= \pm 163 \mathrm{kN} / \text { neoprene }\end{array}$ \\
\hline $\mathrm{C}_{12}$ & $\boldsymbol{\gamma}_{\mathrm{q}} \mathbf{F}_{\mathbf{j k}}$ & 1.0 & $\begin{array}{c}\text { Choque lateral sobre os trilhos } \\
\qquad H_{\mathrm{c} 2}=64 \mathrm{kN} \text { (no eixo } 2 \text { ) } \\
\text { Carga vertical (efeito do tombamento) } \\
\mathbf{V}_{\mathrm{c} 2}= \pm 40 \mathrm{kN} / \text { neoprene (no eixo } 2 \text { ) }\end{array}$ \\
\hline
\end{tabular}

Cargas de curta duração $\left(\mathrm{t}_{\mathrm{ji}} \cong \mathrm{t}_{\mathrm{j} \mathrm{f}}\right)$

B - Pilha complementar: situação limite

Pilha 2 - Sequiência Complementar Desfavorável. 
Exemplos Numéricos

$$
0,35 \mathrm{C}_{12} \rightarrow 0,35 \mathrm{C}_{13} \rightarrow 0,05 \mathrm{C}_{15} \rightarrow 0,5 \mathrm{C}_{16} \rightarrow 0,5 \mathrm{C}_{17} \rightarrow 0,05 \mathrm{C}_{18} \rightarrow 0,05 \mathrm{C}_{19}
$$

$\rightarrow 0,50 \mathrm{C}_{20}$

\begin{tabular}{|c|c|c|c|}
\hline CARGA C $_{j}$ & $\gamma_{\mathrm{j}} \mathrm{F}_{\mathrm{jk}}$ & $\gamma_{j}$ & OBSERVAÇÃO \\
\hline $\mathrm{C}_{12}$ & $\boldsymbol{\gamma}_{\mathbf{j}} \mathbf{F}_{\mathbf{j k}}$ & 0,35 & $\begin{array}{l}\text { Peso da superestrutura } \\
\text { Peso da infra-estrutura }\end{array}$ \\
\hline $\mathrm{C}_{13}$ & $\boldsymbol{\gamma}_{\mathbf{j}} \mathbf{F}_{\mathbf{j k}}$ & 0,35 & Permanente complementar \\
\hline $\mathrm{C}_{14}$ & $\boldsymbol{\gamma}_{\mathbf{j}} \mathbf{F}_{\mathbf{j k}}$ & $\mathbf{0 , 2 0}$ & $\begin{array}{l}\text { Def. inicial: pós - tensão na superestrutura } \\
\text { (não se aplica nesse caso) }\end{array}$ \\
\hline $\mathrm{C}_{15}$ & $\gamma_{\mathbf{j}} \mathbf{F}_{\mathbf{j k}}$ & 0,05 & Sobrecarga na superestrutura \\
\hline $\mathrm{C}_{16}$ & $\boldsymbol{\gamma}_{\mathbf{j}} \mathbf{F}_{\mathbf{j k}}$ & $\mathbf{0 , 5 0}$ & Carga móvel vertical ferroviária \\
\hline $\mathrm{C}_{17}$ & $\boldsymbol{\gamma}_{\mathbf{j}} \mathbf{F}_{\mathbf{j k}}$ & $\mathbf{0 , 5 0}$ & $\begin{array}{c}\text { Carga móvel ( Frenagem ferroviária + } \\
\text { empuxo da sobrecarga) }\end{array}$ \\
\hline $\mathrm{C}_{18}$ & $\boldsymbol{\gamma}_{\mathbf{j}} \mathbf{F}_{\mathbf{j k}}$ & 0,05 & Empuxo do aterro de acesso \\
\hline $\mathrm{C}_{19}$ & $\boldsymbol{\gamma}_{\mathbf{j}} \mathbf{F}_{\mathbf{j k}}$ & 0,05 & Pressão do vento \\
\hline $\mathbf{C}_{20}$ & $\boldsymbol{\gamma}_{\mathbf{j}} \mathbf{F}_{\mathbf{j k}}$ & $\mathbf{0 , 5 0}$ & Choque lateral sobre os trilhos \\
\hline
\end{tabular}

Situação de carregamento crítico: Pilha $1 \rightarrow$ Pilha 2
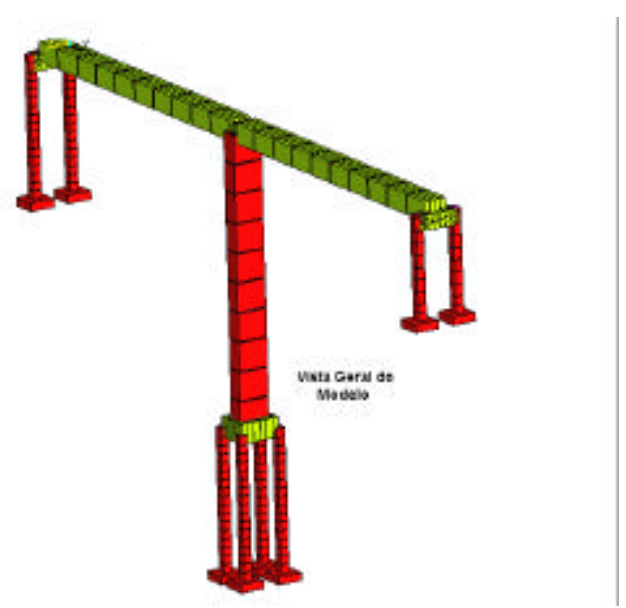

Fig. 7.21 - Vista Geral - Exemplo 3 


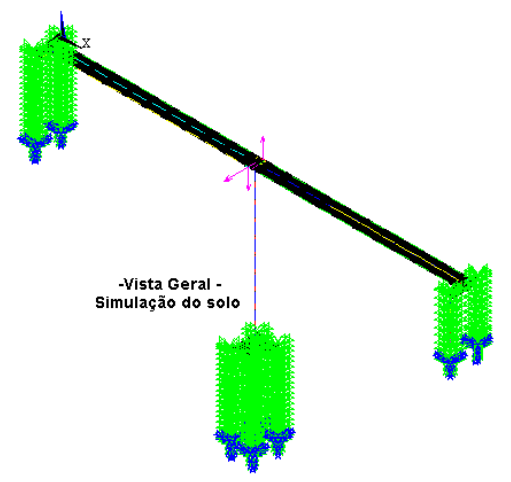

Fig. 7.22 - Vista Geral - Simulação do Solo
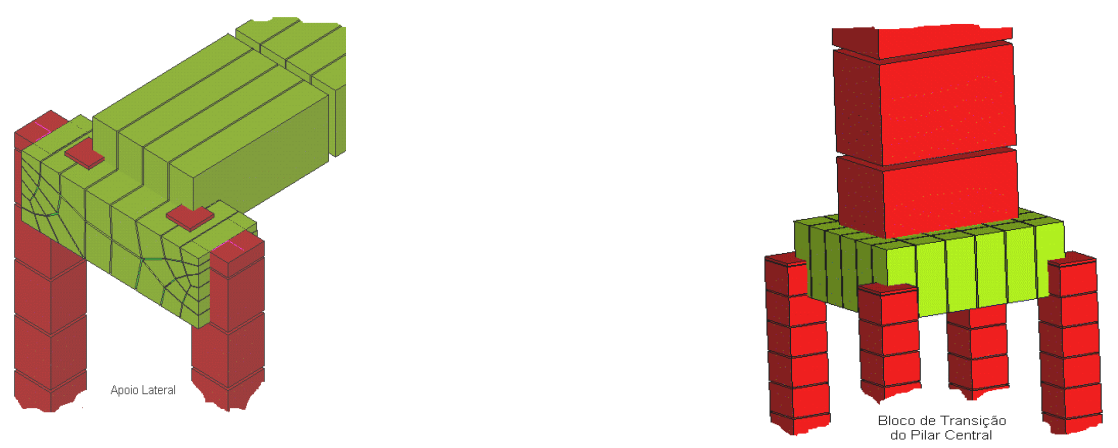

Fig. 7.23 - Detalhes dos Apoios Lateral e Central
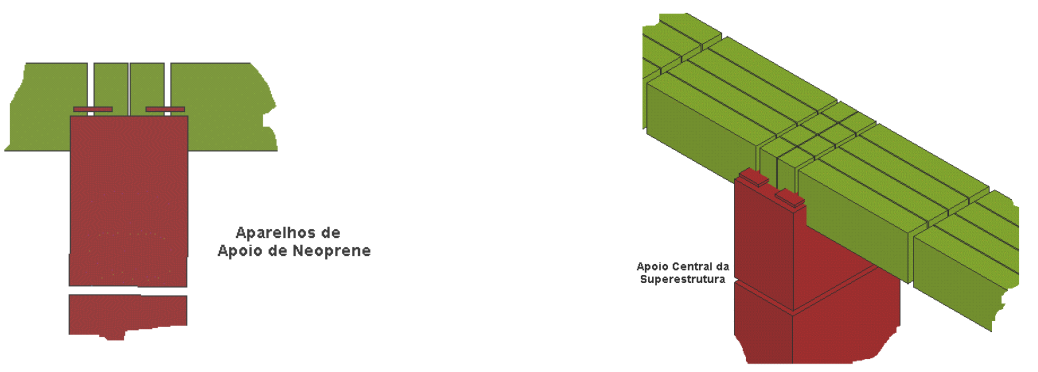

Fig. 7.24 - Detalhes do Apoio da Superestrutura no Eixo Central Resultados da Análise Numérica da Pilha 1 A - Deslocamentos no Pilar Central e Tubulão 6 - Pilha 1 Posição do Trem -Tipo: vão 2 carregado para $\mathrm{R}_{2 \max }$ 
Exemplos Numéricos

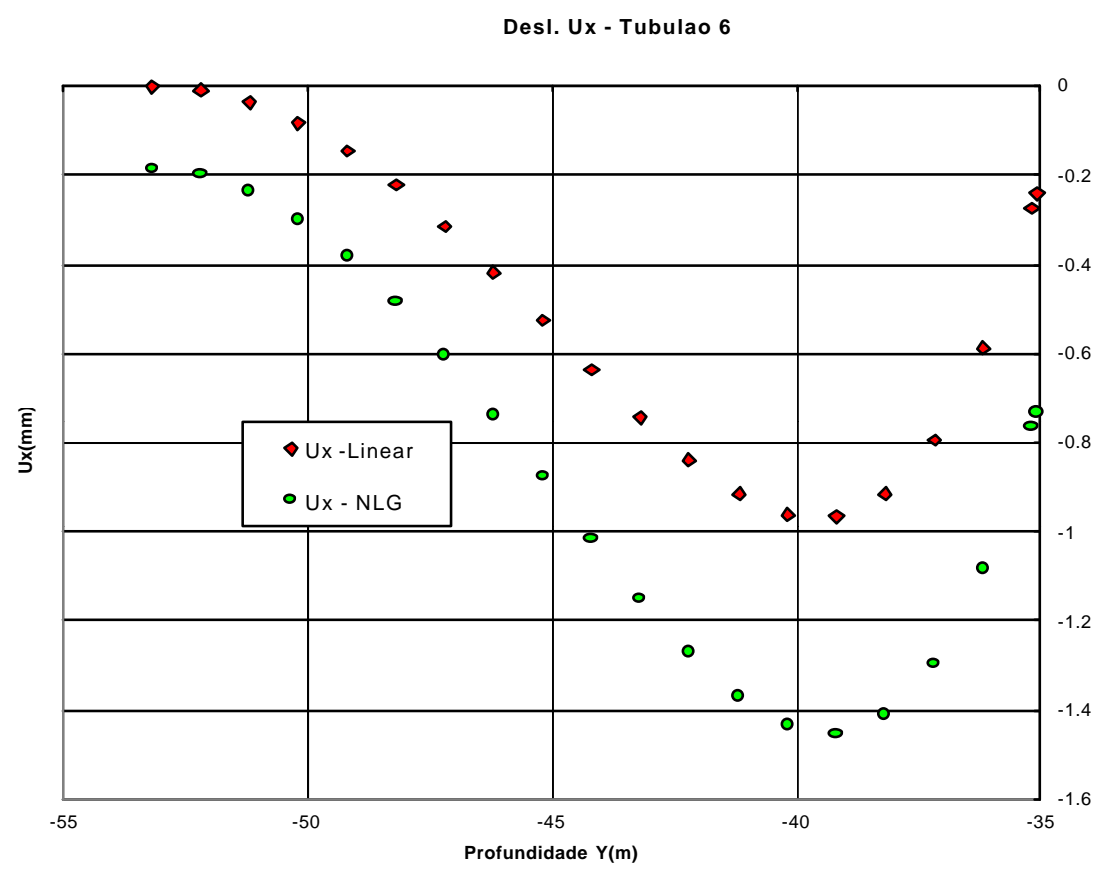

Desl. Uz - Tubulão 6

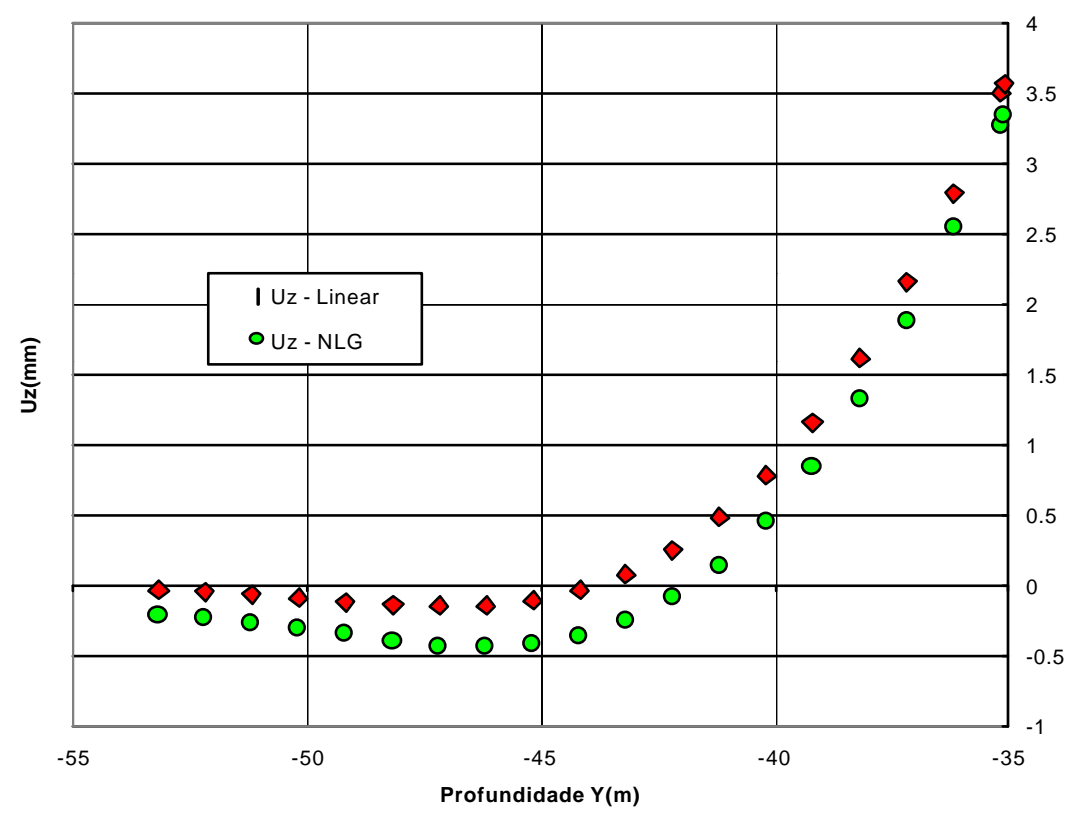

Fig. 7.25 - Deslocamentos Uz e Uz do Tubulão 6 
Exemplos Numéricos

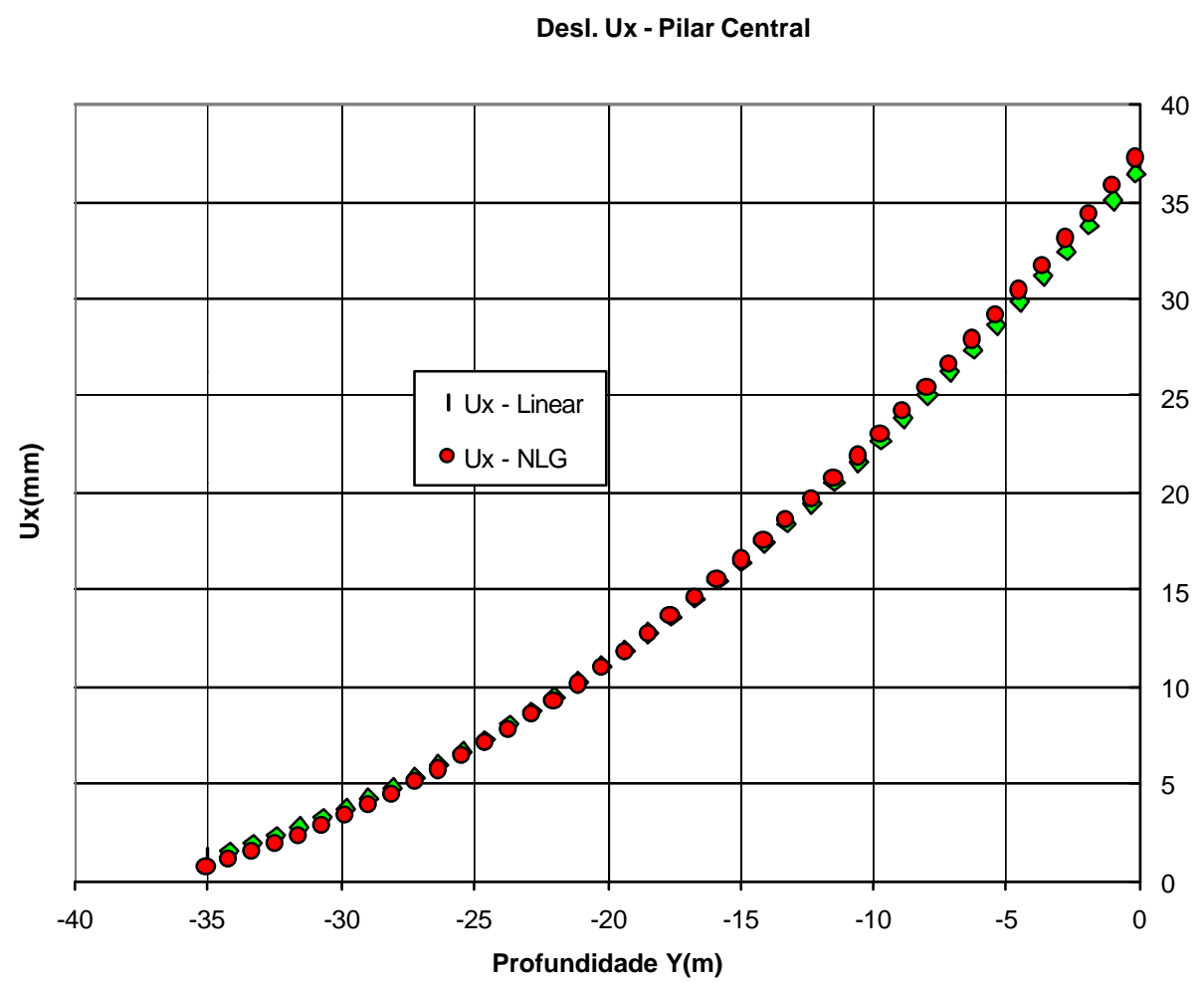

DesI. Uz - Pilar Central

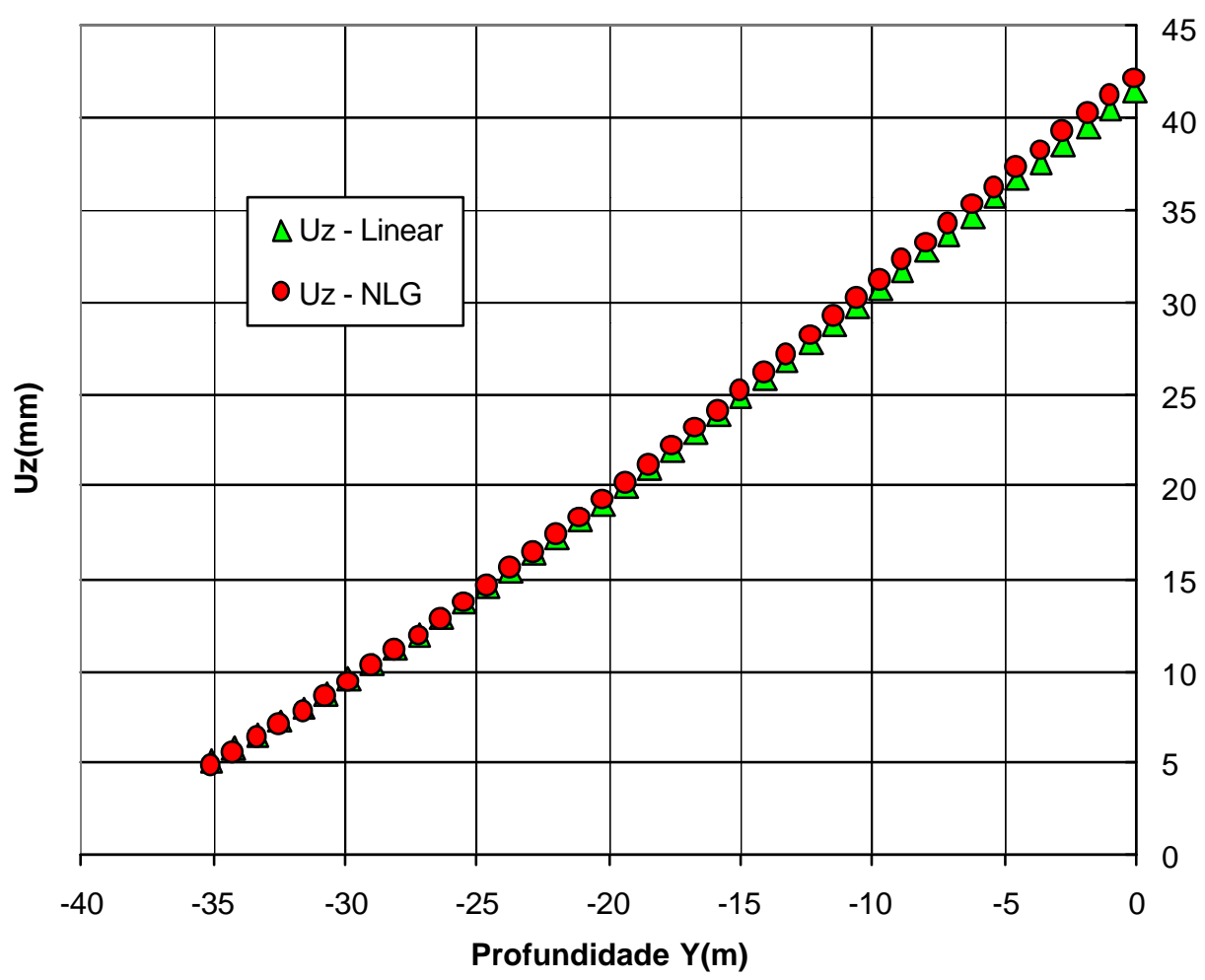

Fig. 7.26 - Deslocamentos Ux e Uz no Pilar Central 


\section{Exemplos Numéricos}

B - Momentos Fletores no Pilar Central e Tubulão 6 para a Pilha 1

Posição do Trem -Tipo: segundo vão carregado para R2max.
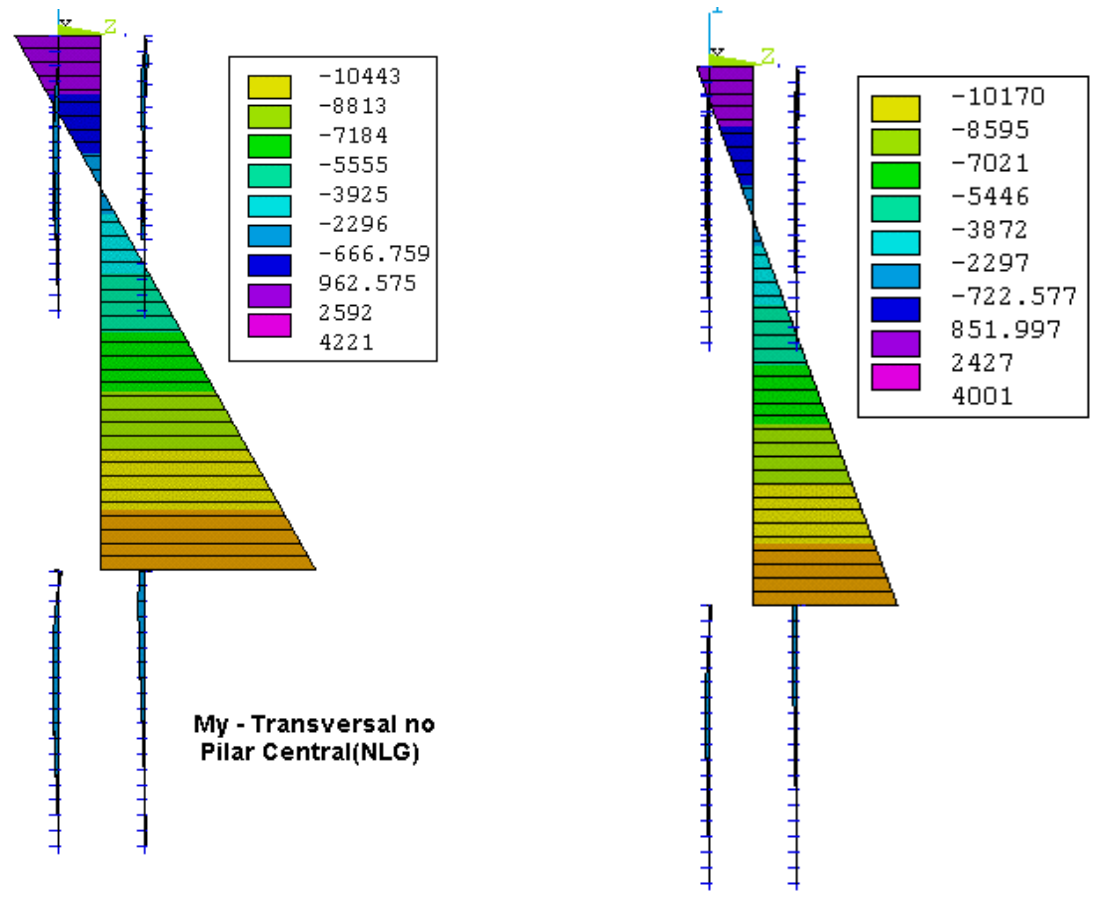

My - Transversal no Pilar Central (Análise Linear)

Fig. 7.27 - Momentos Fletores $\mathrm{M}_{\mathrm{y}}(\mathrm{kN} . \mathrm{m})$ - Pilar Central

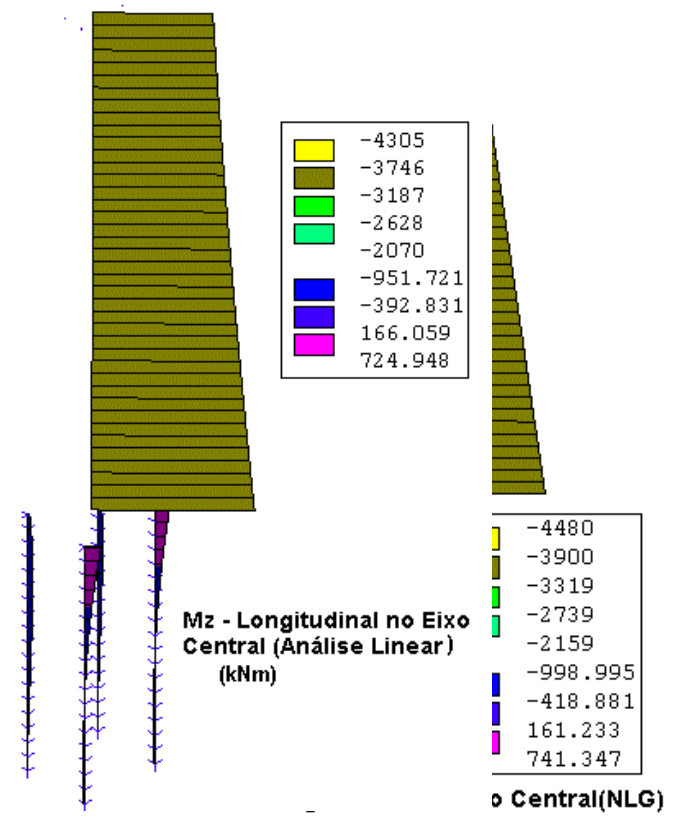

Fig. 7.28 - Momento Fletor $-\mathrm{M}_{\mathrm{z}}(\mathrm{kN} . \mathrm{m})$ no Pilar Central 


\section{Comentários:}

Os momentos fletores $\mathrm{M}_{\mathrm{z}}$ e $\mathrm{M}_{\mathrm{y}}$, assim como os deslocamentos longitudinais e transversais, apresentaram diferenças pouco significativas no que se referem às análises linear e não linear. Outro aspecto importante é a suspeita de que a utilização da placa rígida para simular os blocos de transição nas fundações e no topo dos pilares não seja, de certo modo, plenamente adequada para a redistribuição das tensões e esforços, principalmente no que se refere ao grau de vinculação dos tubulões na placa e a redistribuição das tensões no topo de pilares vazados mais robustos. Os altos valores dos momentos fletores observados nas seções do topo do pilar do exemplo 3 sugerem a necessidade de testar outros elementos mais adequados do que o elemento de casca. 


\section{4 - EXEMPLO 4: PONTE RODOVIÁRIA}

Objetivo: avaliar os efeitos provocados em uma estrutura existente, em decorrência da circulação de Combinações de Veículo de Carga - CVC conforme regulamentado pela Resolução № 068/98 do Conselho Nacional de Trânsito. O veículo adotado na simulação foi o PBTC 74 Tipo 3S2A2S2 com comprimento de $19,80 \mathrm{~m}$ associado a uma multidão de $5 \mathrm{kN} / \mathrm{m}^{2}$ (fig. 7.33).

Características Gerais: Ponte Classe 36 (NB 6/43) sobre o rio MogiGuaçu na rodovia SP 322 no trecho Ribeirão Preto - Bebedouro-SP. Projeto original elaborado pela empresa projetista FIGUEIREDO FERRAZ CONSULTORIA E ENGENHARIA DE PROJETOS LTDA.

- Superestrutura: Constituída por cinco vãos isostáticos, cada um deles composto por uma grelha composta de quatro vigas pré-moldadas protendidas de seção transversal "I" de vão típico de 32m, laje moldada "in loco", pavimento e defensas;

- Aparelhos de apoio: almofadas de neoprene fretado (dureza SHORE A 60), 25x60 $\mathrm{cm}^{2}$ de base, com quatro chapas de aço de $3 \mathrm{~mm}$ e três camadas intermediárias de $10 \mathrm{~mm}$ de neoprene;

- Infra-estrutura: constituída por pórticos transversais, formados cada um deles por uma travessa superior para o apoio das vigas da superestrutura, pilares e tubulões com fuste circular e base alargada (fig. 7.29 a 7.32). Nos encontros E1 e E2 os tubulões têm fuste de seção constante de diâmetro igual a $130 \mathrm{~cm}$ e bases alargadas de $280 \mathrm{~cm}$ e $390 \mathrm{~cm}$ de diâmetro nos encontros E1 e E2 respectivamente. Os eixos internos P1, P2, P3 e P4 têm os pilares e tubulões com fuste em forma escalonada de diâmetro igual a $160 \mathrm{~cm}$ no trecho inferior e diâmetro igual a $130 \mathrm{~cm}$ no trecho superior. Em todos os eixos internos os tubulões têm base alargada com diâmetro igual a $350 \mathrm{~cm}$. Todas as bases dos tubulões estão apoiadas em substrato rochoso. 
Exemplos Numéricos

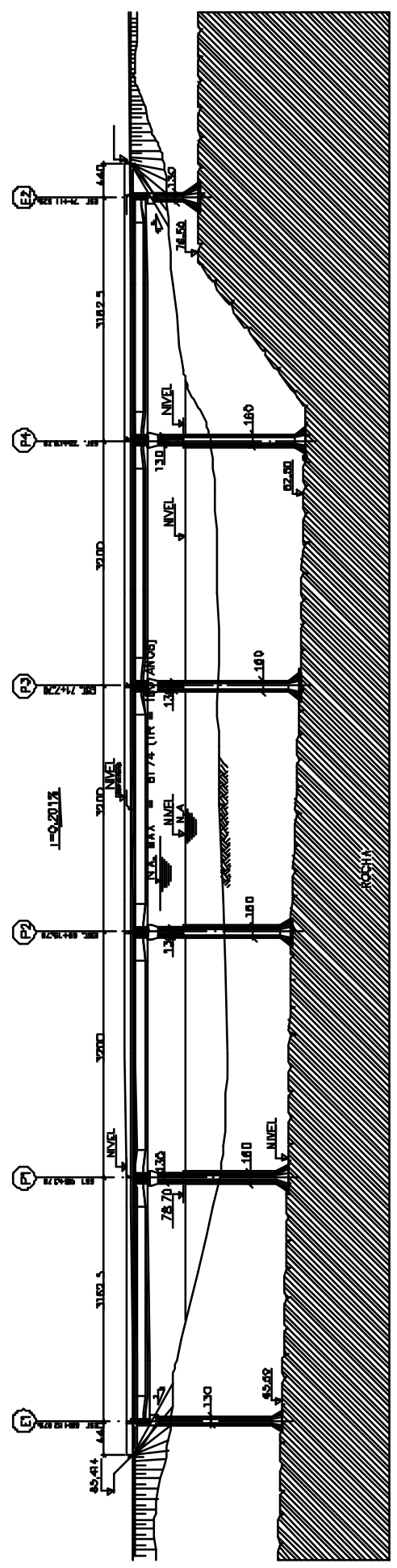

Fig 7.29 Elevação Longitudinal da Estrutura 
Exemplos Numéricos

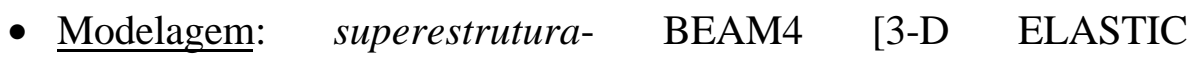
BEAM(ANSYS)];

tubulões e pilares - BEAM4 [3-D ELASTIC BEAM(ANSYS)]; travessa superior dos pórticos (apoio das vigas pré-moldadas) - SOLID65(ANSYS); aparelhos de apoio de neoprene e aterros de acesso - CONTACT52 [3-D Point-toPoint(ANSYS)]; solo do leito do rio - COMBIN39 [Spring Damper(ANSYS)]
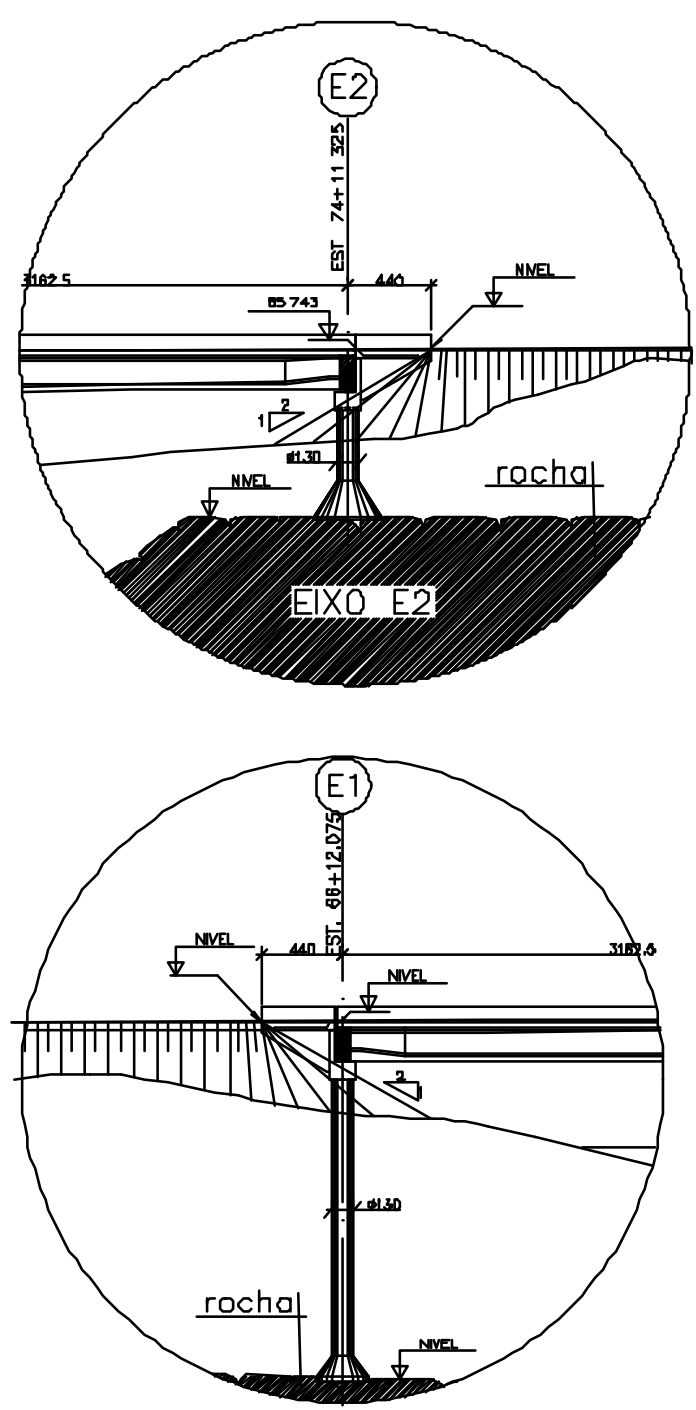

Fig 7.30 Detalhes dos encontros E1 e E2 


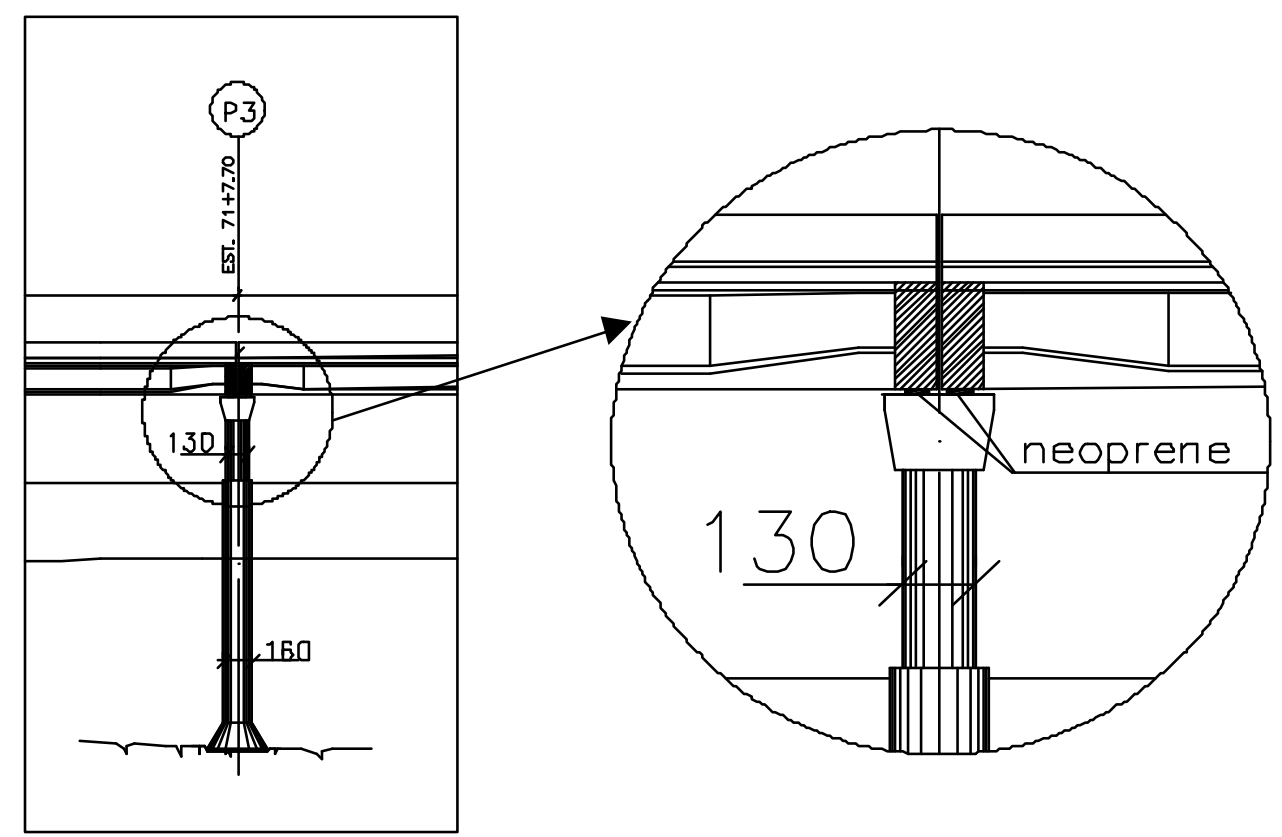

Fig 7.31 Detalhes do Eixo Interno P3

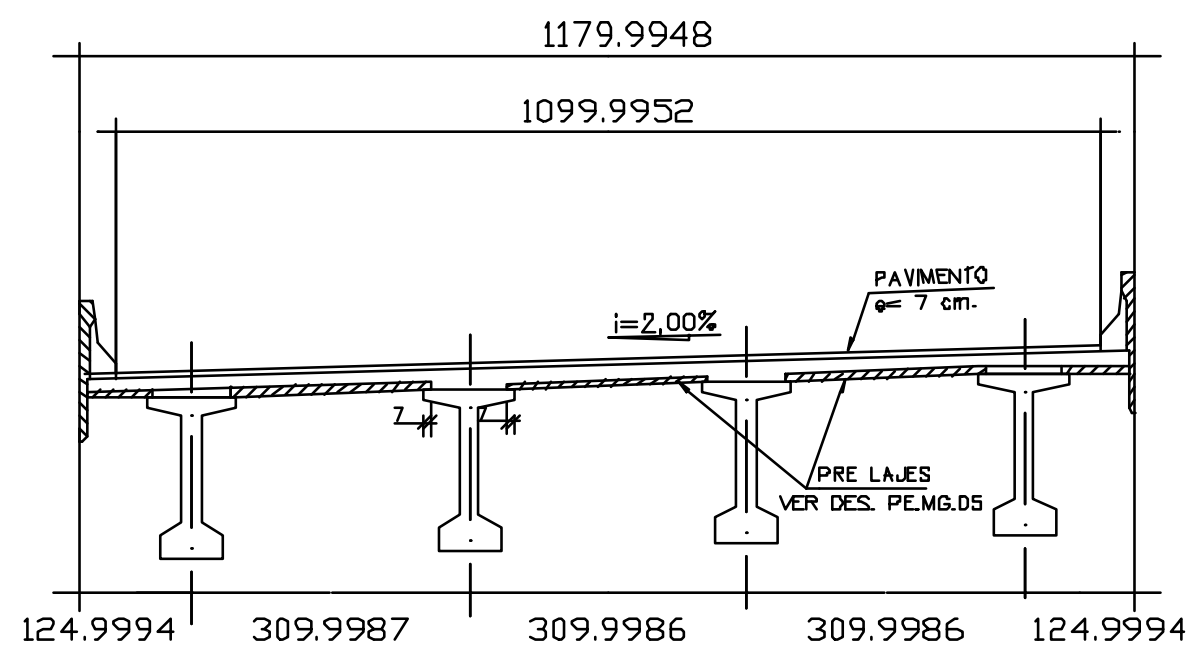

Fig 7.32 Seção transversal típica do tabuleiro

- Perfil do Solo: curvas de reação horizontal p-y para a areia média submersa ( modelo de Matlock - 1974). 


\section{Exemplos Numéricos}

- $\underline{\text { Rigidez do aparelho de apoio: }} \mathrm{S}=0,15 \mathrm{~m}^{2}, \mathrm{G}=1000 \mathrm{kN} / \mathrm{m}^{2}, \mathrm{~h}=$ $36 \times 10^{-3} \mathrm{~m} ; \mathrm{E}=4 \mathrm{~B}^{2} \mathrm{G}+3 \sigma_{\mathrm{m}}, \mathrm{B}=8,82$ (fator de forma); $\mathrm{E}=344170 \mathrm{kN} / \mathrm{m}^{2}$ para $\sigma_{\mathrm{m}}=$ $11 \mathrm{Mpa}$; Rigidez normal $-\mathrm{K}_{\mathrm{N}} \cong \mathrm{SE} / \mathrm{h}=1,43 \mathrm{E}+6 \mathrm{kN} / \mathrm{m}$; Rigidez a distorção dos aparelhos de apoio: $\mathrm{K}_{\mathrm{s}}=\mathrm{SG} / \mathrm{h}=4166,7 \mathrm{kN} / \mathrm{m}$. Limite do esforço tangencial: $\mu\left|\mathrm{F}_{\mathrm{N}}\right|$ $\operatorname{com} \mu \approx 0,19$.

- Carregamentos

\section{Verticais}

a) Cargas Permanentes

a.1) Superestrutura: peso próprio de cada viga pré-moldada $-\mathrm{g}_{1}=$ $590 \mathrm{kN}$; laje do tabuleiro $(22 \mathrm{~cm})-\mathrm{g}_{2}=5,5 \mathrm{kN} / \mathrm{m}^{2}$; regularização, pavimento e recapeamento - $\mathrm{g}_{3}=4,2 \mathrm{kN} / \mathrm{m}^{2}$; guarda rodas e placas pré-moldadas - $7 \mathrm{kN} / \mathrm{m}$;

a.2) Infra-estrutura (pilares, tubulões, cortinas, alas de contenção e travessas)

b) Carga Móvel - Veículo Rodotrem Tipo 3S2A2S2 com Peso Bruto Total Combinado(PBTC) igual a $740 \mathrm{kN}$ associado a uma multidão de $5 \mathrm{kN} / \mathrm{m}^{2}$; comprimento total (CT) igual a 19,80m; largura do veículo 3m; distância entre rodas de todos os eixos igual a $2 \mathrm{~m}$ e impacto vertical $\varphi=1,18$ (fig. 7.33);

\section{Ações horizontais longitudinais}

a) Cargas aplicadas

a.1) Aceleração/Frenagem (NBR 7187 - 7.2.1.5): $\mathrm{F}_{\text {fren. }}=222 \mathrm{kN}(\mathrm{p} /$ cada veículo) ou $440 \mathrm{kN}\left(\right.$ multidão de $5 \mathrm{kN} / \mathrm{m}^{2}$ );

a.2) Empuxo/Sobrecarga: Empuxo devido à sobrecarga no aterro:

Esc $=70,0 \mathrm{kN}$

Empuxo do aterro de acesso: $\mathrm{Ea}=117 \mathrm{kN}$

Obs. Área de contenção da cortina: $3,3 \times 11,8 \mathrm{~m}^{2}$. A ativação do empuxo dos aterros de acesso nos encontros E1 e E2 é obtida com o pré carregamento do dispositivo de contato CONTACT52 [3-D Point-to- 
Point(ANSYS)]. O pré carregamento é simulado por um deslocamento inicial do dispositivo igual a $0,000479 \mathrm{~m}$

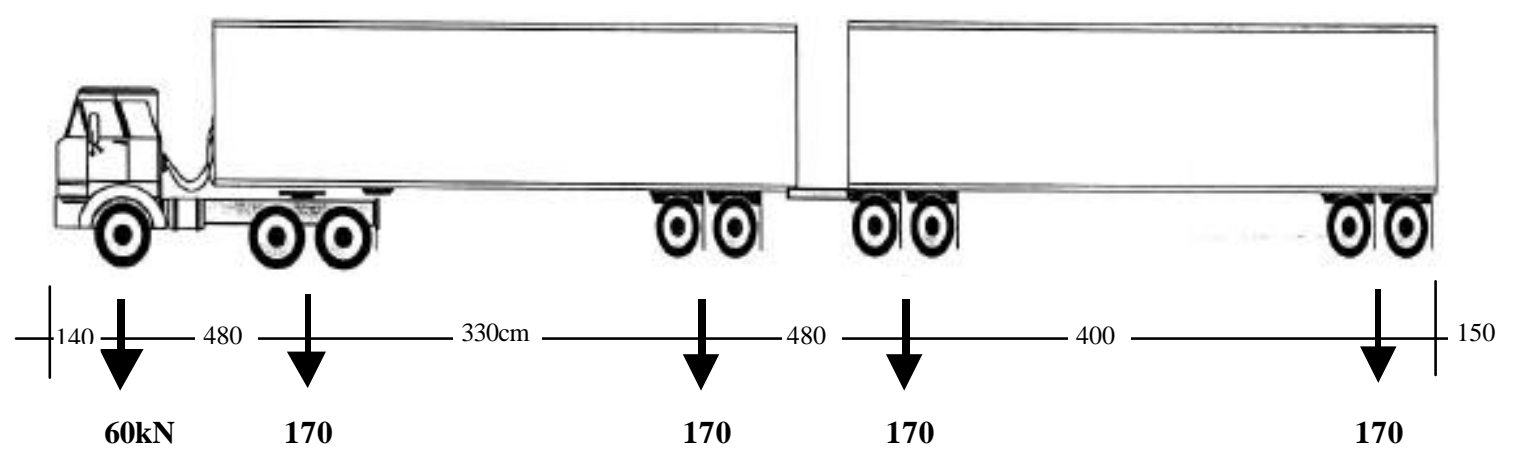

Fig. 7.33 - Veículo Rodotrem Tipo 3S2A2S2, PBTC 74 com CT=19,80m Deformações impostas

a) Deformação inicial nula devido à protensão(fase única de protensão e montagem por içamento)

b) Variação de temperatura na superestrutura: $\Delta \mathrm{t} \cong \pm 15^{\circ} \mathrm{C}$

c) Retração do concreto na superestrutura: Período: 60 dias - 50 anos $\Rightarrow \varepsilon_{\mathrm{i}}=-16,0 \mathrm{E}-5$ ou $\Delta \mathrm{t} \cong-16{ }^{\circ} \mathrm{C}$ (Queda devido à retração: 2,56\%)

d) Encurtamento devido à fluência: Período: 60 dias -50 anos $\Rightarrow \varepsilon_{\mathrm{i}}=$ $21,0 \mathrm{E}-5$ ou $\Delta \mathrm{t} \cong-21{ }^{\circ} \mathrm{C}$ (Queda devido à fluência: 3,4\%)

- Forças horizontais transversais

a) Ação transversal do vento

$\mathrm{H}_{\mathrm{t}, \text { carregada }}= \pm 192 \mathrm{kN} /$ eixo interno

$\mathrm{M}_{\mathrm{t}}= \pm 576 \mathrm{kNm} / \mathrm{eixo}$ interno (efeito do tombamento do vento)

b) Pressão da correnteza

$\mathrm{p}=\mathrm{k}\left[\mathrm{V}_{\mathrm{a}}\right]^{2}$, onde:

p é a pressão estática equivalente, em $\mathrm{kN} / \mathrm{m}^{2}$;

$\mathrm{V}_{\mathrm{a}}$ é a velocidade da água em m/s (valor adotado: $2,5 \mathrm{~m} / \mathrm{s}$ );

K é um coeficiente dimensional (tomado igual a 0,34 para os pilares e tubulões [NBR 7187]); 


\section{Exemplos Numéricos}

$\mathrm{P}_{\mathrm{p}}=2,76 \mathrm{kN} / \mathrm{m}($ para os pilares $) ;$

$\mathrm{P}_{\mathrm{t}}=3,39 \mathrm{kN} / \mathrm{m}$ ( para os tubulões)

\section{Inclinação involuntária}

Desvio construtivo vertical nos pórticos transversais tomado a partir da base dos tubulões. Inclinação média adotada na direção do tráfego no sentido esquerda-direita: $\operatorname{tg} \alpha=1 / 200$

\section{Combinações das Ações}

A - Estrutura em operação

- Pilha 1: Caso da Seqüência Rara das Ações

$\mathrm{C}_{1} \rightarrow \mathrm{C}_{2} \rightarrow \mathrm{C}_{4} \rightarrow \mathrm{C}_{5} \rightarrow \mathrm{C}_{6} \rightarrow 0,7 \mathrm{C}_{7} \rightarrow \mathrm{C}_{8} \rightarrow 0,7 \mathrm{C}_{9} \rightarrow 0,7 \mathrm{C}_{10}$

\begin{tabular}{|c|c|c|c|}
\hline CARGA C $_{\mathrm{j}}$ & $\gamma_{\mathrm{J}} \mathrm{F}_{\mathrm{jk}}$ & $\gamma_{j}$ & OBSERVAÇÃO \\
\hline $\mathbf{C}_{1}$ & $\gamma_{\mathrm{g}} \mathbf{F}_{\mathrm{gk}}$ & 1,0 & $\begin{array}{c}\text { Peso da estrutura } \\
\text { (geração automática ) }\end{array}$ \\
\hline $\mathbf{C}_{2}$ & $\gamma_{\mathrm{g}} \mathbf{F}_{\mathrm{gk}}$ & 1,0 & $\begin{array}{l}\text { Permanente complementar } \\
\text { (geração automática ) }\end{array}$ \\
\hline $\mathbf{C}_{3}$ & $\gamma_{\varepsilon} F_{\varepsilon k}$ & 1,0 & $\begin{array}{l}\text { Carga móvel (frenagem e empuxo da } \\
\text { sobrecarga no aterro de acesso) }\end{array}$ \\
\hline $\mathbf{C}_{4}$ & $\gamma_{\varepsilon} F_{\varepsilon k}$ & 1,0 & $\begin{array}{l}\text { Veículo PBTC } 74 \text { Tipo 3S2A2AS e multidão } \\
\text { Carga móvel: posição crítica } p / R_{\text {max. }} \\
\text { Impacto vertical: } \varphi=1,18\end{array}$ \\
\hline $\mathbf{C}_{5}$ & $\gamma_{\varepsilon} F_{\varepsilon k}$ & 1,0 & Retração do tabuleiro $\left(\Delta t \cong-16^{\circ} \mathrm{C}\right)$ \\
\hline $\mathbf{C}_{6}$ & $\gamma_{\varepsilon} F_{\varepsilon k}$ & 1,0 & $\begin{array}{c}\text { Variação de temperatura (curta dur.) } \\
\left(\Delta \mathrm{t} \cong \pm 15^{\circ} \mathrm{C}\right)\end{array}$ \\
\hline $\mathbf{C}_{7}$ & $\gamma_{\mathbf{q}} F_{\mathbf{q k}}$ & 0,7 & Pressão da correnteza \\
\hline $\mathrm{C}_{8}$ & $\gamma_{\mathbf{q}} \mathbf{F}_{\mathbf{j k}}$ & 1,0 & $\begin{array}{c}\text { Fluência na superestrutura }\left(\Delta t \cong-21^{\circ} \mathrm{C}\right) \\
\rightarrow \text { ação equivalente }\end{array}$ \\
\hline $\mathrm{C}_{9}$ & $\boldsymbol{\gamma}_{\mathbf{q}} \mathbf{F}_{\mathbf{q k}}$ & 0,7 & Empuxo do aterro de acesso \\
\hline $\mathbf{C}_{10}$ & $\gamma_{q} F_{q k}$ & 0,7 & Ação Transversal do vento \\
\hline
\end{tabular}

B - Pilha complementar: situação limite

- Pilha 2 - Seqüência Complementar Desfavorável. 
Exemplos Numéricos

$0,35 \mathrm{C}_{11} \rightarrow 0,35 \mathrm{C}_{12} \rightarrow 0,5 \mathrm{C}_{13} \rightarrow 0,5 \mathrm{C}_{14} \rightarrow 0,05 \mathrm{C}_{15} \rightarrow 0,05 \mathrm{C}_{16}$ $\rightarrow 0,05 \mathrm{C}_{17}$

\begin{tabular}{|cccc|}
\hline CARGA $C_{\mathbf{j}}$ & $\gamma_{\mathbf{j}} \mathrm{F}_{\mathbf{j k}}$ & $\gamma_{\mathrm{j}}$ & OBSERVAÇÃO \\
\hline \hline $\mathrm{C}_{11}$ & $\boldsymbol{\gamma}_{\mathbf{j}} \mathbf{F}_{\mathbf{j k}}$ & $\mathbf{0 , 3 5}$ & Peso da estrutura \\
& & & \\
$\mathrm{C}_{12}$ & $\boldsymbol{\gamma}_{\mathbf{j}} \mathbf{F}_{\mathbf{j k}}$ & $\mathbf{0 , 3 5}$ & Permanente complementar \\
$\mathrm{C}_{13}$ & $\boldsymbol{\gamma}_{\mathbf{j}} \mathbf{F}_{\mathbf{j k}}$ & $\mathbf{0 , 5 0}$ & Carga móvel vertical \\
$\mathrm{C}_{14}$ & $\boldsymbol{\gamma}_{\mathbf{j}} \mathbf{F}_{\mathbf{j k}}$ & $\mathbf{0 , 5 0}$ & Carga móvel ( Frenagem + empuxo da \\
& & sobrecarga no aterro) \\
$\mathrm{C}_{15}$ & $\boldsymbol{\gamma}_{\mathbf{j}} \mathbf{F}_{\mathbf{j k}}$ & $\mathbf{0 , 0 5}$ & Empuxo do aterro de acesso \\
$\mathbf{C}_{\mathbf{1 6}}$ & $\boldsymbol{\gamma}_{\mathbf{j}} \mathbf{F}_{\mathbf{j k}}$ & $\mathbf{0 , 0 5}$ & Ação do vento \\
$\mathbf{C}_{\mathbf{1 7}}$ & $\boldsymbol{\gamma}_{\mathbf{j}} \mathbf{F}_{\mathbf{j k}}$ & $\mathbf{0 , 0 5}$ & Ação da correnteza \\
& & & \\
& & & \\
\hline
\end{tabular}

Situação de carregamento crítico: Pilha $1 \rightarrow$ Pilha 2

Modelagem do Exemplo 4

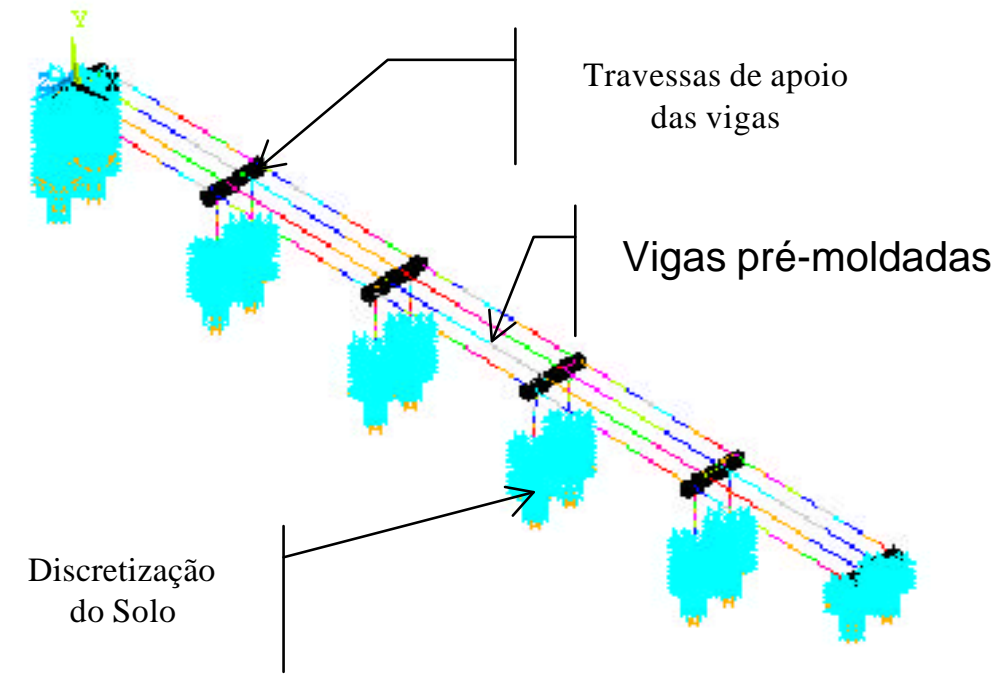

Fig. 7.34 - Vista Geral da modelagem- Exemplo 4 
Exemplos Numéricos

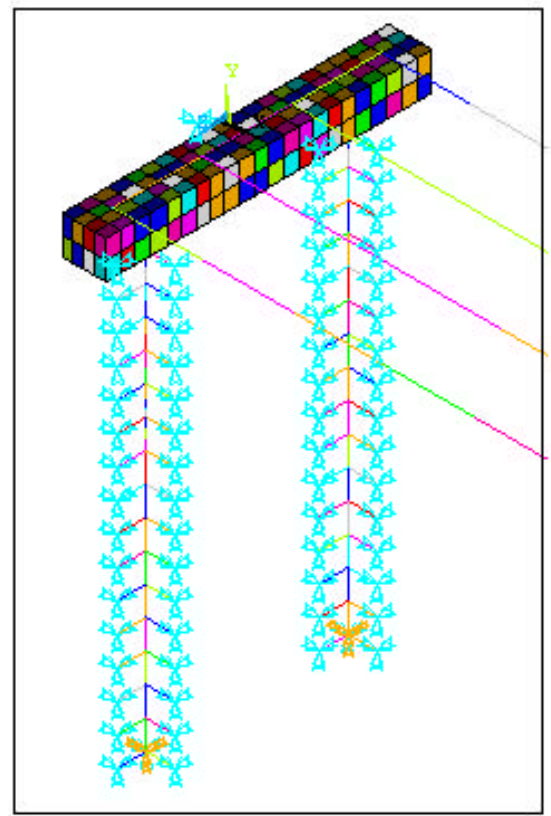

Fig. 7.35 - Detalhes do Encontro E1

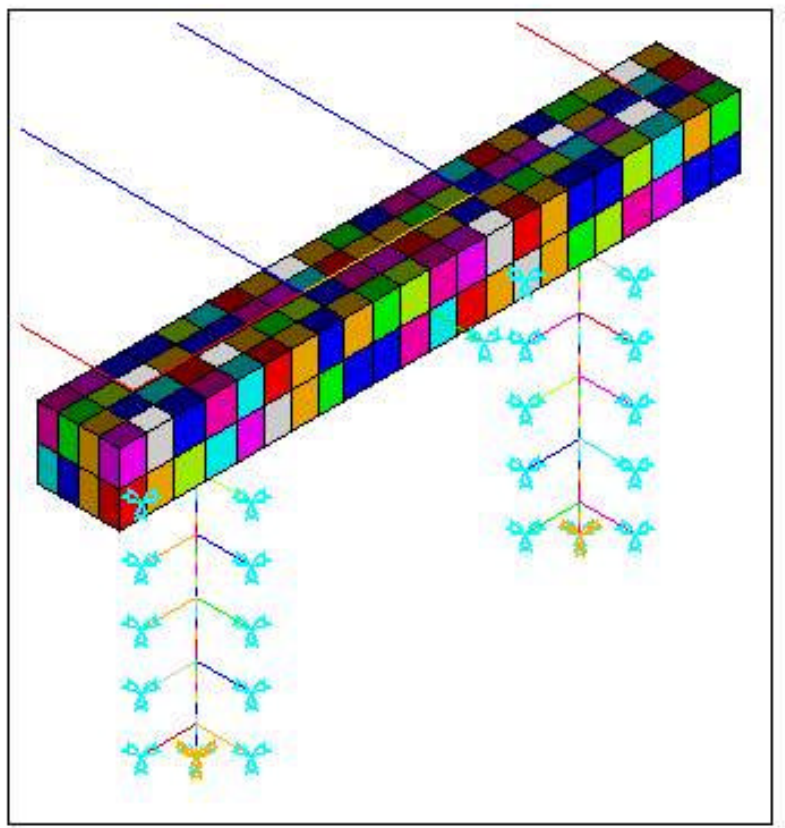

Fig. 7.36 - Detalhes do Encontro E2 


\section{Exemplos Numéricos}

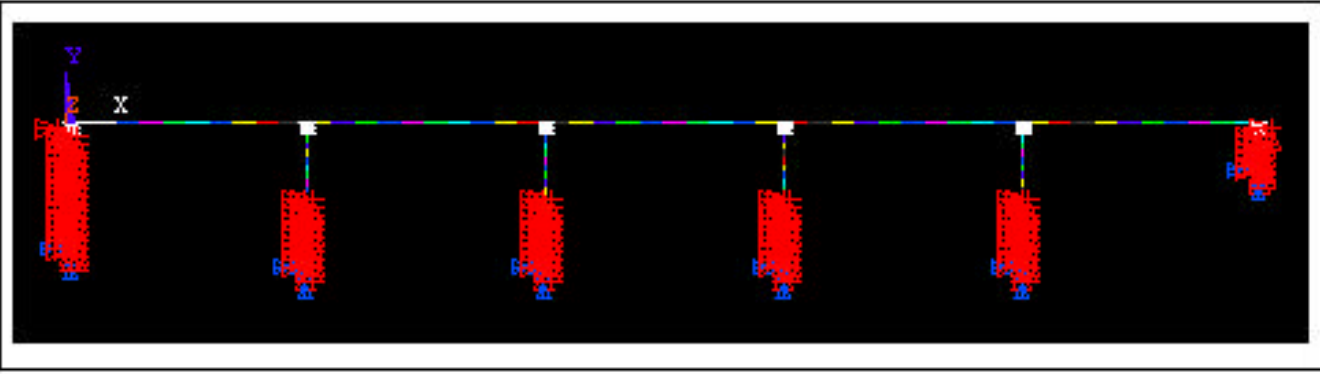

Fig. 7.37 - Vista Geral do Modelo - Elevação

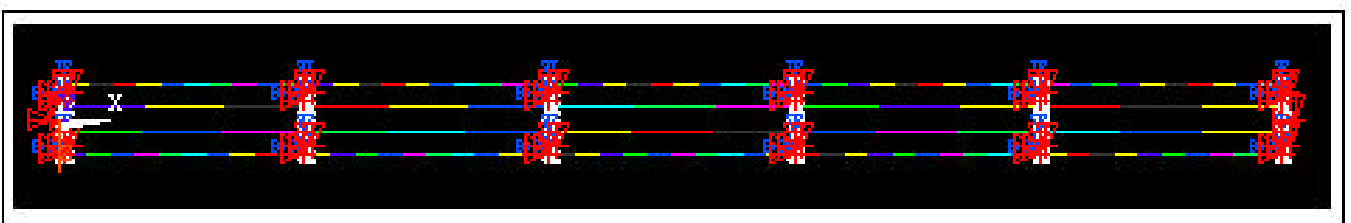

Fig. 7.38 - Vista Superior do Modelo

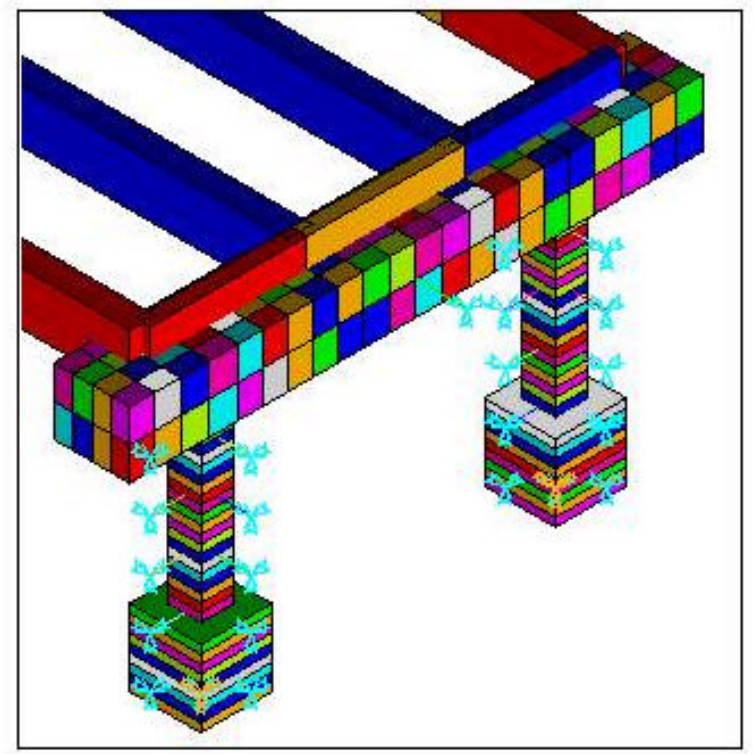

Fig. 7.39 - Vista Isométrica do Encontro E2 


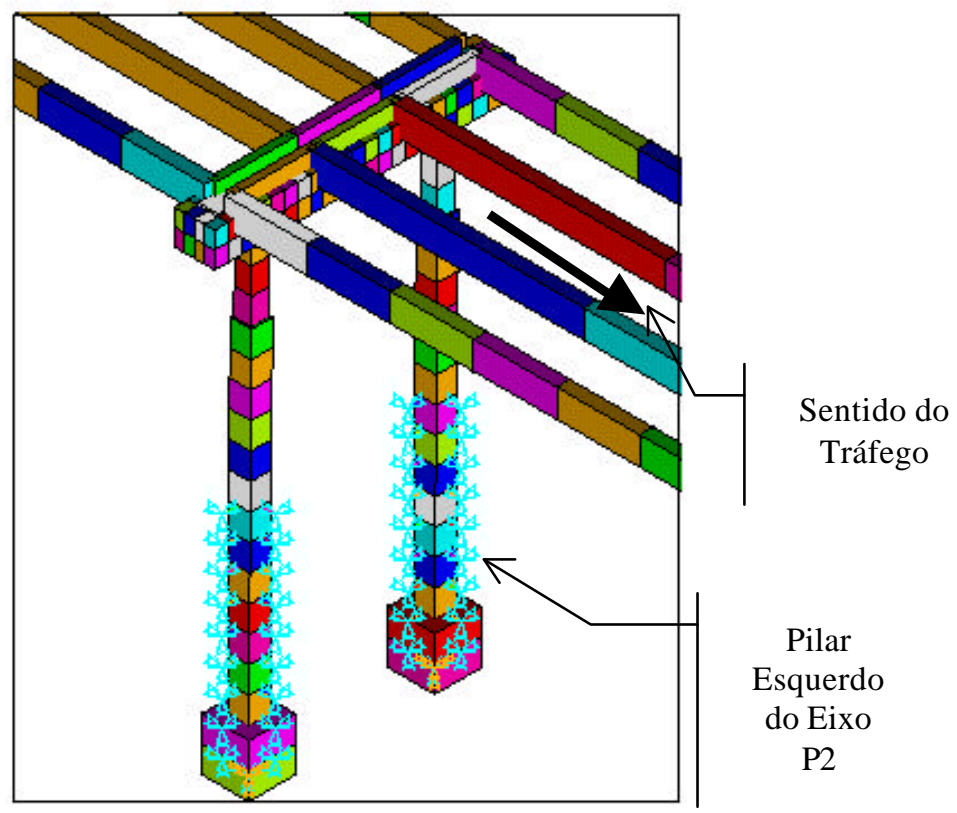

Fig. 7.40 - Eixo Interno Típico - Vista Isométrica do Eixo P2

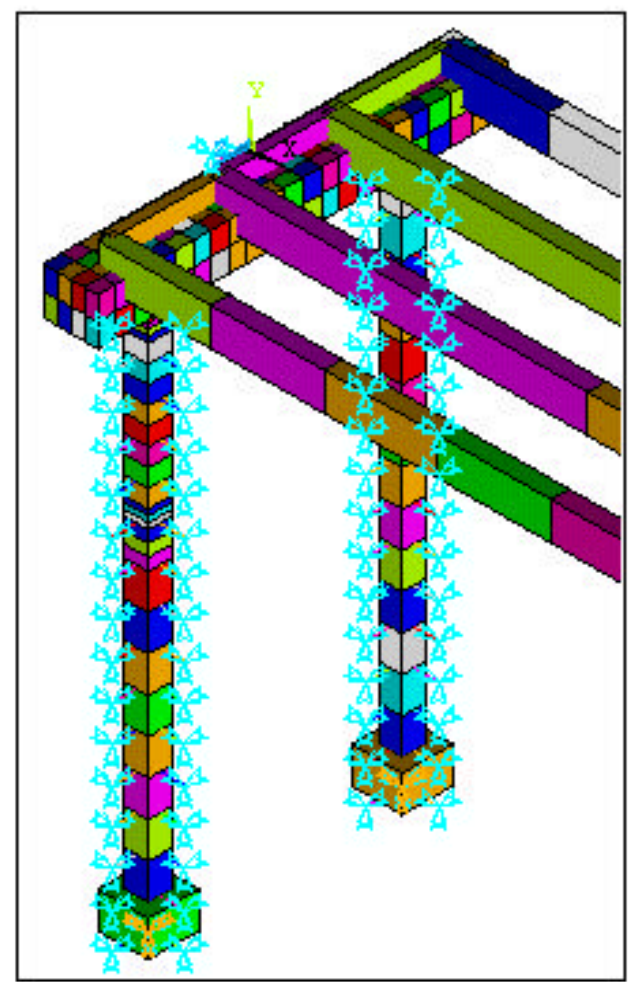

Fig. 7.41 - Encontro E1 - Vista Isométrica 


\section{Exemplos Numéricos}

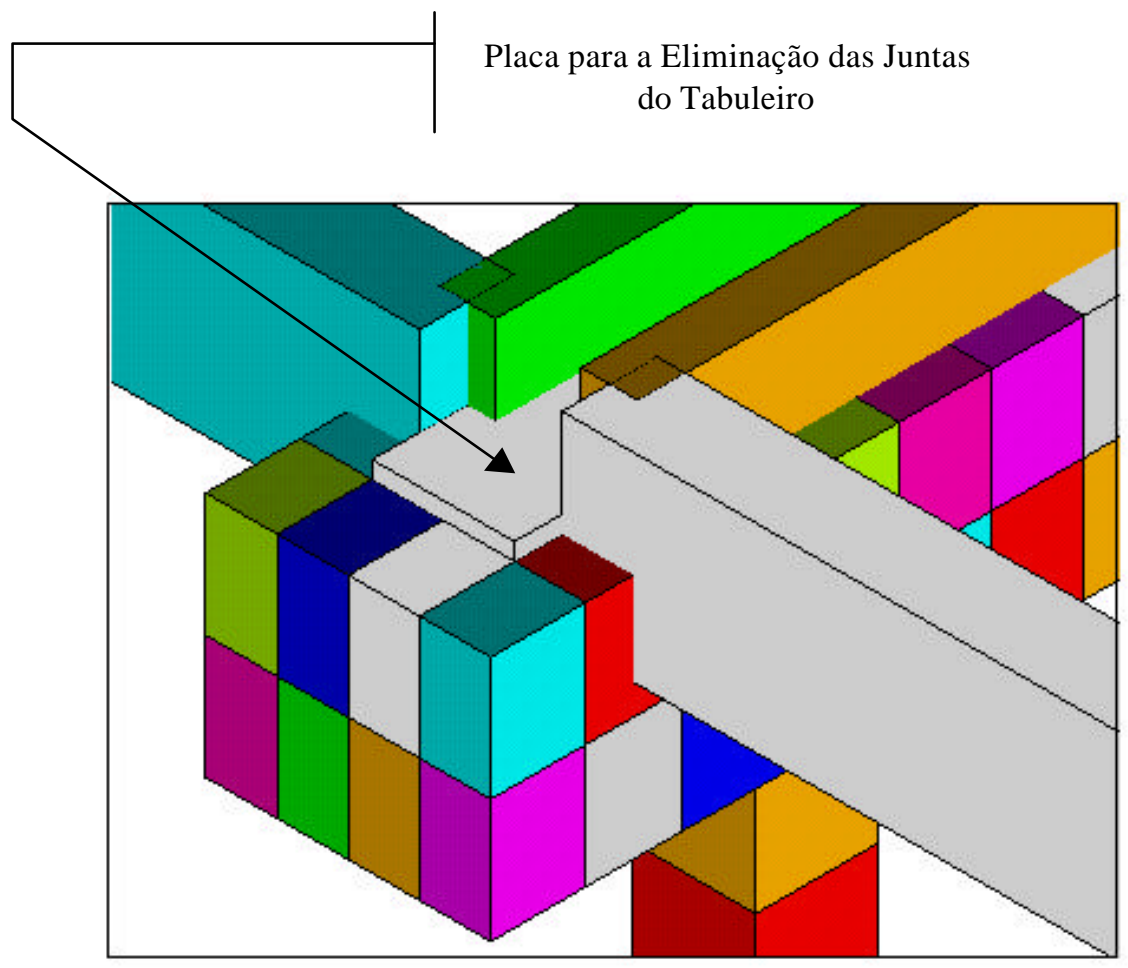

Fig. 7.42 - Apoio Interno das vigas - Vista Isométrica

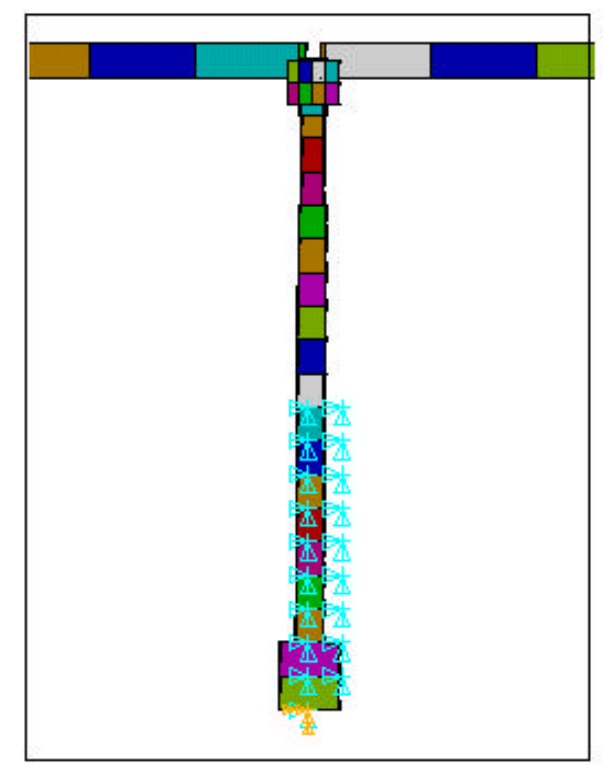

Fig. 7.43 - Eixo Interno Típico - Vista Isométrica 
Exemplos Numéricos

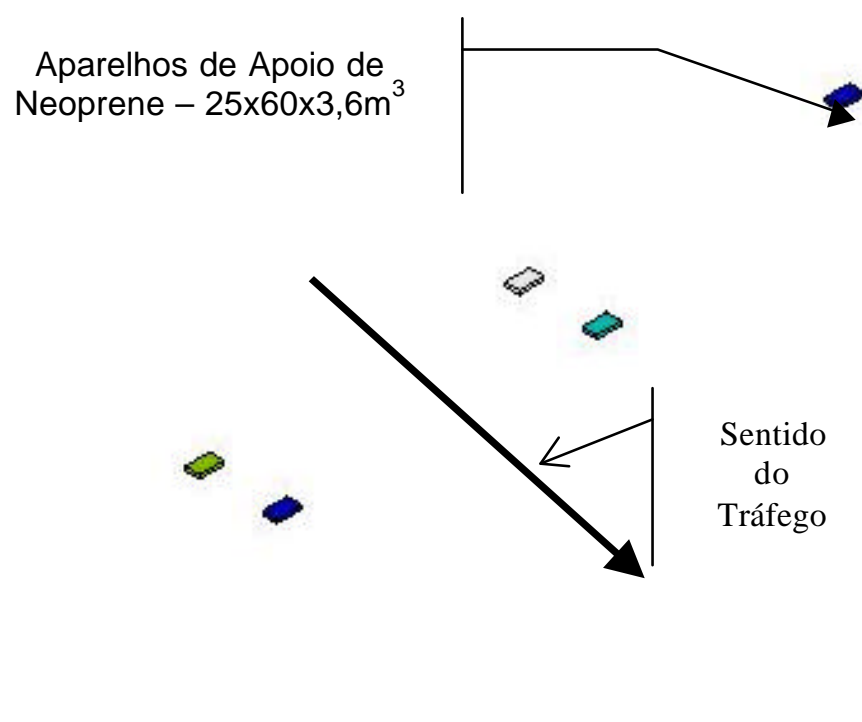

Fig. 7.44 - Disposição dos Aparelhos de Apoio nos Eixos Internos - Vista

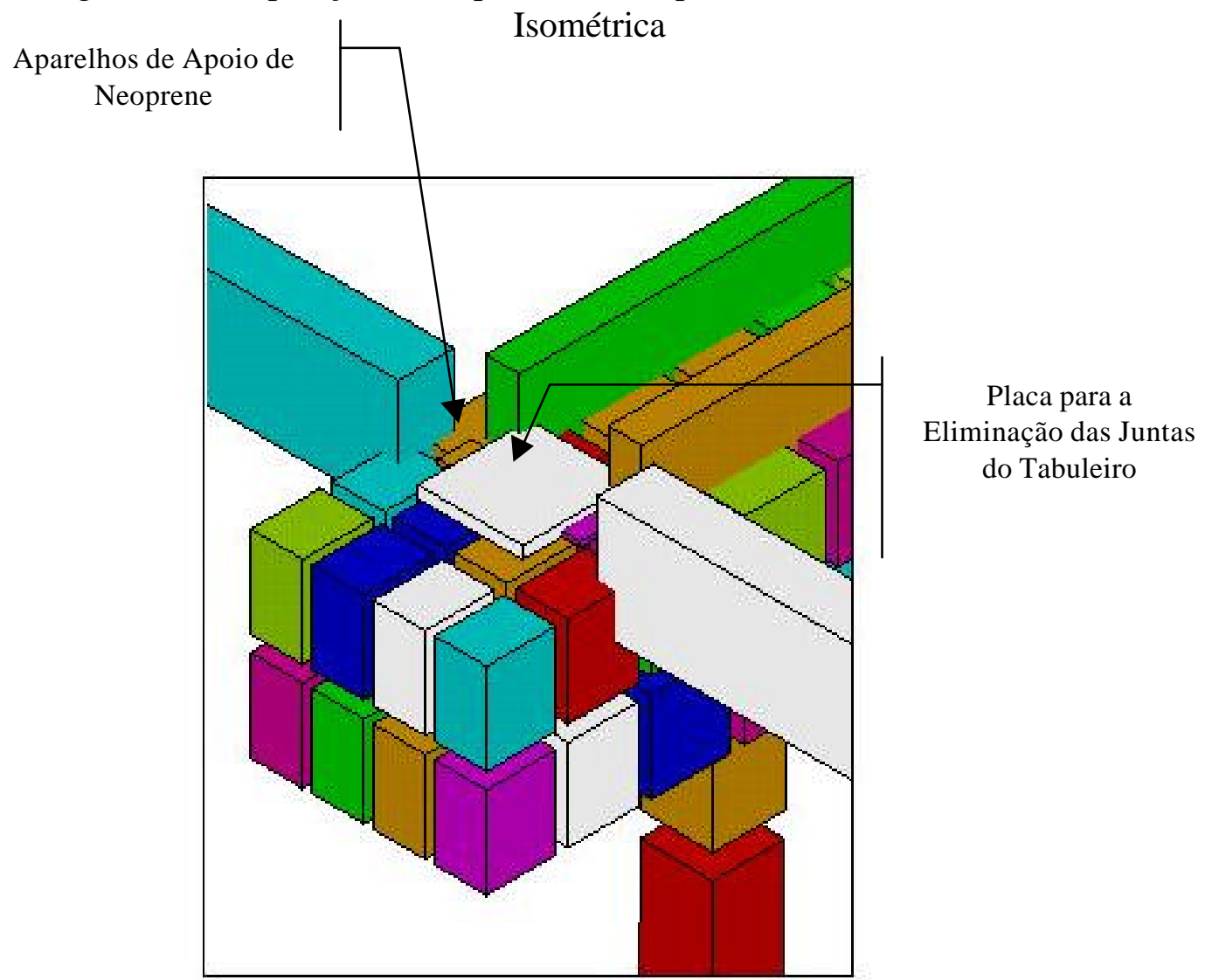

Fig. 7.45 - Detalhes do Apoio das Vigas nos Eixos Internos - Vista Isométrica 


\section{Exemplos Numéricos}

\section{- Análise dos resultados}

$\square$ Simulação 1 - Estrutura com as juntas

a) Ponte descarregada - Análise Linear

Ações consideradas: Carga permanente, retração e fluência após a instalação das vigas pré-moldadas e variação de temperatura no tabuleiro. Os desvios de execução são considerados na modelagem original através dos desaprumos dos pilares, para a direita, no sentido do encontro E1 para o encontro E2.

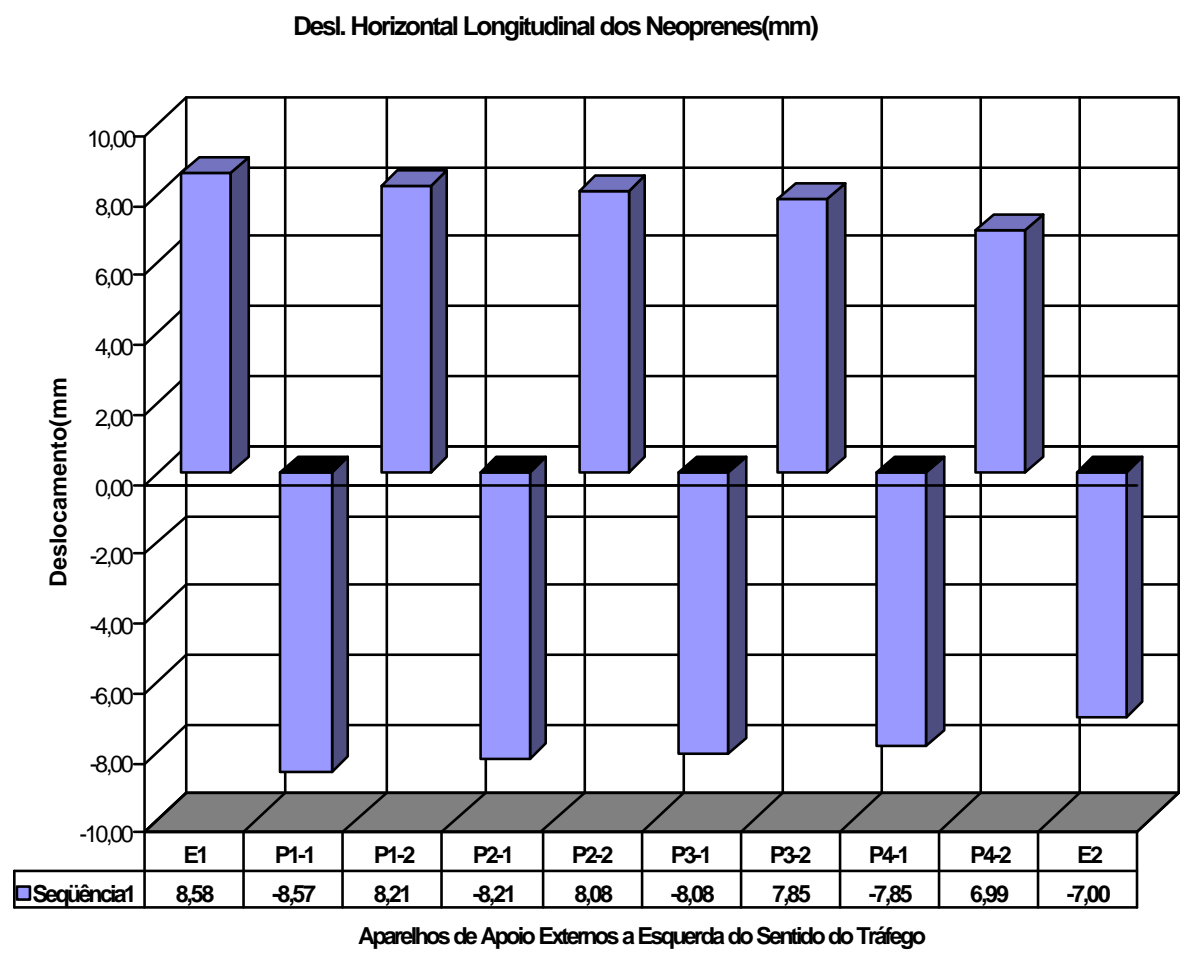

Fig. 7.46 - Deslocamento Longitudinal dos aparelhos de apoio

Obs. Os valores positivos dos deslocamentos estão relacionados à distorção por cisalhamento no sentido horário, e os valores negativos relacionados com a distorção no sentido anti-horário; 
Exemplos Numéricos

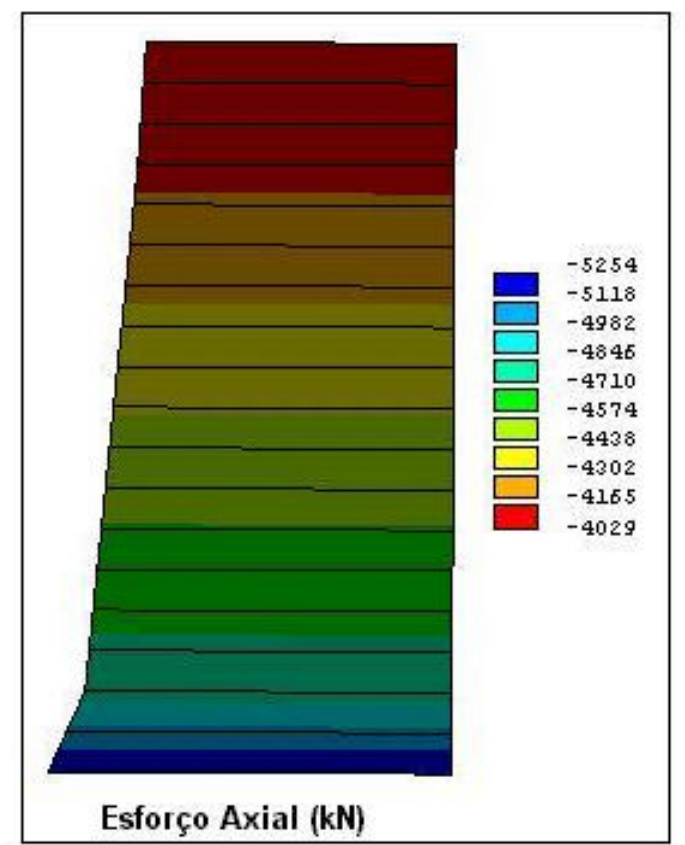

Fig. 7.47 - Esforço Normal no Pilar Esquerdo do Eixo P2

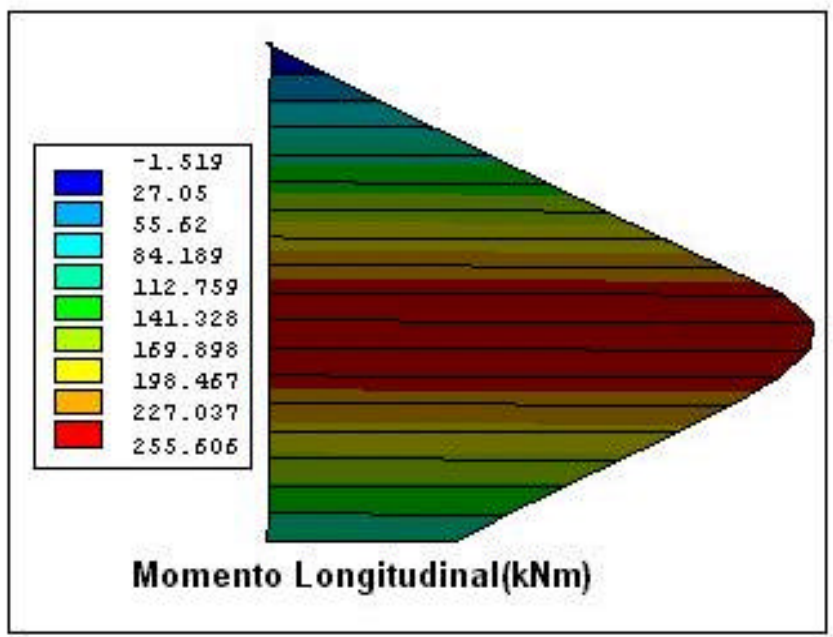

Fig. 7.48 - Momento Fletor Longitudinal no Pilar Esquerdo do Eixo P2 


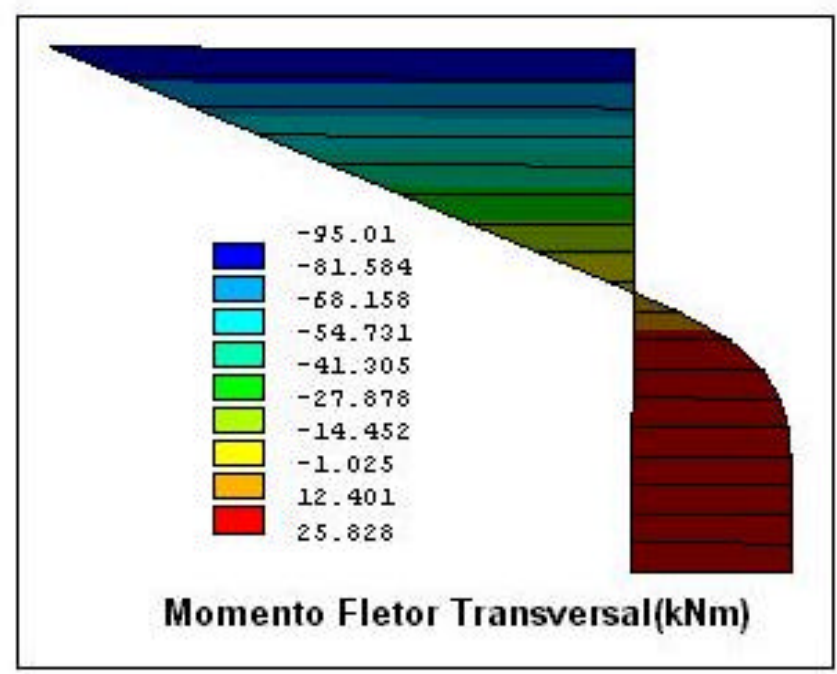

Fig. 7.49 - Momento Fletor Transversal no Pilar Esquerdo do Eixo P2

Os dispositivos de contato representativos dos aterros de acesso na modelagem indicaram, nessa fase do carregamento, o seguinte comportamento:

Encontro E1: Alívio total do empuxo ativo com descolamento de $0,116 \mathrm{~mm}$;

Para a fase do carregamento, onde só a carga permanente é aplicada, foi observado o seguinte comportamento dos aterros de acesso:

Encontro E1: Empuxo ativo remanescente igual a $29,4 \mathrm{kN}$

Encontro E2: Empuxo ativo remanescente igual a $105,5 \mathrm{kN}$

Obs. Os dispositivos de contato foram pré carregados com um empuxo inicial de $187 \mathrm{kN}$.

Ponte carregada: Combinação Rara das ações - Análise Linear Ações consideradas: Carga permanente, retração e fluência ( aplicadas após a instalação das vigas pré-moldadas) variação de temperatura no tabuleiro, vento, ação da correnteza da água, carga móvel vertical e frenagem, ( Um Veículo Rodotrem Tipo 3S2A2S2, PBTC 74 com $\mathrm{CT}=19,80 \mathrm{~m}$ ), sobrecarga no aterro de acesso E1 e desvios de execução. 


\section{Exemplos Numéricos}

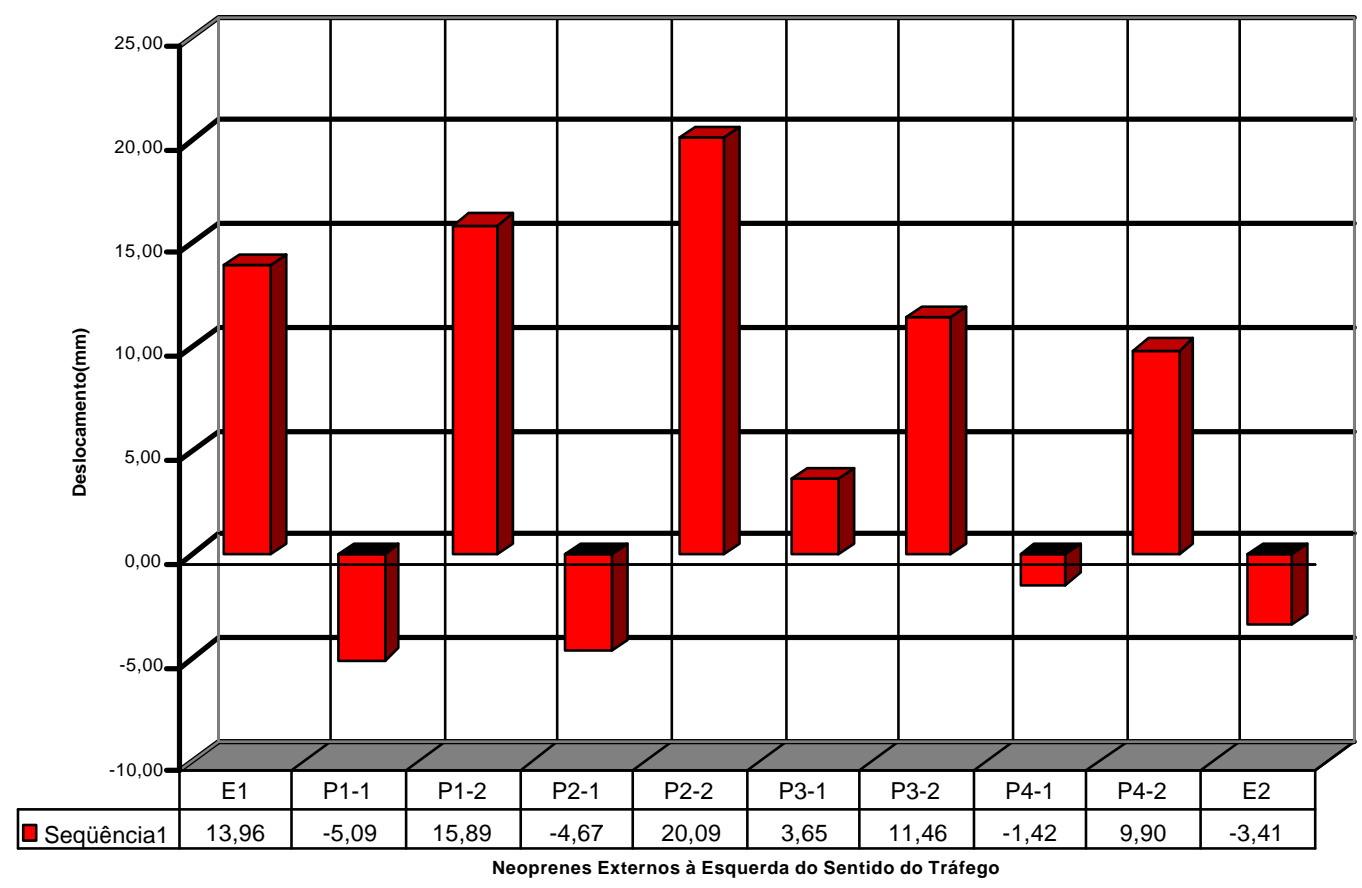

Fig. 7.50 - Deslocamento Longitudinal dos Aparelhos de Apoio

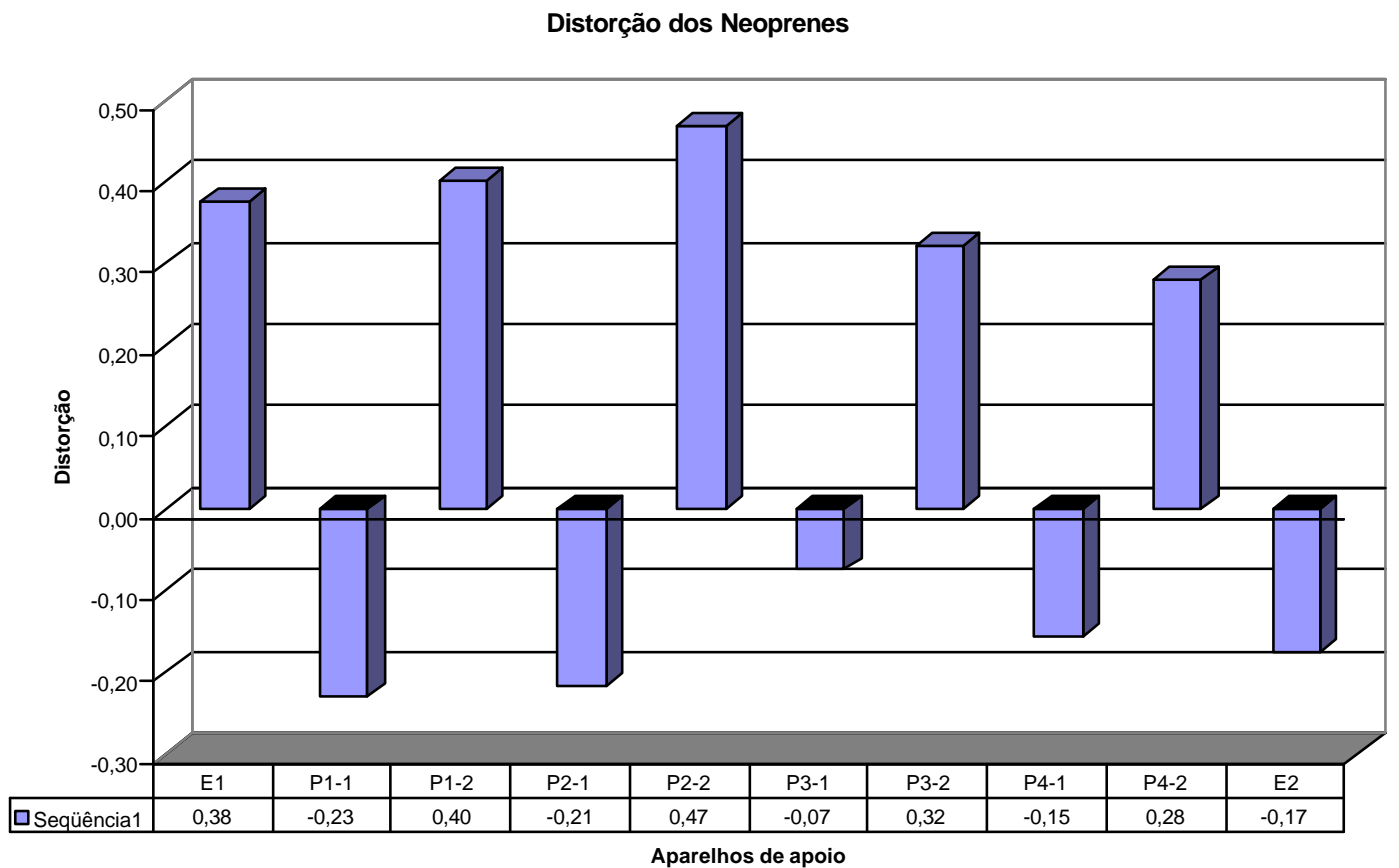

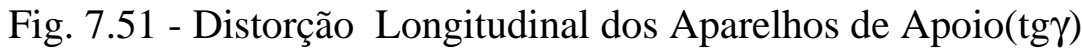




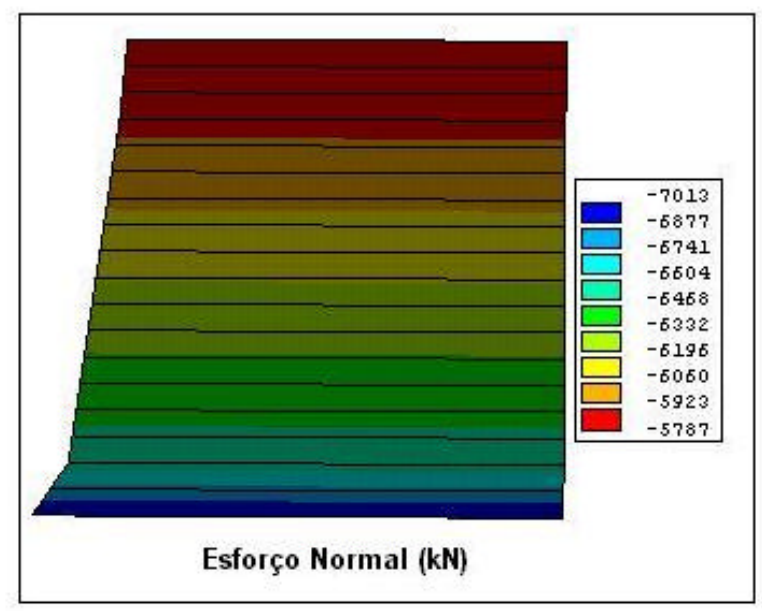

Fig. 7.52 - Esforço Axial no Pilar Esquerdo do Eixo P2

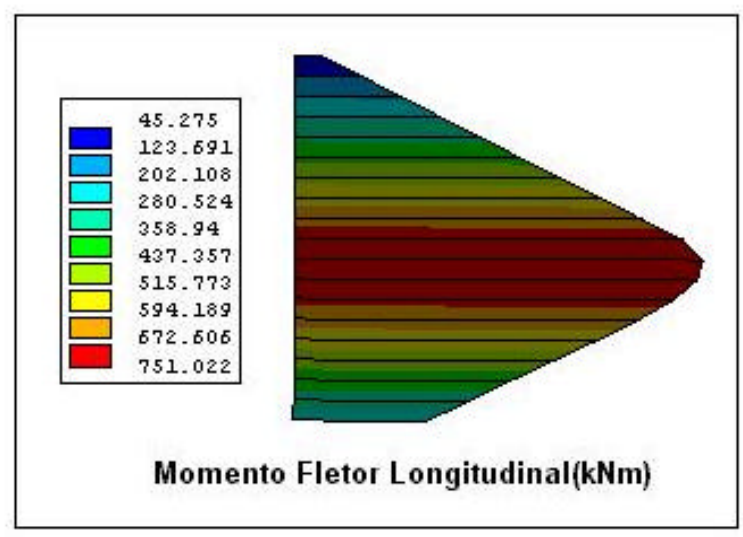

Fig. 7.53 - Momento Fletor Longitudinal no Pilar Esquerdo do Eixo P2

O posicionamento da carga móvel vertical, o sentido do vento e da correnteza do rio foram considerados de modo que ocorresse sobre o pilar esquerdo do eixo P2 uma compressão máxima. A frenagem do veículo é aplicada integralmente no vão (P2-P3).

Distorção Longitudinal tg $\gamma$ :

$\operatorname{tg} \gamma=\left(\Delta \mathrm{h}_{\mathrm{t}}-\Delta \mathrm{h}_{\mathrm{i}} / 2\right) / \mathrm{h}$, onde

$\Delta \mathrm{h}_{\mathrm{t}}=$ deslocamento longitudinal para as ações de longa duração;

$\Delta \mathrm{h}_{\mathrm{i}}=$ deslocamento longitudinal para as ações de curta duraçào;

$\mathrm{h}=$ altura total das almofadas de neoprene $(30 \mathrm{~mm})$. 


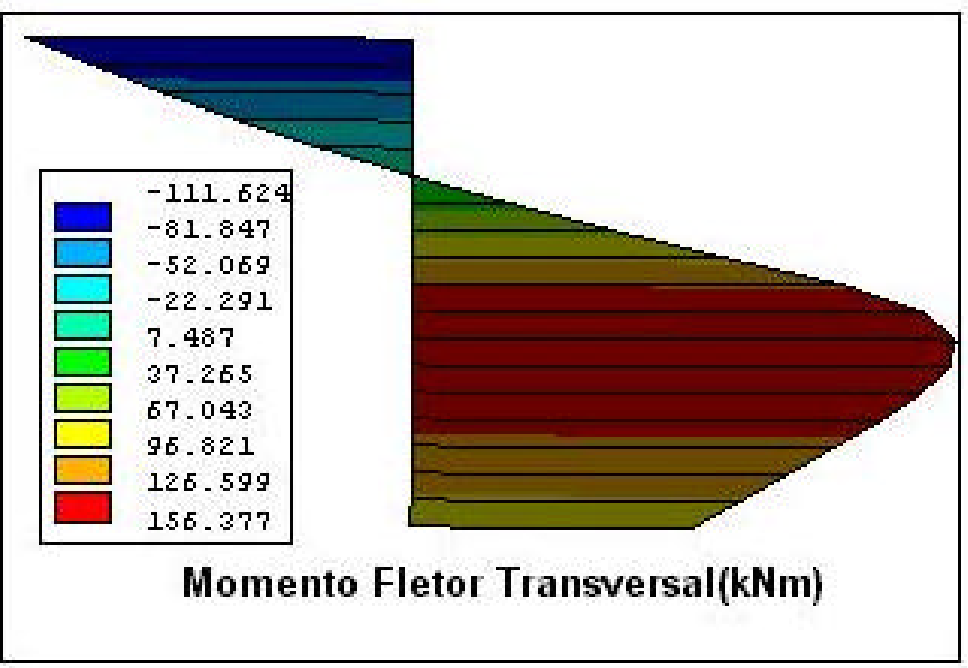

Fig. 7.54 - Momento Fletor Transversal no Pilar Esquerdo do Eixo P2

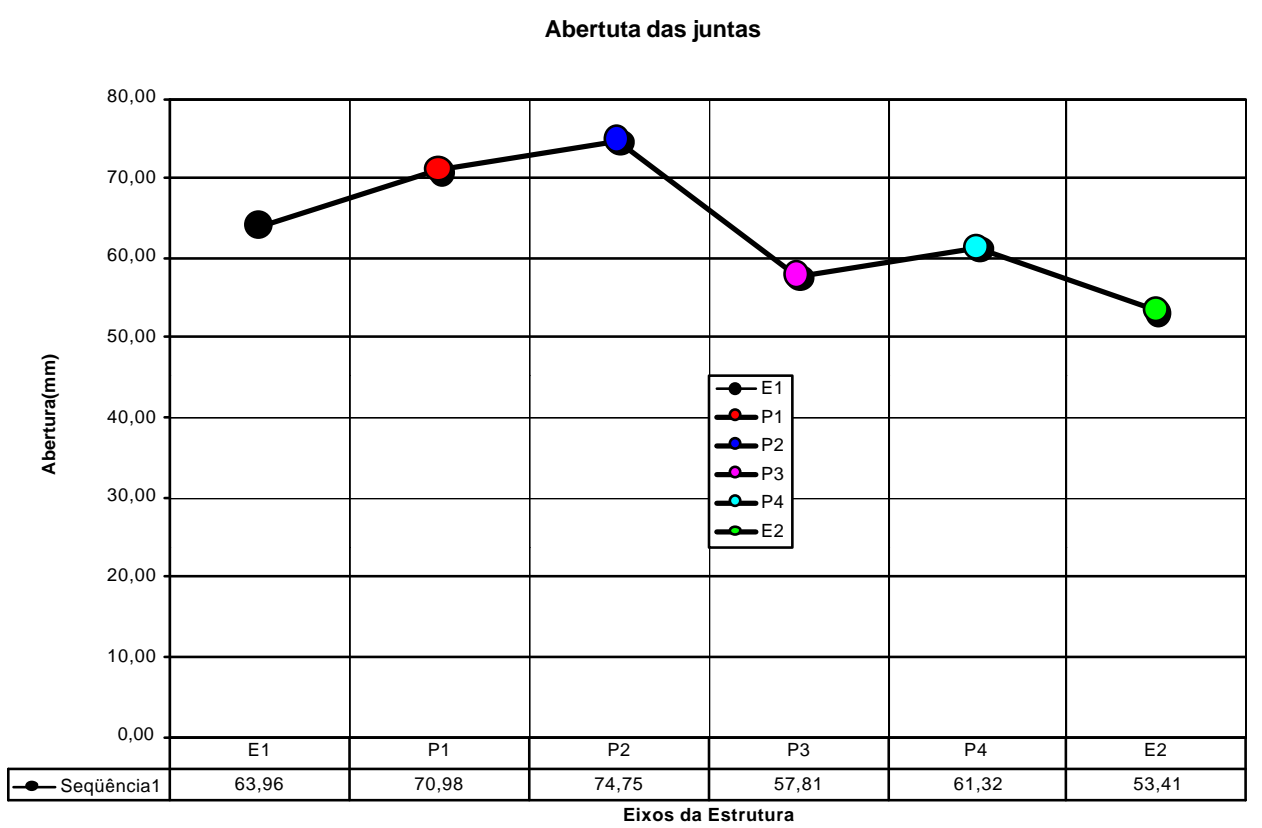

Fig. 7.55 - Abertura Total das Juntas do Tabuleiro - Combinação Rara das Ações

- Simulação 2 - Estrutura Integral com as juntas internas eliminadas

Carregamento:

Fase 1: A mudança de "status" para a Ponte Integral só é efetuada após o tempo necessário para a dissipação das deformações devidas à fluência e retração (estrutura considerada antiga). Nesta fase são aplicadas as todas as cargas 


\section{Exemplos Numéricos}

permanentes de natureza gravitacional e as deformações impostas pela retração fluência das vigas pré-moldadas.

Fase 2: A eliminação das juntas é efetuada pela continuidade da laje do tabuleiro, considerada nas juntas como diafragma. Nesta fase são aplicadas as ações consideradas transitórias: carga móvel, correnteza, vento e variação de temperatura de $-15 \mathrm{C}^{\circ}$

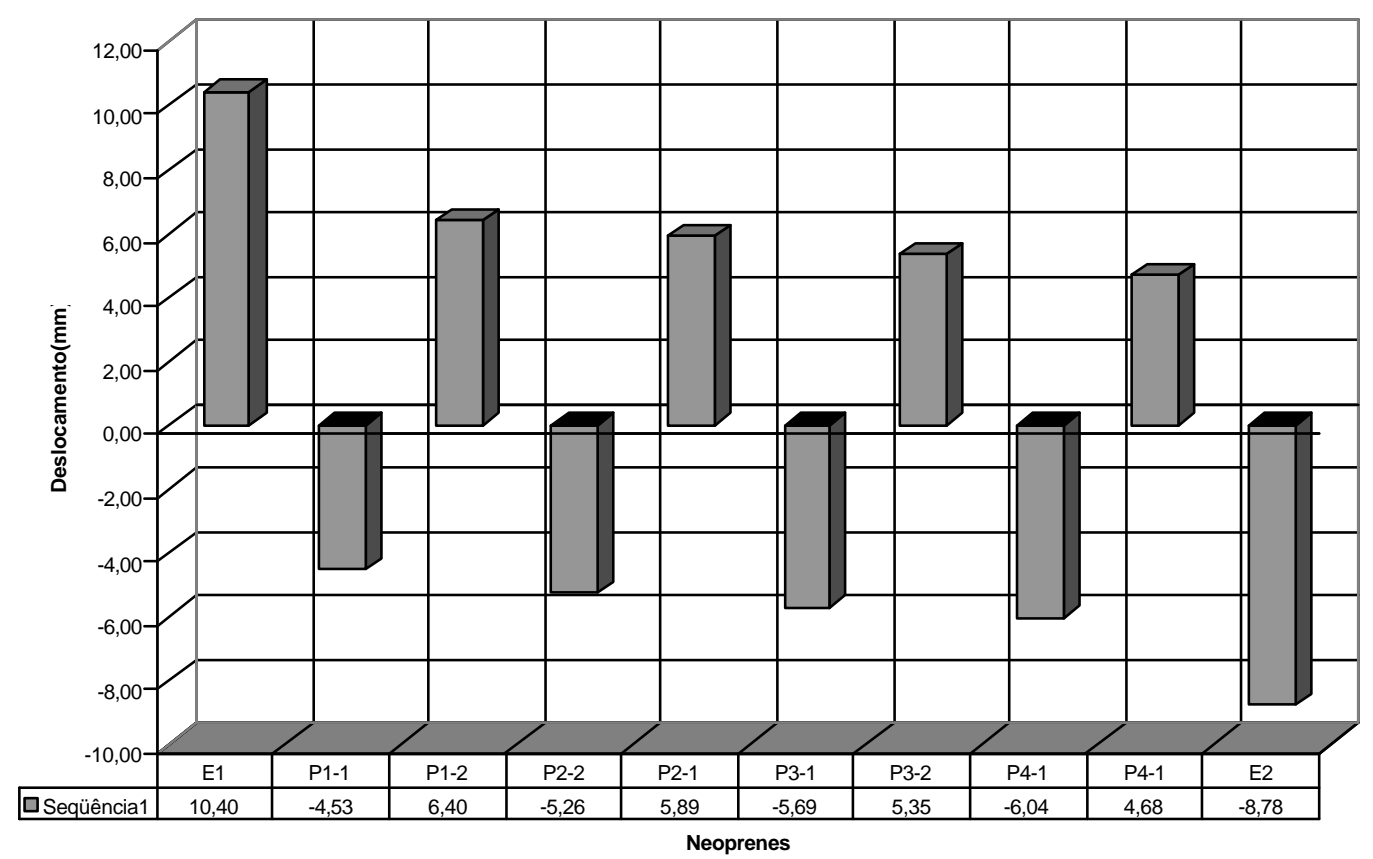

Fig. 7.56 - Deslocamento Longitudinal dos Neoprenes para o Veículo Rodotrem Tipo 3S2A2S2, PBTC 74 com CT=19,80m

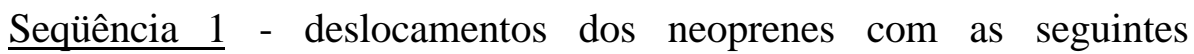
considerações:

a) Estrutura com juntas submetida a cargas de longa duração (permanente, retração e fluência);

b) Estrutura sem juntas submetida a cargas de curta duração(móvel, correnteza, vento e variação de temperatura). 
Exemplos Numéricos

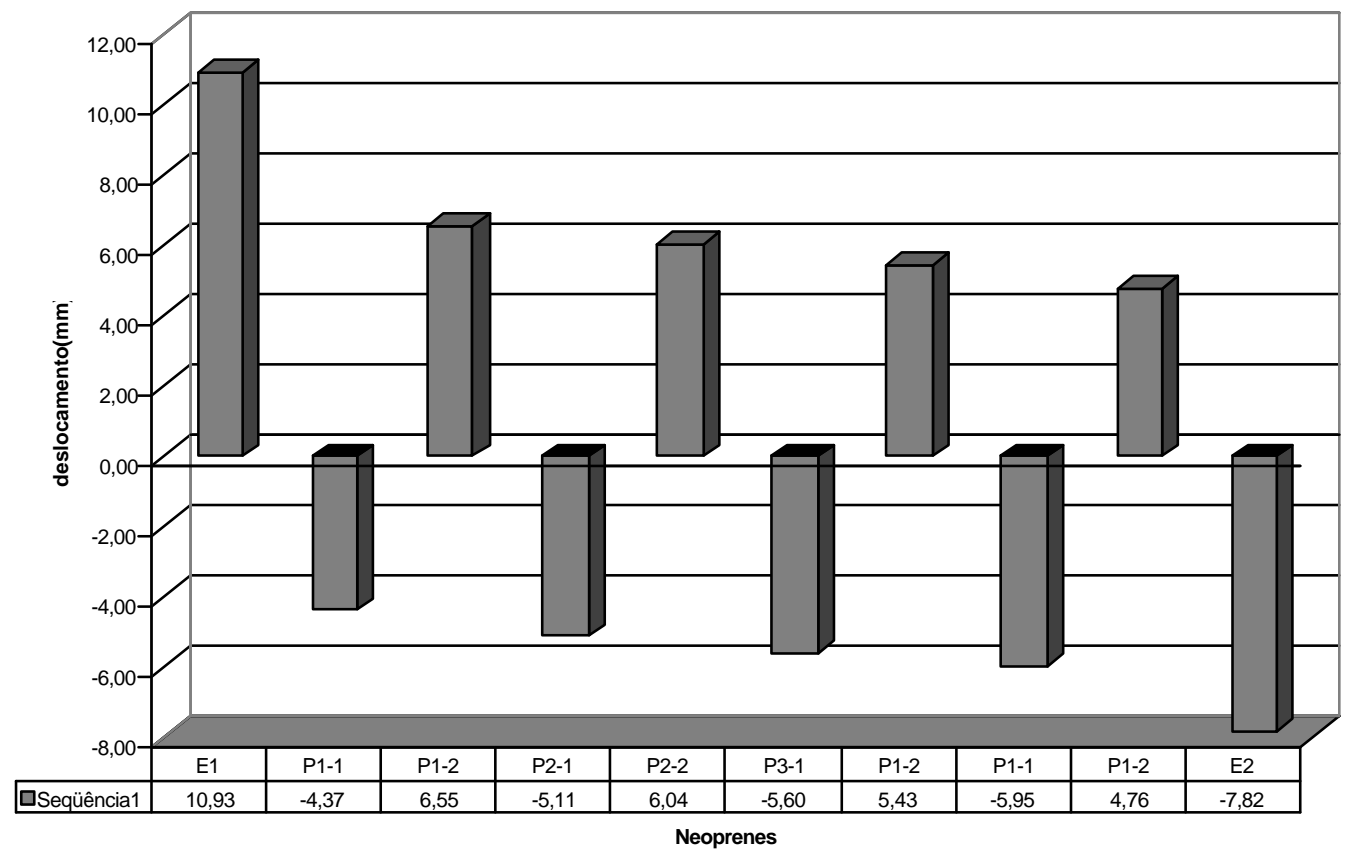

Fig. 7.57 - Deslocamento Longitudinal dos Neoprenes para Frenagem da Multidão

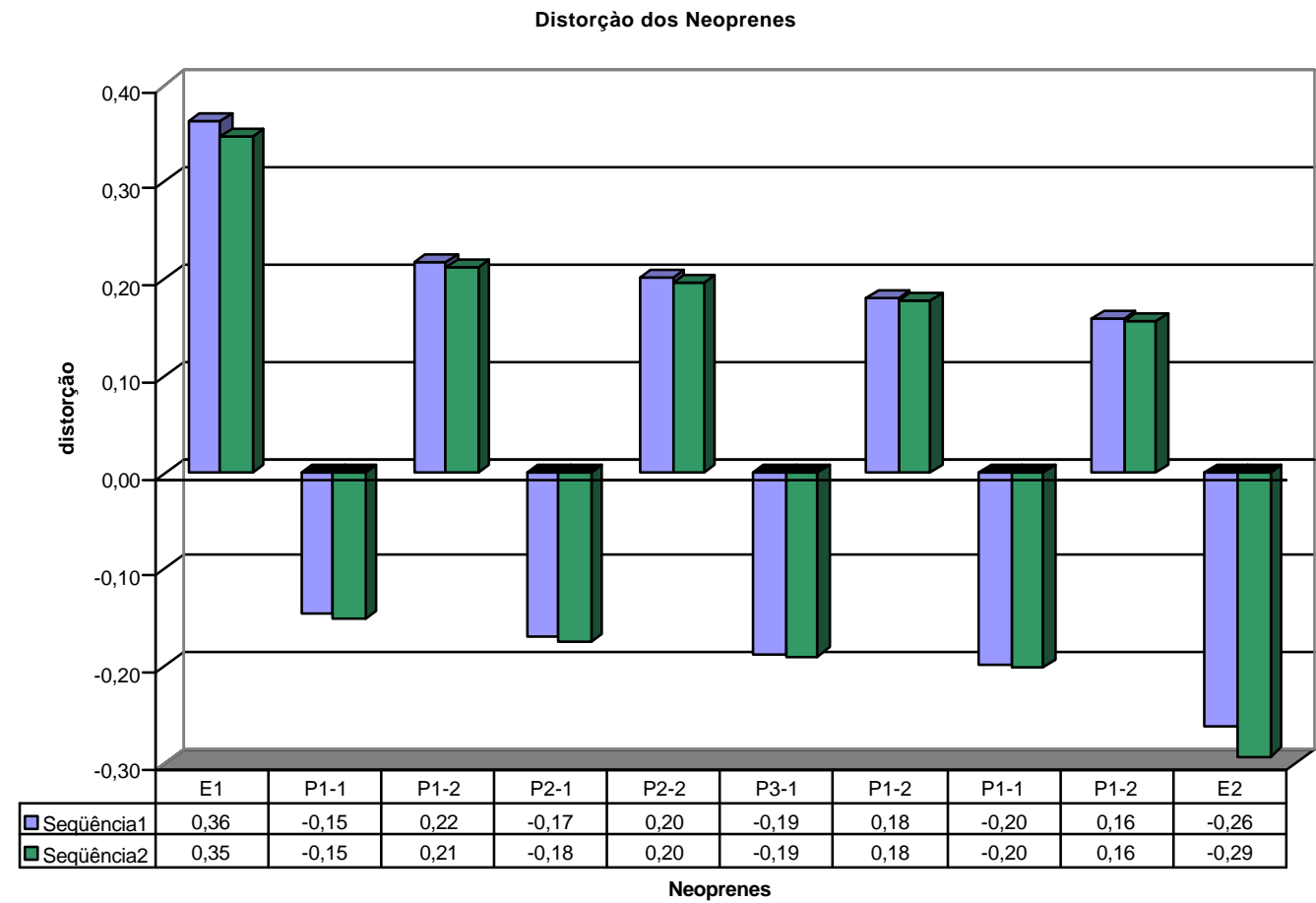

Fig. 7.58 - Distorção dos Neoprenes

Sequência1: Relacionada à frenagem da multidão;

Sequência1: Relacionada à frenagem do veículoTC 74 vãoP2-P3) 


\section{Exemplos Numéricos}

- Simulação 3 - Estrutura Integral com as juntas internas eliminadas logo após a instalação das vigas pré-moldadas

Carregamento:

Fase 1: A mudança de "status" para a Ponte Integral efetuada logo após o a instalação das vigas pré-moldadas. Nesta fase é aplicada a carga permanente de natureza gravitacional..

Fase 2: A eliminação das juntas é efetuada pela continuidade da laje do tabuleiro, considerada nas juntas como diafragma. Nesta fase são aplicadas as deformações impostas pela retração, fluência e variação de temperatura, vento, correnteza e carga móvel com o veículo PBTC 74.

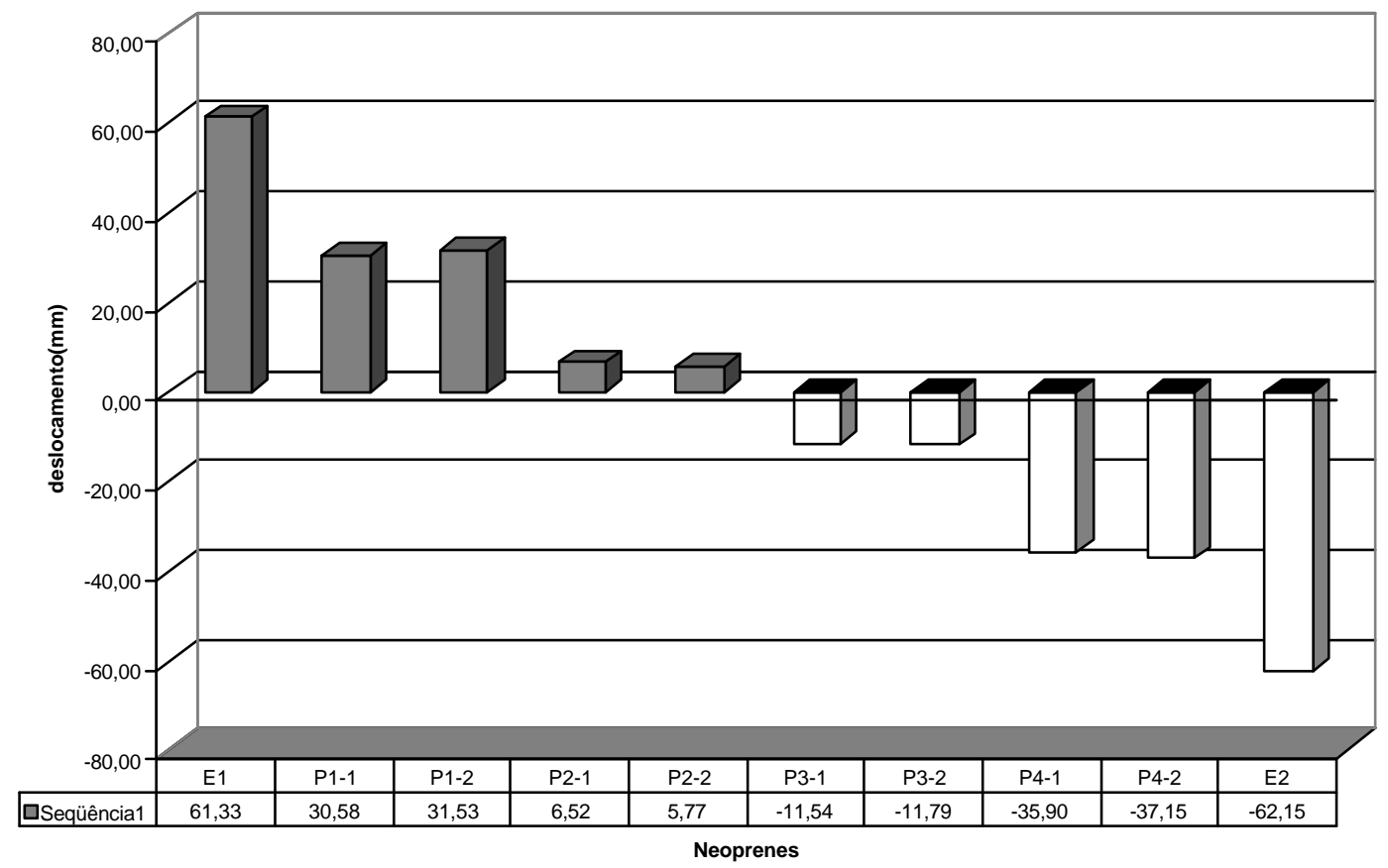

Fig. 7.59 - Fig. 7.59 - Deslocamento Longitudinal dos Neoprenes

Sequiência 1: Representa os valores dos deslocamentos longitudinais dos neoprenes, considerando somente a carga permanente de natureza gravitacional aplicada na estrutura com juntas.

- Simulação 3 - Estrutura Original com Juntas

Carregamento: Sequiência Crítica mais Desfavorável - Estado Limite Último( Pilha $1+$ Pilha 2). 
Exemplos Numéricos

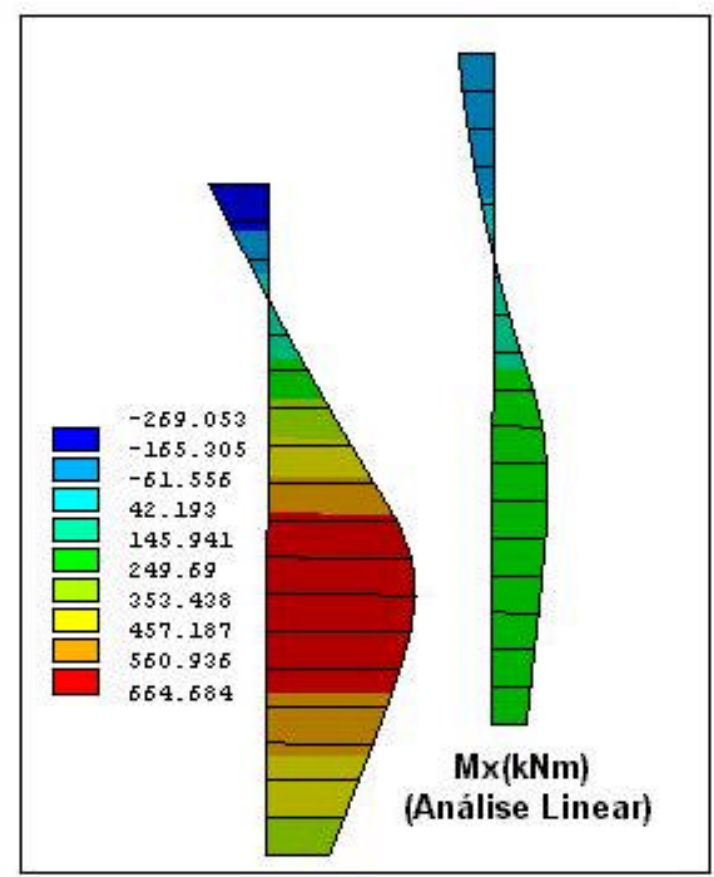

Fig. 7.60 - Momento Fletor Transversal Mx no Eixo P2 - Análise Linear

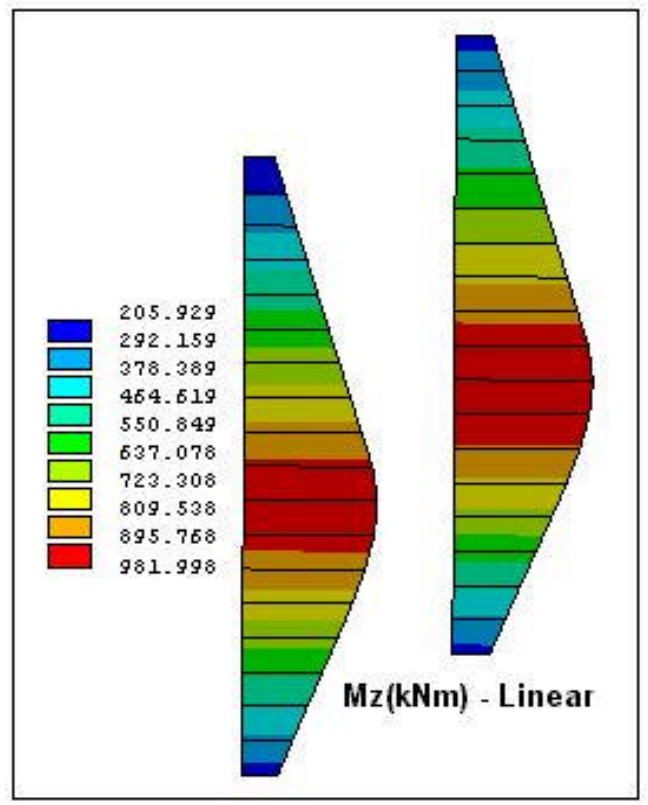

Fig. 7.61 - Momento Fletor Longitudinal Mz no Eixo P2 - Análise Linear 
Exemplos Numéricos

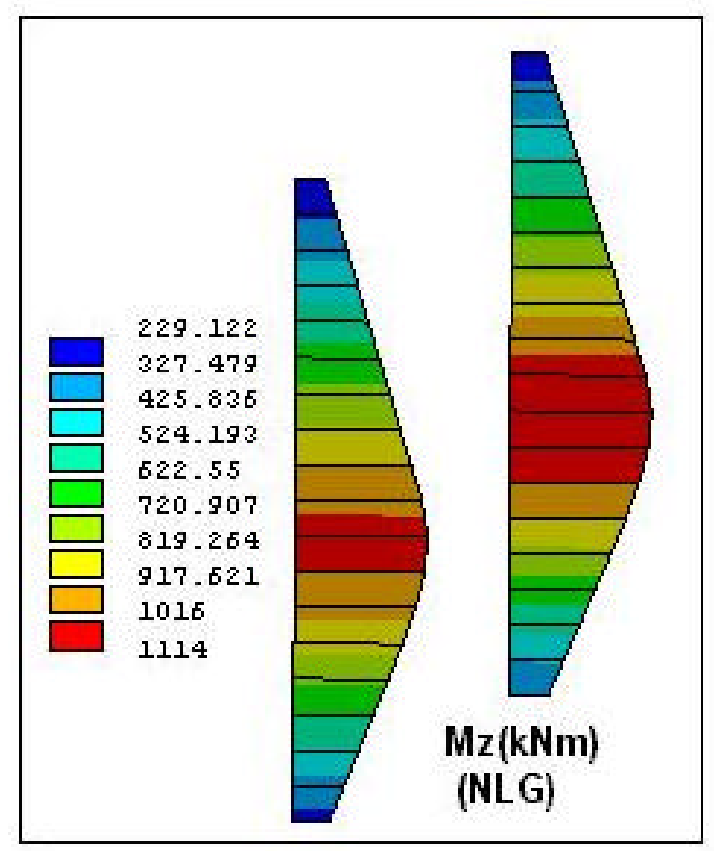

Fig. 7.62 - Momento Fletor Longitudinal Mz no Eixo P2 - NLG

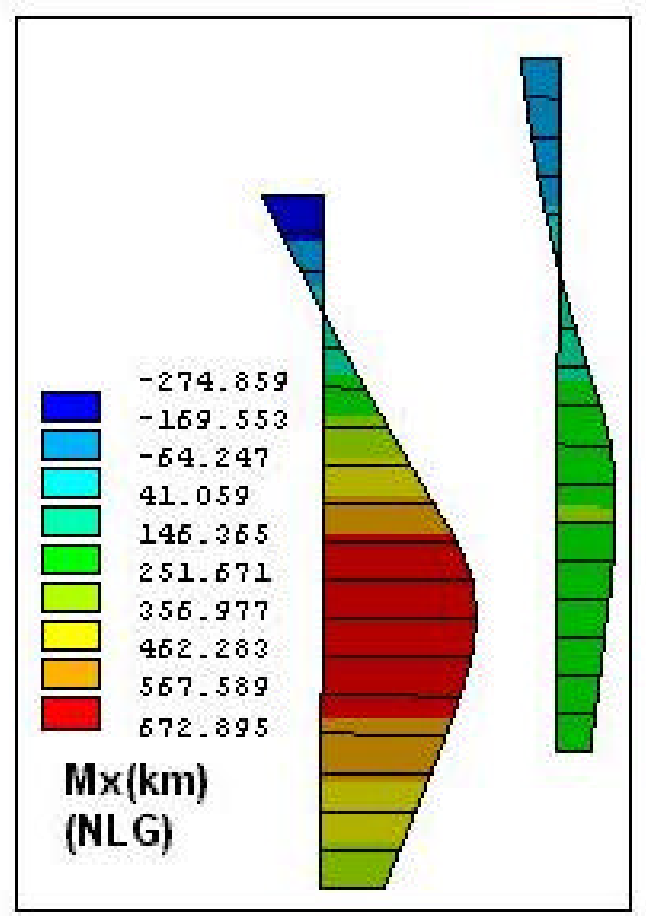

Fig. 7.63 - Momento Fletor Transversal Mx no Eixo P2 - NLG 
Exemplos Numéricos

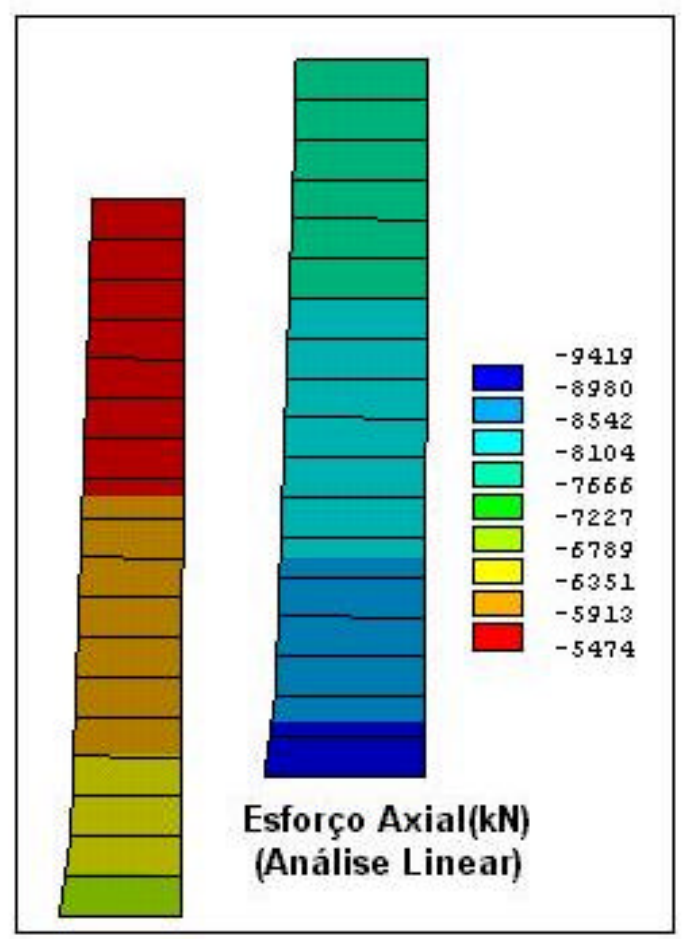

Fig. 7.64 - Esforço Axial no Pórtico do Eixo P2 - Análise Linear

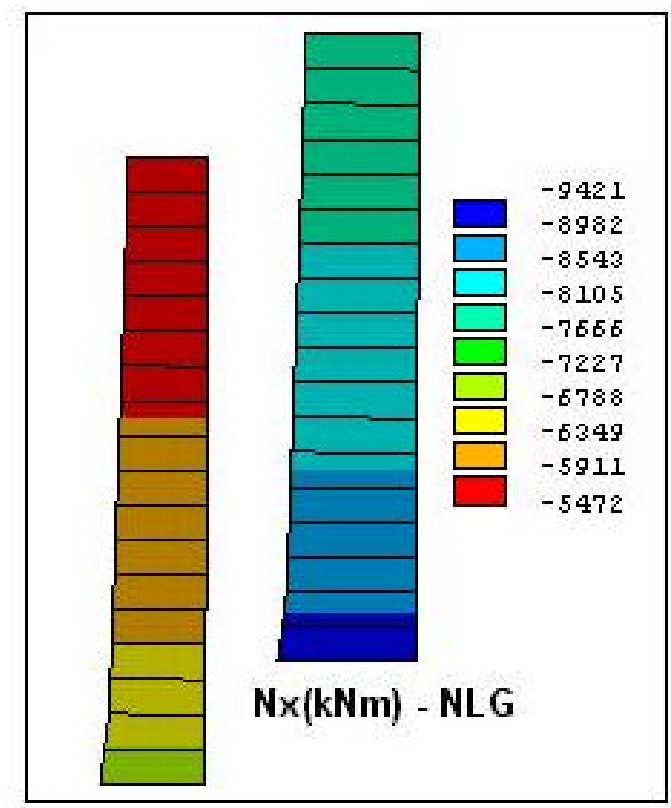

Fig. 7.65 - Esforço Axial no Pórtico do Eixo P2 - NLG 
Exemplos Numéricos

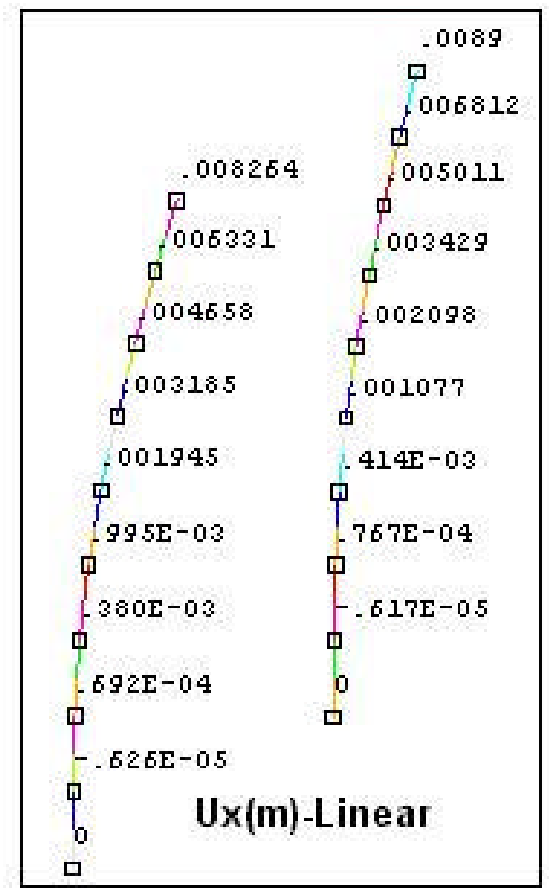

Fig. 7.66 - Deslocamento Longitudinal do Eixo P2 - Análise Linear

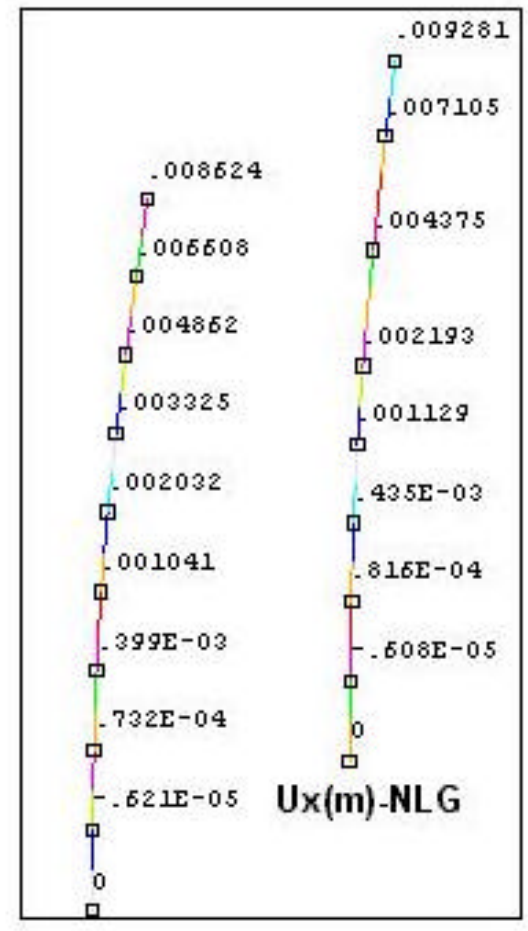

Fig. 7.67 - Deslocamento Longitudinal do Eixo P2 - NLG 
Exemplos Numéricos

\section{Efeitos da NLG no pórtico do eixo P2:}

Momento Fletor Longitudinal na seção de momento máximo: $\Delta \mathrm{M}=132 \mathrm{kNm}$;

Momento Fletor Transversal na seção de momento máximo: $\Delta \mathrm{M}=8 \mathrm{kNm}$

Deslocamento Longitudinal do pórtico no topo dos pilares: $\Delta U \mathrm{Ux}=0,000381 \mathrm{~m}$.

Taxa de variação do deslocamento: $\rho=4 \%$

- Estudo da seção de momento fletor máximo

$\mathrm{Mx}=251 \mathrm{kNm}$

$\mathrm{Mz}=1114 \mathrm{kNm}$

$\mathrm{Nx}=-8374 \mathrm{kN}($ compressão $)$

$\mathrm{Nxo}=-4479 \mathrm{kNm}$ (esforço axial inicial - carga permanente)

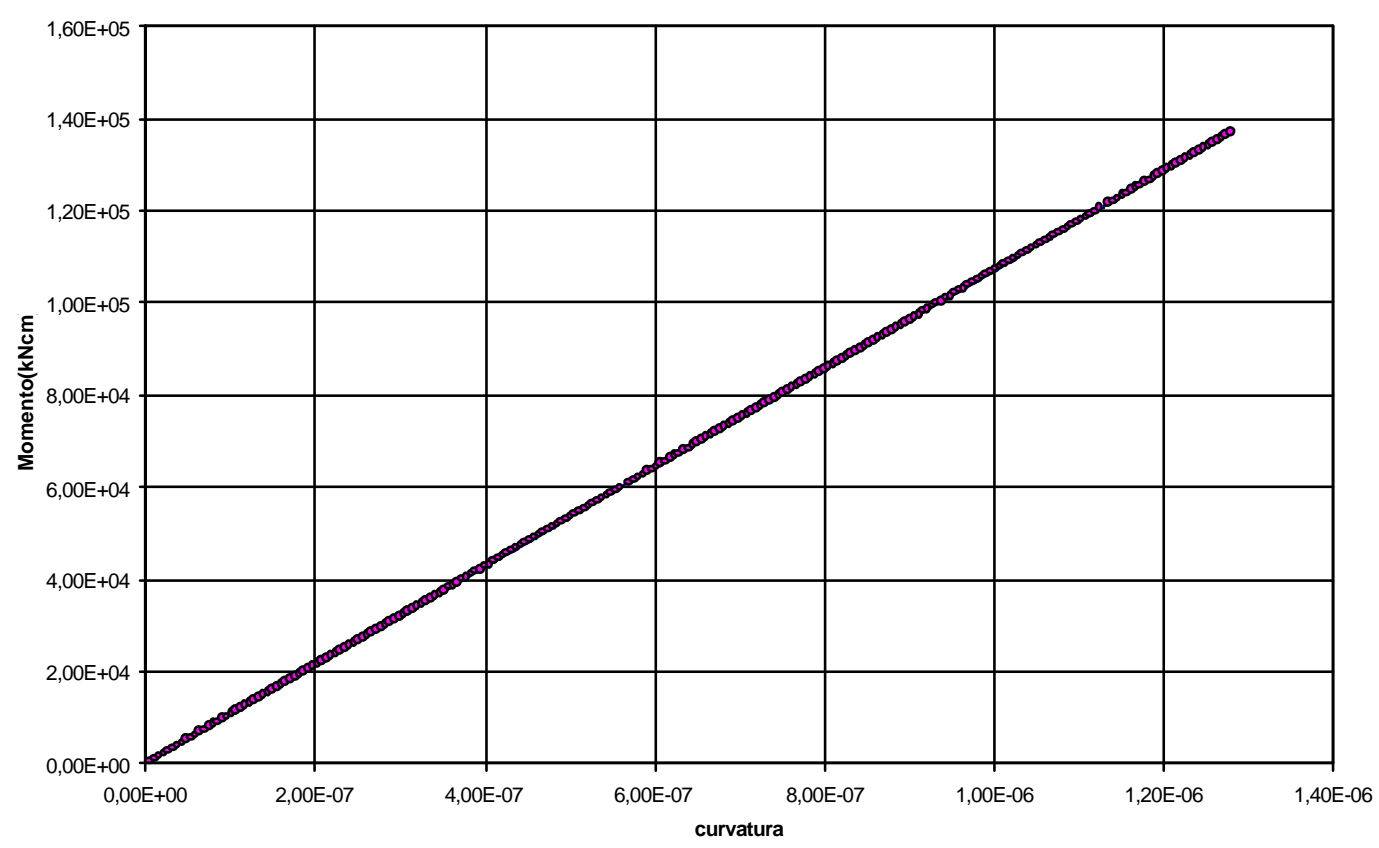

Fig. 7.68 Relação Momento-Curvatura na Seção de Mmax $\mathrm{Df}=160 \mathrm{~cm}$ (diâmetro do fuste do tubulão) 
Exemplos Numéricos

$\mathrm{As}=130 \mathrm{~cm}^{2} \quad(25 \phi 25 \mathrm{~mm}-$ armadura longitudinal disponível na

seção);

$\rho_{\mathrm{l}}=0,65 \%$ (taxa geométrica da armadura principal);

$\mathrm{C}=6 \mathrm{~cm}$ (cobrimento da armadura);

Ast $=\phi 8 \mathrm{c} / 20 \mathrm{~cm}$ (armadura dos estribos);

$\rho_{\mathrm{t}}=0,00063$ (taxa volumétrica dos estribos);

fck=20MPa, Aço: CA 50 A

Estudo da seção com compressão máxima

$\mathrm{Mx}=170 \mathrm{kNm}$

$\mathrm{Mz}=448 \mathrm{kNm}$;

$\mathrm{Nx}=-9421 \mathrm{kN}($ compressão $)$

$\mathrm{Nxo}=-5254 \mathrm{kN}($ esforço axial inicial - carga permanente)

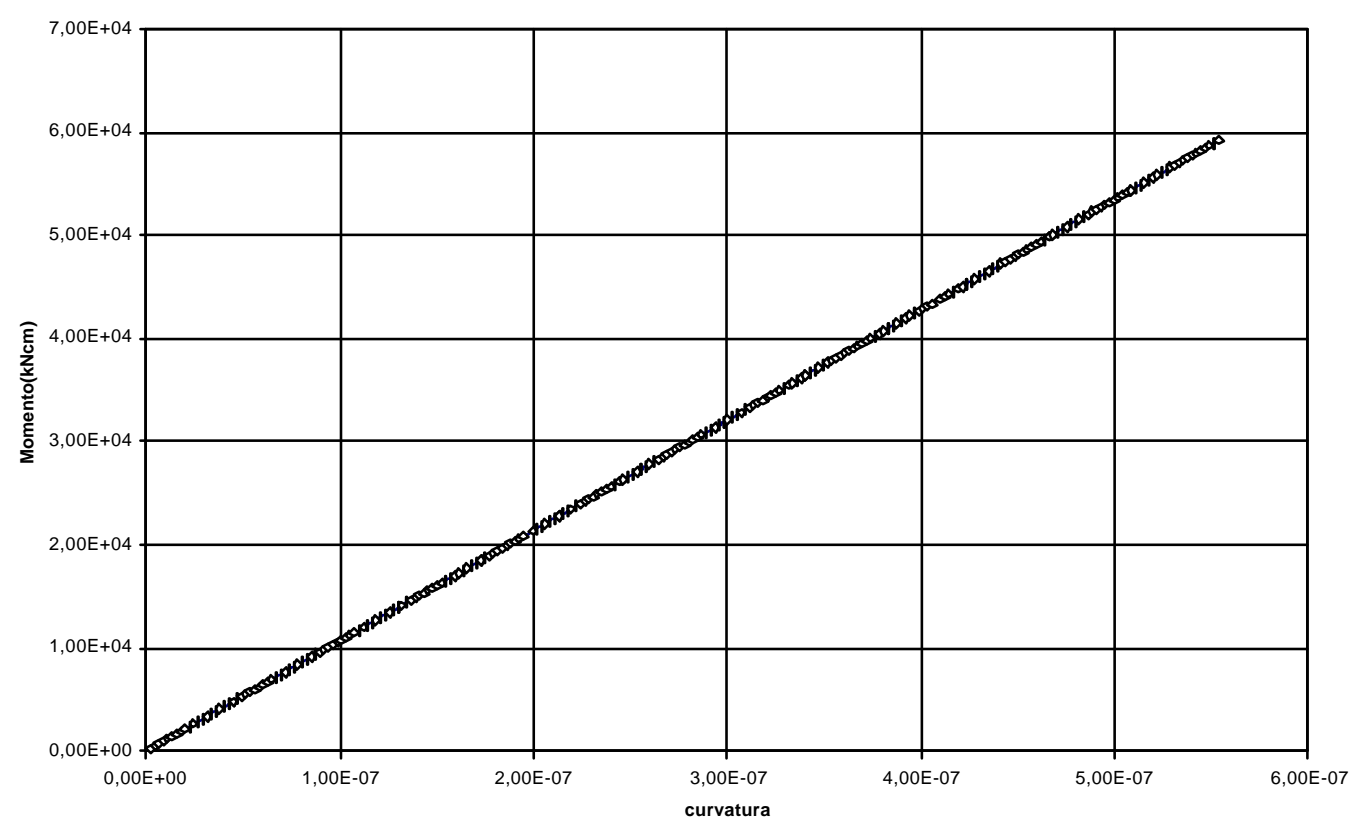

Fig. 7.69 - Relação Momento-Curvatura na Seção de Nmax 


\section{Exemplos Numéricos}

\section{Exemplo 4: comentários}

$\mathrm{Na}$ simulação 1, onde foi efetuada a análise linear da estrutura, considerando-se somente as ações de caráter permanente (peso próprio, retração, fluência e variação de temperatura), os aparelhos de apoio de neoprene apresentaram deslocamentos significativos. No encontro E1 e Eixo P1 os deslocamentos dos neoprenes sofreram deslocamentos em torno de $8,6 \mathrm{~mm}$.Os momentos fletores no pórtico do eixo P2 são pouco significativos em comparação com o esforço axial de compressão. ( Fig. 7.47 a 7.49). Nesta fase, os empuxos ativos dos aterros de acesso sofreram alívios, principalmente no encontro E1, onde o empuxo inicialmente aplicado de $187 \mathrm{kN}$ ficou reduzido a $29,4 \mathrm{kN}$.

Para a ponte carregada, considerando-se a Combinação Rara das Ações o aparelho de apoio P2-2 sofreu um deslocamento de 20,09mm. Esse aumento significativo do deslocamento neste aparelho de apoio se deve à aplicação do veículo PBTC 74 no vão P2-P3. Observa-se ainda, que o esforço axial de compressão no pilar esquerdo do eixo P2 sofreu um acréscimo em média de $40 \%$ relativamente ao mesmo esforço decorrente das ações permanentes. Para essa combinação das ações foi observada uma distorção máxima de 0,47 no aparelho de apoio P2-2. Nestas condições foi observada também uma abertura máxima de $74,75 \mathrm{~mm}$ na junta do eixo P2( junta com abertura inicial de 50mm).

$\mathrm{Na}$ simulação 2 foram analisados os efeitos da eliminação das juntas dos eixos internos da estrutura. Os diafragmas utilizados na eliminação das juntas são instalados após a aplicação da carga permanente. Foi observada a impossibilidade de se eliminar as juntas logo após a instalação das vigas pré-moldadas, uma vez que, os efeitos da retração, da fluência nas vigas do tabuleiro e variação de temperatura induzem nos aparelhos de apoio dos encontros deslocamentos inaceitáveis. Por outro lado, a eliminação das juntas após a dissipação dos efeitos da retração e fluência na estrutura original com juntas revelou-se viável.

Os efeitos provocados nos aparelhos de apoio pela frenagem do PBTC 74 não diferem muito dos efeitos provocados pela frenagem da multidão, aplicada na pista de rolamento da estrutura original com juntas. 


\section{Exemplos Numéricos}

Verificações complementares, principalmente nos elementos estruturais da superestrutura devem ser efetuadas para concluir-se em definitivo da habilitação ou não da circulação desses veículos especiais

\section{- Rigidez das Seções dos Tubulões do Eixo P2}

Dados dos tubulões dos eixos P1 a P4: $\phi=160 \mathrm{~cm}, \mathrm{f}_{\mathrm{ck}}=20 \mathrm{MPa}$, $26 \phi 25 \mathrm{~mm}, \phi 8 \mathrm{c} / 20 \mathrm{~cm}$

$\mathrm{A}_{\mathrm{c}}=2,0 \mathrm{~m}^{2}, \mathrm{~A}_{\mathrm{s}}=130 \mathrm{~cm}^{2}, \rho_{\mathrm{sl}}=0,65 \%, \rho_{\mathrm{st}}=0,065 \%$

Momento de Inércia da Seção Bruta: $I_{c}=0,32 E+08 \mathrm{~cm}^{4}$

Momento de Inércia da Seção Transformada: $\mathrm{I}_{\mathrm{ct}}=0,34 \mathrm{E}+08 \mathrm{~cm}^{4}$

Área da Seção Transformada: $0,208 \mathrm{E}+5 \mathrm{~cm}^{2}$

Idade do concreto: 60 dias (simulação)

Módulo de Elasticidade Secante Utilizado no processamento( $\left.\mathrm{E}_{\mathrm{cs}}\right)$

$\mathrm{E}_{\mathrm{cs}}=0,9 \mathrm{E}_{\mathrm{c}}$, onde

$\mathrm{E}_{\mathrm{c}}=6600 \sqrt{\mathrm{f}_{\mathrm{cj}}}(\mathrm{em} \mathrm{MPa})$

$\mathrm{f}_{\mathrm{cj}}=\mathrm{f}_{\mathrm{ck}}+3,5 \mathrm{MPa}$

$\mathrm{f}_{\mathrm{cj}}(60)=23,5 \times 1.08=25,38 \mathrm{MPa}$

$\mathrm{E}_{\mathrm{cs}} \cong 30000 \mathrm{MPa}$

\section{Rigidez da seção do tubulão}

$\left(\mathrm{EI}_{\mathrm{c}}\right)=9,60 \mathrm{E}+10 \mathrm{kNcm}{ }^{2}$

$\left(\mathrm{EI}_{\mathrm{ct}}\right)=10,20 \mathrm{E}+10 \mathrm{kNcm}{ }^{2}$

Da Fig. 7.67

$(\mathrm{EI})=10,53 \mathrm{E}+10 \mathrm{kNcm} 2$

Da Fig. 7.68

$(E I)=10,80 \mathrm{E}+10 \mathrm{kNcm} 2$

Equação Constitutiva do Concreto - 60 dias (s/ fluência) 
Exemplos Numéricos

Tensão de Pico:

$\mathrm{fcc}=2,665 \mathrm{kN} / \mathrm{cm} 2(\mathrm{c} /$ base na $\mathrm{fcm}) ;$

Módulo de Elasticidade Tangente na origem:

$\mathrm{Eco}=3152,80 \mathrm{kN} / \mathrm{cm} 2$

Deformação relativa à Tensão fcc

$\varepsilon \mathrm{cc}=2,29 \mathrm{E}-3$

Deformação Última Relativa à fcc/2

$\varepsilon \mathrm{u}=2,665 \mathrm{E}-3$

Taxa de Deterioração

$\mathrm{E}_{\mathrm{des}}=33755,88 \mathrm{kN} / \mathrm{cm}^{2}$ 


\section{Conclusões}

\section{CAPÍTULO 8 CONCLUSÕES}

Nos projetos de pontes não há dúvida que o cálculo das suas estruturas deve ser necessariamente baseado em modelagens completas onde todos os seus elementos constitutivos são integrados em um único sistema. Assim sendo, os aparelhos de apoio, os elementos da superestrutura, os elementos da infra-estrutura e principalmente o maciço de solos devem ser tratados como um todo. Tal afirmativa tem como referência os resultados observados nos exemplos numéricos efetuados no capítulo 7. Observa-se que a noção de esbeltez fica seriamente comprometida quando na análise se incorpora o solo como elemento constituinte da estrutura. No primeiro exemplo, modelado para uma areia de compacidade média e submersa, os momentos fletores máximos ocorreram a uma profundidade em torno de 4,5m abaixo do nível do terreno. Nos casos de solo com estratificação mais diversificada, como se apresentam os casos reais, onde cada caso é um caso, torna-se impossível prever onde ocorrerão os pontos de inflexão nos elementos da infra-estrutura. Quais são as consequiências decorrentes desse fato? Um elemento da infra-estrutura constituído por uma associação de um tubulão confinado e a partir do seu topo por um pilar de rigidez menor, como é o caso do exemplo 1, a avaliação dos parâmetros de esbeltez fica seriamente comprometida, e consequentemente a aplicação dos Métodos Simplificados fica inviabilizada. $\mathrm{Na}$ análise do exemplo 1, o deslocamento de segunda ordem ( $8 \mathrm{~mm}$ ) no topo do pilar corresponde a $22,8 \%$ do seu corresponde ao da análise linear, o que caracteriza o conjunto como deslocável. Essa caracterização da estrutura como deslocável ou não, baseada no confronto entre efeitos lineares e os não lineares é dependente da combinação das ações e do seu histórico de aplicação. No caso do exemplo 1, uma estrutura morfologicamente deslocável pode ser classificada como indeslocável, bastando para tal, reduzir a carga de frenagem ou 


\section{Conclusões}

reduzir o seu desvio construtivo acidental. Em todos os exemplos ensaiados os deslocamentos máximos dos tubulões foram da ordem de fração de milímetros, levando a crer que, embora sejam fortemente não lineares, as curvas de resistência py do solo somente são ativadas naquela pequena porção no entorno da sua origem. Isto permite, salvo algumas exceções, modelar o solo como linearmente elástico para os casos típicos de projeto de pontes. Nos Exemplos estudos no capítulo 7, a aplicação do esforço normal, mesmo nas seções críticas onde ocorrem os maiores momentos fletores de cálculo, se restringe ao núcleo central de inércia (pequena excentricidade). Esta situação determina o dimensionamento destas seções no Domínio 5 do Estado Limite Último onde as mesmas são totalmente comprimidas. Nas demais seções onde a combinação dos esforços é menos critica para as seções, este "status" de seção totalmente comprimida leva a crer, salvo melhor juízo, que os pilares de pontes são na sua maioria, salvo em alguns casos especiais, isentos de fissuração e portanto com as relações momento vs. curvatura bem próximo do comportamento linear. A redução da rigidez do tubulão e do pilar no exemplo 1 para 0,8EI apresentou um acréscimo significativo do efeito de segunda ordem em relação aos efeitos lineares. Neste caso, o deslocamento de segunda ordem foi de 19,6mm, correspondendo a 55,3\% dos deslocamentos lineares. No exemplo 2, onde a superestrutura é apoiada diretamente em tubulões totalmente enterrados, os efeitos não lineares nos tubulões não foram significativos. A variação dos momentos fletores nas seções criticas em decorrência dos efeitos não lineares não excederam, em média, $8 \%$ dos valores correspondentes aos de primeira ordem. Os deslocamentos de segunda ordem, relativamente aos de primeira, apresentam uma variação em média não superior a 6\%. Do mesmo modo, a aplicação do esforço normal nessas seções ficou restrito ao núcleo central de inércia, portanto sem fissuração. O fato do esforço normal ficar restrito ao núcleo central de inércia, na maioria dos casos, se deve à própria característica da estrutura que mantém elevados níveis de compressão inicial nas seções. Isto se deve ao seu peso próprio e baixos valores de esforços horizontais. No exemplo 3 os momentos fletores $\mathrm{Mz}$ e My, assim como, os deslocamentos longitudinais e transversais apresentaram diferenças pouco significativas no que se refere às análises linear e NLG. Nas simulações efetuadas no exemplo 4 para uma carga móvel especial, no caso o Rodotrem PBTC 74, os resultados indicaram que o 


\section{Conclusões}

comportamento dos aparelhos de apoio de neoprene e dos elementos da infraestrutura não apontaram para diferenças significativas quanto ao seu projeto original com juntas no tabuleiro. As distorções por cisalhamento nos aparelhos de apoio de neoprene provocadas pela frenagem do PBTC 74 diferem muito pouco das distorções provocadas pela frenagem da multidão aplicada em toda o tabuleiro da estrutura. As simulações efetuadas sinalizaram para a possibilidade de se eliminar as juntas do tabuleiro, somente para as pontes mais antigas, supondo-se nestes casos que as deformações impostas pela retração e fluência do concreto do tabuleiro fiquem dissipadas na estrutura original. A mudança de "status" da ponte do exemplo 4 para uma "Ponte Integral", logo após a instalação das suas vigas pré-moldadas, só seria viável se no seu projeto original fossem previstos aparelhos de apoio compatíveis com as deformações significativas impostas pela retração, pela fluência e pela variação de temperatura da estrutura do tabuleiro. Para o caso de pontes de comprimentos maiores, a eliminação das suas juntas, mesmo em época tardia, deve ser feita com critério, no sentido de selecionar quais juntas devem ser eliminadas e quais devem ser mantidas. As simulações efetuadas com a ponte do exemplo 4 indicam que a carga permanente induz um alívio substancial do empuxo ativo dos aterros de acesso. Portanto a utilização dos aterros de acesso como dispositivos de resistência à frenagem e esforços horizontais é temerária e não recomendável, uma vez que facilmente descolam das cortinas em decorrência da movimentação continua da estrutura. No exemplo 4 também foram observados e avaliados no seu eixo P2 a diferença pouca significativa entre os efeitos de primeira ordem e os de segunda ordem. A obtenção das curvas momento-curvatura para as seções críticas do pórtico P2 indicam um comportamento linear sem perda de estabilidade para os esforços de cálculo, indicando que a rigidez mais adequada para o processamento da estrutura não é o da sua redução, mas sim, a sua majoração. No caso do exemplo 4 a rigidez baseada na seção transformada revelou-se bastante adequada com valores bem próximos da resposta da estrutura. Para a confirmação do que foi observado nos exemplos do capítulo 7,se faz necessária a continuação desse trabalho em outros tipos estruturais de pontes. A interação solo-estrutura com outras abordagem e modelagem que levem em consideração também na interação os deslocamentos verticais, efeitos de grupo, avaliação dos efeitos da eliminação das juntas nos 


\section{Conclusões}

encontros e modelagem mais adequada dos aterros de acesso e avaliação do seu comportamento sob carregamentos repetitivos, são ainda aspectos em aberto que necessitam ser mais estudados. Muitos são os problemas e dúvidas existentes neste campo, diretrizes. 


\section{REFERÊNCIAS BIBLIOGRÁFICAS}

\section{REFERÊNCIA BIBLIOGRÁFICA BÁSICA}

1- AMERICAN ASSOCIATION OF STATE HIGHWAY AND TRANSPORTATION OFFICIALS (AASHTO - 1994). Standadart Specification of Highway Bridges - Washington, D.C..

2 - $\quad$ ABNT(2000). Texto para Revisão da NB - 1 e Comentários

3 - $\quad$ AMERICAN CONCRETE INSTITUTE (ACI). Building Code Requirements for Reinforced Concrete. 318R-89-Revised 1992.

4 - ANTUNES, H. M. C. C (1978). Carregamento Crítico de Instabilidade Geral para Estruturas Tridimensionais de Edifícios Altos. São Carlos, 160p. Tese (Doutorado) - Escola de Engenharia de São Carlos - USP.

5 - $\quad$ AOKI, N. (1986). Modelo Simples de Transferência de Carga de Estaca Vertical Sujeita a Carga Axial de Compressão", IME-RJ.

6 - ARGYRIS, J. H. \& KELSEY, S. (1955). Energy theorems and structural analysis, v. 26/27, Part I por J.H. Argyris e Part II por J.H. Argyris e S. Kelsey, October 1954 to May.1955.

7 - $\quad$ ARGYRIS, J.H. (1965). "Continua and Discontinua", Proceedings, Conference on Matrix Methods in Structural Mechanics, Wright-Patterson A.F.B.. Ohio, Oct. 1965.

8 - $\quad$ ARGYRIS, J.H.; HILPERT, O.; MALEJANNAKIS, G. A. \& SCHARPF, D. W. (1979). On the geometrical stiffiness of a beam in space - A consistent V.W. Approach. Computer Methods in Applied Mechanics and Engineering, v. 20, p. 105-131.

9 - $\quad$ BANNERJEE, K. \& DAVIES,T.G. (1978). The Behavior of Axially and Laterally Loaded Single Piles Embedded in Non-homogeneous Soils. Géotechnique, London, England, 28(3),309-329.

10 - BANNERJEE, K. \& DAVIES,T.G. (1980). Analysis of Some Reported Case Histories of Lateral Loaded Pile Groups. Proc., Conf. on Numer. Meth. In Offshore Piling, Ins. Of Civil Enginieers, London, England, 101-108.

11 - BATHE, K. J., RAMM, E. \& WILSON, E. L. (1975). Finite Element Formulation for Large DeformationDynamic Analysis. INTERNATIONAL Journal for Numerical Methods in Engineering, v. 9, p. 353-386, 1975.

12 - BATHE, K.J. \& CIMENTO, A. P. (1980). "Some Practical Procedures for the Solution of Nonlinear Finite Element Equations", Computer Methods in Appllied Mechanics and Engineering, vol. 22, pp. 59-85. 


\section{Referências bibliográficas}

13 - BATHE, K.J. (1996). Finite Element Procedures. (Revision of: Finite Element Procedures in Engineering Analysis, 1982); New Jersey, Prentice Hall, Inc., Englewood Cliffs,.

14 - BATHE, K.J. et al. (1989). Nonlinear Analysis of Concrete Structures. Computer \& Structures, v. 32, n. 3/4, p. 563-590,.

15 - $\quad$ BAZANT, Z. P. (1982). "Creep and Shrinkage in Concrete Structures. Chichester, John Willey \& Sons $2^{\underline{a}}$ edição.

16 - BENJAMIN, A. C. (1982). “Análise Não-linear Geométrica de Porticos Tridimensionais”. Tese(Mestrado) - Engenharia Civil, COPPE/UFRJ, Rio de Janeiro.

17 - BOWLES, J. E. (1977). "Foundation Analysis and Design", McGraw-Hill, Inc.

18 - BRANSON, D. E. (1972). "Discussion of Variability of Deflections of Simply Supported Reinforced Concrete Beams by ACI Committee 435, ACI Journal, Proccedings, 69, July.

19 - BREEN, J. E., MACGREGOR, J. G., \& PFRANG, E. O. (1972). "Determination of Effective Length Factors for Slender Concrete Columns", ACI Journal, Proceedings V. 69, $\mathrm{N}^{\mathrm{o}} 11$, November, pp. 669-672.

20 - BREBBIA, C. A. \& FERRANTE, A. J. (1975). Finite Element Thechnique - Editora da URGS, Porto Alegre, Brasil.

21 - CADAMURO JÚNIOR, I. W. (1997). Dissertação (Mestrado)-“Dimensionamento de Pilares Esbeltos de Concreto Armado com Seção Qualquer Solicitados por Flexão Composta Oblíqua”. Departamento de Engenharia Estrutural/EESC-USP, São Carlos-SP.

22 - $\quad$ CEB BI № 158 (1985), Manual on Cracking and Deformations.

23 - $\quad$ CEB BI N 142 (1984), Manual on Structrural of Time Dependent Behavior of Concrete.

24 - $\quad$ CEB BI № 235 (1997). Serviceability Models.

25 - C CHELliS, R. D. (1961). "Pile Foundations”, McGraw-Hill Book Co., 2nd ed., New York.

26 - CHEN, Z. Q. \& GAR, T. J. A (1993). Geometric Nonlinear Analysis of Flexible Spatial Beam Structures. Computeres \& Structures, v. 49, n. 6, p. 1083-1094

27 - Clemente, J. L.M. \& POLO, J. M. (1988). Micro-computer Analysis of Pile Group Settlement Using Independent Point and Shaft Loads - Computers \& Structures vol. $29 \mathrm{n}^{\mathrm{o}} 2$ pp. 241-25.

28 - CLOUGH, R. W. (1960). "The Finite Element Method in Stress Analysis", Proceedings, Second ASCE Conference on Electronic Computation, Pittsburgh, PA, Sept.

29 - COMITÉ EURO-INTERNATIONAL DU BÉTON, CEB-FIP (1978). Manual of Buckling and Instability. Lancaster, The construction Press Ltd,.

30 - $\quad$ COMITÉ EURO-INTERNATIONAL DU BÉTON, CEB-FIP Model code (1990).

31 - CORRÊA, M. R. S. (1991). Aperfeiçoamento de Modelos Usualmente Empregados no Projeto de Sistemas Estruturais de Edifícios. São Carlos-SP. Tese( Doutorado) - Escola de Engenharia de São Carlos - USP.

32 - $\quad$ COSENZA, E. \& DEBERNARDI, P. G. (1997), "Calculation of Stresses, Deformations and Deflections of Reinforced and Prestressed Concrete Elements in Sevice”, CEB BI № 235 Serviceability Models, Cap. 3.

33 - COX, W. R., REESE, L. C. \& GRUBBS, B. R. (1974). Field Testing of Laterally Loaded Piles in Sand. Proceedings, Offshore Technology Conference, Paper n. 2079, Houston-Texas, May. 


\section{Referências bibliográficas}

34 - CRISFIELD, M. A. (1981). A Fast Incremental/iterative Solution Procedure that Handles "snap-through". Computers \& Structures, v. 13, p. 55-62.

35 - DAVISSON, M.T. \& GILL, H. L. (1963). Laterally loaded piles in a layered soil system. J. soil mech. Found. Engrg., ASCE, 89(3), 63-94.

36 - DAVISSON, M.T. \& PRAKASH, S. (1963). A Review of Soil-pole Behavior. Stress in Soils in Layered Systems, Highway Research Record, n. 39, Transportation Research Board, National Research Coucil, Washington, D.C., 25-48.

37 - DAVISSON, M.T. \& ROBINSON, K.E. (1965). "Bending and Bucling of Partially Embedded Piles"- Proceedings of the 6th. International Conference on Soil Mechanics and Foundation Engineering Canada.

38 - DIGIOIA, A. M., DONOVAN, T. D. \& CORTESE, F. J. (1975). A Multilayered/Pressuremeter Approach to Laterally Loaded Rigid Caisson Design. ASCE Seminar on Lateral Pressures Related to Large Diameter Piles, Piles, Tunnels, and Caissons, ASCE, New York, N. Y.

39 - DINIZ, R. A. C. (1972). “Análise de Esforços em Estruturas Aporticadas com Fundações em Estacas”, Tese(Mestrado), COPPE/UFRJ, Rio de Janeiro.

40 - DOUGLAS, D. J. \& DAVIS, E. H. (1964). The Movement of Buried Footings Due to Moment and Horizontal Load and the Anchor Plates. Géotechnique, London, England, 14, 115-132.

41 - DUNCAN, J. M., EVANS, L. T. Jr., \& OOI, P. S. K. (1994). "Lateral Load Analysis of Single Piles and Drilled Shafts." Journal of .Geotechnical Engineering, ASCE, 120(6), 10181033.

42 - DYM, C. L. \& SHAMES, I. H. (1973). Solid Mechanics, a Variational Approach - McGrawHill Kogakusha, Ltd.

43 - EL-METWALLY, S. E. (1994). Method of Segment Length for Instability of Reinforced Concrete Beam-Columns, ACI Structural Journal, V. 91, Nㅇ, Dec..

44 - $\quad$ FERGUSON, P. M1.(973). "Reinforced Concrete Fundamentals", 3rd Ed., John Wiley and Sons, Inc., New York.

45 - $\quad$ FERRO, N. C. P. (1993). "Uma Combinação do MEC/MEF para Análise de Fundações Enrijecidas por Estacas”, Dissertação (Mestrado), Departamento de Engenharia Estrutural, EESC-USP, São Carlos-SP.

46 - FRANCO, M. (1985). Problemas de Estabilidade nos Edifícios de Concreto Armado. In: COLÓQUIO SOBRE ESTABILIDADE GLOBAL DAS ESTRUTURAS DE CONCRETO ARMADO, IBRACON, São Paulo.

47 - FULLER, F. M (1983).”Engineering of Pile Installation”, McGraw-Hill Book Co.

48 - FUNG, Y. C. (1975). "Foundations of Solid Mechanics - Prentice-Hall Inc, Englewood Cliffs, New Jersey.

49 - GHALI, A.\& FAVRE, R. (1994). Concrete Strutures: Stress and Deformations. Chapman and Hall, $2_{-}^{\mathrm{a}}$ ed.

50 - GATASS, M., \& ABEL, J. F. (1987). "Equilibrium Considerations of the Updated Lagrangian Formulation of Beam-Colums with Natural Concepts", International Journal for Numerical Methods in Engineering, vol. 24, pp. 2119-2141.

51 - GERE, J.M. \& WEAVER, W.Jr. (1965). "Analysis of Framed Structures", D. Van Nostrand Company, Inc.). 


\section{Referências bibliográficas}

52 - GILL, H. L. \& DEMARS, K. R. (1970). Displacement of Laterally Load Structurres in Nonlinearly Responsive Soil, Naval Civil Engineerring Laboratory, teport R-670, Port Hueneme, California, April.

53 - GRANHOLM, H. (1929). On the Elasric Stability of Piles Surrounded by a Supporting Medium. Handigar Ingeniors Vetenskaps Academien, Stockholm, Sweden, 89.

54 - HETENYI, M. (1946). "Beams on 'Elastic Foundation", Ann Arbor. The University of Michigan Press.

55 - HOGNESTAD, E., HANSON, N. W., \& MCHENRY, D. (1955). "Concrete Stress Distribution in Ultimate Strength Design", Journal of the American Concrete Institute, Proceedings, Vol. R2 № 4, Dec., pp 455-480.

56 - HOShIKUMA, J., KAWASHIMA, K., NAGAYA, K. ANAD TAYLOR, A. W. (1997). Stress-strain Model for Confined Reinforced Concrete in Bridge Piers. J. Struct. Div. ASCE 123(5), 0624-0633.

57 - $\quad$ IZZUDDIN, B.A.; KARAYANNIS, C.G.; \& ELNASHAI, A. S., (1994) Advanced Nonlinear Formulation for Reinforced Concrete Beam-Columns. Journal of Structural Engineering, v. 120, p. 2913-2934, October.

58 - JENNINGS, A (1968). "Frame Analysis Including Change Geometry". Journal of the Structural Dvision, v. 94, n. St 3, March.

59 - JOHNSTON, B. G. (1976). "Guide to Stability Design Critria for Metal Structures (3rd ed.) Structural Stabity Research Council. NY: Wiley.

60 - KENT, D.C. \& PARK, R. (1971): "Flexural Members With Confined Concrete”,ASCE Journal of the Structural Division, Vol. 97(7), 1967-1990.

61 - KRÜGER, S. C. (1989). "Uma Metodologia para Análise de Pórticos Planos de Concreto Armado Sujeitos a Grandes Deslocamentos. Tese(Mestrado) - Departamento de Engenharia Civil, PUC/RJ, Rio de Janeiro.

62 - LENCI, C. MAURICE, J., \& MADIGNIER, F. (1968). Pieu Vertical Sollicite Horizontalement. Annales des Ponts et Chaussees, VI (Nov.- Dec.), 337-383.

63 - MACGREgOR, J. G., BREEN, J. E. \& PFRANG, E. O. (1970). "Design of Slender Concrete Column," ACI Journal, Proceedings, 67, January, 6-28.

64 - MACGREGOR, J.G. HAGE, S. E. (1977). "Stability Analysis and Design of Concrete", Proceedings, ASCE, V. 103, N ST10, October.

65 - MALletT, R. H. \& MARCAL, P. V. (1968). Finite element Analysis of Nonlinear Structures. Journal of Structural Division (ASCE), v. 94, n. St 9, p. 2081-2105, September.

66 - MANDER, J. B., PRIESTLEY, M. J. N., \& PARK, R. (1988a). Theoretical Stress-strain Model for Confined Concrete. J. Struct. Div. ASCE 114(8), 1804-1826.

67 - MANDER, J. B., PRIESTlEY, M. J. N., \& PARK, R. (1988b). Observed Stress-strain Behavior of Model for Confined Concrete. J. Struct. Div. ASCE 114(8), 1827-1849.

68 - MANTILLA, E.P. (1974). Um método Iterativo para Análise da Não Linearidade Geométrica em Estruturas Reticuladas. Rio de Janeiro, Dissertação (Mestrado) - COPPE, Universidade Federal do Rio de Janeiro.

69 - MARTINS, P. C. R. (1979). “Análise Não-linear de Estruturas Reticuladas Espaciais de Concreto Armado”. Tese(Mestrado) - Engenharia Civil, COPPE/UFRJ, Rio de Janeiro.

70 - $\quad$ MARTINS, P. C. R., (1979). “Análise Não-linear de Estruturas Reticuladas Espaciais de Concreto Armada”. Tese M.Sc., Rio de Janeiro-, COPPE-UFRJ. 


\section{Referências bibliográficas}

71 - MATLOCK, H. \& REESE, L. C. (1961). "Foundation Analysis of Offshore Pile Supported Structures", Proceedings 5th International Conference on Soil Mechanics and Foundation Engineering, Paris, France.

72 - $\quad$ MATLOCK, H. \& REESE, L.C. (1962). Generalized Solutions for Laterally Loaded Piles. Journal of the Soil Mechanics and Foundation Division, v. 127 part I, pp. 1220-1251. Proceedings of the American Society of Civil Engineers (Oct).

73 - MATLOCK, H. (1970). Correlation for Design of Laterally Loaded Piles in Soft Clay. Proc., 2nd Offshore Technol. Conf., Offshore Technology Conference, Dallas, Tex., 577-594.

74 - MATTHIES, H. \& STRANG, G. (1979). Int. J. Num. Meth. Engng. v. 14, pp. 1613-1626.

75 - $\quad$ McClELlAND, B. \& FOCHT, J., A., Jr. (1958). "Soil Modulus for Laterraly Loaded Piles", Transactions, American Society of Civil Engineers, 123, 1049-1063.

76 - MEEK, J. L.; LOGANATHAN, S. (1989). Large Displacement Analysis of Space-frame Structures. Computer Methods in Applied Mechanics and Engineering, v. 72, p. 57-75.

77 - MEEK, J. L.; LOGANATHAN, S. (1990). Geometric and Material Non-linear Behavior of Beam-columns. Computer and Strutures, v. 34 n. 1, p. 87-100.

78 - MELLO, V. F. B (1969)."Foundations of Buildings on Clay, State of the Art Report”, Proceedings 7th International Conference of Soil Mechanics and Foundation Engineering, Mexico City, Vol. 2, pp. 49-136,

79 - $\quad$ MURRAY, D. M., El SANATH, M. H. \& BJORHOVDE, R. (1980). "Inelastic Behavior of Multistory Steel Frames", Structural Engineering Report nr. 83, Alberta/Canadá, 1980.

80 - $\quad$ MUSSO, F. Jr. (1987)."Dimensionamento de Seções de Concreto Armado e Verificação da Estabilidade de Vigas-Colunas no Estado Limite", Tese de Mestrado, PUC/RJ, 08/1987.

81 - N N 1 (1978)."Projeto e Execução de Obras de concreto Armado" - Associação Brasileira de Normas Técnicas - Rio de Janeiro.

82 - NB 1 TB (1988/1993)."Projeto e Execução de Obras de concreto Armado" - Associação Brasileira de Normas Técnicas - Rio de Janeiro.

83 - N NBR 7187.(1987). “ Projeto e Execução de Pontes de Concreto Armado e Protendido” ABNT. Rio de Janeiro.

84 - NORRIE, D. H. \& DE VRIES, G. (1973). “The Finite Element Method, Fundamentals and Aplications-Academic Press, N. Y. and London.

85 - OOI, P. S. K. \& DUCAN, J. M. (1994). Lateral Load Analysis of Groups of Piles Drilled Shafts. ASCE - Journal of Geotechnical Engineering, Vol. 120, № 6 , June.

86 - ORAN, C. (1973). Tangent Stiffiness in Space Frames. Journal of the structural division (ASCE), v. 99, n. St 6, p. 987-1001, June.

87 - OWEN, D. R. J. \& GOMES, C .M .B. (1984). Some Recent Developments in Solution Techniques for Nonlinear Finite Element Problems. Swansea, Department of Civil Engineering, University College of Swansea.

88 - PINTO, RIVELLI DA SILVA (1997). Não- linearidade Física e Geométrica no Projeto de Edifícios Usuais de Concreto Armado. Dissertação de Mestrado - EESC-USP, Dpto de Engenharia de Estruturas.

89 - PAGAY, S. N., FERGUSON, P. M. \& BREEN, J. E. (1970). "Importance of Beam Properties on Concrete Column Behavior", ACI Journal, Proceedings, 67, October. 


\section{Referências bibliográficas}

90 - PALMER, L. A. \& THOMPSON, J. B. (1948). The Earth Pressure and Deflection Along Embedded Lengths of Piles Subjected to Lateral Thrust. Proc., 2nd Int. Conf. Soil Mech. and Found. Engrg., GEBR Kesmat, Haarlem, the Netherlangs, v. 5, 156-161.

91 - PARK, R., PRIESTLEY, M. N. J. \& GILL, W. D.: (1982). Ductility of Square-confined Concrete Columns", ASCE Journal of the Structural Division, 108(4), 929-950.

92 - $\quad$ PAUlA, C. F. (1997). "Estudo das Descrições Lagrangiana e Euleriana na Análise Nãolinear Geométrica com o Emprego do Método dos Elementos Finitos”, Dissertação (Mestrado), Departamento de Engenharia Estrutural, EESC-USP, São Carlos-SP

93 - PFRANG, E. O. (1966). "Behavior of Reinforced Concrete Columns with Sidesway,” Journal of the Structural Division, ASCE, 92, June (ST3), 225-252.

94 - PIMENTA, P.M. Análise Não-linear de Pórticos Planos. São Paulo, EPUSP, (1986a). (Boletim Técnico do Departamento de Engenharia de Estruturas e Fundações, 8611).

95 - PIMENTA, P.M. (1986b) Aspectos da Análise Não-linear de Estruturas Reticuladas. In: Congresso Latino-americano sobre Métodos Computacionais para a Engenharia, 7., São Carlos,. p. 449-464.

96 - PIMENTA, P.M. (1989a) Derivation of Tangent Stiffness Matrices of Simple Finite Elements, I. Straight Bar Elemens. São Paulo, EPUSP. (Boletim Técnico do Departamento de Engenharia de Estruturas e Fundações, 8912).

97 - PIMENTA, P.M. (1989b) Nonlinear Analisis of Plane Frames,I. Quasi-Static Analisis of Plane Frames with Initiall Curved Members. São Paulo, EPUSP. (Boletim Técnico do Departamento de Engenharia de Estruturas e Fundações, 8910).

98 - PIMENTA, P.M.; YOJO, T. (1992). Análise Geométricamente Exata de Pórticos Espaciais Através do Método dos Elementos Finitos. In: XIII CILAMCE. Anais., v.1, p. 191-199.

99 - $\quad$ PIMENTA, P.M.; YOJO, T. (1993). "Geometrically Exact Analysis of Spacial Frames with Considerations of Torsion Warping”. In: XIV CILAMCE. Anais., v.1, p. 21-30.

100 - POSTON,R. W., DIAZ, M., BREEN, J. E., ROESSET, J. M. (1983), "Design of Slender, Nonprismatic, and Hollow Concrete Bridge Piers", Center of Transportation Research, The University of Texas at Austin - Austin-Texas-USA.

101 - POULOS, H. G. (1971). Behavior of Laterally Loaded Piles: I - Singles. Piles. J. Soil Mech. Found. Div., ASCE, 97(5), 711-731

102 - POULOS, H. G. (1971). Behavior of Laterally Loaded Piles: II -. Pile Groups. J. Soil Mech. Found. Div., ASCE, 97(5), 733-751.

103 - POULOS, H. G. (1972). Behavior of Laterally Loaded Piles: III - Socketed Piles. J. Soil Mech. Found. Div., ASCE, 98(4), 341-360.

104 - PRAKASH, S. \& SHARMA, H. D. (1990). "Pile Foundations in Engineering Practice", A Wiley Interscience Publication, cap. 2, New York.

105 - PROENÇA, S.P.B. Noções Básicas de Reologia. São Carlos, EESC, USP, 1986.

106 - PROENÇA, S.P.B. Notas sobre análise não-linear física de estruturas - Parte 1: Teoria da plasticidade e técnicas numéricas. São Carlos, EESC, USP, 1989.

107 - PRZENMIENIECKI, J. S. (1968). “Theory of Matrix Strutural Analysis-McGraw-Hill Book Company.

108 - QUIROGA, A. F. S. (1983). "Calculo de Estruturas de Puentes de Hormigon”. Editorial Rueda, Madrid-Espanã. 


\section{Referências bibliográficas}

109 - REESE, L. C. \& MATLOCK, H. (1956). Nondimensional Solutions for Laterally Loadet Piles with Soil Modulus Assumed Proportional to Depth - Proceedings, Eighth Texas Conference on Soil Modulus and Foundation Engineering, Special Publication No. 29, Bureau of Engineering Reserch, The University of Texas, Austin, September.

110 - REDDY, A. S. \& VALSANGKAR, A. J. (1968). Na Analytical Solution for Laterallly Loaded Piles in Layered Soils. Sols-Soils, 21, 23-28.

111 - REESE, L. C \& WELCH, R. C. (1975). Lateral Loading of Deep Foundations in Stiff Clay. J. Geotech. Engrg. Div., ASCE, 101(7), 633-690.

112 - REESE, L. C. (1977). Laterally Loaded Piles: Program Documentation. J. Geotech. Engrg. Div., ASCE, 103(4), 287-305.

113 - REESE, L. C.(1983). Executive Summmary, Behavior of Piles and Pile Groups under Lateral Load - U. S. Department of Transportation Federal Highway Administration Office of Research, Washington, D. C., September-1983.

114 - REESE, L. C., COX, W. R. \& KOOP, F. D. (1975). Field Testing and Analysis of Laterally Loaded Piles in Stiff Clay.Proc., 7th Offshore Tchnol. Conf., Offshore Technology Conference, Houston-Texas, paper n. OTC 2312, pp. 672-690.

115 - REESE, L. C., COX, W. R. \& KOOP, F. D. (1974). Analysis of Laterally Loaded Piles in Sand. Proc., 5th Offshore Tchnol. Conf., Offshore Technology Conference, Houston-Texas, paper n. OTC 2080, pp 473-485.

116 - SAATCIOGLU, M. \& RAZVI, S.R. (1992). Strength and Ductility of Confined Concrete. J. Struct. Div., ASCE, 118(6), 1590-1607.

117 - SANCHES JÚNIOR, F. (1998) Dissertação(Mestrado) - "Cálculo de Esforços e Deslocamentos em Pavimentos de Edifícios, Considerando-se Modelos Próprios para o Concreto Armado". Departamento de Engenharia Estrutural/EESC-USP, São Carlos-SP.

118 - SAYEBH, A F. \& TSO, F. K. (1988). “.Analysis of Linear Structures on Nonlinear Pile Foundations”, Computers \& Structures Vol. 28, N 6, pp. 669-715, 1988.

119 - SCORDELIS, A. C. (1984) .Computer models for nonlinear analysis of reinforced and prestressed concrete structures. ACI Journal, v. 29, n. 6, p. 116-135, Nov/Dez,

120 - SHEIKH, S. A., \& UZUMERI, S. M. (1982). Analytical Model for Concrete Confinement in Tied Columns. J. Struct. Div., ASCE, 108(12), 2703-2722.

121 - SILVA, R.M. (1989). Análise de Estruturas Tridimensionais de Edifícios Altos com Núcleos Resistentes, Considerando o Efeito P - $\Delta$ (Dissertação de Mestrado) - EESC - USP, Depto de Estruturas

122 - SILVA, R.M. (1996). “Análise não-linear de pórticos planos de concreto armado: modelagem numérica e avaliação dos métodos aproximados”. São Carlos,. 264p. Tese (Doutorado) - Escola de Engenharia de São Carlos, USP.

123 - SOLER, J. G. M. (1985). “Análise Não-linear de Pórticos Planos de Concreto Armado". Dissertação(Mestrado), Departamento de Engenharia de Estruturas e Fundações, Escola Politécnica/USP, São Paulo.

124 - SOLER, J. G. M. (1995). “Análise Não-linear de Pórticos Espaciais de Concreto Armado”. Tese(Doutorado), Departamento de Engenharia de Estruturas e Fundações, Escola Politécnica/USP, São Paulo.

125 - SPILlERS, W. R. \& STOLL, R. D. (1964). Lateral Response of Piles. J. Soil Mech. Found. Div., ASCE, 90(6), 1-9. 


\section{Referências bibliográficas}

126 - STURMAN, G. M., SHAH, S. P., \& WINTER, G., "Effect of Flexural Strain Gradients on Microcracking and Sress-Strain Behavior of Concrete", Journal of the American Concrete Institute, Proceedings, Vol. 62 № 7, July-1965, pp 805-822.

127 - SUllivan, W. R. (1977). Development and Evaluation of a Unified Method for Analysis of Laterally Load Piles in Clay, Unpiblished Thesis, The University of Texas at Austin, May, 1977.

128 - SUlliVAN, W. R. , REESE, L. C. \& FENSKE, C. W. (1979). Unified Method of Analysis of Laterally Loaded Piles in Clay. Proc., Conf. On Num. Methods in Offshore Piling, Inst. Of Civil Engineers, London, England, n. 17.

129 - SWAN, C. W \& WRIGHT, S. G. (1986). "Evalution and Development of p-y Based Procedures for Annalysis of Short Drilled Shafts Subbjected to Lateral Loads", Center For Transportation Research- Burreau of Engineering Research- The University of Texas at Austin. Reserch Report 415-1.

130 - TERZAGHI, K. (1955). “.Evaluation of Coefficients of Subgrade Reaction, Geotechnique, vol. $5, n^{\circ} 4$ - Dec..

131 - TOMLINSON, M. J., (1977). "Pile Design and Construction Practice", A Viewpoint Publication, Cement and Concrete Association.

132 - TURnER, M. J., CLOUGH, R. W., MARTIN, H. C. \& POPP, L. J. (1956). "Stiffness and Deflection Analysis of Complex Structures", Journal of the Aeronautical Sciences , Vol. 23 pp. 805-823.

133 - VASCONCELOS A. C.; FRANCO, M. (1991) Practical Assessment of Second Order Effects in Tall Buildings. In: COLLOQUIUM ON THE CEB-FIP MODEL CODE 90, COPPE/CEB, Rio de Janeiro, Agosto.

134 - VENÂNCIO FILHO, F. (1975). Análise Matricial de Estruturas - Almeida Neves Editores, Ltda..

135 - VESIC, A. S. (1977). "Design of Pile Foundations", Transportation Research Board, NRC, Washington, DC,

136 - WANG, C. K \& SALMON, C. G. (1985). "Reinforced Concrete Design”,Harper \& Row, Publishers, NY, Fourth Edition.

137 - ZIENKIEWICZ, O.C. \&. CHEUNG, Y. K. (1967). “The Finite Element Méthod in Structural and Continuum Mechanics. New York, McGraw Hill.

\section{REFERÊNCIA BIBLIOGRÁFICA COMPLENTAR}

1.- AAS-JAKOBSEN, K.; GRENACHER (1974). Analysis of slender reinforced concrete frames. International Association for Bridge and Structural Engineering Publications, v. 34, p. $1-17$.

2.- $\quad$ ASSAN, A.E. (1990a). Matriz de Rigidez de Elemento Finito Tridimensional de Viga para Análise Não-linear Física e Geométrica. In: CONGRESSO IBERO LATINO AMERICANO SOBRE MÉTODOS COMPUTACIONAIS PARA ENGENHARIA, 11., Rio de Janeiro, 1990. Anais. Rio de Janeiro, COPPE-UFRJ/AMC, v. 2, p. 707-716.

3.- $\quad$ ASSAN, A.E. (1990b). Vigas de Concreto Armado com Não Linearidade Física. In: CONGRESSO IBERO LATINO AMERICANO SOBRE MÉTODOS COMPUTACIONAIS PARA ENGENHARIA, 11., Rio de Janeiro, 1990. Anais. Rio de Janeiro, COPPEUFRJ/AMC, 1990. V. 2, p. 741-749. 


\section{Referências bibliográficas}

4.- $\quad$ BALAKRISNAN, S.; ELWI, A.E.; MURRAY, D.W. (1988). Effect of Modeling on NLFE Analysis of Concrete Structures. Journal of Structural Engineering, v. 114, n. 7, p. 1467-1487, July.

5.- $\quad$ BATOZ, J. L. \& DHATT, G. (1979). "Incremental Displacement Algorithms for Nonlinear Problems", International Journal for Numerical Methods in Engineering, vol. 14, pp. 12621266.

6.- $\quad$ BORGES, J. F., LIMA, J.A., COELHO, A.T. \& MONTEIRO, V. (1967). "Analytical Results Concerning the Non-Linear Behavior of Reinforced Concrete Structures", Laboratório Nacional de Engenharia Civil - Memória No 294, Lisboa,.

7.- $\quad$ BROMS, B. B. (1965)."Design of Laterally Loaded Piles", Journal of the soil mechanics and foundation division. Proceedings of the American Society of Civil Engineers, Vol. 91, N ${ }^{0}$ SM3, May, pp. 79-99

8.- DUNNAVANT, T.W., \& O'NEILL, M.W. (1986). "Evaluation of Design-Oriented Methods for Analysis of Vertical Pile Groups Subjected to Lateral Loads." Proc., 3rd Int. Conf. on Numer. Meth. in Offshore Piling, Nantes, France, Editions Technip., Paris, France, 303-316.

9.- $\quad$ FERREIRA, L.T.S. (1986). "Desenvolvimento de um Sistema Geral de Dimensionamento de Estruturas de Concreto Armado usando Microcomputadores", Tese de Mestrado, PUC/RJ.

10.- GUIDAN, M., \& SCHNOBRICH, W. C. (1973). "Finite Element Analysis of Reforced Concrete", Journal of the Structural Division, pp. 2109-2122.

11.- HELliS, R. D. Pile (1962). "Foundations in Foundation Engineering”, cap. 7, G. A . Leonards, ed., McGraw-Hill Book Co.,.

12.- $\quad$ HINTON, E.; OWEN, D. R. J.; \& TAYLOR, C. (1982). Recent Advances in Nonlinear Computational Mechanics. Swansea, U. K., Pineridge Press.

13.- JOHNSON, B. G. \& KAVANAGH (1970). "The Design of Foundations for Building", McGraw-Hill.

14.- $\quad$ KAO, R. (1974). "A Comparison of Newton-Raphson Methods and Incremental Procedures for Geometrically Nonlinear Analysis", Computer \& Structura, vol. 4, p. 1091-1097,.

15.- KROENKE, W.C., GUTZWILLER, M.J., LEE, R.H. (1973). "Finite Element for Reinforced Concrete Frame Study", Journal of the Structural Division, pp. 1371-1390.

16.- MARTIN, H. C. and CAREY, G. F. (1973). "Introduction to Finite Element Analysis, Theory and Application - McGraw-Hill Book Company.

17.- $\quad$ MATTIASSON, K. (1981)."Numerical Results fromm Large Deflection Beam and Frame Problems Analysed by means of Elliptic Integrals", International Journal for Numerical Methods in Engineering, vol. 17, pp. 145-153.

18.- MCCAMMON, G.A. \& ASCHERMAN, J.C. "Resistance of Long Hollow Piles to Applied Lateral Loads", Simposium on Lateral Load Tests on Piles - ASTM Special Technical Publication $\mathrm{n}^{\mathrm{O}} 154$ (1954).

19.- MELLO, V. F. B (1969)."Foundations of Buildings on Clay, State of the Art Report", Proceedings 7th International Conference of Soil Mechanics and Foundation Engineering, Mexico City, Vol. 2, pp. 49-136,

20.- $\quad$ MURRAY, D. M., EL SANATH, M. H. \& BJORHOVDE, R. (1980). "Inelastic Behavior of Multistory Steel Frames", Structural Engineering Report nr. 83, Alberta/Canadá, 1980.

21.- $\quad$ MUSSO, F. Jr. (1987)."Dimensionamento de Seções de Concreto Armado e Verificação da Estabilidade de Vigas-Colunas no Estado Limite", Tese de Mestrado, PUC/RJ, 08/1987. 


\section{Referências bibliográficas}

22.- PAPADRAKAKIS, M. (1981). "Post-Buckling Analysis of Spatial Structures by Vector Iteration Method", Computers and Structures, vol. 14, n 5 e 6, pp. 393-402, 1981.

23.- WINKLER, E. (1987). Die Lehre von Elastizitat und Festigkeit. Publisler, Prague.

24.- RAJASEKARAN, S. \& MURRAY, D. W. (1973). Incremental finite element matrices. Journal fo the structural division (ASCE). v. 99, n. St 12, p. 2423-2438, December.

25.- $\quad$ RAJASEKARAN, S. \& MURRAY, D.W. Incremental finite element matrices. Journal fo the structural division (ASCE). v. 99, n. St 12, p. 2423-2438, December, 1973.

26.- RASHEED, H. A. S. \& DINNO, K. S. (1994). An efficient nonlinear analysis of RC sections. Computer \& Structures, v. 53, n. 3, p. 613-623.

27.- REESE, L.C. \& COX, W.R. (1969). "Soil Behavior From Analysis of Tests of Uninstrumented Piles under Lateral Loading", Performance of Deep Foundation, ASTM Special Technical Publication 444.

28.- $\quad$ REESE, L.C., WRIGHT, S.G., \& AURORA, R. P. (1984). "Analysis of a pile group under lateral loading." Proc. Laterally Loaded Deep Foundations: Analysis and Performance, STP 835, J. A. Langer, E.T.Mosley, and C.D.Thompson, eds., ASTM, Philadelphia, Pa., 56-71.

29.- $\quad$ ROEHL, D.M. "Uma Metologia para a Análise não-linear Geométrica de Pórticos Espaciais com Liberações de Extremidade de Barra e Cargas Distribuídas", Tese de Mestrado, PUC/RJ, 09/1987.

30.- $\quad$ ROEHL, D.M. (1987). "Uma Metologia para a Análise não-linear Geométrica de Pórticos Espaciais com Liberações de Extremidade de Barra e Cargas Distribuídas", Tese de Mestrado, PUC/RJ.

31.- ROGEDO, P. I. (1970). "Estacas Submetidas à Solicitações Horizontais - Cálculo pelo Método dos Elementos Finitos". LNEC. Outubro.

32.- $\quad$ RUBINSTEINS, M.F. "Matrix Computer Analysis of Structures", Prentice-Hall, Inc. (1966).

33.- $\quad$ SHIBATA, T., YASHIMA, A., KIMURA M., \& FUKADA, H. (1988). "Analysis of laterally loaded piles by quasi-three dimensional finite element method." Proc., 6th Int. Conf. on Numer. Meth. in Geomech., A.A.Balkema, Rotterdam, The Netherlands, 2, 1051-1058.

34.- $\quad$ SKEMPTON, A. W. (1951). The Bearing Capacity of Clays, Poeceedings, Building Research Congress, Division I, London, England, pp. 180-189.

35.- WOOD, B.R., BEAUliEU, D. and ADAMS, P.F. "Column Design by P-Delta Method", Proceedings, ASCE, V. 102, N ST2, February 1976, pp. 411-427.

36.- WOOD, R.D., ZIENKIEWICZ, O. C. (1977). "Geometrically Nonlinear Finite Element Analysis of Beams. Frames, Arches, and Axisymmetric Shells", Conputers and Structures, vol. 7, pp. 725-735.

37.- ZIENKIEWICZ, O. C. "Incremental Displacement in Nonlinear Analysis", International Journal for Numerical Methods in Engineering, vol. 3, 1971, pp. 587-588. 


\section{ANEXO A (COMPLEMENTA O CAPÍTULO 4)}

\section{Matriz $\mathrm{K}_{\mathrm{NL}}$}

Para uma configuração intermediária " $n$ " de equilíbrio, a matriz $\mathrm{K}_{\mathrm{T}}$ de um elemento de barra no espaço não carregado internamente, adquire a seguinte forma para uma descrição Lagrangeana Atualizada (referencial móvel):

$$
\begin{aligned}
& \mathrm{K}_{\mathrm{T}}=\mathrm{K}_{\mathrm{NL}}+\mathrm{K}_{\mathrm{L}} \\
& \mathrm{K}_{\mathrm{NL}}=\mathrm{K}_{\mathrm{N}}=-\mathrm{N}\left[\mathrm{G}_{\mathrm{ij}}\right] \text { onde, }-\mathrm{N}\left[\mathrm{G}_{\mathrm{ij}}\right] \text { é denominada Matriz de Rigidez }
\end{aligned}
$$

Geométrica do elemento no sistema móvel.

$\operatorname{Matriz}\left[\mathrm{G}_{\mathrm{i}, \mathrm{j}}\right]$

\begin{tabular}{|c|c|}
\hline $\mathrm{G}_{2,6}=\frac{1}{10}$ & $\mathrm{G}_{2,2}=\frac{6}{5 \mathrm{~L}}$ \\
\hline $\mathrm{G}_{2,12}=\mathrm{G}_{2,6}$ & $\mathrm{G}_{2,8}=\frac{6}{5 \mathrm{~L}}$ \\
\hline $\mathrm{G}_{3,3}=\frac{6}{5 \mathrm{~L}}$ & $\mathrm{G}_{12,12}=\mathrm{G}_{6,6}$ \\
\hline $\mathrm{G}_{3,5}=\frac{1}{10}$ & $\mathrm{G}_{3,9}=\frac{6}{5 \mathrm{~L}}$ \\
\hline $\mathrm{G}_{3,11}=\frac{1}{10}$ & $\mathrm{G}_{5,5}=\frac{2 \mathrm{~L}}{15}$ \\
\hline
\end{tabular}


Anexos

\begin{tabular}{|c|c|}
\hline $\mathrm{G}_{5,9}=\frac{1}{10}$ & $\mathrm{G}_{6,6}=\frac{2 \mathrm{~L}}{15}$ \\
\hline $\mathrm{G}_{5,11}=-\frac{\mathrm{L}}{30}$ & $\mathrm{G}_{6,12}=-\frac{\mathrm{L}}{30}$ \\
\hline $\mathrm{G}_{6,8}=\frac{1}{10}$ & $\mathrm{G}_{8,8}=\mathrm{G}_{2,2}$ \\
\hline $\mathrm{G}_{8,12}=\mathrm{G}_{2,6}$ & $\mathrm{G}_{9,9}=\mathrm{G}_{3,3}$ \\
\hline $\mathrm{G}_{9,11}=\mathrm{G}_{3,5}$ & $\mathrm{G}_{11,11}=\mathrm{G}_{5,5}$ \\
\hline
\end{tabular}

Obs. A matriz do elemento $\left[\mathrm{G}_{\mathrm{i}, \mathrm{j}}\right.$ ] é simétricas, sendo nulos os demais termos não enumerados. O elemento não carregado internamente, a torção e os esforços cortantes no seu interior são constantes e os momentos fletores são lineares.

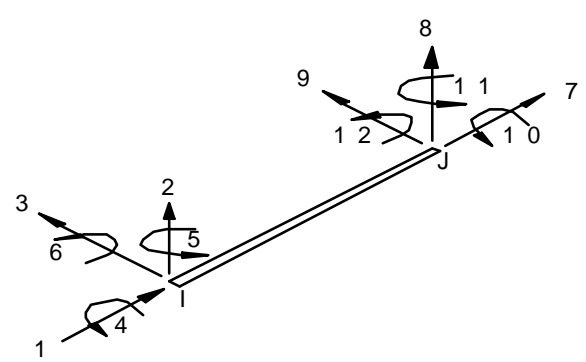

Fig. A1-Graus de liberdade

(Matriz Linear Elástica $\mathrm{K}_{\mathrm{L}}$ )

$$
K_{L}=\left[\begin{array}{cccccccccccc}
\frac{A E}{L} & & & & & & & & & & \\
0 & a_{z} & & & & & & & & & \\
0 & 0 & a_{y} & & & & \text { I } & M & & & \\
0 & 0 & 0 & \frac{G J}{L} & & & & & & & & \\
0 & 0 & d_{y} & 0 & e_{y} & & & & & & & \\
0 & c_{z} & 0 & 0 & 0 & e_{z} & & & & & & \\
\frac{A L}{L} & 0 & 0 & 0 & 0 & 0 & \frac{A E}{L} & & & & & \\
\hline 0 & b_{z} & 0 & 0 & 0 & d_{z} & 0 & a_{z} & & & & \\
0 & 0 & b_{y} & 0 & c_{y} & 0 & 0 & 0 & a_{y} & & & \\
0 & 0 & 0 & \frac{-G J}{L} & 0 & 0 & 0 & 0 & 0 & \frac{G J}{L} & & \\
0 & 0 & d_{y} & 0 & f_{y} & 0 & 0 & 0 & c_{z} & 0 & e_{y} & \\
0 & c_{z} & 0 & 0 & 0 & f_{z} & 0 & d_{y} & 0 & 0 & 0 & e_{z}
\end{array}\right]
$$

$\mathrm{L}=$ comprimento do elemento; 
$\mathrm{G}=$ módulo de elasticidade transversal;

$J=$ constante de torção de Saint $\operatorname{Venant}\left(J=I_{x}\right.$ se $I_{x} \neq 0$ ou $J=J_{x}$ se $I_{x}=0$

)

$\mathrm{J}_{\mathrm{x}}=$ momento de inércia polar $\left(\mathrm{J}_{\mathrm{x}}=\mathrm{I}_{\mathrm{y}}+\mathrm{I}_{\mathrm{z}}\right)$;

$a_{z}=a\left(I_{z}, \phi_{y}\right), b_{y}=b\left(I_{y}, \phi_{z}\right), f_{z}=f\left(I_{z}, \phi_{y}\right), f_{y}=f\left(I_{y}, \phi_{z}\right) ; \quad$ onde,

$\mathrm{a}(\mathrm{I}, \phi)=\frac{12 \mathrm{EI}}{\mathrm{L}^{3}(1+\phi)}$

$\mathrm{b}(\mathrm{I}, \phi)=\frac{-12 \mathrm{EI}}{\mathrm{L}^{3}(1+\phi)}$

$\mathrm{c}(\mathrm{I}, \phi)=\frac{6 \mathrm{EI}}{\mathrm{L}^{2}(1+\phi)}$

$\mathrm{a}(\mathrm{I}, \phi)=\frac{12 \mathrm{EI}}{\mathrm{L}^{3}(1+\phi)}$

$\mathrm{c}(\mathrm{I}, \phi)=\frac{6 \mathrm{EI}}{\mathrm{L}^{2}(1+\phi)}$

$\mathrm{d}(\mathrm{I}, \phi)=\frac{-6 \mathrm{EI}}{\mathrm{L}^{2}(1+\phi)}$

$\mathrm{e}(\mathrm{I}, \phi)=\frac{(4+\phi) \mathrm{EI}}{\mathrm{L}(1+\phi)}$

$\mathrm{f}(\mathrm{I}, \phi)=\frac{(2-\phi) \mathrm{EI}}{\mathrm{L}(1+\phi)} \quad$ onde,

$\phi_{\mathrm{y}}=\frac{12 \mathrm{EI}_{\mathrm{z}}}{\mathrm{GA}_{\mathrm{z}}^{\mathrm{s}} \mathrm{L}^{2}}$

$\phi_{\mathrm{z}}=\frac{12 \mathrm{EI}_{\mathrm{y}}}{\mathrm{GA}_{\mathrm{y}}^{\mathrm{s}} \mathrm{L}^{2}}$

$I_{i}=$ momento de inércia normal à direção “i”;

$\mathrm{A}_{\mathrm{i}}^{\mathrm{s}}=\mathrm{A} / \mathrm{F}_{\mathrm{i}}^{\mathrm{s}}=$ área de cisalhamento na direção normal $\mathrm{i}$;

$\mathrm{F}_{\mathrm{i}}^{\mathrm{s}}=$ coeficiente de cisalhamento. 


\section{ANEXO B (COMPLEMENTA O CAPÍTULO 5)}

Modelo de PARK \& KENT (1971)

$$
\begin{array}{ll}
\mathrm{f}_{\mathrm{c}}=\mathrm{f}_{\mathrm{cc}}\left[2\left(\frac{\varepsilon}{\varepsilon_{0}}\right)-\left(\frac{\varepsilon}{\varepsilon_{0}}\right)^{2}\right] & \varepsilon \leq \varepsilon_{0} \\
\mathrm{f}_{\mathrm{c}}=\mathrm{f}_{\mathrm{cc}}\left[1.0-\mathrm{z}\left(\varepsilon-\varepsilon_{0}\right)\right] & \varepsilon_{0} \leq \varepsilon \leq \varepsilon_{20 \mathrm{u}} \\
\mathrm{f}_{\mathrm{c}}=0.2 \mathrm{f}_{\mathrm{cc}} & \varepsilon>\varepsilon_{20 \mathrm{u}} \\
\varepsilon_{0}=0,002 & \varepsilon_{50 \mathrm{u}}=\frac{3.0+0.29 \mathrm{f}_{\mathrm{cc}}}{145 \mathrm{f}_{\mathrm{cc}}-1000.0} \\
\mathrm{z}=\frac{0.5}{\varepsilon_{50 \mathrm{~h}}+\varepsilon_{50 \mathrm{u}}-\varepsilon_{0}}, & \varepsilon_{50 \mathrm{~h}}=\frac{3}{4} \rho \sqrt{\frac{\mathrm{b}^{\prime}}{\mathrm{s}}} \\
\rho=\frac{2\left(\mathrm{~b}^{\prime}+\mathrm{d}^{\prime}\right) \mathrm{A}_{\mathrm{s}}}{\mathrm{b}^{\prime} \mathrm{d}^{\prime} \mathrm{s}}, &
\end{array}
$$

$\mathrm{A}_{\mathrm{s}}=$ seção transversal da barra do estribo;

$\mathrm{s}=$ espaçamento dos estribos de centro a centro;

$\mathrm{f}_{\mathrm{cc}}=$ resistência cilíndrica de pico a compressão $\left(\mathrm{N} / \mathrm{mm}^{2}\right)$.
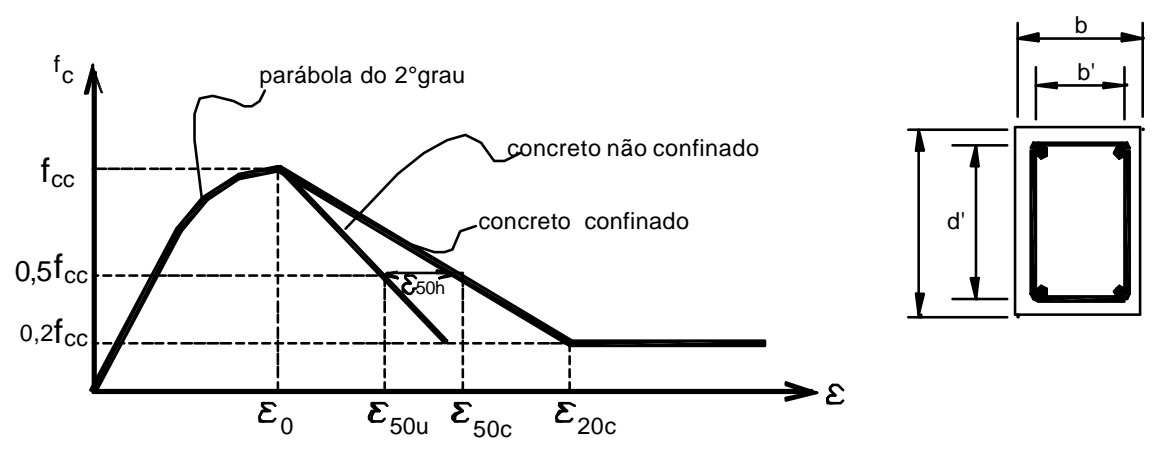

Fig. B1- Modelo Proposto por PARK \& KENT (1971) 


\section{ANEXO C (COMPLEMENTA OS CAPÍTULOS 3 E 6)}

\section{C1 - CONTRIBUIÇÃO DE TERZAGHI - RESPOSTA LINEAR}

TERZAGHI (1955) apresentou uma extensa discussão relativa à influência da área carregada sobre o módulo de reação. Usando o conceito de bulbo de pressões, TERZAGHI demonstra a influência da largura ou diâmetro da estaca no valor do módulo de reação do solo, cujo valor e variação com a profundidade dependem das suas características de deformação.

A Fig.C1 mostra duas estacas verticais, uma confinada em uma argila adensada e a outra em solo arenoso, ambas com deslocamento $y_{1}$ conforme indicado na figura. Na argila o módulo de reação horizontal é considerado constante:

$$
\mathrm{k}_{\mathrm{h}}=\frac{\mathrm{p}}{\mathrm{y}_{1}}
$$

Se, porém, o terreno é de característica arenosa, considera-se $\mathrm{p}$ crescendo linearmente com a profundidade e $\mathrm{k}_{\mathrm{h}}$ será então definido por:

$$
\mathrm{k}_{\mathrm{h}}=\frac{\mathrm{p}}{\mathrm{y}_{1}}=\mathrm{n}_{\mathrm{h}} \mathrm{x} \quad \text { onde }
$$

$\mathrm{n}_{\mathrm{h}}\left(\mathrm{FL}^{-3}\right)$ é denominada constante de reação horizontal que depende da densidade relativa da areia e da área em que atua "p".

Duas estacas de largura $\mathrm{B}_{1}$, considerada padrão, e outra de largura $\mathrm{nB}_{1}$, com os respectivos comprimentos dos bulbos de pressão L e nL (Fig. C1).

Como horizontalmente, os módulos de elasticidade, tanto da argila como da areia, são considerados constantes, o deslocamento $\mathrm{y}_{\mathrm{n}}$ horizontal sendo proporcional ao comprimento do bulbo de pressão, também o será proporcional à largura (ou diâmetro) $\mathrm{B}_{1}$ da estaca:

$$
\mathrm{y}_{\mathrm{n}}=\mathrm{ny}_{1} \quad(\mathrm{C} 3)
$$


onde $\mathrm{y}_{\mathrm{n}}$ é o deslocamento horizontal da estaca de largura ( ou diâmetro) $\mathrm{nB}_{1}$.

Para o caso de solo argiloso a expressão do módulo de reação horizontal para a estaca de lado $\mathrm{nB}_{1}$ :

$$
\mathrm{k}_{\mathrm{hn}}=\frac{\mathrm{p}}{\mathrm{y}_{\mathrm{n}}}=\frac{\mathrm{p}}{\mathrm{ny}_{1}}=\frac{\mathrm{pB}_{1}}{\mathrm{ny}_{1} \mathrm{~B}_{1}}
$$

fazendo-se: $\mathrm{k}_{\mathrm{hn}}=\mathrm{k}_{\mathrm{h}}, \mathrm{k}_{\mathrm{h} 1}=\mathrm{p} / \mathrm{y}_{1}, \mathrm{~B}=\mathrm{nB}_{1}, \mathrm{~B}_{1}=1 \mathrm{ft}$ onde,

$$
\mathrm{k}_{\mathrm{h}}=\mathrm{k}_{\mathrm{h} 1} / \mathrm{B} \quad(\mathrm{C} 5
$$
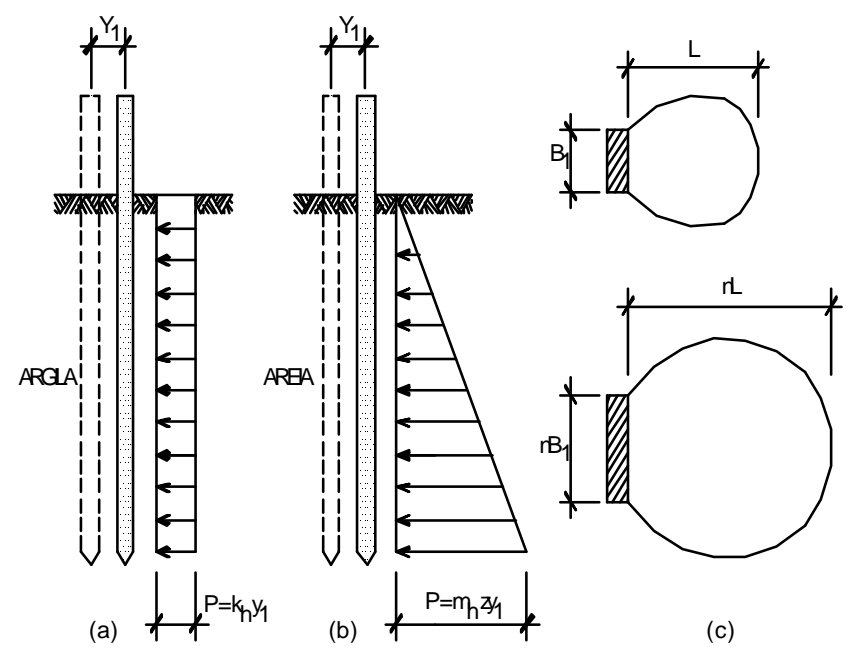

Fig. C1 - Módulos de reação horizontal adotados

$\mathrm{O}$ valor de $\mathrm{K}_{\mathrm{h} 1}$ representa o módulo de reação horizontal do terreno para o caso de uma viga de largura unitária igual a $1 \mathrm{ft}(30 \mathrm{~cm})$ em solo de argila dura.

Os valores de $\mathrm{k}_{\mathrm{h} 1}$ são tomados iguais aos de $\mathrm{k}_{\mathrm{s} 1}$, que representam coeficientes de reação vertical para o caso de placas com lados de $1 \mathrm{ft}(30 \mathrm{~cm})$ ou vigas de $1 \mathrm{ft}(30 \mathrm{~cm})$ de largura, em terreno de argila pré adensada. Estes por sua vez são obtidos através dos valores empíricos de $\overline{\mathbf{k}}_{\mathbf{s} \mathbf{1}}$. sugeridos por Terzaghi (tab. C1). Para o caso de placas com largura de $1 \mathrm{ft}$ e comprimento $\ell$ em $\mathrm{ft}$ tem-se:

$$
\mathrm{k}_{\mathrm{s} 1}=\overline{\mathrm{k}}_{\mathrm{s} 1} \frac{\ell+0.5}{1.5 \ell}
$$




\section{Anexos}

sendo $\overline{\mathbf{k}}_{\mathrm{s} \mathbf{1}}$ dado na unidade adequada (ft).

Para o caso de vigas ou estacas de comprimento infinito e largura ( ou diâmetro) B, considerar-se-á a expressão:

$$
\begin{aligned}
& \mathrm{k}_{\mathrm{s} 1}=30 \frac{\overline{\mathrm{k}}_{\mathrm{s} 1}}{1,5 \mathrm{~B}} \quad(\mathrm{C} 7) \\
& \text { sendo } \overline{\mathrm{k}}_{\mathrm{s} 1} \mathrm{em} \mathrm{N} / \mathrm{cm}^{3} .
\end{aligned}
$$

Para solos com características arenosas tem-se a expressão do módulo de reação horizontal do solo para a viga de largura $\mathrm{nB}_{1}$ :

$$
\mathrm{k}_{\mathrm{hn}}=\frac{\mathrm{p}}{\mathrm{y}_{\mathrm{n}}}=\frac{\mathrm{p}}{\mathrm{ny}_{1}}=\frac{\mathrm{pB}}{\mathrm{ny}_{1} \mathrm{~B}_{1}}
$$

Tabela C1 - Valores de $\overline{\mathrm{k}}_{\mathrm{s} 1}\left(\mathrm{~N} / \mathrm{cm}^{3}\right)$

\begin{tabular}{||c|c|c|c|}
\hline Consistência da argila & rija & muito rija & dura \\
\hline $\begin{array}{c}\text { Resistência à compressão simples } \\
\left(\mathrm{N} / \mathrm{cm}^{3}\right)\end{array}$ & $10-20$ & $20-40$ & $>40$ \\
\hline Valores limites & $16-32$ & $32-64$ & $>64$ \\
\hline Valores propostos & 24 & 8 & 96 \\
\hline
\end{tabular}

fazendo-se: $\mathrm{k}_{\mathrm{hn}}=\mathrm{k}_{\mathrm{h}}, \mathrm{p} / \mathrm{y}_{1}=\mathrm{m}_{\mathrm{h} 1} \mathrm{x}, \mathrm{nB}_{1}=\mathrm{B}, \mathrm{B}_{1}=1 \mathrm{ft} \quad \mathrm{e}$

$$
\begin{aligned}
& \mathrm{n}_{\mathrm{h}}=\mathrm{m}_{\mathrm{h}} \mathrm{B}_{1} \text {, vem: } \quad(\mathrm{C} 9) \\
& \mathrm{k}_{\mathrm{h}}=\frac{\mathrm{n}_{\mathrm{h}}}{\mathrm{B}} \mathrm{k} \quad, \text { onde } \mathrm{n}_{\mathrm{h}} \text { representa a constante de reação do solo, }
\end{aligned}
$$

depende da densidade da areia. 
Anexos

Tabela C2 - Valores de $\mathrm{n}_{\mathrm{h}}\left(\mathrm{N} / \mathrm{cm}^{3}\right)$

\begin{tabular}{|c|c|c|c|}
\hline $\begin{array}{c}\text { DENSIDADE RELATIVA } \\
\text { DA AREIA }\end{array}$ & fofa & $\begin{array}{c}\text { medianamentecomp } \\
\text { acta }\end{array}$ & compacta \\
\hline Areia seca ou úmida & 22,3 & 7,0 & 118,7 \\
\hline areia submersa & 11,3 & 4,7 & 111,3 \\
\hline
\end{tabular}

\section{C2 - Contribuição de MATLOCK (1970)}

\section{$\underline{\text { Resposta da Argila Mole Abaixo do Lençol Freático }}$}

Matlock em 1970 desenvolveu um procedimento para prever as curvas p-y em depósitos argilosos submersos baseando-se em resultados de testes de estacas tubulares flexíveis submetidas a cargas estáticas de curta duração e cargas cíclicas. Foram feitas correlações entre os resultados de campo e os testes de laboratório em amostras indeformadas do solo, extraídas no local dos ensaios.

O critério apresentado por Matlock para a obtenção das curvas p-y para cargas estáticas consiste de duas partes: Inicialmente começa pela obtenção de uma expressão para descrever a variação da resistência última $\mathrm{p}_{\mathrm{u}}$ do solo com a profundidade. A segunda etapa visa obter uma expressão para descrever a resistência do solo em função dos deslocamentos laterais da estaca para uma profundidade particular. A diferença básica entre essas duas etapas é que a teoria pode geralmente ser usada para determinar a variação de $\mathrm{p}_{\mathrm{u}}$ com a profundidade, ao contrário da segunda fase, onde o empirismo predomina na determinação da forma real das curvas p-y. A resistência última do solo pode ser obtida usando a seguinte equação:

$$
\begin{aligned}
& \mathrm{p}_{\mathrm{u}}=\mathrm{N}_{\mathrm{p}} \mathrm{C}_{\mathrm{x}} \mathrm{B} \text { onde, }(\mathrm{C} 10) \\
& \mathrm{N}_{\mathrm{p}}=\text { resistência última normalizada do solo; } \\
& \mathrm{C}_{\mathrm{x}}=\text { resistência ao cisalhamento do solo não drenado na }
\end{aligned}
$$
profundidade $\mathrm{x}$;

$$
\mathrm{B}=\text { largura da estaca. }
$$

$\mathrm{O}$ valor de $\mathrm{N}_{\mathrm{p}}$ é determinado em função da profundidade abaixo da superfície do terreno [MATLOCK (1970), REESE \& WELCH (1975), REESE et al (1975)]. O valor de $\mathrm{N}_{\mathrm{p}}$ cresce com a profundidade até alcançar um valor limite em 
um determinado ponto, a partir do qual se mantêm constante para profundidades maiores.

A função geral que descreve a variação de $\mathrm{N}_{\mathrm{p}}$ para baixas profundidades, é dada por:

$\mathrm{N}_{\mathrm{p}}=\mathrm{A}_{0}+\frac{\overline{\mathrm{\sigma}}_{\mathrm{x}}}{\mathrm{c}_{\mathrm{x}}}+\mathrm{J} \frac{\mathrm{x}}{\mathrm{B}} \quad$ onde, $\quad(\mathrm{C} 11)$

$\mathrm{A}_{0}=$ resistência última normalizada do solo na superfície do terreno;

$\bar{\sigma}_{\mathrm{x}}=$ tensão efetiva, devido a sobrecarga na profundidade $\mathrm{x}$;

$\mathrm{x}=$ profundidade abaixo da superfície do terreno

$\mathrm{J}=$ coeficiente empírico.

Resposta da Argila Mole Submersa

Recomendações para a determinação das curvas p-y.

a) Cargas estáticas:

1) Obtenção da melhor estimativa possível da variação de $C_{x}$ e o peso específico submerso $\gamma$ com a profundidade. Determinação do valor de $\varepsilon_{50}$ (deformação correspondente à metade da máxima diferença das tensões principais determinada no ensaio tri-axial de compressão). Se não se dispõe de nenhuma curva $\sigma-\varepsilon$ do ensaio de compressão, alguns valores típicos de $\varepsilon_{50}$ indicados na tabela $\mathrm{C} 3$ podem ser utilizados;

2) Cálculo da resistência última por unidade de comprimento de estaca, usando o menor dos dois valores dados pelas expressões:

$$
\begin{aligned}
& \mathrm{p}_{\mathrm{u}}=\left(3+\frac{\gamma_{\mathrm{m}}}{\mathrm{C}_{\mathrm{x}}} \mathrm{x}+\frac{\mathrm{J}}{\mathrm{b}} \mathrm{x}\right) \mathrm{C}_{\mathrm{x}} \mathrm{B} \\
& \mathrm{p}_{\mathrm{u}}=9 \mathrm{C}_{\mathrm{x}} \mathrm{B}
\end{aligned}
$$


Anexos

Tabela C3 - Valores típicos de $\varepsilon_{50}$

\begin{tabular}{|c|c|}
\hline Consistência da Argila & $\boldsymbol{\varepsilon}_{\mathbf{5 0}}$ \\
\hline Mole & 00,020 \\
Média & 00,010 \\
Dura & 00,005 \\
\hline
\end{tabular}

Baseando-se em testes realizados MATLOCK(1970) recomendou o valor 3 para $\mathrm{A}_{0}$. Para a argila mole o valor $\mathrm{J}=0,5$ e para a argila média o valor $\mathrm{J}=0.25$. Para profundidades maiores, Matlock recomendou $\mathrm{N}_{\mathrm{p}}=9$. A profundidade na qual essa transição ocorre para um depósito com resistência ao cisalhamento uniforme pode ser obtida usando a seguinte expressão:

$$
\mathrm{X}_{\mathrm{r}}=\frac{6 \mathrm{~B}}{\frac{\mathrm{B} \gamma_{\mathrm{m}}}{\mathrm{C}_{\mathrm{x}}}+\mathrm{J}}
$$

$\mathrm{O}$ valor de $\mathrm{X}_{\mathrm{r}}$ representa a profundidade a partir da qual a ruína ocorre por escoamento do solo ao redor da estaca (expressão C13). Para as profundidades acima de $\mathrm{x}_{\mathrm{r}}$ a ruína é governada pela formação de cunhas[expressão (C12)].

$\gamma_{\mathrm{m}}=$ peso específico médio entre a superfície do terreno e a profundidade $\mathrm{x}$ considerada.

3) Cálculo do deslocamento y50, correspondente à metade da resistência última do solo:

$$
\mathrm{y}_{50}=2,5 \varepsilon_{50} \mathrm{~B}
$$

4) Descrição da curva p-y calculada pela seguinte relação:

$$
\frac{\mathrm{p}}{\mathrm{p}_{\mathrm{u}}}=0.5\left(\frac{\mathrm{y}}{\mathrm{y}_{50}}\right)^{\frac{1}{3}}
$$

$\mathrm{O}$ valor de $\mathrm{p}$ permanece constante para valores de $\mathrm{y}$ superiores a $8 \mathrm{y}_{50}$ (Fig. C2). 


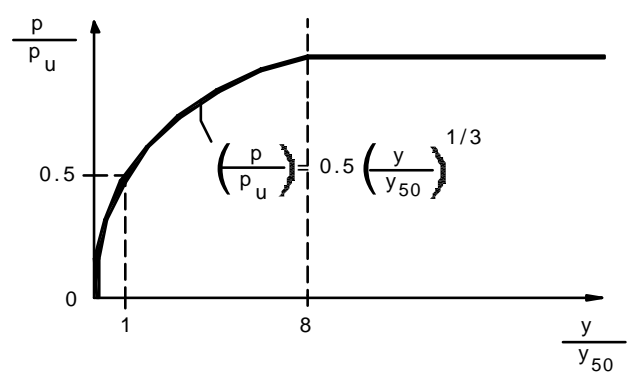

Fig. C2 - Curva p-y para Argila Mole-Carga Estática

Os efeitos da carga cíclica estão relacionados à redução da resistência última do solo para 0.72 pu além de reduzir a sua resistência para deslocamentos maiores do que $3 \mathrm{y}_{50}$ para profundidades menores que $\mathrm{x}_{\mathrm{r}}$. Uma curva p-y para carga cíclica usando o critério p-y de Matlock (1970) é mostrada na Fig. 4.5.7;

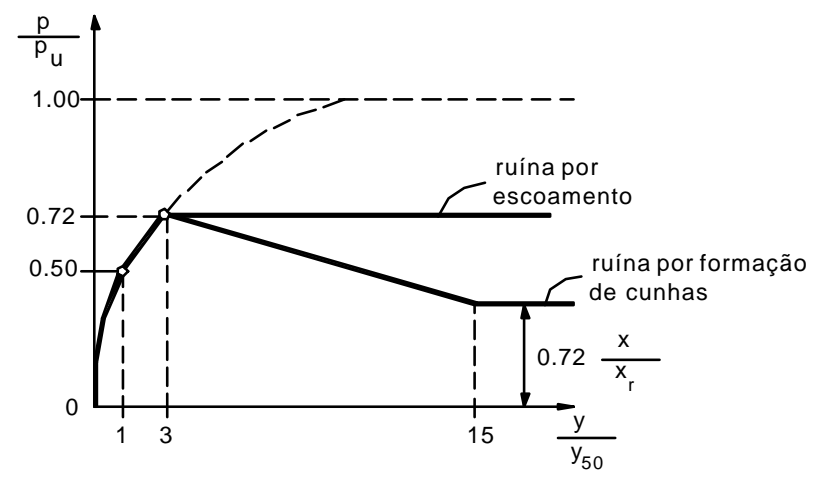

Fig. C3 - Curva p-y para Argila Mole-Carga Cíclica

\section{C3 - CONTRIBUIÇÃO DE REESE et al. (1975)}

\section{Resposta da Argila Dura Submersa}

Para um carregamento estático a resposta de uma argila dura submersa pode ser obtida de acordo com a seguinte seqüência:

1) Obtenção dos valores da resistência ao cisalhamento do solo não drenado $C_{x}$, peso específico submerso do solo $\gamma$, e o diâmetro da estaca $B$;

2. Determinação da resistência média ao cisalhamento $C_{a}$ do solo não drenado acima da profundidade $\mathrm{x}$; 
Anexos

3) Cálculo da resistência última do solo por unidade de comprimento da estaca, adotando-se o menor dos dois valores abaixo:

a) Resistência próximo à superfície do terreno;

$p_{c t}=2 C_{a} B+\gamma_{m} B x+2,83 C_{a} x$

b) Resistência do solo bem abaixo da superfície do terreno;

$\mathrm{p}_{\mathrm{cd}}=11 \mathrm{CB}$

4) Valor de $A_{s}$ para uma profundidade específica x ( Fig.C4);

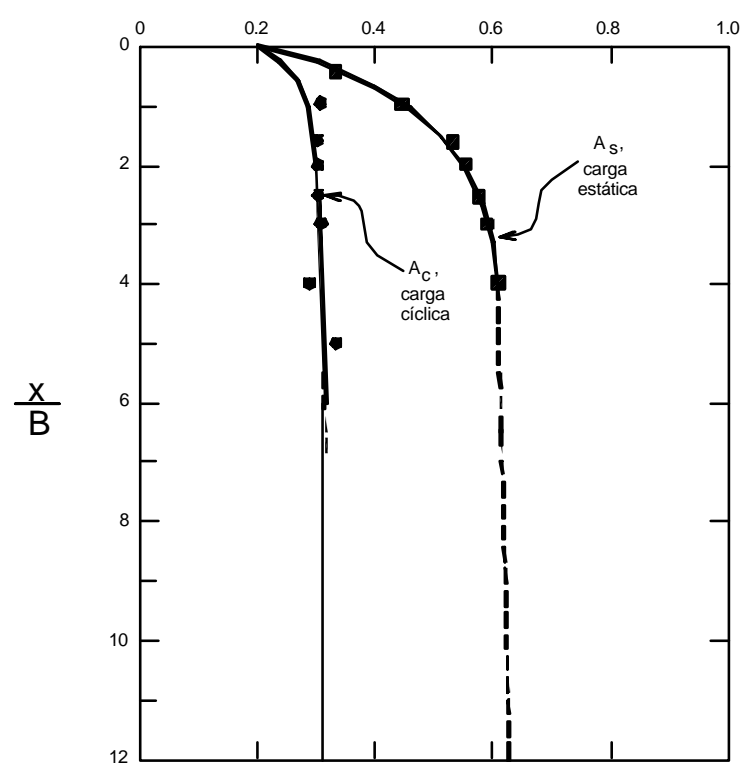

Fig. C4 - Valores das Constantes $\mathrm{A}_{\mathrm{s}}$ e $\mathrm{A}_{\mathrm{c}}$

5) Definição da porção reta inicial da curva p-y;

$\mathrm{p}=\left(\mathrm{k}_{\mathrm{s}} \mathrm{x}\right) \mathrm{y}$ ou $\mathrm{p}=\left(\mathrm{k}_{\mathrm{c}} \mathrm{x}\right) \mathrm{y}$

Valores de $\mathrm{k}$ adotados da tabela C4 
Anexos

Tabela C4 - Valores de $\mathrm{k}_{\mathrm{s}} \mathrm{k}_{\mathrm{c}}$ e $\varepsilon_{50}$

\begin{tabular}{|c|c|c|c|}
\hline $\begin{array}{c}\text { Resistência Média ao Cisalhamento } \mathrm{kN} / \mathrm{m}^{2} \\
\text { (carregamento não-drenada) }\end{array}$ & $50-100$ & $\begin{array}{c}100- \\
200\end{array}$ & $200-400$ \\
\hline $\mathrm{k}_{\mathrm{s}}\left(\right.$ carga estática-N $\left./ \mathrm{cm}^{3}\right)$ & 140 & 280 & 560 \\
$\mathrm{k}_{\mathrm{c}}\left(\right.$ carga cíclica-N/cm $\left.{ }^{3}\right)$ & 55 & 110 & 220 \\
$\varepsilon_{50}$ & 0,007 & 0,005 & 0,004 \\
\hline
\end{tabular}

A resistência média ao cisalhamento pode ser definido como a metade da máxima diferença entre as tensões principais do ensaio tri-axial para a argila não drenada e não adensada.

6) Determinação de $y_{50}$;

$\mathrm{y}_{50}=\varepsilon_{50} \mathrm{~B} \quad(\mathrm{C} 20)$

Para $\varepsilon_{50}$ devem ser adotados os valores obtidos de resultados de laboratório. $\mathrm{Na}$ ausência destes resultados podem ser tomados os valores constantes da tabela C4.

7) Estabelecer o trecho inicial não-linear da curva p-y usando a relação abaixo:

$$
\mathrm{p}=0.5 \mathrm{p}_{\mathrm{c}} \sqrt{\frac{\mathrm{y}}{\mathrm{y}_{50}}}
$$

Obs. $p_{c}$ assume valor de $p_{c t}$ ou o valor de $p_{c d}$. Esse primeiro trecho curvilíneo inicia-se no ponto de sua interseção com o primeiro trecho reto, até o ponto onde y assume o valor $\mathrm{A}_{\mathrm{s}} \mathrm{y}_{50}$.

8) Estabelecer o segundo trecho não-linear da curva p-y definida pela expressão abaixo:

$$
\mathrm{p}=0.5 \mathrm{p}_{\mathrm{c}} \sqrt{\frac{\mathrm{y}}{\mathrm{y}_{50}}}-0.055 \mathrm{p}_{\mathrm{c}}\left(\frac{\mathrm{y}}{\mathrm{A}_{\mathrm{s}} \mathrm{y}_{50}}-1\right)^{1.25}
$$

Esse trecho curvilíneo da curva p-y é definido do ponto onde $\mathrm{y}=\mathrm{A}_{\mathrm{s}} \mathrm{y}_{50}$ até o ponto onde y assume o valor $6 \mathrm{~A}_{\mathrm{s}} \mathrm{y}_{50}$. 
Anexos

9) Estabelecer o próximo trecho reto da curva p-y definido pela expressão:

$$
\mathrm{p}=0.5 \mathrm{p}_{\mathrm{c}} \sqrt{6 \mathrm{~A}_{\mathrm{s}}}-0.41 \mathrm{p}_{\mathrm{c}}-\frac{0.0625}{\mathrm{y}_{50}} \mathrm{p}_{\mathrm{c}}\left(\mathrm{y}-6 \mathrm{~A}_{\mathrm{s}} \mathrm{y}_{50}\right)(\mathrm{C} 23)
$$

Essa expressão define a porção linear da curva p-y entre o ponto onde $\mathrm{y}=6 \mathrm{~A}_{\mathrm{s}} \mathrm{y}_{50}$ ao ponto para o qual $\mathrm{y}=18 \mathrm{~A}_{\mathrm{s}} \mathrm{y}_{50}$.

Estabelecer o trecho final linear da curva p-y, válido para os pontos com valores de y superiores a $18 \mathrm{~A}_{\mathrm{s}} \mathrm{y}_{50}$,

$$
\mathrm{p}=\mathrm{p}_{\mathrm{c}}\left(1.225 \sqrt{\mathrm{A}_{\mathrm{s}}}-0.75 \text { As }-0.411\right)
$$

Esse procedimento seqüencial é ilustrado na Fig.C5;

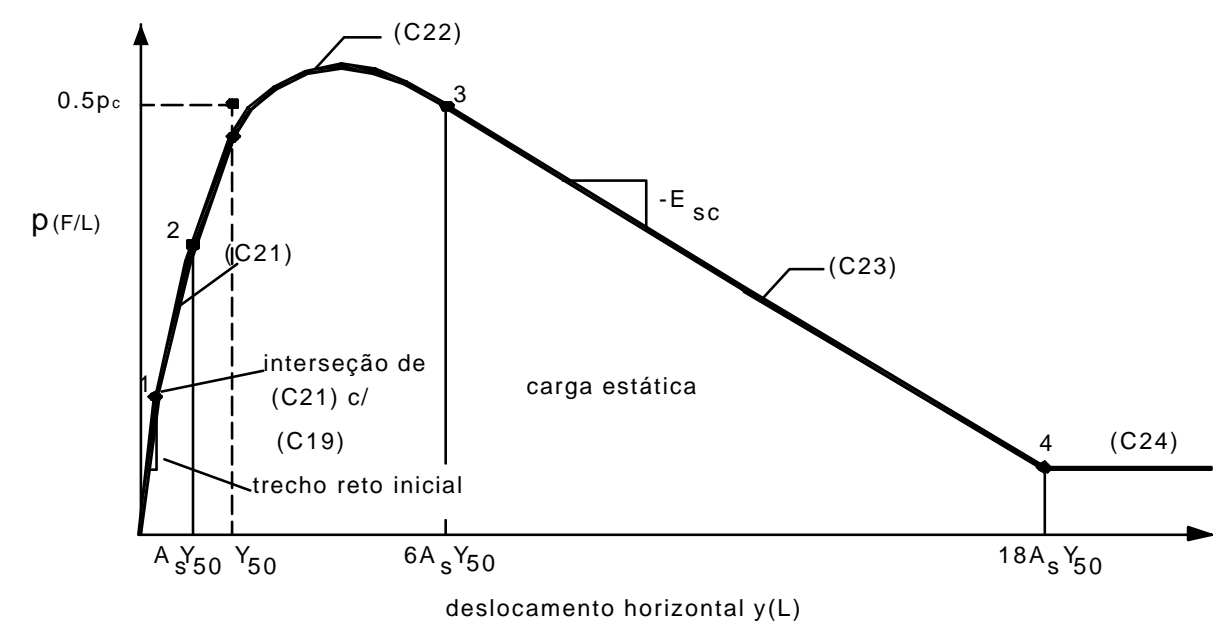

Fig. C5 - Forma Característica das Curvas p-y para Argila Dura Submersa [Carregamento Estático (REESE et al - 1975)]

Para o caso de carregamento cíclico, adota-se o seguinte procedimento:

Os passos 1,2,3,5 e 6 são os mesmos adotados para carga estática;

7) Escolher do valor apropriado de $A_{c}$ (Fig.4.5.8) para uma profundidade particular.

8) Cálculo de $y_{p}$;

$$
\mathrm{y}_{\mathrm{p}}=4,1 \mathrm{~A}_{\mathrm{c}} \mathrm{y}_{50}
$$


Anexos

9) Estabelecer o trecho parabólico da curva p-y;

$$
\mathrm{p}=\mathrm{A}_{\mathrm{c}} \mathrm{p}_{\mathrm{c}}\left[1-\left|\frac{\mathrm{y}}{0.45 \mathrm{y}_{\mathrm{p}}}-1\right|^{2.5}\right]
$$

Esse trecho curvilíneo da curva p-y vai da sua interseção com a reta inicial até o ponto onde y assume o valor $0.6 \mathrm{y}_{\mathrm{p}}$

10. Estabelecer o trecho linear definido pela seguinte expressão:

$$
\mathrm{p}=0,936 \mathrm{~A}_{\mathrm{c}} \mathrm{p}_{\mathrm{c}}-\frac{0,085}{\mathrm{y}_{50}} \mathrm{p}_{\mathrm{c}}\left(\mathrm{y}-0,6 \mathrm{y}_{\mathrm{p}}\right)
$$

11. Esse trecho reto inicia-se no ponto onde $\mathrm{y}=0.6 \mathrm{y}_{\mathrm{p}}$ até o ponto com $\mathrm{y}=1.8 \mathrm{y}_{\mathrm{p}}$

Trecho linear final da curva p-y,

$$
\mathrm{p}=0.936 \mathrm{~A}_{\mathrm{c}} \mathrm{p}_{\mathrm{c}}-\frac{0.102}{\mathrm{y}_{50}} \mathrm{p}_{\mathrm{c}} \mathrm{y}_{\mathrm{p}}
$$

Essa constante define a curva p-y para valores de y superiores a $1,8 y_{p}$

(Fig. C6)

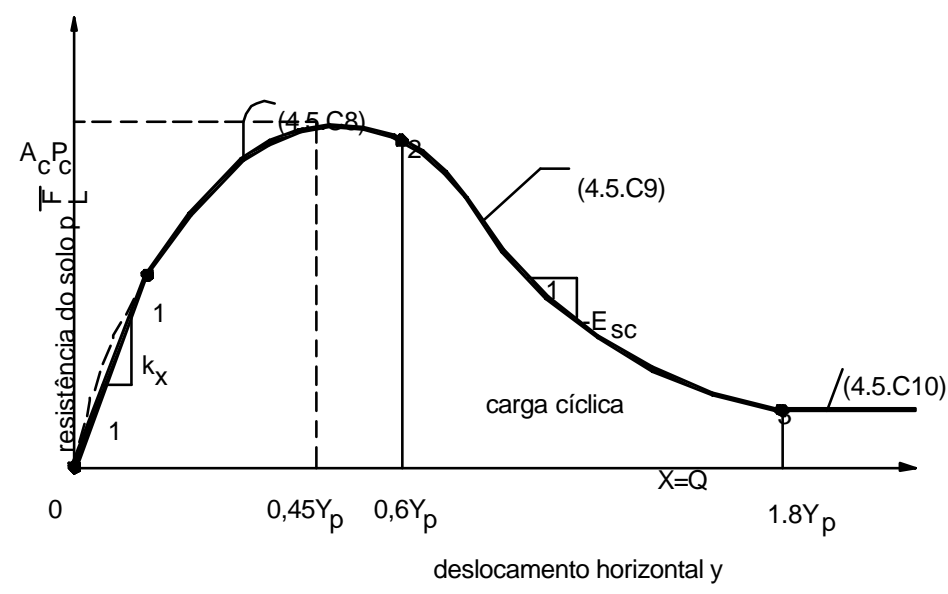

Fig. C6 - Forma Característica das Curvas p-y para Argila Dura Submersa Carregamento Cíclico (REESE et al - 1975) 
Anexos

\section{C3 - CONTRIBUIÇÃO DE COX, REESE, \& GRUBBS (1974)}

\section{$\underline{\text { Resposta de uma Areia }}$}

Recomendações para a determinação das curvas p-y

1) Obtenção dos parâmetros necessários:

$\phi$ - ângulo de atrito interno da areia;

$\gamma$ - peso específico da areia;

B - diâmetro da estaca;

$\mathrm{X}$ - profundidade abaixo da superfície do terreno.

2) Cálculo preliminar dos seguintes parâmetros:

$$
\alpha=\frac{\phi}{2} ; \quad \beta=45^{\circ}+\frac{\phi}{2} ; \quad \mathrm{k}_{0}=0.4 ; \quad \mathrm{k}_{\mathrm{a}}=\tan ^{2}\left(45^{\circ}-\frac{\phi}{2}\right)
$$

Cálculo da resistência última $\mathrm{p}_{\mathrm{u}}$ do solo por unidade de comprimento da estaca usando o menor dos dois valores, $\mathrm{p}_{\mathrm{st}}$ ou $\mathrm{p}_{\mathrm{sd}}$.

$$
\begin{aligned}
& \mathrm{p}_{\mathrm{st}}=\gamma \mathrm{x}\left[\frac{\mathrm{k}_{0} \mathrm{x} \tan \phi \sin \beta}{\tan (\beta-\phi) \cos \alpha}+\frac{\tan \beta}{\tan (\beta-\phi)}(\mathrm{B}+\mathrm{x} \tan \beta \tan \alpha)+\right. \\
& \left.+\mathrm{k}_{0} \mathrm{x} \tan \beta(\tan \phi \sin \beta-\tan \alpha)-\mathrm{k}_{\mathrm{a}} \mathrm{B}\right] \\
& \mathrm{p}_{\mathrm{sd}}=\mathrm{k}_{\mathrm{a}} \mathrm{B} \gamma \mathrm{x}\left(\tan ^{8} \beta-1\right)+\mathrm{k}_{0} \mathrm{~B} \gamma \mathrm{x} \tan ^{8} \phi \tan ^{4} \beta \quad(\mathrm{C} 30)
\end{aligned}
$$

Para areia submersa deve ser usado nas expressões o seu peso específico efetivo.

4) Calculando-se os valores de $p_{s t}$ e $p_{s d}$, determinar a profundidade $x_{t}$ na qual há uma interseção entre $\mathrm{p}_{\mathrm{st}} \mathrm{e} \mathrm{p}_{\mathrm{sd}}$. Para as profundidades superiores a $\mathrm{x}_{\mathrm{t}}$ são 
Anexos

usados os valores de $\mathrm{p}_{\mathrm{st}}$, e para as profundidades abaixo de $\mathrm{x}_{\mathrm{t}}$ são utilizados os valores de $\mathrm{p}_{\mathrm{sd}}$.

5) Selecionar a profundidade "x "onde se deseja a curva $p-y$;

6) Estabelecer o valor $y_{u}$ como 3B/80. Calcular $p_{u}$ pelas equações:

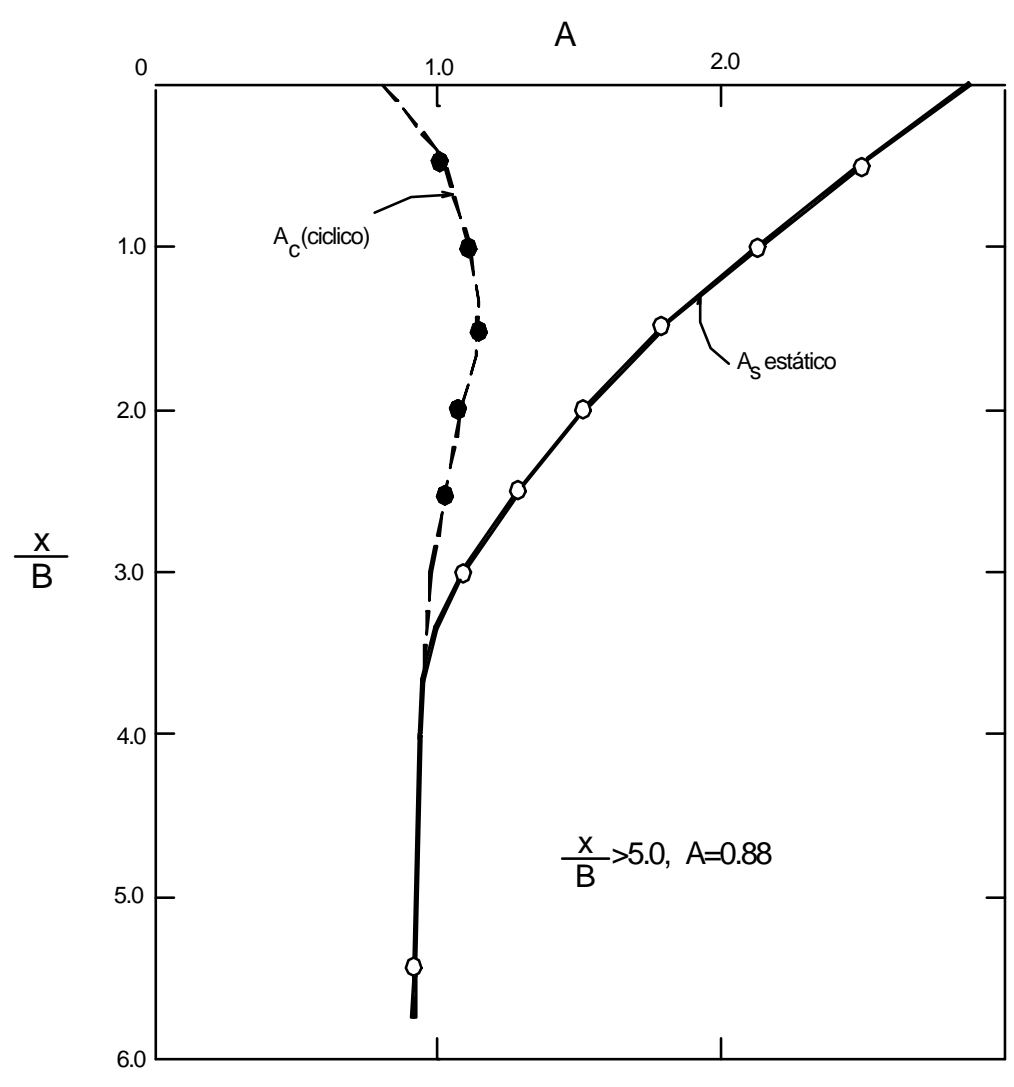

Fig. C7 - Valores de $A_{s}$ e $A_{c}$

$$
\begin{aligned}
& \mathrm{p}_{\mathrm{u}}=\mathrm{A}_{\mathrm{s}} \mathrm{p}_{\mathrm{s}} \quad \text { ou } \quad(\mathrm{C} 31) \\
& \mathrm{p}_{\mathrm{u}}=\mathrm{A}_{\mathrm{c}} \mathrm{p}_{\mathrm{s}} \quad \text { onde, }
\end{aligned}
$$

$A_{s}$ e $A_{c}$ são fatores empíricos de ajustamento obtidos da Fig.C7 para uma profundidade particular $\mathrm{x}$.

7) Define-se $y_{m}$ como B/60. Calcula-se $p_{m}$ pelas seguintes expressões: 
Anexos

$$
\begin{aligned}
& \mathrm{p}_{\mathrm{m}}=\mathrm{B}_{\mathrm{s}} \mathrm{p}_{\mathrm{s}} \quad \text { ou } \quad(\mathrm{C} 32) \\
& \mathrm{p}_{\mathrm{m}}=\mathrm{B}_{\mathrm{c}} \mathrm{p}_{\mathrm{s}}
\end{aligned}
$$

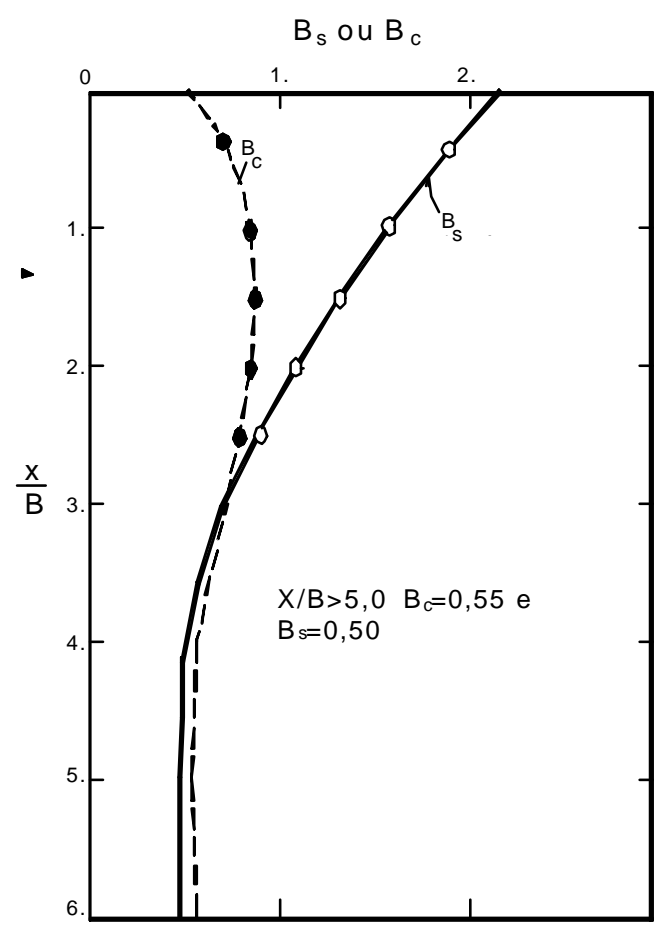

Fig. C8 - Valores de $\mathrm{B}_{\mathrm{s}}$ e $\mathrm{B}_{\mathrm{c}}$

Os fatores de ajustamento $B_{s}$ e $B_{c}$ são obtidos da Fig. C8 para uma determinada profundidade x a partir da superfície do terreno.

8) Estabelecer o trecho linear inicial da curva p-y;

$$
\mathrm{p}=\left(\mathrm{k}_{\mathrm{s}} \mathrm{x}\right) \mathrm{y}
$$

Usar valores apropriados de $\mathrm{k}_{\mathrm{s}}$ da tabela C5 para areia abaixo ou acima do lençol freático;

10) Estabelecer o trecho não-linear da curva p-y válido entre os pontos "m" e "k" como segue (Fig. C9):

$$
\mathrm{p}=\overline{\mathrm{cy}}^{1 / \mathrm{n}}
$$


Anexos

Tabela C5 - Valores representativos de k para areia

\begin{tabular}{|c|c|c|c|}
\hline Densidade Relativa da Areia & hfofa & Mmédia & Ddensa \\
\hline \begin{tabular}{c}
$\mathrm{k}_{\mathrm{s}}\left(\begin{array}{c}\text { (recomendado) }\left(\mathrm{N} / \mathrm{cm}^{3}\right) \\
(\text { areia submersa })\end{array}\right.$ \\
\hline $\begin{array}{c}\mathrm{k}_{\mathrm{s}}\left(\text { recomendado) }\left(\mathrm{N} / \mathrm{cm}^{3}\right)\right. \\
(\text { areia não submersa })\end{array}$
\end{tabular} & 05 & 016 & 035 \\
\hline
\end{tabular}

10) Estabelecer o trecho não linear da curva p-y válido entre os pontos "m" e "k" como segue (Fig.C9):

$$
\mathrm{p}=\overline{\mathrm{cy}}^{1 / \mathrm{n}}
$$

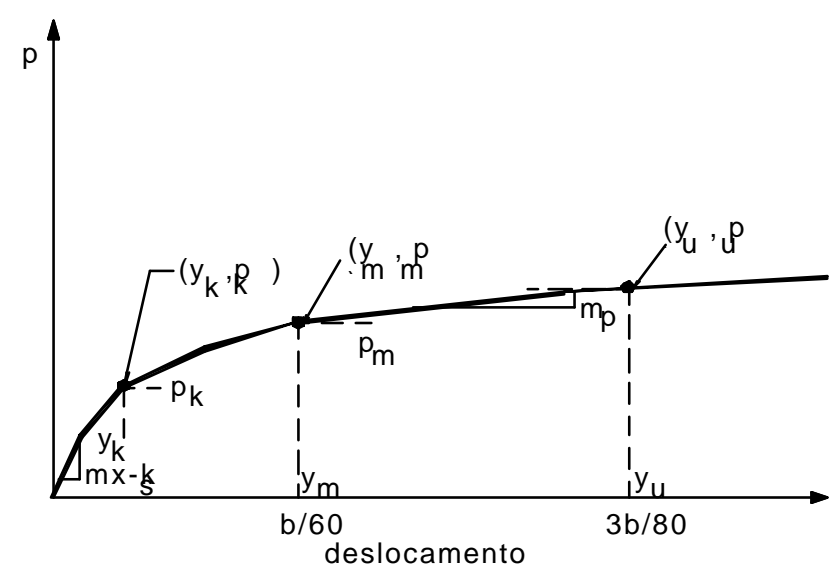

Fig. C9 - Características de uma Família de Curvas p-y p/ a Areia[COX, REESE, \& GRUBBS (1974)]

11) Cálculo da inclinação da linha reta entre os pontos "m" e "u" pela expressão:

$$
\mathrm{m}=\frac{\mathrm{p}_{\mathrm{u}}-\mathrm{p}_{\mathrm{m}}}{\mathrm{y}_{\mathrm{u}}-\mathrm{y}_{\mathrm{m}}}
$$

12) Potência do trecho não linear entre "k" e "m";

$$
\mathrm{n}=\frac{\mathrm{p}_{\mathrm{m}}}{\mathrm{my} \mathrm{m}_{\mathrm{m}}}
$$

13) Obtenção do coeficiente $\bar{c}$; 
Anexos

$$
\bar{c}=\frac{p_{m}}{\left(y_{m}\right)^{1 / n}} \quad(C 37)
$$

14) Determinação do ponto "k".

$$
\mathrm{y}_{\mathrm{k}}=\left(\frac{\overline{\mathrm{c}}}{\mathrm{k}_{\mathrm{s}} \mathrm{x}}\right)^{\frac{\mathrm{n}}{\mathrm{n}-1}} \quad ; \quad \mathrm{p}_{\mathrm{k}}=\left(\mathrm{k}_{\mathrm{s}} \mathrm{x}\right) \mathrm{y}_{\mathrm{k}} \quad(\mathrm{C} 38)
$$

Obs. Outras curvas p-y estão disponíveis e detalhadas na obra "Handbook on Design of Piles and Drilled Shafts under Lateral Load", U. S. Department of Transportation of Federal Highway Administration - Office of Research, Washington, DC [ Aput Reese (1983)]. 